\title{
FACULTAD DE MEDICINA
}

DEPARTAMENTO DE CIENCIAS BIOMÉDICAS Y DEL DIAGNÓSTICO ÁREA DE MEDICINA PREVENTIVA Y SALUD PÚBLICA
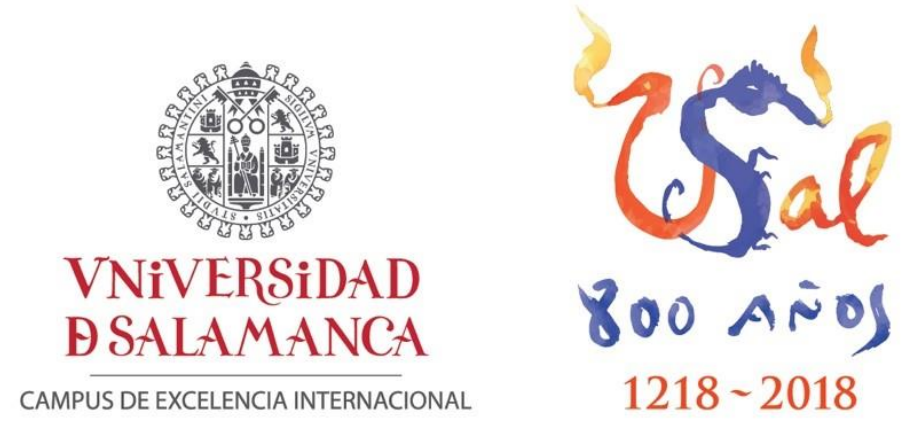

TESIS DOCTORAL CON MENCIÓN DOCTOR INTERNACIONAL

ADHERENCIA AL TRATAMIENTO FARMACOLÓGICO EN PERSONAS CON PATOLOGÍAS CRÓNICAS EN GRUPOS DE POBLACIÓN VULNERABLES

\author{
MEDICATION ADHERENCE AMONG VULNERABLE \\ POPULATIONS WITH CHRONIC DISEASES
}

César Ignacio Fernández Lázaro 

D. JOSE ANTONIO MRÓN CANELO, Profesor Titular de Medicina Preventiva y Salud Pública del Departamento de Ciencias Biomédicas de la Facultad de Medicina de la Universidad de Salamanca.

\section{CERTIFICA}

Que el presente trabajo de investigación titulado "Adherencia al Tratamiento Farmacológico en Personas con Patologías Crónicas en Grupos de Población Vulnerables/ Medication Adherence among Vulnerable Populations with Chronic Conditions" realizado bajo $\mathrm{mi}$ dirección por D. CÉSAR IGNACIO FERNÁNDEZ LÁZARO, reúne, los méritos de rigor, fiabilidad, y originalidad, necesarios para optar al Grado de Doctor con Mención Internacional por la Universidad de Salamanca.

Y para que así conste a los efectos oportunos, firmo la presente en Salamanca, a dos de noviembre de dos mil dieciséis.

Fdo. Prof. Jose A. Mirón Canelo 

"If you can't fly then run, if you can't run then walk, if you can't walk then crawl, but whatever you do you have to keep moving forward" - Dr. Martin Luther King Jr. 

Este trabajo está dedicado:

"A mis padres Gregorio y María Paz, que me dieron mi Vida, iluminan mi Camino, y a los que siempre llevo en mi Corazón"

"A mi hermano Diego, mi Sangre, mi Ejemplo, mi Todo, porque aquí o allí siempre estaremos juntos" 



\section{Mi agradecimiento/Acknowledgements:}

Al Profesor, Dr. José Antonio Mirón Canelo, por darme la Oportunidad de aprender junto a él durante el transcurso de esta etapa. Por compartir su experiencia de trabajo, visión de la vida, y su filosofía, que me acompañarán a partir de ahora allí donde vaya. Gracias por su ayuda, orientación, y constante apoyo que ha sido imprescindible para la realización de este trabajo.

I must also express my sincerest gratitude to Professor, Dr. Adams for his advices and continuous support throughout the research. He is one of the most inspirational professors that I have ever met in my college career; his help, suggestions, and wise advises have been absolutely essential for this research, gracias amigo!

I would also extend my deepest gratitude to the director of St. Mary's Health Center and Good Samaritan Clinic, Sr. Pat Baber who allowed me to carry out the research and made my path very easy by providing all facilities to perform the research.

Al Dr. Juan Manuel García González, por su inestimable ayuda e incalculable paciencia. Su contribución sobre los análisis estadísticos y sus meticulosas correcciones han sido imprescindible para la realización de este trabajo.

Al Departamento de Ciencia Biomédicas y del Diagnóstico de la Facultad de Medicina de la Universidad de Salamanca por facilitarme el desarrollo de este trabajo. También quiero agradecer al Programa de Doctorado "Salud y Desarrollo en los Trópicos”, y en especial a la coordinadora Dra. Del Olmo Fernández por su comprensión y facilidades en los temas administrativos. Likewise, I would also like to express thanks to the Health Sciences Department from Armstrong State University for coordinating this whole project and supporting me during the course of the research.

Special thanks to all the St. Mary's and Good Samaritan's staff for the love and affection received every single day during the course of the research. They made every day at work into a fun day. Thanks for treating me so well fox! 
A mi familia, por su amor, constante apoyo, y todos los esfuerzos que han realizado durante este tiempo para que pudiera llevar a cabo este trabajo. Sin ellos nada de mi Vida tendría sentido. Mi padre Gregorio, por la paciencia que transmite y la facilidad que posee para quitar importancia a las cosas que realmente no la tienen. A mi madre, María Paz, mi ejemplo en la Vida y a la que realmente admiro, ella me ha enseñado que con trabajo y esfuerzo se consigue todo. A mi hermano Diego, al que amo con todas mis fuerzas y que siempre me hace sentir cerca de él, incluso cuando miles de kilómetros nos separan; su ayuda y sus consejos siempre me han acompañado.

I am also thankful to Professor and Cross Country Coach Michael Sergi from Armstrong State University. He has been my family during my time in the States and has always taken good care of me.

I would also thanks to all the patients that participated in the research. Sin vuestra disposición y ganas de colaboración este estudio no podría haberse llevado a cabo. Thanks, from the very bottom of my heart.

No voy a olvidarme de todas esas personas que han navegado junto a mí durante toda esta travesía, o a las que se subieron en alguna parte del trayecto, y han permanecido a bordo hasta llegar a puerto. Desde amigos, buddies, classmates, profesores, teammates, my American family, my Canadian family, todos ellos han contribuido, de una manera u otra, a la realización de esta investigación. Gracias también a todos aquellos que subieron a bordo a principio de trayecto, pero que, de una manera u otra, temerosamente abandonaron el barco, pues ellos también han contribuido, mínimamente, a la realización del presente trabajo.

Por último, también quería agradecer a todos esos obstáculos, voluntarios o involuntarios, encontrados en este largo camino que ha sido recorrido, pues ellos me han proporcionado una motivación extra para seguir adelante. Durante el transcurso de esta investigación he aprendido que no importa las dificultades e inconvenientes encontrados, siempre existe un camino alternativo para conseguir tus sueños, pero hagas lo que hagas, you have to keep pushing forward.

A los miembros del Tribunal por acceder amablemente a formar parte del mismo. 


\section{Í NDICES}



INTRODUCCIÓN

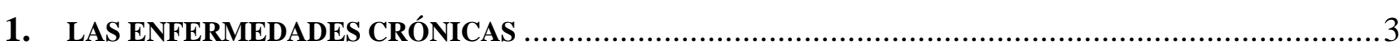

1.1. El Progresivo Aumento de la Esperanza de Vida: Avances en Materia Sanitaria y Transición Epidemiológica..................................................................................

1.2. La Transformación de la Estructura de Edad de la Población Mundial: el Envejecimiento Demográfico

1.3. Enfermedades Crónicas, Enfermedades No Transmisibles o

Enfermedades No Comunicables ........................................................................... 13

1.4. Situación Epidemiológica e Impacto de las Enfermedades Crónicas ......................... 14

1.5. Factores de Riesgo de las Enfermedades Crónicas ......................................................20

1.6. El Fenómeno de la Co-Existencia de Múltiples Enfermedades Crónicas ....................23

1.7. Comorbilidad, Multimorbilidad, y Pluripatología..................................................24

1.8. Multimorbilidad: Fundamentos y Situación ..............................................................28

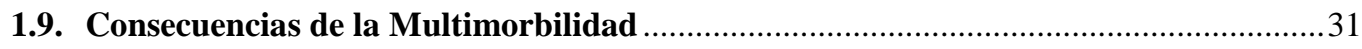

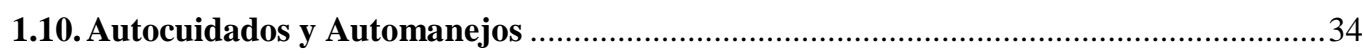

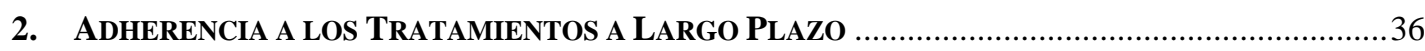

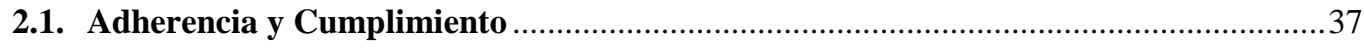

2.2. Contexto y Situación Actual de la Adherencia al Tratamiento Terapéutico de las Enfermedades Crónicas ................................................................................... 39

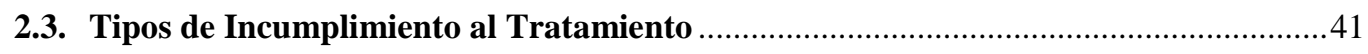

2.4. Factores Relacionados con la Adherencia Terapéutica ...............................................43

2.4.1. Factores Relacionados con las Características Socioeconómicas ............................44

2.4.2. Factores Relacionados con el Sistema o el Equipo de Asistencia Sanitario................46

2.4.3. Factores Relacionados con la Enfermedad............................................................. 48

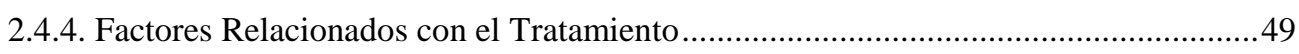

2.4.5. Factores Relacionados con el Paciente.................................................................... 51

2.5. Consecuencias y Repercusiones de la Falta de Adherencia al Tratamiento ................53

2.6. Métodos de Valoración de la Adherencia al Tratamiento Farmacológico....................56

3. Salud en los Grupos de Población Vulnerables.........................................................6 62

3.1. Contexto y Situación de las Desigualdades en los Grupos Sociales de Población

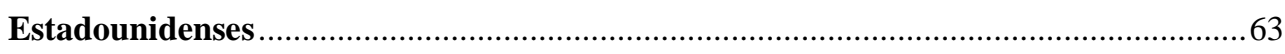

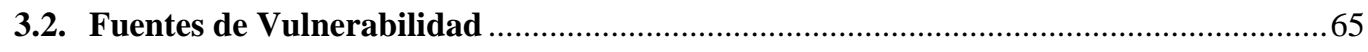

3.2.1. Nivel Económico y Área de Residencia ...................................................................66

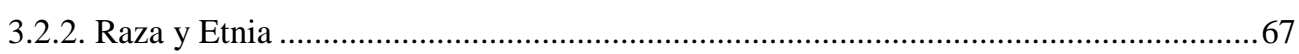

3.2.3. Severidad de la Enfermedad, Edad, y Estado Funcional o Desarrollo del Individuo ..68

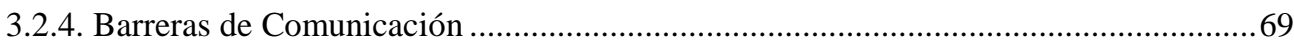


3.3. La Salud y el Bienestar como Derechos Fundamentales ........................................... 70

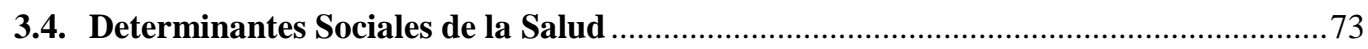

3.5. Esfuerzos para Reducir las Disparidades de Salud ............................................. 75

3.5.1. Ley de Protección al Paciente y Cuidado de Salud Asequible ...................................75

3.5.2. Programas Federales Medicare y Medicaid ......................................................... 76

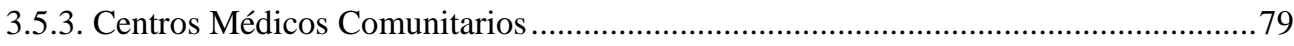

3.6. Poblaciones de Grupos de Población Vulnerables en Investigación..............................82

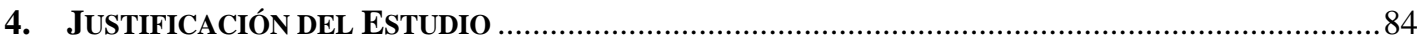

HIPÓTESIS Y OBJETIVOS.............................................................................................8 89

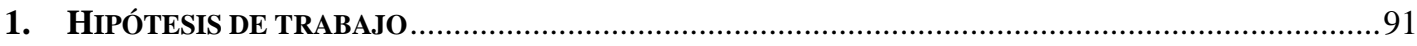

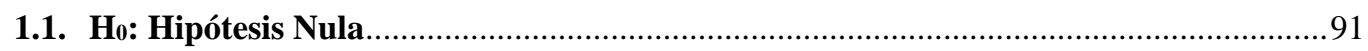

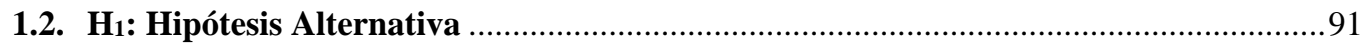

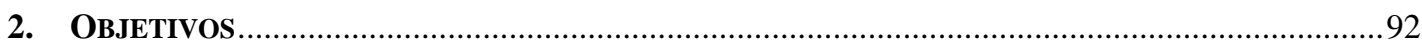

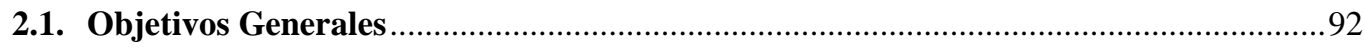

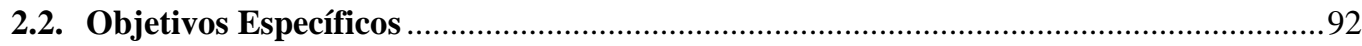

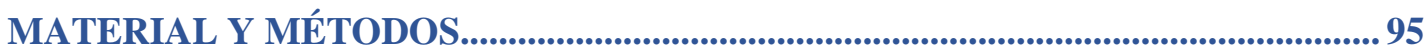

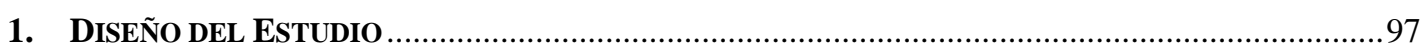

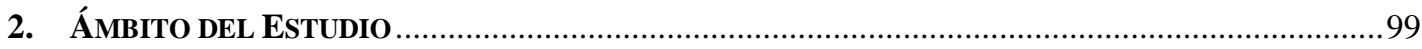

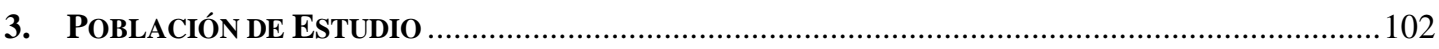

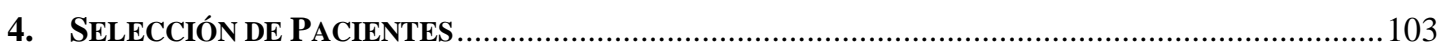

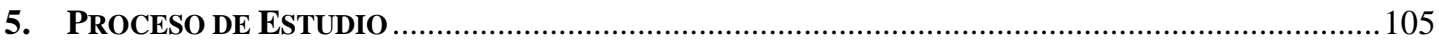

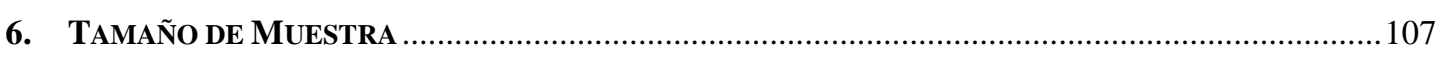

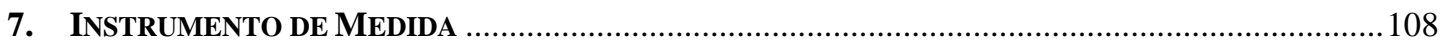

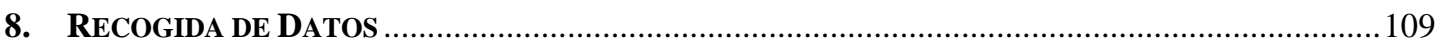

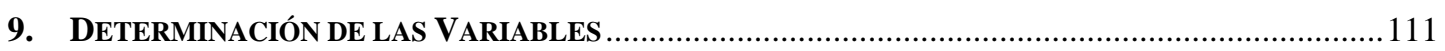

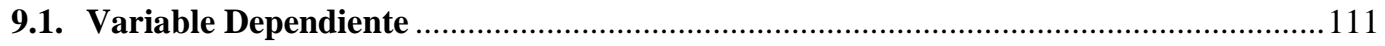

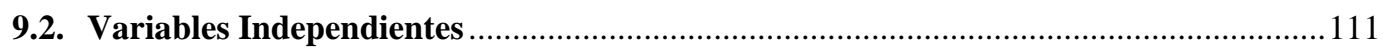

9.2.1. Factores Relacionados con las Características Socioeconómicas ..............................112

9.2.2. Factores Relacionados con el Sistema o el Equipo de Asistencia Sanitaria ................114

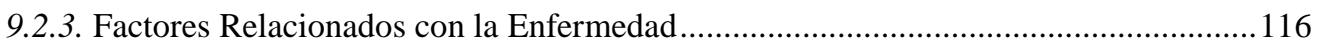

9.2.4. Factores Relacionados con el Tratamiento................................................................ 120

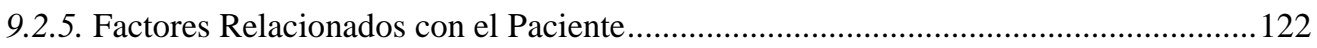

9.2.6. Metodología de la Entrevista..................................................................................... 126 


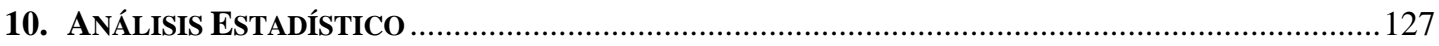

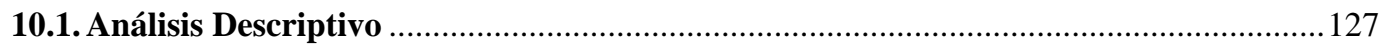

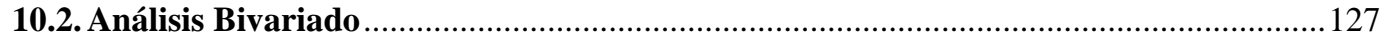

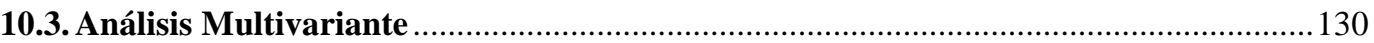

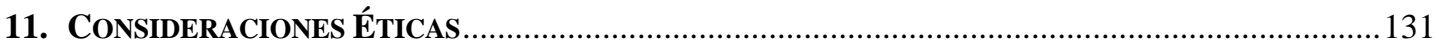

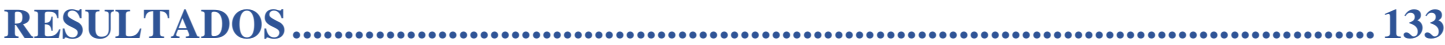

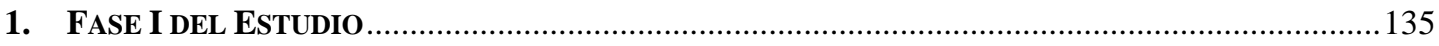

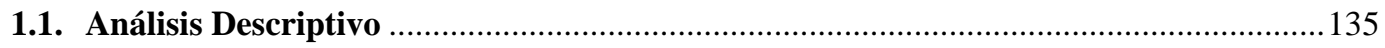

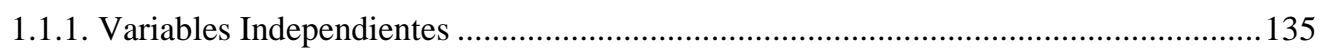

1.1.1.1. Factores Relacionados con las Características Socioeconómicas.....................136

1.1.1.2. Factores Relacionados con el Sistema o el Equipo de Asistencia Sanitaria ..... 144

1.1.1.3. Factores Relacionados con la Enfermedad .................................................... 149

1.1.1.4. Factores Relacionados con el Tratamiento.................................................... 155

1.1.1.5. Factores Relacionados con el Paciente ............................................................. 162

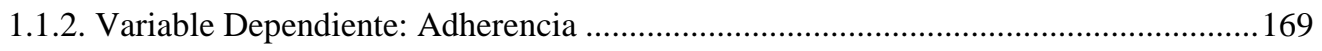

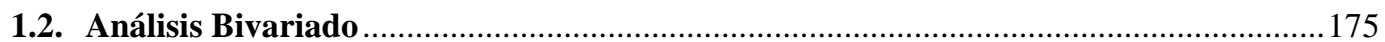

1.2.1. Factores Relacionados con las Características Socioeconómicas ...............................175

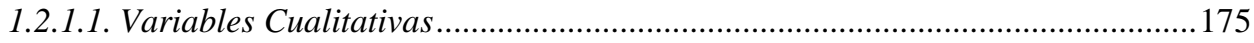

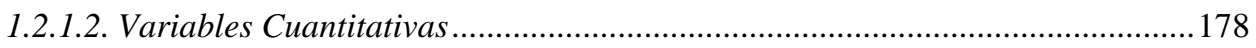

1.2.2. Factores Relacionados con el Sistema o el Equipo de Asistencia Sanitaria ................179

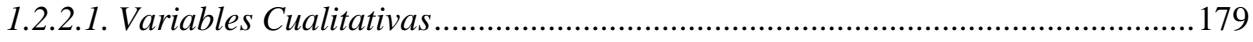

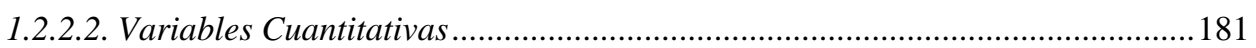

1.2.3. Factores Relacionados con la Enfermedad............................................................... 182

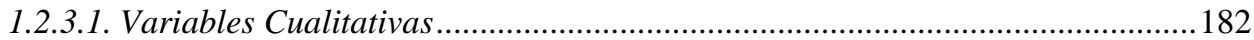

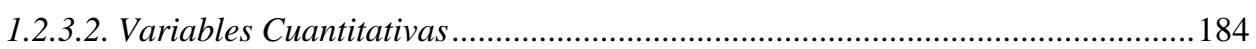

1.2.4. Factores Relacionados con el Tratamiento......................................................... 184

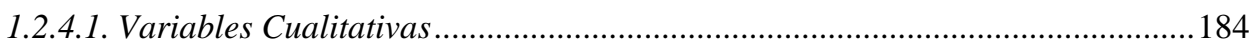

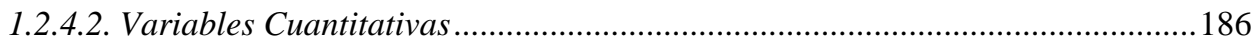

1.2.5. Factores Relacionados con el Paciente............................................................................ 188

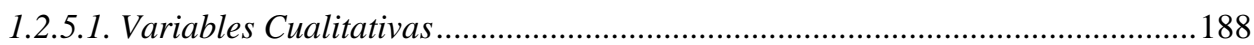

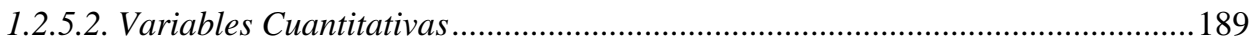

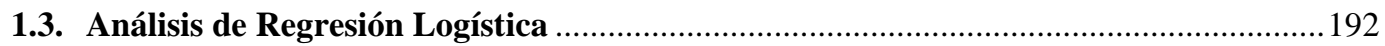




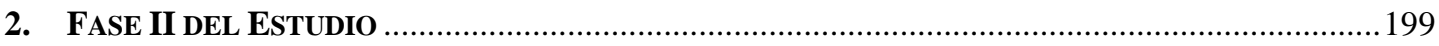

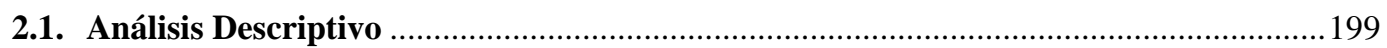

2.1.1. Variables Independientes ........................................................................................ 199

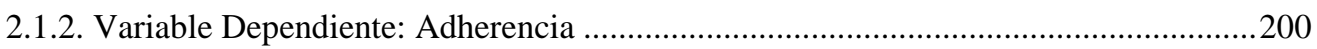

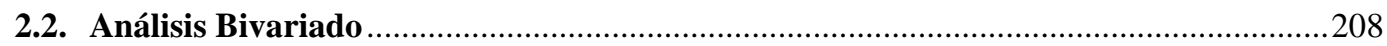

2.2.1. Factores Relacionados con las Características Socioeconómicas ................................208

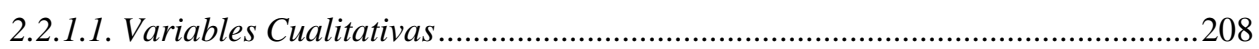

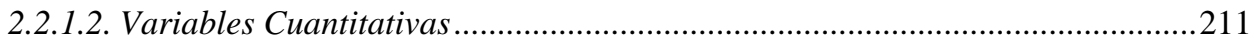

2.2.2. Factores Relacionados con el Sistema o el Equipo de Asistencia Sanitaria ................212

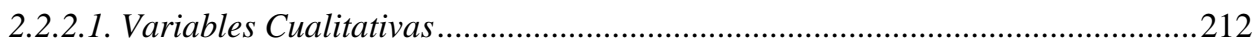

2.2.2.2. Variables Cuantitativas ..............................................................................212

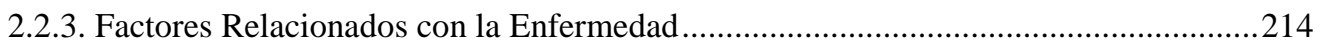

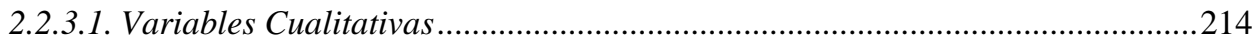

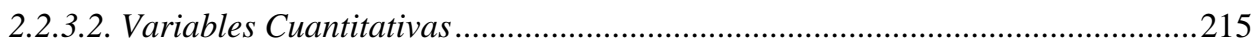

2.2.4. Factores Relacionados con el Tratamiento................................................................216

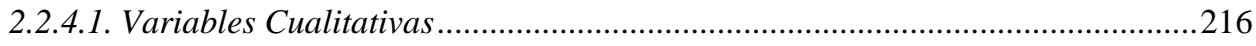

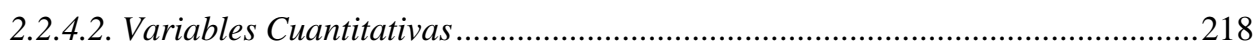

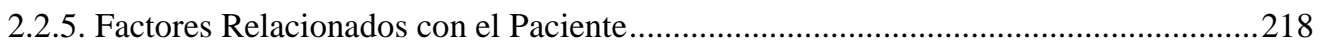

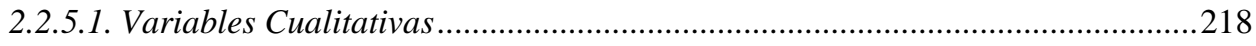

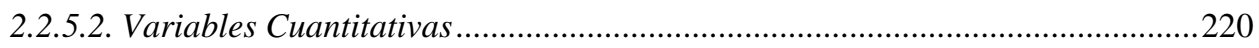

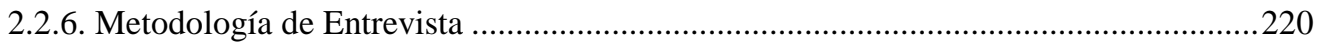

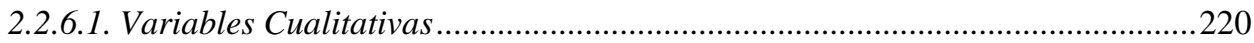

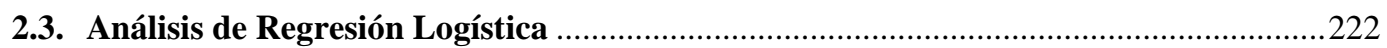

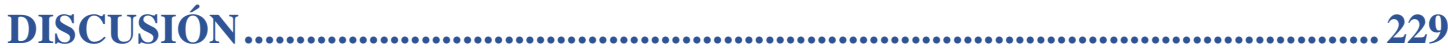

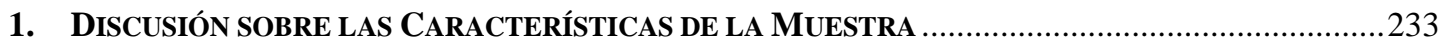

2. DISCUSIÓN SOBRE LOS RESULTADOS DE INCUMPLIMIENTO TERAPÉUTICO ……......................237

3. Discusión SOBRE LOS RESUltados de LOS FACTORES QUE INCIDEN EN LA ADHERENCIA ...245

3.1. Factores Relacionados con la Características Socioeconómicas ....................................245

3.2. Factores Relacionados con el Sistema o el Equipo de Asistencia Sanitaria ...................253

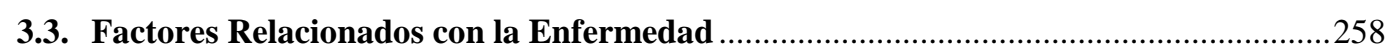

3.4. Factores Relacionados con el Tratamiento …………………………………………....22

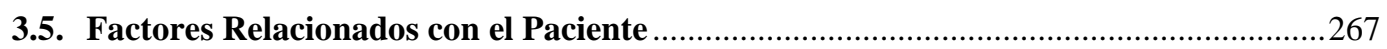

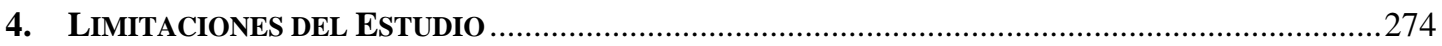

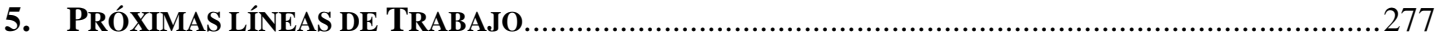


CONCLUSIONS

ANEXOS I

A-I. DEFINICIÓN FUNCIONAL DE PACIENTE PLURIPATOLÓGICO...............................................II

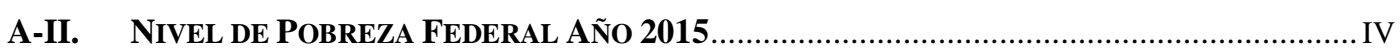

A-III. Condiciones Crónicas InCluidas en el Estudio, Categorizadas por SISTEMA Y DEFINIDAS POR FRECUENCIA DE PRESCRIPCIÓN Y CIE-9 ………….............. V

A-IV. Cuestionario de AdHerencia a la MedicaCión Morisky-Green-LeVine ........... VII

A-V. Versión VALIDAda en ESPañol del Cuestionario de AdHerencia a la MEDICACIÓN MORISKY-GREEN-LEVINE VIII

A-VI. Autorización para la Utilización del Cuestionario de AdHerencia a la MEDICACIÓN MORISKY-GREEN-LEVINE ..................................................................... IX

A-VII. Cuestionario de Recogida De Datos (VERSIÓn EN INGLÉS) ...................................... X

A-VIII. CuESTIONARIO DE RECOGIDA DE DATOS (VERSIÓn EN ESPAÑoL) .....................................

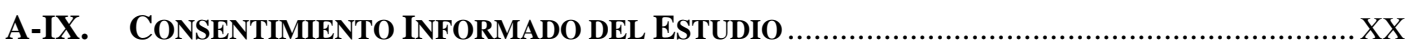

A-X. APROBACIÓN DEL ESTUdIO POR EL IRB DE LA UNIVERSIDAD ARMSTRONG STATE ....... XXIII

A-XI. APRObaCión del ESTUdio POR EL IRB DE La FUNDACIÓn ST. JOSEPH'S/CANDLER ... XXIV

A-XII. Certificado Protecting Human ReSEarch Participants XXV 


\section{ÍNDICE DE TABLAS}

Tabla 1-A. Factores Relacionados con las Características Socioeconómicas

Tabla 1-B. Continuación de los Factores Relacionados con las Características Socioeconómicas ......139

Tabla 2-A. Factores Relacionados con el Sistema o el Equipo de Asistencia Sanitaria

Tabla 2-B. Continuación de los Factores Relacionados con el Sistema o el Equipo de Asistencia

Sanitaria

Tabla 3-A. Factores Relacionados con la Enfermedad.

Tabla 3-B. Continuación de los Factores Relacionados con la Enfermedad

Tabla 4-A. Factores Relacionados con el Tratamiento.

Tabla 4-B. Continuación de los Factores Relacionados con el Tratamiento

Tabla 5-A. Factores Relacionados con el Paciente

Tabla 5-B. Continuación de los Factores Relacionados con el Paciente

Tabla 6. Distribución de los Pacientes del Estudio en Función de su Adherencia al

Tratamiento Farmacológico según el Cuestionario de Morisky-Green-Levine en la

Fase I del Estudio $(\mathrm{n}=150)$

Tabla 7. Grado de Adherencia al Tratamiento Farmacológico de los Pacientes del Estudio en

la Fase I según el Cuestionario de Adherencia Morisky-Green-Levine

Tabla 8. Distribución de los Pacientes No Adherentes $(n=78)$ en Función de las Causas de Incumplimiento en la Fase I del Estudio

Tabla 9. Distribución de los Pacientes No Adherentes $(n=78)$ por Conducta de Incumplimiento

Tabla 10. Factores Relacionados con las Características Socioeconómicas Estadísticamente

Significativas de la Fase I del Estudio (Variables Cualitativas)

Tabla 11. Factores Relacionados con el Sistema o el Equipo de Asistencia Sanitaria

Estadísticamente Significativos de la Fase I del Estudio (Variables Cualitativas)

Tabla 12. Diferencias Estadísticamente Significativas de los Factores Relacionados con el Sistema o el Equipo de Asistencia Sanitaria de la Fase I del Estudio (Variables Cuantitativas) ......181

Tabla 13. Factores Relacionados con la Enfermedad Estadísticamente Significativos

Asociados a Adherencia de la Fase I del Estudio (Variables Cualitativas)

Tabla 14. Factores Relacionados con el Tratamiento Estadísticamente Significativos en la

Fase I del Estudio (Variables Cualitativas)

Tabla 15. Diferencias Estadísticamente Significativas de los Factores Relacionados con

El Tratamiento de la Fase I del Estudio (Variables Cuantitativas)

Tabla 16. Factores Relacionados con el Paciente Estadísticamente Significativos en la Fase I del Estudio (Variables Cualitativas).....

Tabla 17. Clasificación del Modelo de Regresión Logística Binaria de la Fase I del Estudio 
Tabla 18. Resultados del Modelo Final Predictor de Incumplimiento al Tratamiento Farmacológico de la Fase I del Estudio por el Método Forward de Wald

Tabla 19. Resultados del Grado de Exactitud del Modelo de la Fase I del Estudio

Tabla 20. Distribución de los Pacientes del Estudio en Función de su Adherencia al Tratamiento Farmacológico según el Cuestionario Morisky-Green-Levine en Fase II del Estudio ( $\mathrm{n}=72$ )

Tabla 21. Distribución del Total de Pacientes del Estudio en función de su Adherencia al

Tratamiento Farmacológico según el Cuestionario Morisky-Green-Levine en la

Fase II del Estudio $(\mathrm{n}=150)$

Tabla 22. Grado Adherencia al Tratamiento Farmacológico de los Pacientes del Estudio en la Fase II de Estudio

Tabla 23. Distribución de los Pacientes No Adherentes $(n=121)$ en Función de las Causas de Incumplimiento en la Fase II del Estudio

Tabla 24. Distribución de los Pacientes No Adherentes $(n=121)$ por Conducta de Incumplimiento ..206

Tabla 25. Resultados de la Prueba de Rangos con Signo de Wilcoxon

Tabla 26. Resultados de los Estadísticos de Contraste de la Prueba de Rangos con Signo de Wilcoxon

Tabla 27. Factores Relacionados con las Características Socioeconómicas Estadísticamente Significativos de la Fase II del Estudio (Variables Cualitativas)

Tabla 28. Diferencias Estadísticamente Significativas de los Factores Relacionados con el Sistema o el Equipo de Asistencia Sanitaria de la Fase II del Estudio (Variables Cuantitativas)

Tabla 29. Factores Relacionados con la Enfermedad Estadísticamente Significativos Asociados a Adherencia de la Fase II del Estudio (Variables Cualitativas)

Tabla 30. Factores Relacionados con el Tratamiento Estadísticamente Significativos en la Fase II del Estudio (Variables Cualitativas)

Tabla 31. Factores Relacionados con el Paciente Estadísticamente Significativos en la Fase II del Estudio (Variables Cualitativas)

Tabla 32. Distribución de los Pacientes de la Muestra de la Fase II según Metodología de la Entrevista (Variables Cualitativas)

Tabla 33. Clasificación del Modelo de Regresión Logística Binaria de la Fase II del Estudio 224

Tabla 34. Resultados del Modelo Final Predictor de Incumplimiento al Tratamiento

Farmacológico de la Fase II del Estudio por el Método Forward de Wald 225

Tabla 35. Resultados del Grado de Exactitud del Modelo de la Fase II del Estudio 226 


\section{ÍNDICE DE FIGURAS}

Figura 1. Esperanza de Vida Mundial vs Países Desarrollados vs Países en Desarrollo, 1820-2003..7

Figura 2. Pirámide de Población Mundial Años 1950, 2015, 2050, y 2100

Figura 3. Mortalidad en la Población Mundial: Principales Causas de Muerte entre

las Enfermedades Crónicas, Año 2014 15

Figura 4. Principales Causas de Defunción en el Mundo Año 2000 vs 2012 ................................... 16

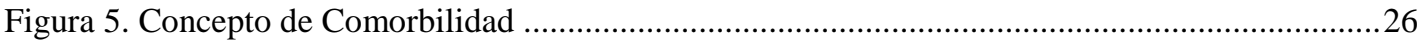

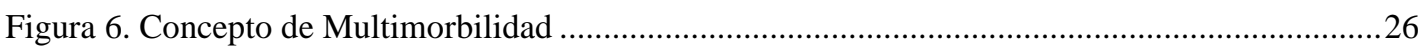

Figura 7. Porcentaje de Población Estadounidense con Múltiples Enfermedades Crónicas en 2010..29

Figura 8. Los Cinco Grupos o Dimensiones de la Adherencia Terapéutica ......................................43

Figura 9. Características de los Métodos de Evaluación de Adherencia Directos vs Indirectos .........57

Figura 10. Impacto de los Diferentes Factores de Riesgo de Mortalidad Prematura .........................73

Figura 11. Comparación de la Distribución de los Grupos de Población entre el Área Metropolitana de Savannah y a Nivel Nacional Estadounidense ...................................101

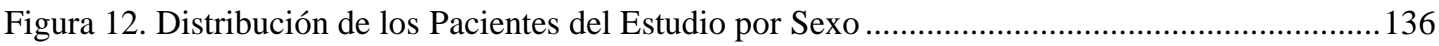

Figura 13. Distribución de los Pacientes del Estudio por Intervalos de Edad ....................................137

Figura 14. Distribución de los Grupos Raciales/Étnicos de la Población de Estudio......................... 140

Figura 15. Distribución de los Pacientes del Estudio por Lugar de Nacimiento ................................ 140

Figura 16. Distribución de los Sujetos del Estudio por Ingresos Anuales (en dólares americanos) ....141

Figura 17. Distribución de los Pacientes del Estudio por Situación Laboral..................................... 142

Figura 18. Dificultades de los Pacientes del Estudio para Acceder a la Medicación

Figura 19. Distribución de los Sujetos del Estudio por la Información Recibida acerca de su Tratamiento, Enfermedades Crónicas, e Información Adicional ....................................146

Figura 20. Distribución de los Pacientes del Estudio por Frecuencia de Consulta ............................. 147

Figura 21. Satisfacción de los Sujetos del Estudio con los Profesionales Sanitarios ......................... 147

Figura 22. Comunicación y Apoyo Social Percibido por los Pacientes del Estudio con los Profesionales Sanitarios 148

Figura 23. Distribución de las Enfermedades Crónicas de los Pacientes del Estudio ........................ 152

Figura 24. Distribución del Número Total de Condiciones Crónicas/Paciente

Figura 25. Distribución de los Pacientes del Estudio según Multimorbilidad ................................... 153

Figura 26. Distribución de los Pacientes del Estudio por Grupo de Riesgo Clínico ........................... 154

Figura 27. Distribución de los Pacientes del Estudio por el Número Total de Prescripciones. 157

Figura 28. Distribución de los Pacientes del Estudio por el Número de Pastillas/Día Incluidas en sus Tratamientos Farmacológicos 
Figura 29. Distribución de los Pacientes del Estudio por la Utilización de Inyecciones/Día, Inhaladores/Día y otras Formas Medicamentosas Prescritas en sus Tratamientos Farmacológicos.

Figura 30. Distribución de los Pacientes del Estudio según las Recomendaciones de Dieta para la/s Patología/s Padecida/s (n=147)

Figura 31. Distribución de los Pacientes del Estudio Según su Empleo de Técnicas de Monitorización fuera del Entorno Clínico

Figura 32. Distribución de los Pacientes del Estudio Según Grado de Polifarmacia

Requerido en su Tratamiento

Figura 33. Distribución de los Pacientes del Estudio por su Dependencia Física y

Funcional en la Realización de las Actividades de la Vida Diaria

Figura 34. Auto-Valoración del Estado de Salud de los Pacientes en el Último Año......

Figura 35. Distribución de los pacientes del Estudio por su Conocimiento acerca de las

Condiciones Padecidas y su Tratamiento Farmacológico

Figura 36. Distribución de los Pacientes del Estudio por la Persona Responsable para la Toma y Control de su Medicación.

Figura 37. Distribución de los Pacientes del Estudio en Función del Método/Estrategia Utilizada para la Toma de la Medicación

Figura 38. Resultados de Adherencia al Tratamiento Farmacológico en la Fase I del Estudio según el Cuestionario Morisky-Green-Levine $(n=150)$.....

Figura 39. Grado de Adherencia al Tratamiento Farmacológico de los Pacientes del Estudio en la Fase I según el Cuestionario de Adherencia Morisky-Green-Levine

Figura 40. Distribución de los Pacientes No Adherentes $(n=78)$ en Función de las Causas de su Comportamiento Incumplidor en la Fase I del Estudio.

Figura 41. Área Bajo la Curva (ROC) del Modelo de la Fase I del Estudio.

Figura 42. Resultados de Adherencia al Tratamiento Farmacológico según el Cuestionario Morisky-Green-Levine en la Segunda Entrevista del Estudio $(n=72)$

Figura 43. Resultados de Adherencia al Tratamiento Farmacológico en la Fase II del Estudio según el Cuestionario Morisky-Green-Levine $(n=150)$.

Figura 44. Grado de Adherencia al Tratamiento Farmacológico de los Pacientes del Estudio en la Fase II según el Cuestionario de Adherencia Morisky-Green-Levine

Figura 45. Distribución de los Pacientes No Adherentes (n=121) en Función de las

Causas de su Comportamiento Incumplidor en la Fase II del Estudio

Figura 46. Área Bajo la Curva (ROC) del Modelo de la Fase II del Estudio 226 


\section{RESUMEN}

Introducción: a pesar de la amplia oferta y la contrastada efectividad de los tratamientos a largo plazo que existen en la actualidad para controlar la clínica y la progresión de las enfermedades crónicas, la efectividad de estos puede quedar comprometida debido al elevado incumplimiento existente en la población. Relativamente, poco es conocido sobre la adherencia al tratamiento en sujetos que padecen enfermedades crónicas pertenecientes a grupos de población vulnerable. Un mayor conocimiento de los factores y de las barreras que condicionan y/o determinan el tratamiento terapéutico de estos grupos poblacionales permitirá a los profesionales sanitarios identificar y controlar a aquellas personas con problemas de incumplimiento.

Objetivos: analizar el fenómeno de incumplimiento, sus causas, y los factores relacionados de acuerdo al marco conceptual propuesto por la OMS: i) factores socioeconómicos; ii) factores relacionados con el sistema o el equipo de asistencia médica; iii) factores relacionados con la enfermedad; iv) factores relacionados con el tratamiento y v) factores relacionados con el paciente.

Material y Métodos: estudio observacional, descriptivo, y transversal, con dos momentos de recogida de información en el tiempo, en los primeros seis meses tras la inicialización de un nuevo tratamiento y al noveno mes de tratamiento, realizado en dos centros médicos comunitarios del condado de Chatham, GA, USA. Sujetos $\geq 19$ años, con al menos una enfermedad crónica y régimen farmacológico prescrito en los primeros seis meses de tratamiento fueron invitados a participar en el estudio. Se utilizó como instrumento de medida el cuestionario de adherencia a mediación Morisky-Green-Levine para analizar dicho cumplimiento. 
Resultados: un total de 150 pacientes (49.8 \pm 10.9 años, 36.7\% hombres) fueron entrevistados. El porcentaje de incumplimiento evaluado al noveno meses de tratamiento alcanza el $81 \%$, siendo el olvido de la medicación la principal causa de incumplimiento. El análisis bivariado ha identificado la raza/etnia, el lugar de nacimiento, las dificultades en el transporte, la comunicación y el apoyo social recibido, el grupo de riesgo clínico del paciente, las prácticas de monitorización fuera del entorno clínico, y los métodos o estrategias para recordar la toma de medicación como factores estadísticamente significativos asociados con el incumplimiento del tratamiento farmacológico $(\mathrm{p}<0.005)$. El análisis multivariado establece la raza afroamericana (odds ratio ajustado $\left[\mathrm{OR}_{\mathrm{A}}\right]=1.07$, intervalo de confianza $95 \%[\mathrm{IC}]=1.03-8.31$, vs blancos), la etnia hispana/latina $\left(\mathrm{OR}_{\mathrm{A}}=2.11,95 \%\right.$ [IC] $=1.91-35.56$ vs blancos $)$, las dificultades de transporte para recoger las medicinas $\left(\mathrm{OR}_{\mathrm{A}}=1.98,95 \%[\mathrm{IC}]=2.06-25.41\right)$, el grupo de riesgo clínico $\mathrm{G} 2\left(\mathrm{OR}_{\mathrm{A}}=5.49,95 \%\right.$ [IC] $=1.54-19.57$, vs $\left.\mathrm{G} 3\right)$, y la ausencia de un método o estrategia para recordar la toma de medicación $\left(\mathrm{OR}_{\mathrm{A}}=6.32,95 \%\right.$ [IC] $\left.=1.61-24.83\right)$, como variables independientes predictoras de incumplimiento.

Conclusiones: el cumplimiento al tratamiento farmacológico de las enfermedades crónicas de los grupos de población vulnerables es más elevado que el incumplimiento de la población general de referencia de los países desarrollados. La mejor comprensión de los factores del marco multidimensional de la OMS ha permitido la construcción de un perfil predictivo de paciente en riesgo de incumplimiento para ayudar a los profesionales sanitarios a identificar a dichos pacientes y proporcionarles recomendaciones y apoyo para evitar el incumplimiento y mejorar su calidad de vida.

Implicaciones Prácticas: una apreciación de las barreras relacionadas con la adherencia al tratamiento farmacológico permite diseñar futuras intervenciones desde un punto de vista multidimensional para mejorar la calidad asistencial y reducir las desigualdades en los grupos de población vulnerables. Futuras investigaciones centradas en estudios de comparación trans-poblacionales, particularmente en aquellos sistemas donde estas poblaciones reciben más asistencia, como por ejemplo los sistemas de 
atención sanitaria universal, revelarán nuevas observaciones aplicables a estas poblaciones para mejorar el acceso y la calidad a la atención sanitaria y, por tanto, mejorar su bienestar y calidad de vida.

Palabras Clave: adherencia, barreras al tratamiento terapéutico, grupos de población vulnerables, enfermedades crónicas, calidad de vida, desigualdades en salud. 


\section{ABSTRACT}

Introduction: although the current availability of a wide range of effective long-term therapies to control the symptoms and the progression of chronic diseases, the effectiveness of these therapies may be reduced due to the alarmingly high rates of nonadherence. Relatively little is known about treatment adherence among vulnerable populations with chronic diseases. A greater appreciation of factors and barriers that condition and/or determine treatment adherence among vulnerable populations will allow health professionals to identify and manage patients with those issues.

Objectives: to analyze the extend, the causes, and the related factors of medication adherence according the conceptual framework proposed by the WHO: i) social and economic factors, ii) healthcare team and system-related factors, iii) condition-related factors, iv) therapy-related factors, and v) patient-related factors.

Materials and Methods: an observational, cross sectional study across two time points, including data collection within first six months of treatment and data collection at the ninth month of treatment, was carried out in two community health centers from Chatham County, Georgia, in the United States among subjects $\geq 19$ years with at least one chronic condition and a prescribed meditation within the first 6 months of treatment, were invited to participate in the study. The Morisky-Green-Levine adherence questionnaire was used to assess medication adherence.

Results: a total of 150 patients $(49.8 \pm 10.9$ years, $36.7 \%$ men $)$ were interviewed. Non-adherence rate was $81 \%$ at the $9^{\text {th }}$ month of treatment, being forgetfulness in taking medication the main reason for non-adherence. Factors-related identified in the bivariate analyses were: race/ethnicity, place of birth, transportation issues, communication received, social support received, clinical risk group, monitoring techniques in non- 
clinical settings, and medication reminders $(\mathrm{p}<0.005)$. In the multivariate analyses, AfroAmericans (adjusted odds ratio $\left[{ }_{A} \mathrm{OR}\right]=1.07,95 \%$ confidence interval $[\mathrm{CI}]=1.03-8.31$, vs whites), Hispanic/Latinos ( ${ }_{\mathrm{A}} \mathrm{OR}=2.11,95 \% \mathrm{CI}=1.91-35.56$, vs whites), transportation issues to pick up medicines $\left({ }_{\mathrm{A}} \mathrm{OR}=1.98,95 \% \mathrm{CI}=2.06-25.41\right)$, clinical risk group $\mathrm{G} 2$ $\left({ }_{\mathrm{A}} \mathrm{OR}=5.49,95 \% \mathrm{CI}=1.54-19.57, \mathrm{vs} \mathrm{G} 3\right)$, and lack of reminders to remember the medication intake $\left({ }_{\mathrm{A}} \mathrm{OR}=6.32,95 \% \mathrm{CI}=1.61-24.83\right)$, were independently associated with non-adherence.

Conclusions: medication non-adherence rates among vulnerable populations groups is higher than among reference population in developed countries. A larger comprehension of the multidimensional framework proposed by the WHO has allowed to create a non-adherence predictive risk profile. This profile will help health professionals to identify such patients and provide them with recommendations and social support to avoid the non-adherence problem and improve their quality of live.

Practical Implications: an understanding of the related barriers to medication adherence allow to design further interventions from a multidimensional perspective to improve healthcare quality and reduce inequalities among vulnerable populations. Future research focused on cross-population comparisons, particularly on those healthcare systems where vulnerable populations receive more assistance, e.g., universal healthcare systems, will yield new findings that can improve access to and quality of healthcare and, consequently, improve their well-being and quality of life.

Key Words: adherence, barriers to medication adherence, vulnerable populations, condition diseases, quality of life, health disparities. 
INTRODUCCIÓN 



\section{Las Enfermedades Crónicas}

En la historia de la epidemiología muchos científicos han desempeñado un papel transcendental para entender y explicar enfermedad, trastornos, o sucesos relacionados con la Salud y la mortalidad desde un punto de vista científico observacional. Desde los tiempos de Hipócrates (460-377 a.C.) hasta los tiempos más modernos de John Snow, Louis Pasteur o Robert Koch, el estudio de la epidemiología recaía fundamentalmente en la causa y control de las epidemias trasmitidas por enfermedades transmisibles, puesto que históricamente, las enfermedades infecciosas eran las principales causas de muerte entre la población. El desafío de la epidemiología se centraba entonces en aislar la bacteria, virus o parásito responsable de una única enfermedad. Así es como nació la epidemiología moderna de manos de John Snow. Sus estudios sobre los brotes de cólera realizados en Londres a mitad del siglo XIX por una "materia mórbida", a la que más tarde Robert Koch aisló e identificó como Vibrio cholerae, llevaron a asentar las bases de la epidemiología moderna. Las contribuciones de Snow dieron lugar a una nueva era en la comprensión y control de enfermedades infecciosas hasta tal punto, que actualmente se considera a Snow el padre de la epidemiología moderna.

Como consecuencia del mejor entendimiento y control de las enfermedades infecciosas, el mundo experimentó una serie de fenómenos que condujeron a nuevos cambios epidemiológicos y tendencias poblacionales. De especial interés es el fenómeno 
producido en las últimas dos o tres décadas en las que se produce, por múltiples factores, un cambio de patrón epidemiológico por la aparición de enfermedades crónicas. Entre los factores que favorecieron el cambio de patrón, se encuentran las mejoras socioeconómicas y la implantación de calendarios de vacunación que alcanzaron amplias coberturas poblacionales. Además, se produjo una concienciación de la población en relación al binomio Salud-enfermedad que hizo que la población y los gobiernos tomaran conciencia del valor de la Salud como recurso esencial para el individuo y la Sociedad ${ }^{1}$.

Las enfermedades crónicas, también conocidas como no transmisibles, no comunicables o enfermedades relacionadas con el estilo de vida, como son por ejemplo enfermedades cardiovasculares, respiratorias, osteomusculares, diabetes, o cánceres, han desplazado a las enfermedades infecciones como cólera, neumonía, o tuberculosis, como principales causas de muerte en la población mundial. Las enfermedades crónicas han llegado a convertirse en las enfermedades del siglo XXI y son objeto de estudio de la mayoría de los proyectos de la investigación aplicada, epidemiológica, o de Salud Pública. Las enfermedades crónicas originan importantes repercusiones económicas, sociales, y de Salud en la población y en los Sistemas de Salud de todos los países con independencia del modelo sanitario que exista, ya sea un Sistema Nacional de Salud, Sistema Mixto o Privado. El fenómeno de las enfermedades crónicas destaca por su elevada prevalencia entre la población, y llega a provocar la co-existencia de más de una enfermedad en un mismo individuo. Este hecho ha dado paso a un continuo y creciente interés por parte de la comunidad científica por estudiar y comprender la compleja interrelación y combinación de patologías y enfermedades co-existentes en un mismo individuo.

El fenómeno de las enfermedades crónicas demanda de una mejor compresión de los pacientes, de la Sociedad y de los Sistemas Sanitarios. A continuación, se examina el ámbito, alcance, y repercusión de las enfermedades crónicas para realizar posteriores abordajes en el campo de la Salud Pública de acuerdo a las necesidades que presenta la Sociedad actual. 


\subsection{El Progresivo Aumento de la Esperanza de Vida: Avances en Materia Sanitaria y Transición Epidemiológica}

Desde los inicios de la humanidad el ser humano ha perseguido prolongar su vida. Desde la antigua civilización china, donde ya se utilizaban metales con la finalidad de aumentar la longevidad, hasta la Europa occidental, donde se perseguía un elixir que curara enfermedades y prolongara la vida eternamente, numerosas civilizaciones han centrado sus esfuerzos en la búsqueda de un método para aplazar la muerte y vivir lo máximo posible. Sin embargo, no será hasta el progreso de las políticas sanitarias, cuando los intentos de sustentar la vida empiecen a ser efectivos. Desde entonces, el aumento de la longevidad del ser humano no ha parado de incrementar, y hoy en día, el ser humano disfruta de la mayor esperanza de vida desde su existencia ${ }^{2}$.

El aumento de la longevidad es uno de los logros más importantes de la historia de la Humanidad, pero también representa uno de los mayores desafíos del siglo $\mathrm{XXI}^{2,3}$. En el último siglo, la población mundial ha experimentado un elevado incremento de la esperanza de vida media ${ }^{2-8}$, pasando de situarse en 31 años a comienzos de $1900^{4}$, hasta superar ligeramente los 70 años en la actualidad, y alcanzar, según las proyecciones, los 76 años hacia la mitad de siglo, y los 82 años a finales de éste ${ }^{4-6}$.

Los primeros incrementos de expectativa de vida empezaron a producirse previamente a la revolución industrial, sin embargo, estos incrementos fueron mínimos e irregulares ${ }^{7}$. Es a partir de 1870 , cuando comienzan a producirse los primeros aumentos significativos en la esperanza de vida como consecuencia de una serie de avances en materia sanitaria, que fueron resultado de los fenómenos de industrialización y modernización que el mundo experimentó en aquellos momentos ${ }^{7,8}$. Los avances en materia sanitaria fueron posibles gracias a las mejoras en Sanidad, los servicios de 
saneamiento, la educación, el acceso a vivienda, las medidas de Salud Pública, y el incremento de ingresos, que originaron una notable disminución de la mortalidad, especialmente de la mortalidad infantil y juvenil ${ }^{2-10}$. Por primera vez, los niveles de mortalidad infantil y juvenil se situaron en torno al 2-3\% hacia mitad del siglo XX, alejándose de los históricos niveles del 20-30\%, y alcanzando el 0.5-1\% tan sólo unas décadas después ${ }^{7,8}$.

Con el desarrollo de las mejoras sanitarias, el mundo experimentó una reducción de enfermedades infecciosas, fenómeno conocido como transición epidemiológica. Desde la perspectiva de la Salud Pública, la transición epidemiológica hace referencia al cambio producido en los altos niveles de mortalidad, causados principalmente por las enfermedades infecciosas, hacia niveles reducidos de mortalidad, pasando a ser las enfermedades crónicas degenerativas la principal causa de mortalidad ${ }^{4}$. Como resultado de esta transición epidemiológica, la población pudo sobrepasar la etapa infantil y juvenil sin sucumbir a ninguna enfermedad infecciosa. Una vez superadas estas etapas críticas, las probabilidades de alcanzar edades más avanzadas incrementaron considerablemente y como consecuencia aumentó el riesgo a padecer enfermedades degenerativas crónicas. El resultado final, fue un giro en las tasas de mortalidad de enfermedades infecciosas hacia enfermedades crónicas ${ }^{11}$.

Es importante reseñar que las mejoras sanitarias no llegaron al mismo tiempo en todas las regiones del planeta. Mientras que los países más prósperos económicamente fueron los primeros en experimentar los avances sanitarios a finales del siglo XIX, en las regiones menos desarrolladas los avances sanitarios se iniciaron significantemente más tarde, e incluso a día de hoy, algunas regiones no han terminado de completar la transición epidemiológica ${ }^{10}$. Este hecho ha provocado las diferencias en expectativa de vida que hoy conocemos entre los países desarrollados y en vías de desarrollo. Por ejemplo, una persona que nace en un país desarrollado disfruta en la actualidad de una esperanza de vida media de 79 años mientras que una persona que nace en un país en vías de desarrollo disfruta de una esperanza de vida media de 62 años ${ }^{10}$. 
Asimismo, la llegada de las mejoras sanitarias a distintos intervalos de tiempo, originó grandes diferencias en los ritmos de crecimiento de la esperanza de vida entre los países desarrollados y los menos desarrollados ${ }^{12}$. Prueba de este hecho es que, durante la primera mitad del siglo XX, el incremento de la esperanza de vida en los países desarrollados estuvo caracterizada por su gran velocidad, mientras que, en la segunda mitad, sufrió una deceleración que se extiende hasta el día de hoy ${ }^{12}$ (Figura 1).

En cambio, en los países menos desarrollados, la dinámica en el incremento de la esperanza de vida ha sido totalmente contraria, experimentando un incremento en la esperanza de vida prácticamente nulo en la primera mitad del siglo y uno muy marcado en la segunda mitad que se prolonga hasta el presente ${ }^{12}$ (Figura 1).

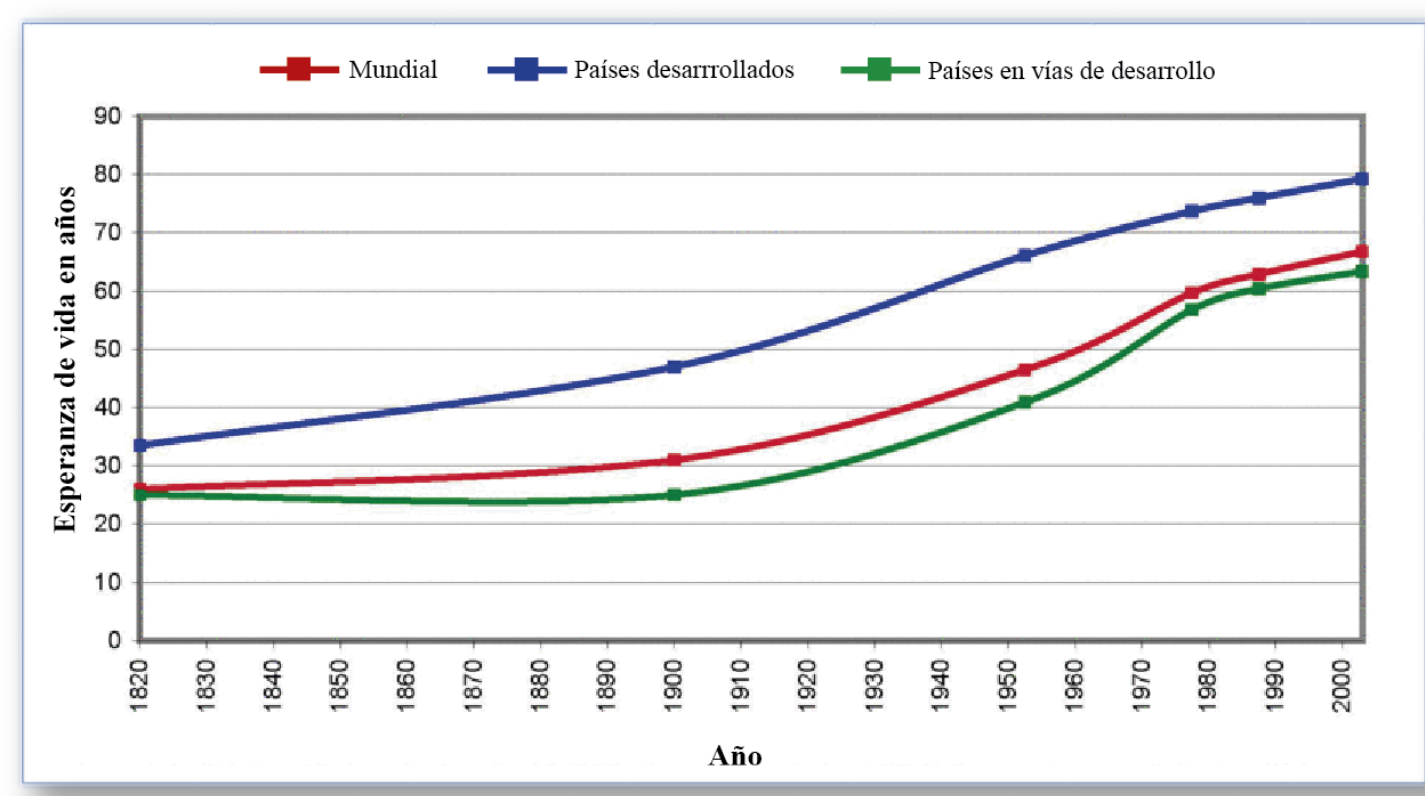

* Francia usado como país representante de los países desarrollados hasta 1900.

Figura 1. Esperanza de Vida Mundial vs Países Desarrollados vs Países en Desarrollo, 1820-2003.

* Obtenido de Goklany, 2007 ${ }^{12}$, modificado por autor. 
Estos acontecimientos explican las diferencias en los incrementos de vida de los países en la segunda mitad del siglo XX. Por ejemplo, el incremento de esperanza de vida fue de tan solo 9 años en los países desarrollados como Australia, Japón, Nueva Zelanda, la región de América del Norte, y la mayor parte de los países europeos, que fueron los primeros en experimentar las mejoras sanitarias. En los países africanos, los países más pobres de Asia, la Región del Mediterráneo Oriental y América Latina, que a día de hoy todavía no han completado la transición sanitaria, el incremento de la esperanza de vida alcanzado en la segunda mitad del siglo XX fue de 17 años. Y, por último, los países en desarrollo con baja mortalidad como por ejemplo Armenia, Argentina, Chile, China, o Cuba que han completado la transición demográfica recientemente, el incremento de esperanza de vida experimentado fue de 26 años ${ }^{10}$.

El marcado descenso de los niveles de mortalidad a nivel mundial motivado por los avances en materia sanitaria, produjo la aparición de un fenómeno demográfico poblacional denominado la transición demográfica ${ }^{2-4,10}$. La transición demográfica, es el término empleado para explicar el rápido crecimiento de la población mundial marcado por profundos cambios en los niveles demográficos de mortalidad y natalidad ${ }^{13}$.

Anteriormente a este período de transición, el mundo estaba caracterizado por poseer una esperanza de vida corta, niveles altos de mortalidad y de natalidad, una población joven, y un crecimiento lento. Durante la transición, los niveles de mortalidad descendieron en primer lugar, acompañados posteriormente por los de natalidad. El resultado fue un gran crecimiento de la población, produciéndose un desplazamiento hacia niveles bajos de fertilidad, una esperanza mayor de vida, y una población con una mayor proporción de personas de edad avanzada ${ }^{13}$.

La transición demográfica comienza alrededor de inicios del siglo XIX, aunque no empieza a ser más notable hasta finales de siglo como consecuencia del mayor progreso en los avances sanitarios ${ }^{7,8}$. El fenómeno de la transición se ha extendido actualmente por todo del mundo, y se prevé que finalice en todas las regiones del planeta en torno al año $2100^{13}$. 
El elevado crecimiento de la población mundial viene marcado por dos fases distintas en la transición demográfica ${ }^{4,13}$. La primera fase está caracterizada por un marcado incremento de la población, ya que, a medida que las tasas de mortalidad iban disminuyendo, debido a los avances sanitarios y al desarrollo de la transición epidemiológica, las tasas de natalidad se mantenían elevadas. En esta primera fase, la población alcanzó niveles de crecimiento superiores al $2 \%$ anual y se prolongó hasta 1980, año que se considera el punto intermedio de la transición ${ }^{4}$.

La segunda fase está caracterizada por la deceleración del ritmo del crecimiento de la población mundial hasta niveles anuales del 1.18\% (año 2015), debido al descenso de la natalidad que se aproximó cerca de los niveles de mortalidad ${ }^{4}$. El periodo de transición mundial tiene como resultado un drástico incremento neto de la población mundial, pasando de los 1.7 billones de personas al inicio del siglo XX, a los 2.5 billones en 1950, y sobrepasando los 6 billones de personas en el año $2000^{4}$. Actualmente la población mundial se sitúa en los 7.3 billones de personas (año 2015), y las proyecciones de futuro indican que la población continuará creciendo hasta alcanzar los 9.7 billones en el año 2050, y los 11.2 billones en el año 2100, continuando con la dinámica de deceleración experimentada en las últimas décadas ${ }^{4}$.

La llegada de las mejoras sanitarias en diferentes espacios de tiempo también caracterizó las dinámicas de transición demográfica entre los países más desarrollados económicamente y los países menos desarrollados. En el caso de los países económicamente más desarrollados, la transición demográfica se inicia en el siglo XIX, y se encuentra totalmente completada en la actualidad ${ }^{14}$. En estos países, el actual crecimiento neto de la población es consecuencia del descenso de la mortalidad en la edad adulta, y aunque el crecimiento se mantiene todavía positivo, se prevé un crecimiento neto negativo de la población para la mayoría de países desarrollados en las próximas décadas, cuando el decline de las tasas de natalidad supere al decline de las tasas de mortalidad $^{14}$. 
Por otra parte, en los países menos desarrollados económicamente, el comienzo de la transición se inicia más tarde y todavía hoy está en proceso ${ }^{10}$. Un ejemplo de este fenómeno lo constituyen los países del África Subsahariana, los cuales están experimentando la primera fase de la transición demográfica. Las tasas de mortalidad entre la población se mantienen elevadas debido principalmente a la severa pandemia del virus de la inmunodeficiencia humana (VIH) que esta región está experimentando. Sin embargo, la población continuará creciendo a un ritmo acelerado debido a las altas tasas de natalidad que se mantendrán por encima de las tasas de mortalidad, duplicando, triplicando, o cuadriplicando la población en tamaño, como por ejemplo será el caso de países como Níger ${ }^{10}$.

\subsection{La Transformación de la Estructura de Edad de la Población Mundial: el Envejecimiento Demográfico}

El descenso en los niveles de mortalidad y de natalidad que se produjeron en el transcurso de la transición demográfica mundial originaron profundos cambios demográficos en la composición de los grupos de edad de la población ${ }^{2-4,6-8,10-14}$. Al cambio en la estructura por edades de una población caracterizado por un aumento relativo de personas mayores y una reducción relativa de niños y jóvenes, se denomina envejecimiento demográfico ${ }^{15}$, no confundir con la denominación "envejecimiento" referido a una población, puesto que el proceso de envejecimiento es irreversible y exclusivo del ser humano, a diferencia del envejecimiento demográfico que es reversible y exclusivo de las poblaciones ${ }^{15,16}$. 
El envejecimiento demográfico caracteriza la dinámica poblacional de las últimas décadas de la mayor parte de las regiones del planeta, especialmente de la mayoría de los países desarrollados y gran parte de los países en vías de desarrollo. Prueba de ello son los 901 millones de personas de 60 o más años de edad que viven actualmente en el mundo y que representan el 12\% de la población mundial (año 2010), comparado con los 202 millones de personas que vivían en 1950 y que representaban el 8\% del total de la población ${ }^{3}$. Las previsiones indican que el envejecimiento demográfico cobrará más fuerza en el futuro y la población mundial de 60 o más años de edad superará el $20 \%$ a mitad de siglo XXI ${ }^{2-6,10,11,14}$.

En términos gráficos, la dinámica poblacional de las últimas décadas queda reflejada al comparar entre sí las pirámides de 1950 y $2015^{4}$ (Figura 2). En estas representaciones, se observa como la base de la pirámide de población de 2015 experimenta una notable transformación respecto a la pirámide de 1950 al ir perdiendo anchura, y ganarla por su cúspide. La conversión de la base de la pirámide corresponde al descenso de la natalidad, mientras que las ganancias en la cúspide corresponden al aumento del número de personas en edad avanzada. En el futuro, la pirámide poblacional continuará transformando su base y los grupos más jóvenes de población seguirán reduciendo en importancia, y la pirámide poblacional alcanzará formas más rectangulares en 2050 y se aproximará a una forma rectangular en $2100^{4}$ (Figura 2).

La gran proporción de personas mayores en la población mundial plantea nuevos desafíos para la Sociedad y los gobiernos de los países, puesto que el paso del tiempo en el ser humano conduce de manera irreversible a un proceso caracterizado por una serie de modificaciones morfológicas, funcionales, y psicológicas que conllevan a un deterioro paulatino de órganos y sus funciones asociadas a una disminución de la capacidad de respuesta a los retos como son los agentes nocivos. Con una elevada proporción de personas mayores a nivel mundial, los procesos crónicos alcanzan una mayor prevalencia que los procesos infecciosos en la Sociedad y conducen a un marcado incremento del número de enfermedades crónicas padecidas por la población ${ }^{17-19}$. 


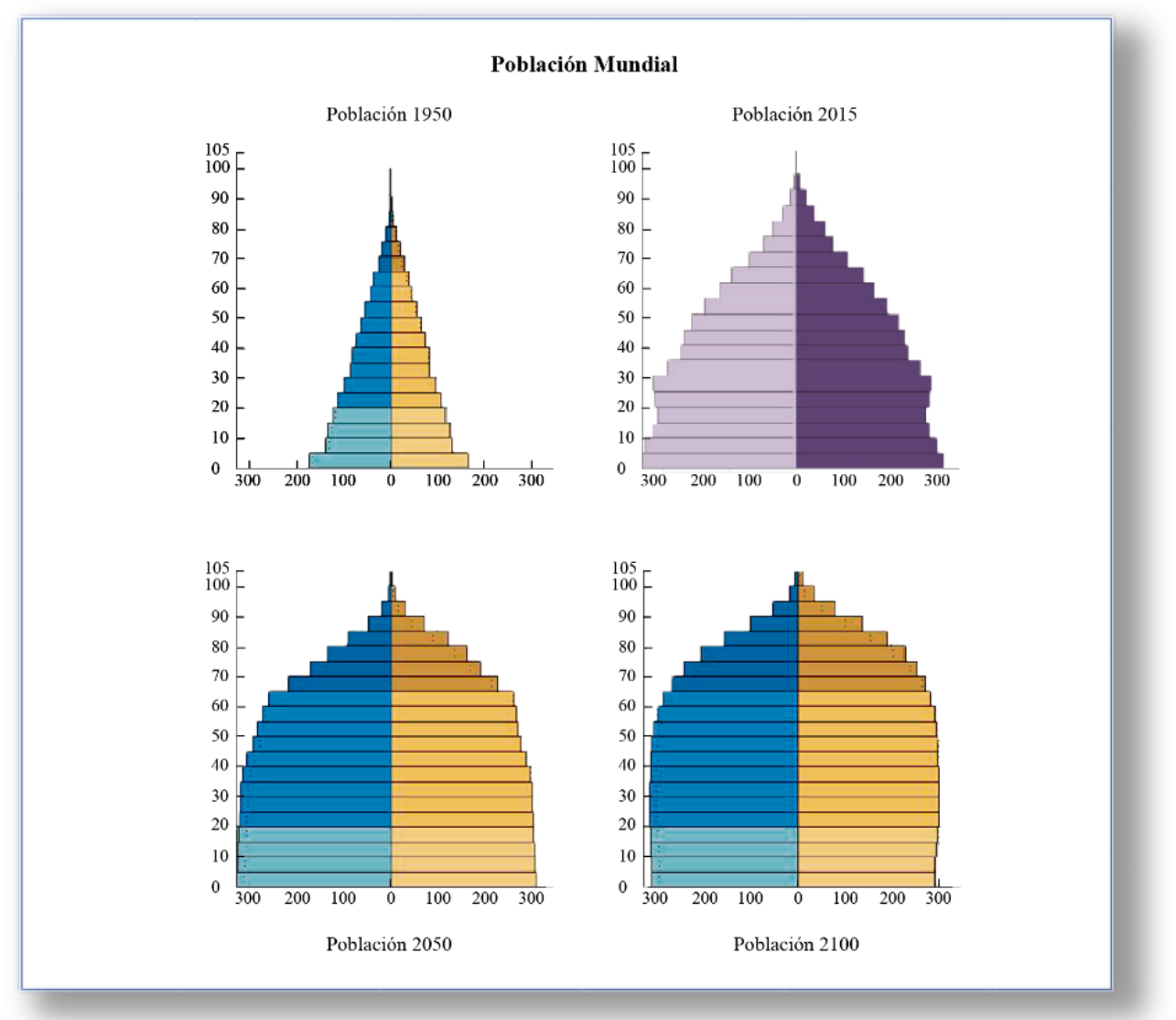

Figura 2. Pirámide de Población Mundial Años 1950, 2015, 2050, y 2100.

* Obtenido de United Nations, 20154, modificado por autor.

Además, gracias a los constantes avances tecnológicos en Medicina, los progresos en las políticas sanitarias de Salud, y las mejoras de vida de la población, el incremento de enfermedades no trasmisibles se verá especialmente acentuado por la mayor supervivencia de pacientes con enfermedades crónicas que solían ser fatales en décadas $\operatorname{pasadas}^{20}$. 


\subsection{Enfermedades Crónicas, Enfermedades No Transmisibles o Enfermedades No Comunicables}

Las enfermedades crónicas son referidas generalmente con el término de enfermedades no transmisibles o enfermedades no comunicables, utilizados para diferenciarlas de aquellas enfermedades infecciosas o transmisibles. Sin embargo, algunas enfermedades crónicas tienen un componente infeccioso en su causa, como, por ejemplo, el virus del papiloma humano, la hepatitis B, y el Helicobacter pylori que pueden desarrollar enfermedades no transmisibles como cáncer de cérvix, cáncer de hígado, y cáncer de estómago. Asimismo, algunas enfermedades transmisibles como el virus de la inmunodeficiencia humana (VIH) o la tuberculosis (TB), han pasado de ser enfermedades infecciosas letales, a ser consideradas enfermedades crónicas puesto que son controlables y de progresión lenta ${ }^{20}$. Cuando las enfermedades trasmisibles se convierten en problemas crónicos, la delimitación entre enfermedades no transmisibles y transmisibles se vuelve artificial y difícil de determinar.

Además, las enfermedades crónicas también son referidas en diferentes contextos como condiciones o patologías crónicas, a pesar de que estos términos difieren ligeramente en significado. Ante esta coyuntura, en la presente memoria de Tesis, se utilizará la definición propuesta por la Organización Mundial de la Salud (OMS) para definir enfermedades, patologías, o condiciones crónicas o también conocidas como enfermedades no comunicables como aquellas de larga duración con una progresión generalmente lenta ${ }^{21}$. Esta definición se extiende más allá de la definición clásica de enfermedades no transmisibles, y engloba ciertas enfermedades transmisibles o comunicables, como, por ejemplo, cánceres de origen infeccioso, hepatitis virales, desórdenes mentales, deficiencias, discapacidades, y desórdenes musculo-esqueléticos ${ }^{22}$. 


\subsection{Situación Epidemiológica e Impacto de las Enfermedades Crónicas}

Las enfermedades crónicas representan la mayor carga de Salud en la mayoría de los países desarrollados y en vías de desarrollo, a excepción del continente africano ${ }^{23}$.

Los procesos crónicos se caracterizan por su alta prevalencia en la Sociedad, y la elevada carga de morbilidad y de mortalidad que causan en el individuo. Las enfermedades crónicas se extienden globalmente, sin distinción de región o clase social. Los países de ingresos medios y bajos son los más afectados, acarreando el $80 \%$ de las muertes producidas a nivel mundial por enfermedades crónicas, mientras que los países con altos ingresos el porcentaje sólo alcanza el $20 \%{ }^{22}$. Además, las enfermedades crónicas se han convertido en una amenaza para las propias personas que padecen las enfermedades, sus familias, los Sistemas de Salud, y la propia Sociedad ${ }^{24}$ debido al impacto en materia económica y en recursos de Salud que desencadenan insostenibilidad.

Actualmente es muy difícil establecer la prevalencia de enfermedades crónicas a nivel mundial, pues no hay suficiente información disponible de todas las condiciones crónicas en todos los países del mundo, particularmente en los países menos desarrollados. Sin embargo, en los países más desarrollados como por ejemplo Estados Unidos (EEUU), la información acerca de la prevalencia de estas enfermedades está bien documentada, y sitúan la prevalencia de al menos una enfermedad crónica entre los adultos estadounidenses en un $51.7 \%$.

Las patologías crónicas han llegado a convertirse en la principal causa de muerte a nivel mundial ${ }^{26}$, provocando 38 millones de fallecimientos en el año 2012, de los 56 millones de muertes que se produjeron ese mismo año a nivel mundial. Las enfermedades cardiovasculares son responsables del mayor número de fallecimientos, con 17.5 millones, seguidas de cáncer, enfermedades crónicas respiratorias, y diabetes (Figura 3). 


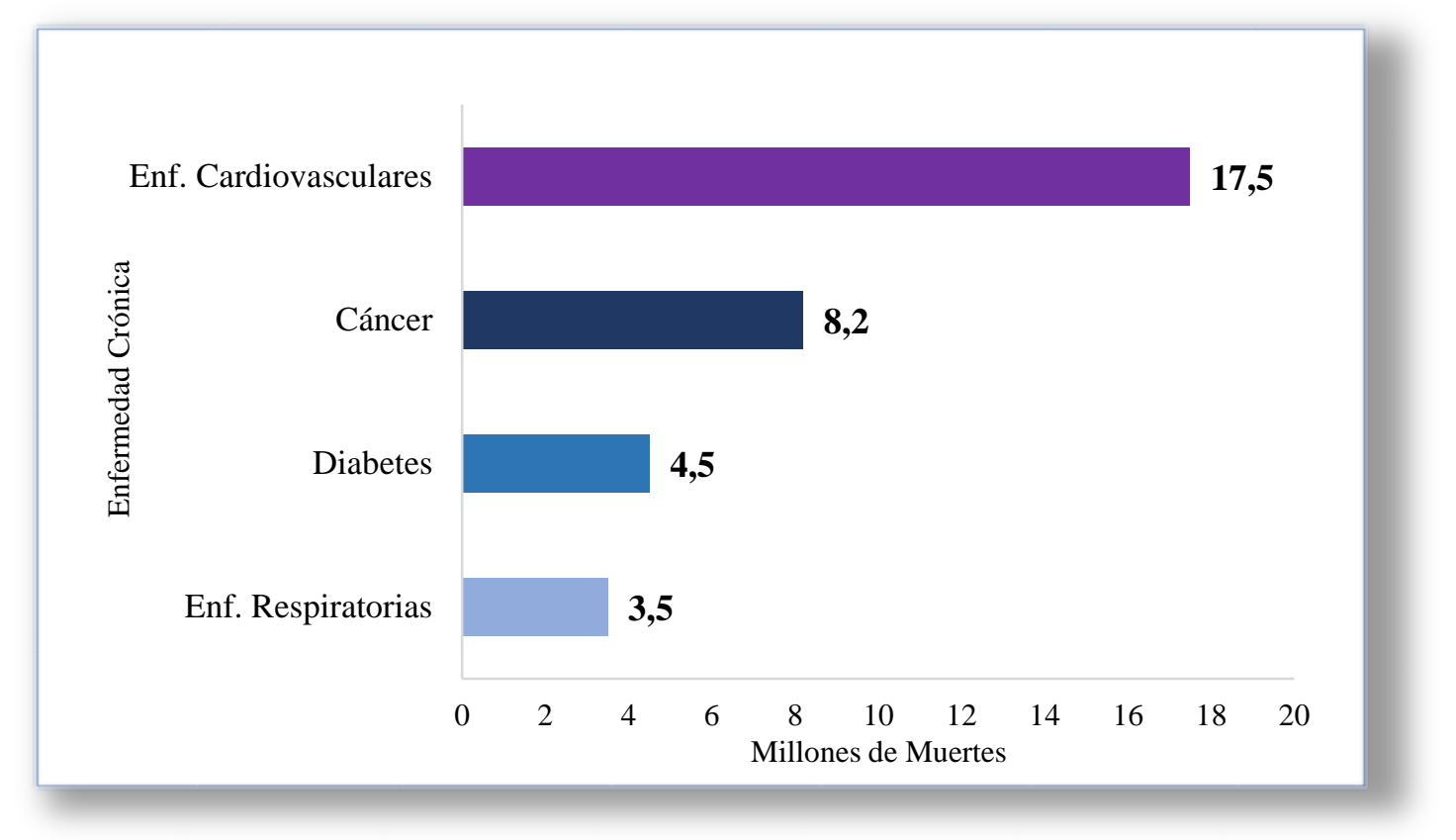

Figura 3. Mortalidad en la Población Mundial: Principales Causas de Muerte entre las Enfermedades Crónicas, Año 2014.

Según el informe de la OMS, las cifras de mortalidad ocasionadas por enfermedades crónicas en el año 2012 representan un incremento del 8\% con respecto al año $2000^{23}$. El notable incremento de las muertes producidos a nivel mundial a causa de enfermedades crónicas y la notable disminución de las muertes producidas por enfermedades infecciosas en la última década queda de manifiesto en los siguientes ejemplos: la diabetes causó 1.5 millones (2.7\%) de muertes en 2012 en comparación con el 1.0 millón (2.0\%) que causó en 2000; mientras, que el cáncer pulmonar causó 1.6 millones $(2.9 \%)$ de fallecimientos en 2012 respecto a los 1,2 millones $(2,2 \%)$ producidos en $2000^{26}$.

Por otro lado, la disminución de las defunciones producidas por enfermedades infecciosas se observa en las siguientes cifras: las enfermedades diarreicas disminuyeron de los 2.5 millones (4.7\%) en 2000 hasta los 1.5 millones (2.7\%) millones en 2012; 
mientras que las muertes a causa de tuberculosis disminuyeron de los 1.3 millones $(2.6 \%)$ en 2000 hasta los 0.9 millones (1.6\%) en $2012^{26}$ (Ver figura 4).

Estos ejemplos evidencian que las enfermedades crónicas han desplazado a las enfermedades infecciosas como principales causas de muerte a nivel mundial como consecuencia del proceso de transición epidemiológica finalizado en la mayoría de los países del mundo.

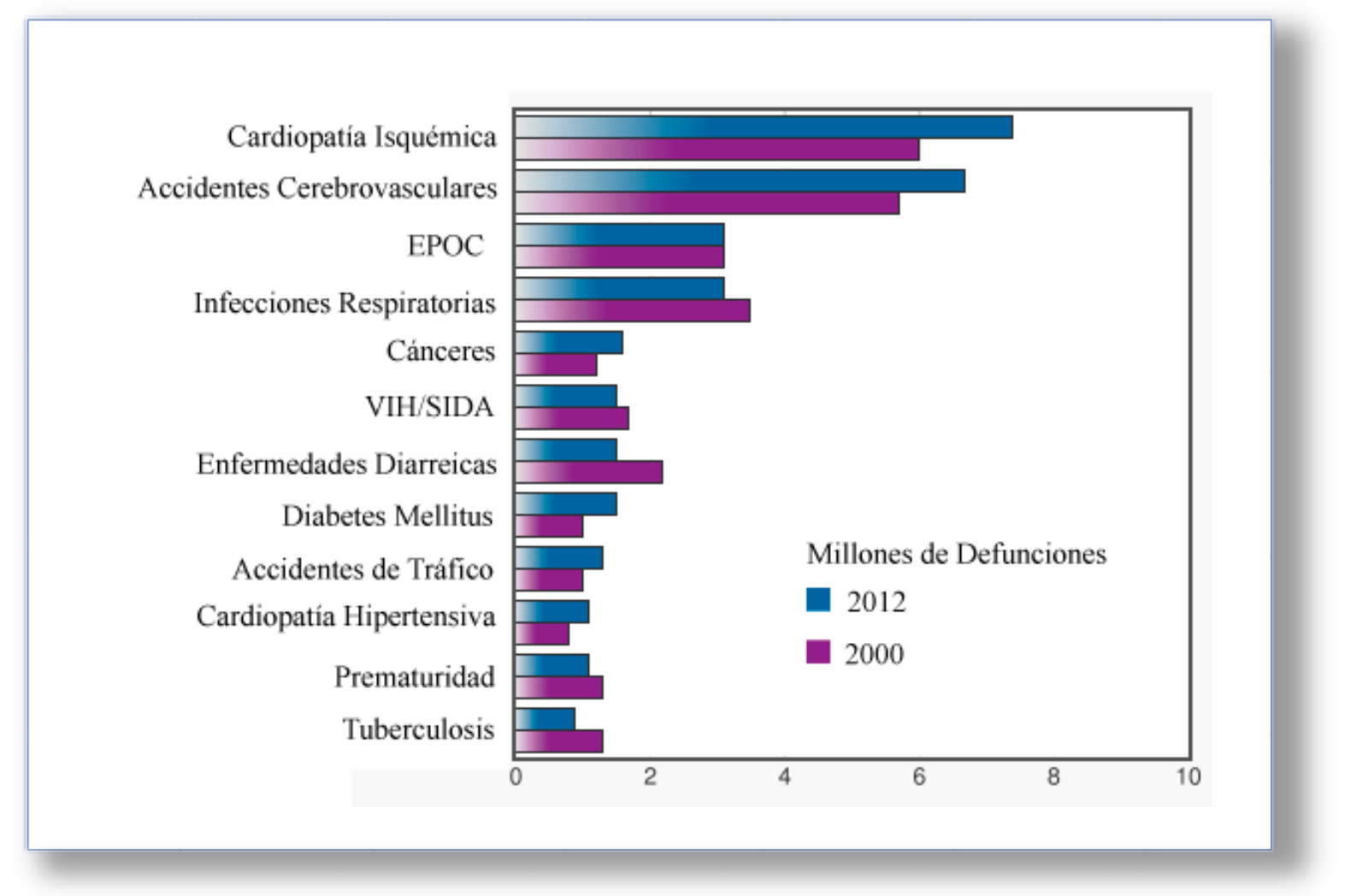

Figura 4. Principales Causas de Defunción en el Mundo Año 2000 vs 2012.

* Obtenido de Organización Mundial de la Salud $2014^{26}$. 
Las enfermedades crónicas también se caracterizan por las importantes cargas de morbilidad que originan ${ }^{27}$. La carga de morbilidad viene marcada por el grado de discapacidad y por las muertes prematuras. En el año 2012, el 44\% del total de muertes producidas por enfermedades crónicas a nivel mundial se produjeron en personas menores de 70 años y ocasionaron el $48 \%$ de los años de vida ajustados por discapacidad $(\mathrm{AVAD})^{28}$, frente al $40 \%$ ocasionado por las enfermedades transmisibles. La OMS ${ }^{29}$ define el indicador AVAD como una medida para "cuantificar las pérdidas de vida sana, ya sea por mortalidad prematura o por el tiempo vivido con una salud menguada"(p1).

Las proyecciones epidemiológicas de la $\mathrm{OMS}^{23}$ sugieren que las enfermedades crónicas continuarán siendo las responsables de un marcado número de muertes en las próximas décadas, particularmente en los países en vías de desarrollo, como los países africanos, las regiones del sudeste asiático y del este mediterráneo, donde las muertes por enfermedades crónicas se incrementarán en un $20 \%{ }^{22}$.

Las enfermedades crónicas también serán las responsables de un aumento de las muertes prematuras y del grado de discapacidad, alcanzando para el año 2030 tres veces más de AVAD y casi cinco veces más muertes que las enfermedades transmisibles, maternas, perinatales, y las condiciones nutricionales combinadas ${ }^{23}$.

El alcance de las enfermedades crónicas también afecta en el plano económico a los individuos, familias, Sistemas de Salud, y a la Sociedad como se ha mencionada anteriormente $^{24}$. Las familias cargan con gastos de Salud catastróficos ocasionados por las enfermedades crónicas, que hacen empobrecer a la familia llegando a una situación económica insostenible. Por otro lado, a nivel nacional los gobiernos tienen que afrontar cada vez más gastos y una pérdida mayor de productividad. En definitiva, todos los gastos económicos derivados de las enfermedades crónicas surgen desde un mismo todo, pero de diferentes procedencias. 
En una primera aproximación a la magnitud económica de las enfermedades crónicas, el factor coste de enfermedad (cost-of-illness) se establece como la primera consecuencia de las enfermedades crónicas y sus factores de riesgo ${ }^{30}$. El factor coste enfermedad origina desembolsos en materia monetaria derivados de gastos médicos y de pérdidas de productividad para la sociedad o el Sistema ${ }^{28}$.

El coste de enfermedad tiene tres componentes básicos ${ }^{30,31}$ : costes directos, derivados de los costes relacionados con la prevención, diagnóstico y el tratamiento de la enfermedad como por ejemplo ambulancias, consultas médicas, rehabilitación, medicación, investigación, personal sanitario, y equipo; costes indirectos, relacionados con la pérdida de recursos humanos causados por muerte prematura o morbilidad como queda reflejado en la reducida productividad del paciente, las prestaciones de desempleo, la disminución de ingresos del paciente, y la pérdida de futuros ingresos económicos; y los costes intangibles referidos a los dimensiones psicológicas que causan las enfermedades como por ejemplo, dolor, ansiedad, estrés, angustia, sufrimiento, frustración, y depresión.

El impacto de las enfermedades crónicas a nivel nacional e internacional se refleja en la carga de las enfermedades que los Sistemas de Salud tienen que enfrentarse para proveer servicios de Salud a largo plazo a los pacientes. Se estima que los gastos derivados del coste de enfermedad y sus factores de riesgo oscilan entre el $0.02 \%$ y el $6.77 \%$ del PIB de un país ${ }^{31}$.

Una segunda aproximación de la magnitud económica de las enfermedades crónicas son las consecuencias microeconómicas que estas entraman. El impacto económico de las enfermedades crónicas y sus factores de riesgo para los individuos y las familias se observa en los elevados gastos que deben de afrontar para el tratamiento, puesto que por definición las enfermedades crónicas precisan de un tratamiento sobre un período de tiempo substancialmente $\operatorname{largo}{ }^{26}$, lo que complica la sostenibilidad de la economía de las familias. 
Además, las enfermedades crónicas comprometen la productividad laboral, como consecuencia del absentismo de los trabajadores que sufren condiciones crónicas o de su menor producción al no encontrarse plenamente en su máximo estado funcional. Por ejemplo, en EEUU los hombres que padecen enfermedades crónicas trabajan un $6.1 \%$ menos con respecto al número total de horas, mientras en el caso de las mujeres se sitúan en un $3.9 \%$ menos $^{31}$.

Por último, la magnitud económica de las enfermedades crónicas también implica una aproximación macroeconómica. Las enfermedades crónicas constituyen la mayor parte de la carga sanitaria y de la mortalidad adulta de una nación, lo que hace presuponer un impacto negativo en el crecimiento de la economía. Según Barro ${ }^{32}$, un aumento en la esperanza de vida en 5 años de un país, ocasiona un incremento del 0.3-0.5\% anual del PIB en los sucesivos años. Mientras que, por otro lado, un aumento del $10 \%$ en la prevalencia de enfermedades crónicas implica una disminución del 0.5\% del crecimiento del PIB anual ${ }^{23}$.

La alta prevalencia de las enfermedades crónicas y sus serias consecuencias a los niveles explicados, ha intensificado la búsqueda en investigación de factores de riesgo y determinantes asociados a enfermedades crónicas, que puedan aumentar la probabilidad de las personas a padecer enfermedades crónicas. Las variables relacionadas con los individuos y otras más globales, ha dado lugar al desarrollo de importantes investigaciones sobre los factores de riesgo de las enfermedades crónicas. 


\subsection{Factores de Riesgo de las Enfermedades Crónicas}

Mientras algunos factores de riesgo de las enfermedades crónicas están biológicamente determinados, la mayoría de ellos dependen de los comportamientos o conductas del individuo y de factores socio-ambientales. Dentro de estos últimos, los estilos de vida adquiridos por la población y los procesos de urbanización del siglo XXI son los factores de riesgo que causan más enfermedades crónicas ${ }^{24}$.

Los estilos de vida adquiridos son factores modificables por las personas o las poblaciones que pueden influir positivamente o negativamente en la Salud ${ }^{28}$. La OMS ${ }^{23}$ destaca cuatro conductas modificables en el individuo como factores altamente relacionados con las enfermedades crónicas: el consumo de tabaco, la ingesta de alcohol, la inactividad física, y la alimentación no saludable.

Se estima que el consumo de tabaco causa el $71 \%$ de los cánceres de pulmón, el $42 \%$ de las enfermedades respiratorias crónicas, y cerca del 10\% de las enfermedades cardiovasculares $^{23}$. Aproximadamente el $50 \%$ de las muertes producidas por el uso abusivo del alcohol son el resultado de enfermedades crónicas como enfermedades cardiovasculares y diabetes $(33.4 \%)$, cánceres $(12.5 \%)$, y cirrosis hepática $16.2 \%)^{26}$. La inactividad física, causa alrededor del 21-25\% del cáncer de mama y colon, el $27 \%$ de los casos de diabetes, y el $30 \%$ de las enfermedades cardíacas isquémicas ${ }^{9}$. Por último, la alimentación no saludable como por ejemplo una ingesta excesiva de sal, aumenta considerablemente el riesgo de padecer enfermedades cardiovasculares, así como el consumo de grasas saturadas y grasas trans también eleva el riesgo de padecer enfermedades coronarias y diabetes tipo $\mathrm{II}^{23}$.

El consumo de tabaco, la ingesta de alcohol, la inactividad física, y una alimentación no saludable son conductas o estilos de vida que desencadenan, al mismo tiempo, cuatro factores de riesgo fuertemente ligados a enfermedades crónicas: el 
aumento de la presión arterial, el sobrepeso y la obesidad, la hiperglicemia, y la hiperlipidemia ${ }^{23}$.

El aumento de la presión arterial está fuertemente relacionado con el aumento a padecer accidentes cerebrovasculares, enfermedades coronarias, insuficiencias cardíacas, enfermedades periféricas vasculares, trastornos renales, y trastornos visuales. Alrededor del $40 \%$ de los adultos mayores de 25 años a nivel mundial, es decir un billón de personas, tienen hipertensión arterial (año 2008) ${ }^{33}$, siendo la causa del $51 \%$ de los accidentes cerebrovasculares y originando el $45 \%$ de las enfermedades coronarias isquémicas 9 .

El riesgo de padecer enfermedades coronarias, accidentes cerebrovasculares, diabetes tipo II, cáncer de mama, de colon, de próstata, de endometrio, de riñón, de esófago, y de páncreas, está relacionado con el incremento del índice de masa corporal $^{9}$. En el año 2008 el 35\% de los adultos mayores de 20 años a nivel mundial tenían sobrepeso, mientras que el $10 \%$ de los hombres y el $14 \%$ de las mujeres eran obesas, lo que supone que 300 millones de personas a nivel mundial padecían obesidad ${ }^{34}$.

Las personas con altos niveles de glucemia en sangre, están expuestas a padecer un mayor riesgo a desarrollar resistencia a insulina originando diabetes tipo II y enfermedades cardiovasculares ${ }^{9}$. La diabetes tipo II, es la causa principal de fallo renal, de trastornos visuales, y además el riesgo a sufrir accidentes cerebrovasculares aumenta considerablemente. En el año 2008 la prevalencia de niveles elevados de glucemia en sangre en adultos mayores de 25 años a nivel mundial se situaba en el $10 \%{ }^{23}$.

Por su parte, los altos niveles de colesterol y lipoproteínas de baja densidad en sangre están asociados un mayor riesgo de padecer enfermedades coronarias, accidentes cerebrovasculares, y otras enfermedades cardiovasculares ${ }^{9}$. En el año 2008, la prevalencia de niveles elevados colesterol en adultos a nivel mundial se situaba en el 39\%, y causaba un tercio de las enfermedades isquémicas coronarias ${ }^{23}$. 
Junto a los nuevos estilos de vida y las nuevas conductas adquiridas de la Sociedad, los procesos de urbanización constituyen los factores de riesgo más significativos de enfermedades crónicas. La progresiva migración de la población mundial a las ciudades ha provocado una serie de cambios significativos en los niveles de vida, comportamiento social, y Salud que han aumentado la prevalencia de enfermedades crónicas entre la población ${ }^{22}$. En la actualidad, más del 50\% de la población mundial vive en zonas urbanas, y para el año 2050 se estima que el $70 \%$ de la población vivirá en zonas urbanas ${ }^{35}$.

Los entornos urbanos se presentan como nuevas oportunidades para la población ofreciendo un mejor acceso a la Sanidad, pero también pueden llegar a presentar escasez de infraestructuras y de servicios básicos, especialmente para aquellas personas con menos recursos económicos ${ }^{22}$. De este modo, la escasez de vivienda, escasez de infraestructuras (carreteras, suministros de agua, saneamiento, drenajes, electricidad) y escasez de servicios básicos (recogida de residuos, atención primaria de Salud, educación, servicios de emergencia) representan los nuevos peligros de Salud en las urbes del actual siglo $\mathrm{XXI}^{35}$.

Adicionalmente a los factores de riesgo, los determinantes sociales de la Salud, es decir, "las circunstancias en que las personas nacen, crecen, viven, trabajan, y envejecen, incluido el sistema de salud"36,p1, están directamente o indirectamente relacionadas con las enfermedades crónicas en el individuo. Factores como por ejemplo acceso a educación, vivienda, Sanidad, oportunidades de trabajo, apoyo social, etc., no se distribuyen equitativamente en todas las áreas del planeta y originan desigualdades e inequidades que conducen a un mayor riesgo de padecer enfermedades crónicas entre las poblaciones de los grupos más vulnerables ${ }^{36}$. El determinante socioeconómico ha sido motivo de estudio en muchas investigaciones, y los grupos económicamente más desfavorecidos experimentan una mayor exposición a riesgos asociados con enfermedad que aquellos grupos económicamente más ${ }^{37}$. 
Los factores de riesgo son las causas más frecuentes de las enfermedades crónicas. Como se ha explicado, una gran mayoría de factores de riesgo pueden prevenirse adoptando estilos de vida y hábitos saludables. Sin embargo, vivimos en una época de globalización en la que los estilos de vida y los factores medioambientales asociados a enfermedades crónicas cada vez acechan más a la población. Esta realidad, junto con la nueva estructura mundial de la población donde la proporción de personas mayores va tomando más peso, está originando la aparición de un nuevo fenómeno a nivel mundial: la co-existencia de múltiples enfermedades en un mismo individuo.

\subsection{El Fenómeno de la Co-Existencia de Múltiples Enfermedades Crónicas}

El envejecimiento del ser humano, como se ha reflejado anteriormente, está relacionado con un mayor riesgo de padecer enfermedades crónicas en el individuo ${ }^{17-19}$. Con la elevada proporción de personas mayores a nivel mundial existentes en la actualidad, su incremento en el futuro, los actuales estilos de vida, y los procesos de urbanización, la prevalencia de enfermedades crónicas continuará aumentando drásticamente en la población. Además, la persona que padece una enfermedad crónica tiene más probabilidades de padecer más enfermedades crónicas ${ }^{38}$, debido a que muchas de ellas ocurren frecuentemente en combinación ${ }^{39}$.

De hecho, la mayoría de los individuos con enfermedades crónicas en la sociedad, presentan más de una afección concomitante ${ }^{17,40,41}$. Por ejemplo, el estudio del Reino Unido llevado a cabo por Barnett et al. ${ }^{40}$, concluyó que más de la mitad de los individuos escoces que padecían enfermedades crónicas presentaban más de una condición. De 
manera similar, Pati et al. ${ }^{41}$ encontraron en su estudio transversal de población adulta de atención primaria en Odihsa, India, que el 52\% de los pacientes con enfermedades crónicas, presentaban más de una condición crónica. Es más, para algunos autores como Tinetti et al. ${ }^{42}$ la co-existencia de múltiples enfermedades crónicas es la condición crónica más frecuente experimentada en los adultos.

Por consiguiente, la co-existencia de múltiples enfermedades crónicas en un mismo individuo demanda de una especial atención puesto que cada enfermedad puede estar influenciada por la otra/s enfermedad/es concomitante/es, por medio de interacciones entre terapias, y/o contraindicaciones de una terapia por otra afección concomitante. Esta situación requiere de una conceptualización clara y precisa, por lo que los autores han formulado distintas propuestas para definir el fenómeno de la co-existencia de múltiples enfermedades crónicas en un mismo individuo.

\subsection{Comorbilidad, Multimorbilidad, y Pluripatología}

Actualmente no existe una definición común aceptada internacionalmente para definir la presencia de múltiples enfermedades crónicas en un paciente. Esta circunstancia ha sido frecuentemente motivo de discusión en la literatura de las Ciencias de la Salud ${ }^{20,43}$. Las definiciones varían dependiendo del autor, de los objetivos, del diagnóstico, de la prognosis, del tratamiento, de la prevención, y de la etiología de la investigación ${ }^{44}$.

Además, es frecuente que muchos autores no precisen una definición en sus estudios y presuponen que el termino es "comúnmente entendido" ${ }^{45}$, pudiendo resultar en impactos negativos tanto en clínica como en investigación. 
Los términos empleados con más frecuencia en investigación que refieren la presencia de múltiples enfermedades crónicas en un mismo individuo son comorbilidad, multimorbilidad, polimorbilidad, polipatología, pluripatología, y multipatología. Dentro de estos términos, comorbilidad y multimorbilidad son los más usados en los estudios anglosajones ${ }^{45}$, mientras que pluripatología es más frecuente utilizado en los estudios españoles y de habla hispana ${ }^{46-50}$.

El concepto de comorbilidad, fue introducido por primera vez por Feinstein ${ }^{51}$ en 1970 para denotar "cualquier entidad clínica distinta adicional que ha existido o que puede ocurrir durante el curso clínico de un paciente que presenta una enfermedad índice bajo estudio"(pp456-457). Esta definición engloba cualquier trastorno, enfermedad, patología, condición, entidad clínica, o evento clínicamente relevante diferente de la enfermedad primaria de interés que se produce mientras el paciente está sufriendo la enfermedad primaria, incluso si este fenómeno secundario no puede considerarse como una enfermedad per $\mathrm{se}^{51}$. Por lo tanto, comorbilidad implica una condición o trastorno índice, así como sus posibles complicaciones como resultado de su prognosis (Figura 5).

El término multimorbilidad, utilizado mucho más en artículos y estudios europeos, fue redefinido por Van den Akker et al. ${ }^{43}$ para hacer referencia a la existencia de dos o más condiciones o enfermedades diagnosticados médicamente en un mismo individuo, que pueden o no pueden estar vinculadas a un trastorno índice (Figura 6). Asimismo, cuando se utiliza el término multimorbilidad, es importante considerar la naturaleza de la condición, la importancia de las condiciones coexistentes, su cronología de presentación, así como la complejidad del paciente y la carga de morbilidad que implican ${ }^{43,52}$. 


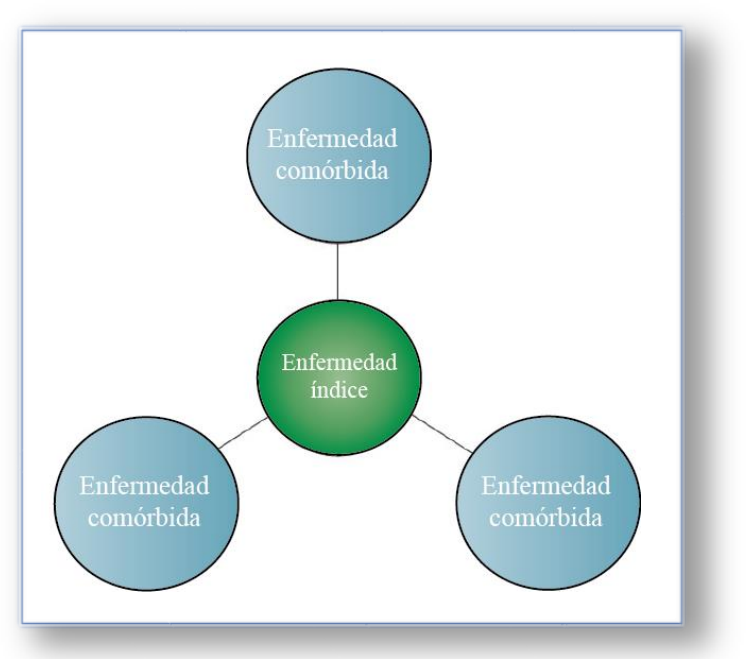

Figura 5. Concepto de Comorbilidad.

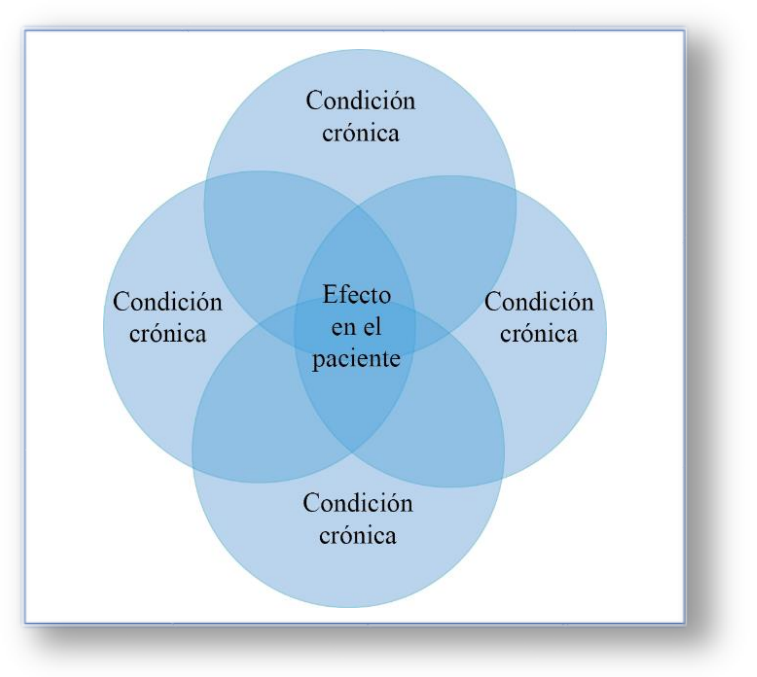

Figura 6. Concepto de Multimorbilidad.

* Obtenido de Davies $2013^{53}$, modificado por autor.

Otro término utilizado para hacer referencia a la presencia de múltiples enfermedades crónicas es pluriapotología. Este término, utilizado principalmente en los estudios españoles y de habla hispana, es definido por el Ministerio de Sanidad y Política Social de España como ${ }^{54}$,

"la coexistencia de dos o más enfermedades crónicas que conllevan la aparición de reagudizaciones y patologías interrelacionadas que condicionan una especial fragilidad clínica que agrava al paciente con un deterioro progresivo, y una disminución gradual de su autonomía y capacidad funcional generando una frecuente demanda de atención a diferentes ámbitos asistenciales (atención primaria, atención especializada, servicios sociales)”(p31). 
Los pacientes pluripatológicos desde el contexto de los procesos clínicos presentan unas características comunes y homogéneas en cuestión de complejidad, vulnerabilidad clínica, fragilidad, mortalidad, deterioro funcional, polifarmacia, pobre Calidad de Vida relacionada con la Salud (CVRS), y frecuente situación de dependencia funcional ${ }^{55}$. Estos pacientes, además, están caracterizados por una frecuencia alta de visitas e ingresos en hospitales, que plantean diferentes dificultades a nivel primario por la especial complejidad del manejo de los distintos problemas de Salud que padecen, y las complicaciones para acceder de forma rápida a interconsultas y medios diagnósticos ${ }^{48}$.

Para los propósitos del presente trabajo y con la finalidad de evitar cualquier tipo de ambigüedad, se empleará un único término, multimorbilidad, para hacer referencia a la coexistencia de múltiples enfermedades, patologías o condiciones crónicas de larga duración, sin considerar la existencia de un trastorno índice, y entendiéndose como múltiples la co-existencia de dos o más enfermedades. Esta definición es la más empleada en la investigación clínica y epidemiológica ${ }^{45}$. En adición, el empleo del término paciente pluripatológico hará referencia a la definición funcional establecida por Ollero-Baturone et al. ${ }^{55}$ (Anexo I).

Asimismo, es importante señalar que la co-existencia de enfermedades, patologías o condiciones crónicas, entendidas como procesos patológicos con una serie de signos y síntomas y que en ocasiones incluyen distintos problemas de Salud más allá de los tradicionales, requiere una respuesta compleja a lo largo de un período prologando con la implicación de esfuerzos coordinados por medio diferentes profesionales sanitarios y un acceso a medicamentos esenciales y sistemas de control, incluidos de manera óptima dentro de un Sistema que promueva la participación activa del paciente. Actualmente, existe un conocimiento muy limitado de cómo se distribuyen las enfermedades o concurren en un individuo ${ }^{56}$. La mayoría de los estudios de la literatura se centran en el estudio de una sola condición cónica ${ }^{57-59}$, olvidando la compleja mezcla de interacciones entre las diferentes condiciones concomitantes en un individuo. 
Hasta la fecha de hoy, las investigaciones y conocimientos existentes de multimorbilidad son insuficientes para proveer un marco científico que aborde la existente problemática de las interacciones acumulativas entre las enfermedades en el paciente multimórbido ${ }^{60}$. Existe una clara necesidad de incrementar el conocimiento y la compresión de esta importante temática, como lo han puesto de manifiesto diferentes autores $^{58,61-63}$. A continuación, se abordará y profundizará en la problemática de la multimorbilidad con la finalidad de desarrollar una mejor compresión sobre el tema.

\subsection{Multimorbilidad: Fundamentos y Situación}

A pesar de la amplia variación de prevalencia de multimorbilidad encontrada en estudios epidemiológicos ${ }^{19,64}$, la mayoría de los investigadores coinciden en destacar la elevada prevalencia que alcanza el fenómeno de multimorbilidad en la actual Sociedad. La multimorbilidad se ha incrementado alarmantemente en los últimos años convirtiéndose en un predominante común en todos los grupos de población ${ }^{65,66}$, particularmente en los grupos de edad más avanzada ${ }^{60,63,67}$, y en los grupos de población más vulnerables ${ }^{68,69}$. Esta prevalencia de multimorbilidad alcanza en la población general el 1-1.5\% $\%^{48}$, alrededor del $\mathbf{2 0 - 3 0 \%}$ en el total de la población adulta que recibe atención médica $^{58,65,70}$, y en torno al $\mathbf{5 5 - 9 8 \%}$ en población de edad avanzada ${ }^{19,48,60,63,67}$. Se estima un porcentaje de mortalidad a causa de multimorbilidad alrededor del 6-10\% al año en la población general, y alrededor de un $37 \%$ en el entorno hospitalario ${ }^{48}$.

La alta prevalencia de multimorbilidad destaca no sólo en la población de países desarrollados ${ }^{17,40,58,61,70-72}$, sino que también destaca en la población de los países en vías de desarrollo ${ }^{41,73}$ alcanzando porcentajes de multimorbilidad similares o incluso 
superiores a los de los países desarrollados. Por ejemplo, el porcentaje de multimorbilidad que presenta la población total de España, país desarrollado en base a su renta per cápita, se sitúa en un $7.8 \%$, mientras que el porcentaje de multimorbilidad de países en vía de desarrollo como Filipinas alcanza el 7.1\%, Namibia el 7.9\%, Sudáfrica el 11.2\%, Hungría el 15\%, Brasil el 13.4\%, y Nepal el $15.2 \%^{73}$.

En EEUU, el fenómeno multimorbilidad ha sido objeto de especial estudio debido al vertiginoso crecimiento del número de enfermedades crónicas padecidas en la población en las últimas décadas. De este modo en el año 2000 alrededor de 145 millones de personas, es decir, el $45 \%$ de la población estadounidense, padecía al menos una enfermedad crónica ${ }^{17}$, y un $21 \%$ de la población, tenía dos o más condiciones ${ }^{17,71}$; diez años después, el porcentaje de personas con múltiples enfermedades crónicas alcanzaba el $26 \%{ }^{71}$ (Figura 7). Las proyecciones de futuro apuntan hacia un continuo incremento de estas enfermedades entre la población, y sitúan en 81 millones el número de personas estadounidenses que padecerá múltiples enfermedades crónicas en el año $2020^{74}$.

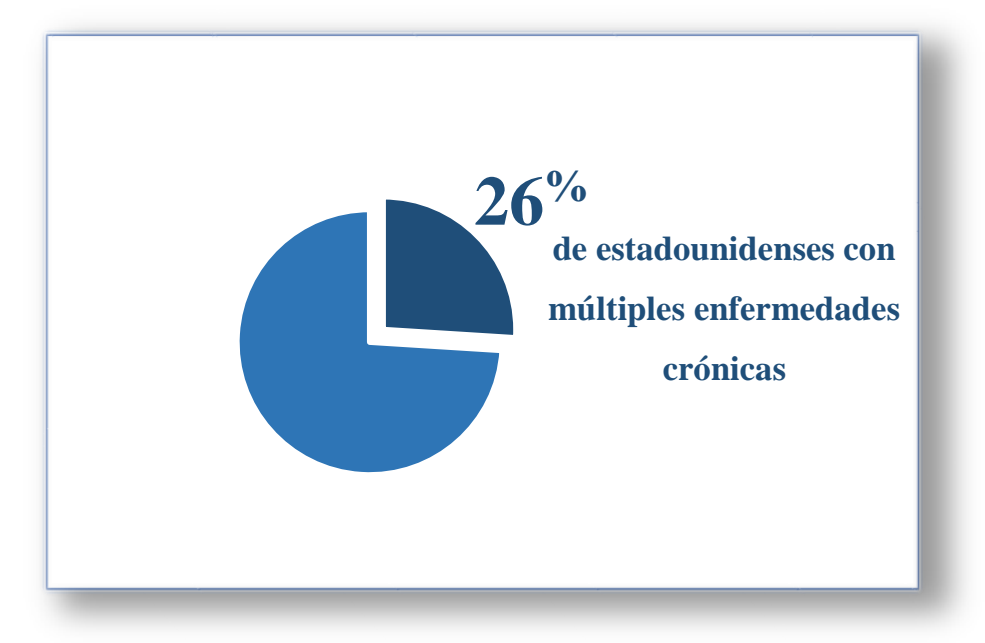

Figura 7. Porcentaje de Población Estadounidense con Múltiples Enfermedades Crónicas en 2010 71 . 
Los sujetos con múltiples enfermedades crónicas requieren una Atención Sanitaria continua sobre un período de años o décadas. Además, estos pacientes disponen de unas necesidades de Salud complejas y, por tanto, necesitan de una mayor atención, asistencia, y cuidados sanitarios a distintos niveles que aquellos pacientes que padecen una sola enfermedad crónica ${ }^{38}$ o ninguna ${ }^{75}$.

Las consecuencias del fenómeno multimorbilidad para los Sistemas de Salud se traduce en una mayor demanda de asistencia sanitaria, en materia de consultas de atención primaria, de ingresos hospitalarios, y de atención médica domiciliaria. Mientras que las consecuencias de multimorbilidad para el propio paciente resultan en un deficiente Estado de Salud ${ }^{18}$ y una mayor vulnerabilidad y/o fragilidad como resultado de un mayor riesgo de mortalidad, una mayor y más rápida disminución de la discapacidad funcional o Calidad de $\mathrm{Vida}^{54}$, y un número elevado de prescripciones.

Las consecuencias anteriormente citadas van a derivar en un elevadísimo gasto económico en servicios sanitarios ${ }^{18,19}$, lo que está obligando a realizar un cambio en la organización sanitaria del nivel de Atención Primaria y Hospitalaria. Además, se está realizando una mejora en la coordinación y colaboración entre estos niveles y los servicios sociales a través de la Atención Sanitaria con el fin de que la asistencia a los enfermos crónicos y pluripatológicos sea integral, integrada, y continuada. De este modo se podrá lograr efectividad, calidad, y seguridad del paciente, al mismo tiempo que se podrá alcanzar la eficiencia y sostenibilidad del Sistema. 


\subsection{Consecuencias de la Multimorbilidad}

Numerosos estudios han demostrado una asociación significativa entre el número de enfermedades crónicas y el número de visitas anuales al médico ${ }^{66,76-78}$. Por ejemplo, Schneider et al. ${ }^{76}$ y Starfield et al. ${ }^{77}$, observaron un incremento del número de consultas al aumentar el número de enfermedades crónicas padecidas en los pacientes. Otros autores como Rapoport et al. ${ }^{66}$ estimaron en 1.29 visitas más al médico por enfermedad crónica padecida. Asimismo, Calderón-Larrañaga ${ }^{78}$ encontró además de una frecuencia alta de visitas al médico de familia, un número muy alto de remisiones al especialista en los pacientes con multimorbilidad, y consecuentemente, diferentes recomendaciones dadas a los pacientes. Estas recomendaciones, numerosas, y en ocasiones confusas e incluso contradictorias, pueden llegar a provocar en el paciente dudas, por el dilema de qué recomendación seguir ${ }^{79}$.

Por otra parte, la relación entre múltiples enfermedades crónicas y la duración de las estancias en hospital ha sido también motivo de investigación, demostrándose una asociación positiva entre el número de enfermedades crónicas y los días de hospitalización ${ }^{76}$. Wolff et al. ${ }^{38}$ y Bernabeu-Wittel et al. ${ }^{49}$ encontraron un mayor número de hospitalizaciones en aquellos sujetos que padecían múltiples enfermedades crónicas. En su estudio, Wolff et al. ${ }^{38}$ hallaron un riesgo de hospitalizaciones 99 veces mayor en aquellas personas que padecían cuatro enfermedades crónicas frente a las personas que no padecían ninguna.

La relación de multimorbilidad y mortalidad también ha sido examinada en profundidad en la literatura. Gijsen et $\mathrm{al}^{18}$ revisaron treinta y cinco estudios que relacionaban comorbilidad y enfermedades no asociadas a un trastorno índice con todo tipo de causas de muerte. Cerca de la totalidad de los estudios confirmaron el fenómeno de multimorbilidad, como un factor determinante de mortalidad. 
Los pacientes con múltiples enfermedades crónicas también están asociados con un mayor uso de prescripciones médicas ${ }^{49,80}$. El $90 \%$ de los sujetos del estudio de Ramage-Morin $^{81}$ que padecían dos enfermedades crónicas afirmaron tomar prescripciones farmacológicas, mientras que el porcentaje alcanzó el $94 \%$ en aquellos pacientes con tres o más enfermedades. Sujetos con múltiples condiciones crónicas reciben más prescripciones y toman más medicaciones que aquellos que no padecen ninguna enfermedad crónica.

El mayor uso de prescripciones médicas en los pacientes con múltiples enfermedades crónicas conduce frecuentemente a polifarmacia ${ }^{78}$, definido como el uso de cinco o más prescripciones médicas ${ }^{49,81}$, resultando en una compleja combinación de preparaciones farmacéuticas cuya interacción, eficacia, y alcance combinado no ha sido bien documentado hasta el momento. Además, el uso de múltiples prescripciones incrementa el riesgo de interacciones medicamentosas, errores médicos en prescripción, duplicidades, sobredosificaciones e infradosificaciones, uso inapropiado de los medicamentos por parte del paciente, baja adherencia a la medicación, y la aparición de efectos adversos ${ }^{81}$. En adición, el uso de múltiples prescripciones médicas supone un gasto farmacéutico considerablemente mayor en los pacientes con multimorbilidad de entre al menos un $285-400 \%{ }^{80}$, y que continúa aumentando progresivamente por cada enfermedad crónica adicional. Por ejemplo, Moxey ${ }^{82}$ encontró en su estudio un gasto farmacéutico de $\$ 471, \$ 1503$, y $\$ 3112$ para los pacientes con cero, una o dos, y tres enfermedades crónicas, respectivamente. Dados los gastos ocasionados por el fenómeno de multimorbilidad, es comprensible que muchos pacientes se vean obligados a declararse en bancarrota, pedir préstamos o ayudas para afrontar sus gastos médicos ${ }^{83}$.

El fenómeno de multimorbilidad también ha sido objeto de estudio en relación con la Calidad de Vida y el estado funcional del individuo. Fortin et al. ${ }^{20}$ examinaron la relación entre multimorbilidad y la CVRS. La revisión sistemática de treinta artículos les condujo a afirmar que existe una relación inversamente proporcional entre el número de condiciones médicas y la Calidad de Vida relacionada con los dominios físicos. 
Wikman et al ${ }^{84}$ realizaron un estudio poblacional donde también investigaron el Bienestar y la CVRS del individuo y sus aspectos sociales como habilidad para alcanzar metas, limitaciones de la persona, barreras en oportunidades, y el logro de la felicidad. Estos autores, consistentes con los hallazgos de Fortin et al. ${ }^{20}$, encontraron una asociación entre enfermedad crónica y una reducida CVRS y Bienestar emocional. Adicionalmente, determinadas enfermedades como accidentes cerebrovasculares, enfermedades pulmonares, y artritis reumatoides fueron asociadas con mayor discapacidad y menor Calidad de Vida ${ }^{84}$.

A escala macroeconómica, las consecuencias de multimorbilidad se reflejan en los enormes gastos de utilización que los Sistemas de Salud tienen que afrontar. Por ejemplo, en un país como EEUU dónde el gasto sanitario se sitúa en el 17.5\% del PIB, o lo que es lo mismo, en 3.0 trillones netos de dólares (año 2014) (5) $^{85}$ el $78 \%$ total del gasto se atribuye a individuos que padecen enfermedades crónicas. En población mayor, el gasto es incluso superior. Por ejemplo, el 95\% del total del gasto sanitario de Medicare se atribuye a pacientes con múltiples enfermedades crónicas ${ }^{82}$.

Por tanto, el paciente que padece enfermedades crónicas se encuentra en una situación en la que tiene que hacer frente a una serie de problemas patológicos, que, generalmente, comparten unas dificultades específicas frente a su atención como son, por ejemplo, aprender nuevas habilidades para utilizar dispositivos y ayudas; adquirir conocimientos para controlar los síntomas, el dolor, y hacer frente a la discapacidad; seguir las indicaciones para la toma de medicación; mantener un grado adecuado de nutrición, ingesta calórica, y ejercicio; adaptarse a las exigencias física, sociales, y psicológicas; y establecer una relación activa y eficaz con los profesionales de la $\operatorname{Salud}^{30}$. Es decir, el paciente con enfermedades crónicas debe de adquirir una serie de competencias y responsabilidades para minimizar el impacto de sus enfermedades, mejorar su Salud, y prevenir un mayor deterioro funcional mediante su participación activa por medio de una serie de autocuidadados (self-care $)^{86}$. 


\subsection{Autocuidados y Automanejos}

Los autocuidados forman parte de la vida diaria de las personas con múltiples enfermedades crónicas. $\mathrm{La} \mathrm{OMS}^{23}$ define autocuidados como "actividades que los individuos, familias, y comunidades desarrollan con la intención de mejorar la Salud, prevenir trastornos, limitar enfermedad, y restaurar Salud"(pp65-66). Por tanto, los autocuidados aumentan la capacidad de las personas para mejorar su propia Salud, controlar los síntomas, y la progresión de las enfermedades. Una condición indispensable de los autocuidados es la relación de colaboración entre el paciente y los profesionales de la Salud, la familia, los amigos, y la comunidad ${ }^{86}$, puesto que estos vínculos ayudan los buenos resultados de los autocuidados.

Sin embargo, en última instancia, el propio paciente es el responsable de sus autocuidados mediante la toma diaria de decisiones. Como ha sido desarrollado previamente, los estilos de vida adquiridos como el consumo de tabaco, el uso abusivo del alcohol, la inactividad física, la alimentación no saludable, y otros factores de riesgo pueden contribuir negativamente al desarrollo y evolución de las enfermedades crónicas. Por tanto, el paciente con enfermedades crónicas puede prevenir o modificar la progresión de las enfermedades y síntomas asociados, cuando se enfrenta a la toma diaria de decisiones como, por ejemplo, qué alimentos comer, si realizar ejercicio o no, si tomar la medicación, o simplemente, si no realizar ninguna acción en absoluto. En otras palabras, el paciente se hace sujeto activo de su tratamiento mediante el automanejo (selfmanagement) diario de sus propias enfermedades.

El automanejo, acorde con Barlow et al ${ }^{87}$, conlleva la toma de decisiones por parte del paciente que influyen en el estilo de vida, en la toma de medicación, y en la ejecución de acciones preventivas. Barlow et al. ${ }^{87}$ definen el automanejo como "la capacidad del paciente de supervisar su condición y efectuar las respuestas cognitivas, conductuales, y emocionales necesarias para mantener una calidad de vida satisfactoria" (pp177-178). 
Esta definición, incorpora como componentes novedosos los factores psicológicos y sociales en el cuidado de la enfermedad crónica puesto que algunas enfermedades como la artritis reumatoide o el VIH necesitan de cambios conductuales y estrategias de afrontamiento para combatir los síntomas de la enfermedad y superar el estigma $\operatorname{asociado}^{88}$.

Sin embargo, muchos pacientes con enfermedades crónicas tienen dificultades para alcanzar un efectivo control de los autocuidados como lo ponen de manifiesto los elevados porcentajes de incumplimiento al tratamiento existentes entre la población. A continuación, se abordará el problema de la adherencia al tratamiento, con una especial atención a los pacientes con tratamientos a largo plazo, como es el caso de aquellos que padecen enfermedades crónicas. 


\section{Adherencia a los Tratamientos a Largo Plazo}

La adherencia a los tratamientos constituye uno de los temas prioritarios en la Salud Pública actual, dada su extensión y sus consecuencias clínicas y económicas. El cumplimiento del tratamiento es un factor fundamental para controlar la enfermedad y juega un papel todavía más trascendental en tratamientos a largo plazo como ocurre en las enfermedades crónicas ${ }^{89}$.

Los tratamientos a largo plazo, comparten frecuentemente una serie de características comunes de automanejos y autocuidados que pueden durar varios años o acompañar al paciente para el resto de su vida y resultan imprescindibles para poder mantener las patologías estables y controladas; como por ejemplo, seguir regímenes farmacológicos complejos, mantener una alimentación sana y equilibrada, mantener un cierto nivel de ejercicio físico, realizar técnicas de monitorización para controlar la enfermedad, y eliminar o disminuir ciertos factores de riesgo para las enfermedades (alcohol y/o tabaco).

De ahí la necesidad que el paciente se convierta en sujeto activo de su propio tratamiento mediante los autocuidados y automanejos, y tome una mayor consciencia y responsabilidad para mantener y mejorar su propia Salud, es decir ponga en valor su Estado de Salud. 
Sin embargo, el cumplimento de los tratamientos es un tema que no recibe la atención necesaria por medio de los profesionales sanitarios, pasando a un segundo plano, como lo demuestran las dificultades de los pacientes para cumplir los tratamientos y que se refleja en las elevadas tasas de incumplimiento del tratamiento y las escasas estrategias en la práctica clínica para mejorarlas ${ }^{90}$. Es necesario, por tanto, un análisis exhaustivo y una profundización del incumplimiento terapéutico en pacientes que sufren enfermedades crónicas.

\subsection{Adherencia y Cumplimiento}

Diferentes términos se han empleado en la literatura para referirse al cumplimiento de los tratamientos médicos. En la literatura anglosajona quizás los términos más utilizados correspondan a cumplimiento (compliance) y adherencia (adherence), aunque también se han propuesto otros como por ejemplo cooperación, colaboración, alianza terapéutica, seguimiento, obediencia, observancia, y concordancia $^{91,92}$. Por otra parte, la falta de adherencia ha sido acuñada con el término incumplimiento.

El cumplimiento terapéutico, ha sido definido por Haynes et al. ${ }^{93}$ como el "grado en el que el comportamiento del paciente, en términos de tomar medicación, seguir dietas o introducir cambios en el estilo de vida coincide con la prescripción clínica"(pp1-2). Esta definición de cumplimiento es la de mayor aceptación entre la comunidad científica. Sin embargo, ha sido puesta en entre dicho a lo largo de los años debido al rol pasivo que se presupone al paciente, puesto que únicamente se limita a seguir las indicaciones de los profesionales sanitarios ${ }^{94}$. Como se ha mencionado 
anteriormente, el propio paciente es el último responsable de la toma de su medicación, por lo que se convierte en sujeto activo que toma sus propias decisiones de manera autónoma en un proceso dinámico, y no un mero cumplidor de las prescripciones médicas ${ }^{95}$.

Este hecho ha dado lugar a la introducción del término adherencia terapéutica, donde el paciente cumple un rol más activo y ha sido definido por la $\mathrm{OMS}^{90}$ como " $\mathrm{el}$ grado de comportamiento de una persona -tomar medicamentos, seguir un régimen alimentario, y ejecutar cambios del modo de vida- se corresponde con las recomendaciones acordadas con un prestador de asistencia sanitaria"(p3). Esta nueva definición, implica un mayor compromiso por parte del paciente y por parte del médico para crear un contexto en el que el paciente entienda sus problemas de Salud, las consecuencias positivas de seguir su tratamiento, y facilite las tomas de decisiones compartidas, entre profesional y paciente, sobre medicación ${ }^{94}$. De este modo, adherencia implica un modelo de decisión compartida entre paciente y médico, dejando atrás el modelo autoritario por parte del médico que implicaba el término cumplimiento.

Por lo tanto, el paciente tendrá que comportarse de acuerdo a las recomendaciones acordadas durante el período de tiempo prescrito para el tratamiento, es decir, el número total de días desde que el paciente comienza su régimen terapéutico hasta que lo interrumpe, término conocido como persistencia ${ }^{96}$.

Sin embargo, en la práctica médica estos conceptos suelen circunscribirse casi exclusivamente al uso de los medicamentos por parte del paciente de una forma determinada con el profesional sanitario ${ }^{91}$. Por ello, la mayoría de estudios existentes en la literatura evalúan la adherencia al tratamiento farmacológico o también denominada adherencia a medicación ${ }^{97}$. 


\subsection{Contexto y Situación Actual de la Adherencia al Tratamiento Terapéutico de las Enfermedades Crónicas}

La falta de adherencia terapéutica constituye un problema a nivel mundial que tiende a incrementar, especialmente entre los sujetos que padecen enfermedades crónicas ${ }^{98}$. Ante esta problemática, los estudios relacionados con la adherencia terapéutica han ido aumentando en número vertiginosamente en las últimas décadas con la finalidad de entender y mejorar la adherencia a los regímenes de medicación del tratamiento en pacientes crónicos ${ }^{99}$.

Los porcentajes o tasas de adherencia terapéutica, varían dependiendo del estudio, de las enfermedades incluidas, del método empleado, y de la definición de adherencia/cumplimiento ${ }^{100,101}$. Por ello, es muy frecuente observar diferentes estudios de adherencia al tratamiento con un amplio rango de porcentaje de cumplimiento/incumplimiento. Por ejemplo, en España, el cumplimiento terapéutico en los estudios de patologías crónicas tiene un rango de prevalencia que varía desde $83.3 \%$ hasta el $33.8 \%{ }^{102}$. En Estados Unidos, el porcentaje de población que incumple los regímenes de medicación se encuentra entre el $20 \%$ y el $80 \%{ }^{103,104}$.

A pesar de la gran variabilidad de cumplimiento en las investigaciones, los estudios de adherencia terapéutica coinciden en señalar que aproximadamente un $\mathbf{5 0 \%}$ de los sujetos que padecen enfermedades crónicas en los países desarrollados incumple el régimen farmacológico con independencia de la patología y el escenario ${ }^{90,105}$, llegándose a producir porcentajes más elevados en personas de edad más avanzada ${ }^{97,106}$, y en los países en vías de desarrollo ${ }^{90}$. Este porcentaje disminuye hasta niveles del $20-30 \%$ si se le acompañan cambios en el estilo de vida ${ }^{99}$. 
Más ejemplos que analizan la problemática de falta de adherencia al tratamiento terapéutico lo demuestran los resultados del metaanálisis llevado a cabo por DiMatteo ${ }^{107}$. Los resultados de este estudio indican que el porcentaje medio de incumplimiento de los 569 estudios revisados sobre la adherencia al tratamiento de las últimas décadas alcanza el 24.8\%. Además, los hallazgos del estudio demuestran que los porcentajes de adherencia al tratamiento varían dependiendo de la patología, siendo los trastornos el sueño (65.5\%), diabetes $(67.5 \%)$, y enfermedades pulmonares $(68.8 \%)$ las patologías con menor tasa de adherencia a medicación; el VIH (88.3\%), desórdenes gastrointestinales (80.4\%), y cáncer $(79.1 \%)$, las condiciones con mayor porcentaje de adherencia a medicación.

La magnitud del problema de incumplimiento afecta tanto a los países desarrollados como a los países en desarrollo ${ }^{90}$. Por ejemplo, en EEUU solamente el $51 \%$ de los pacientes se adhiere a su régimen de medicación antihipertensivo; en China, este porcentaje disminuye hasta el 43\%; mientras que en Gambia el porcentaje disminuye hasta el $27 \%^{90}$.

Existe una extensa literatura sobre los estudios de adherencia al tratamiento en sujetos que sólo padecen una enfermedad crónica ${ }^{89,97,99,108,109}$. Sin embargo, no existen muchos estudios en los que examinen la adherencia en pacientes que sufren más de una enfermedad, a pesar de que la mayoría de los individuos con condiciones crónicas en la Sociedad, presentan más de una afección concomitante ${ }^{17,40,41}$, como ha quedado explicado anteriormente.

Algunos autores, como Briesacher et al. ${ }^{110} \mathrm{y}$ Yeaw et al. ${ }^{111}$ han comparado las tasas de adherencia a medicación de manera uniforme por patología, entre las diferentes condiciones seleccionadas para el estudio. Otros investigadores, como Basak et al. ${ }^{112} \mathrm{y}$ Choudhry et al. ${ }^{101}$ han llevado a cabo estudios de adherencia en pacientes con múltiples prescripciones para una condición médica. Sin embargo, sólo existen unos pocos estudios en donde se realice análisis en profundidad de los factores relacionados con la adherencia que afecten a pacientes con diferentes condiciones crónicas ${ }^{113}$. 


\subsection{Tipos de Incumplimiento al Tratamiento}

Generalmente la adherencia al tratamiento se estima como una variable binaria dicotómica (paciente adherente vs paciente no adherente o paciente cumplidor vs paciente incumplidor $)^{95}$. En algunas ocasiones, cuando el método utilizado para valorar la adherencia terapéutica permite realizar una valoración cuantitativa, se considera como paciente adherente o buen adherente aquel sujeto que toma el $100 \%$ de la dosis prescrita, aunque algunos estudios admiten variaciones de dosis en el intervalo 80-100\%, puesto que, para la mayoría de las patologías, niveles de adherencia a medicación del $80 \%$ se ha relacionado con resultados positivos para la Salud ${ }^{14,115}$. Por consiguiente, el paciente no adherente, incumplidor, o pobre adherente se considera aquel cuya toma de medicación se encuentra por debajo de este intervalo; mientras que se considera paciente hipercumplidor aquel cuya toma de medicación se encuentra por encima del $110 \%$ de la dosis prescrita ${ }^{116}$.

Las situaciones en las que el paciente puede incumplir el régimen de medicación establecido pueden ser varias. Atendiendo a la voluntad del paciente, el incumplimiento puede producirse por actos involuntarios (incumplimiento no intencionado) y actos voluntarios (incumplimiento intencionado). El incumplimiento no intencionado es un proceso pasivo que comprende acciones como por ejemplo olvidarse la toma de medicamentos, descuidarse con la hora en la que tomar los medicamentos, u otras circunstancias fuera del control por parte del paciente. El incumplimiento no intencionado es la causa más frecuente de falta de adherencia ${ }^{102}$ y los porcentajes de incumplimiento no intencionado varían aproximadamente entre el $20 \%$ y el $70 \%{ }^{102,117}$.

Por otro lado, el incumplimiento intencionado es una decisión activa por parte del paciente que renuncia a su tratamiento prescrito e incluye acciones como dejar de tomar la medicación por diversas causas como, la mejoría en los síntomas de la 
enfermedad, los efectos secundarios de la medicación, la propia motivación del paciente, las experiencias pasadas o los conocimientos acerca de la medicación ${ }^{95,117}$. Estudios más recientes han relacionado el incumplimiento intencionado con características socioeconómicas como disponer de unos limitados ingresos, y consecuentemente, tener problemas para acceder a la medicación ${ }^{108,117}$. Por otra parte, los pacientes, pueden presentar, y de hecho presentan frecuentemente, un incumplimiento mixto, es decir, presentan ambos tipos de conducta, incumplimiento no intencionado e intencionado ${ }^{117}$.

La falta de adherencia también puede clasificarse en primaria, cuando el sujeto no se lleva la prescripción de la consulta o no la retira de la farmacia; y en secundaria, que incluye la toma de dosis incorrectas, posología incorrecta, olvido de la dosis, aumento de su frecuencia, e interrupción del tratamiento demasiado pronto, dejándolo de tomar antes de la fecha recomendada o no obteniendo una nueva prescripción ${ }^{95}$.

Una situación muy frecuente, y poco estudiada, es el incumplimiento producido en los primeros meses de tratamiento en las terapias a largo plazo de las enfermedades crónicas, ocasionado, principalmente, por los cambios de dosificación, posología, principio activo, y/o vía de administración, que el médico realiza hasta tener estable y controlada la patología. Osterber y Blaschke ${ }^{97}$ señalan que existe una marcada disminución de la adherencia al tratamiento en enfermedades crónicas después de los seis primeros meses de tratamiento. Este hecho lo ponen de manifiesto estudios como el de adherencia a medicación de cardiopatía isquémica de Jackevicius y Mamdani ${ }^{109}$ y el estudio de Benner et al. ${ }^{118}$ de estatinas, donde los porcentajes de adherencia a medicación tras los primeros seis meses disminuyeron considerablemente.

Por último, es importante señalar que la duración del tratamiento es un factor directamente relacionado con el incumplimiento. Generalmente, a medida que la duración del tratamiento se prolonga en el tiempo, la probabilidad de incumplimiento incrementa, como lo ponen de manifiesto los porcentajes de incumplimiento más elevados de las de los tratamientos a largo plazo que los porcentajes de incumplimiento relacionados con los procesos patológicos agudos ${ }^{90,97}$. 


\subsection{Factores Relacionados con la Adherencia Terapéutica}

Durante décadas, los investigadores han buscado comprender y mejorar la adherencia al tratamiento terapéutico de los pacientes que sufren enfermedades crónicas. Tras la realización de múltiples estudios donde se han investigado más de doscientas variables, se han determinado los principales factores relacionados con la adherencia terapéutica a tratamientos a largo plazo en un nuevo marco conceptual propuesto por la $\mathrm{OMS}^{90}$. Este nuevo marco conceptual propone la adherencia terapéutica como "un fenómeno multidimensional determinado por la acción recíproca de cinco conjuntos de factores, denominados dimensiones" ${ }^{(90, p 27)}$. Estos conjuntos o dimensiones son: factores relacionados con las características socioeconómicas, factores relacionados con el sistema o el equipo de asistencia sanitaria, factores relacionados con la enfermedad, factores relacionados con el tratamiento, y factores relacionados con el paciente (Figura 8).

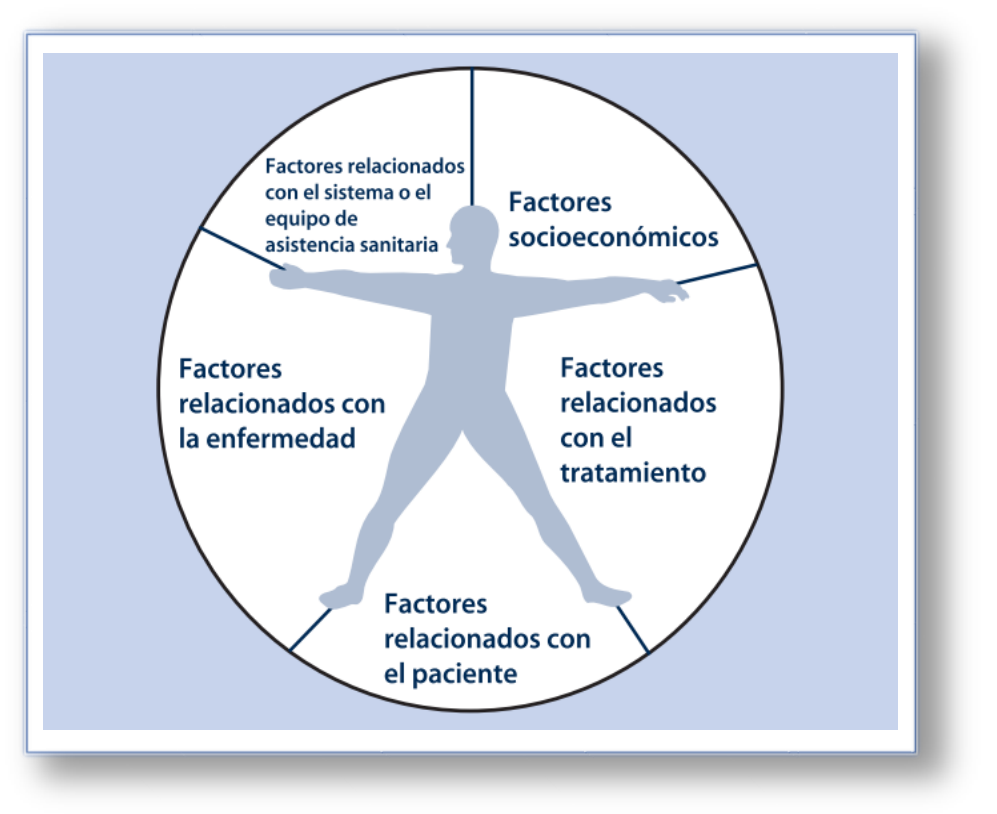

Figura 8. Los Cinco Grupos o Dimensiones de la Adherencia Terapéutica.

* Obtenido de Sabaté $2003^{90}$ 


\subsubsection{Factores Relacionados con las Características Socioeconómicas}

Entre los factores relacionados con las características socioeconómicas (incluyendo los factores demográficos), que pueden incidir en la adherencia se encuentran los siguientes: sexo, edad, raza/etnia, lugar de nacimiento, nivel de alfabetización, nivel de educación, clase social, cohabitación, área de residencia, estado civil, situación laboral, nivel económico, acceso a Salud, dificultades con el lenguaje, condiciones de vida, dificultades para acceder a la farmacia, y coste de la medicación ${ }^{90,92,98,100,119-121 . ~}$

Los factores demográficos como edad, sexo, educación, estado civil, raza/etnia, se les ha adjudicado, por lo general, un papel relacionado con la adherencia reducido debido a que han resultado ser pobres variables predictores de adherencia porque, o no se han encontrado asociaciones significativas relacionadas con la adherencia terapéutica, o bien, esas asociaciones han sido inconsistentes entre distintos estudios, y no se ha podido establecer una dirección precisa de las asociaciones ${ }^{98,122}$.

Por otro lado, las variables relacionadas con los factores sociales y económicos se les ha atribuido una importancia superior y más consistente que los factores demográficos. De este modo, el estado socioeconómico bajo, el nivel de pobreza, el analfabetismo, el bajo nivel educativo, la situación de desempleo, las condiciones de vida inestables, la mendicidad, largas distancias a recorrer al centro de tratamiento o recoger la medicación, el coste elevado del trasporte, el alto coste de la medicación, un inadecuado seguro médico, las situaciones ambientales cambiantes, el bajo nivel cultural, la mala disfunción familiar, y las erróneas creencias populares acerca de la enfermedad, se les ha asociado, por lo general, con un efecto desfavorable sobre la adherencia terapéutica dificultando el cumplimiento por parte del paciente ${ }^{90,100,120-124}$. 
La edad ha sido un factor incluido en la mayoría de los estudios, aunque con un rango diferente en cada uno de ellos. Generalmente, a medida que aumenta la edad, aumenta el grado de adherencia, hasta aproximadamente los 65-70 años donde la adherencia al tratamiento terapéutico comienza a disminuir ${ }^{122}$. Éste decline en el grado de adherencia puede estar enmascarado por otros factores, como un deterioro físico e intelectual con una disminución de las habilidades y la memoria, una disminución de la movilidad, y un número mayor de medicinas como consecuencia del mayor número de patologías padecidas ${ }^{122,125}$.

Algunos estudios ${ }^{90,122}$, sugieren que la raza/etnia y el nivel educativo constituye un factor predictivo de la adherencia independientemente si los miembros de la raza/etnia viven en su país de origen o en otro sitio como inmigrantes ${ }^{122,126}$. Para algunos autores, las creencias culturales arraigada a la raza/etnia, el analfabetismo, el lenguaje limitado, las desigualdades sociales, y las barreras que deben de enfrentarse estas personas, pueden ser la causa subyacente de estas diferencias étnicas/raciales ${ }^{122,127}$. Por esta razón, el entender completamente las indicaciones del tratamiento, y comprender la importancia de este, puede cobrar un papel muy relevante para el cumplimiento de éste ${ }^{122}$.

Otro factor objeto de numerosas investigaciones, son los costes que los pacientes tienen que hacer frente y que suponen una gran barrera para el cumplimiento del tratamiento ${ }^{90,128}$, particularmente entre aquellos sujetos con bajos recursos económicos. La ausencia de seguro médico, principalmente en aquellos países donde el Sistema de Salud es Privado, como por ejemplo EEUU, es a su vez, un importante factor relacionado con el incumplimiento terapéutico ${ }^{90,122,129}$. En algunas ocasiones, incluso el hecho de disponer un seguro médico no asegura un acceso al tratamiento, pues en determinadas situaciones, el sujeto debe pagar por su visita médica ${ }^{130}$.

En segundo lugar, el elevado precio de los medicamentos que los pacientes deben de afrontar, repercute negativamente en el cumplimiento terapéutico ${ }^{90,98,129,131,132}$, especialmente en aquellos pacientes con prescripciones farmacológicas para tratamientos a largo plazo como ocurre en el caso de las enfermedades crónicas. Numerosos 
estudios $^{132-138}$, han demostrado que, debido al precio de medicamentos, los pacientes toman menor medicación que la prescrita para ahorrar dinero, e incluso dividen los comprimidos y se saltan algunas dosis para "que duren más". Además, algunos individuos no llegan a retirar la medicación de la farmacia por su alto coste monetario ${ }^{131}$, y en cuantiosas ocasiones se ven forzados a pedir dinero para retirar sus prescripciones ${ }^{135}$.

De igual forma, las dificultades relacionadas con el transporte a las que los pacientes deben de enfrentarse suponen una importante barrera para el cumplimiento del tratamiento de los tratamietos ${ }^{130,139}$. Las dificultades de los costes en el transporte ${ }^{140}$, así como las dificultades para recoger la medicación como recorrer largas distancias o encontrar un medio de transporte adecuado ${ }^{130}$, han resultado jugar un papel negativo en la adherencia al tratamiento.

\subsubsection{Factores Relacionados con el Sistema o el Equipo de Asistencia Sanitaria}

Las autoridades en Salud juegan un papel fundamental para satisfacer las necesidades de los usuarios, pues ellos contribuyen a configurar el Sistema Sanitario en diferentes niveles y con diferentes carteras de servicios que tienen distintos grados de accesibilidad y cobertura. La manera en que el Sistema Sanitario interviene, los tipos de servicios, los recursos disponibles y accesibles a la población, y la manera de proporcionar los tratamientos, son decisiones que tienen que ser tomadas por los expertos sanitarios para el máximo Bienestar del paciente. Sistemas de distribución de medicamentos ineficaces, dificultades de accesibilidad, corta duración de las consultas, largos tiempo de espera para visitas clínicas, pobre capacidad del Sistema para educar pacientes y llevar un seguimiento de ellos, e incapacidad para establecer apoyo comunitario, han resultado influir negativamente en el cumplimiento terapéutico ${ }^{90}$. 
Desde un punto de vista a nivel micro, la relación entre médico-paciente ha resultado ser un factor crucial en la adherencia terapéutica ${ }^{90,98}$, siendo la comunicación y la satisfacción del paciente los aspectos más importantes de esta ${ }^{141}$. La mejora de la satisfacción del paciente se ha relacionado con su rol más activo en la consulta, haciéndose partícipe de las decisiones sobre su propio tratamiento, entendiendo sus enfermedades, su tratamiento farmacológico, y la naturaleza de sus problemas clínicos. Por otro lado, un diálogo abierto sobre las preocupaciones del paciente, sus expectativas, y sus sentimientos, ha sido asociado a una mejora en la comunicación ${ }^{141}$. Además, cuando el paciente recibe apoyo social y emocional, confianza, y se le trata por igual, se experimentan mejores resultados de cumplimiento ${ }^{98}$.

Adicionalmente, una información apropiada recibida por el paciente acerca de las enfermedades padecidas, sus medicaciones, y la importancia que cobra la adherencia en su CVRS, ha demostrado influir en la mejora del cumplimiento ${ }^{142,143}$. Si el paciente no recibe la información deseada, éste intenta ampliar conocimientos acerca de su enfermedad/es consultando otras fuentes como pueden ser otros médicos, farmacéuticos, enfermeras, páginas web relacionadas con la Salud, folletos educativos, redes sociales, y miembros de la familia y/o amigos. No es sorprendente que esta información sea contradictoria dada el número de fuentes $\operatorname{consultadas}^{144}$, y que varíe dependiendo si la información es recibida pasivamente, como por ejemplo de dos médicos especialistas distintos, o que la información haya sido obtenida activamente por el propio paciente mediante búsquedas, como por ejemplo información en internet no adecuada.

Finalmente, una pobre comunicación con el paciente, una sobrecarga de trabajo de los profesionales sanitarios, una corta duración de las consultas, una incapacidad para proporcionar apoyo social, un desconocimiento sobre la incidencia de los factores relacionados con la adherencia, e ineficaces intervenciones para mejorarla, han resultado condicionar e influir negativamente en el cumplimiento ${ }^{90}$. Estos hallazgos demuestran la necesidad de cooperación entre pacientes y profesionales sanitarios para establecer una relación saludable y de confianza, que permita mejorar la Salud del paciente. 


\subsubsection{Factores Relacionados con la Enfermedad}

Los factores relacionados con la enfermedad que inciden en la adherencia terapéutica incluye aquellos componentes específicos de cada condición o patología a la que los pacientes deben de enfrentarse diariamente. Ejemplos de estos factores son aquellos relacionados con la severidad de los síntomas, el número de patologías crónicas co-existentes, la velocidad de progresión de la enfermedad y su gravedad, los estilos de vida adquiridos, y la disponibilidad de tratamientos efectivos ${ }^{90}$.

El tipo de enfermedad o patología está estrechamente relacionado con la adherencia terapéutica; por ejemplo, el grado de adherencia ha resultado ser sustancialmente mayor en las enfermedades agudas, comparadas con las enfermedades crónicas ${ }^{90,97}$. Además, dentro de las enfermedades crónicas, la adherencia depende de la naturaleza de esta. Por ejemplo, Briesacher et al. ${ }^{110}$ observaron mejores tasas de adherencia a la medicación en individuos con tratamiento para enfermedad antihipertensiva (72.3\%) e hipotiroidismo (68.4\%), comparados con las tasas de adherencia al tratamiento de los individuos con hiperuricemia (24.2\%) y osteoporosis $(14.7 \%)$. La depresión y desórdenes mentales mayores como esquizofrenia, desorden bipolar, y psicosis han sido asociados generalmente con reducidos porcentajes de cumplimiento, debido principalmente a la dificultad de los pacientes en seguir el régimen de medicación recomendado ${ }^{97}$. Además, enfermedades que comprometen la conciencia y el desempeño social han sido asociadas a menores niveles de adherencia $^{145}$.

Asimismo, se ha encontrado que la multimorbilidad, el abuso de drogas, alcohol, y tabaco, también influyen negativamente en el cumplimiento del tratamiento ${ }^{24,90}$. La percepción subjetiva de severidad de la enfermedad también influye en la adherencia. Una percepción elevada de severidad de la enfermedad está asociada con porcentajes más elevados de cumplimiento ${ }^{145,146}$. Además, se ha observado que cuando la enfermedad del paciente es asintomática, tienen mínimos síntomas, o se trata de un tratamiento 
preventivo, la adherencia ha resultado ser menor ${ }^{145}$. Por ejemplo, Kyngas y Lahdenpera ${ }^{147}$ encontraron una relación significativa entre la presencia de síntomas de hipertensión y la reducción de la ingesta de sodio. Del mismo modo, Lim et al. ${ }^{148}$ encontraron mejores niveles de adherencia en los pacientes del estudio que experimentaron mejoras en los síntomas relacionados con la enfermedad gracias al tratamiento. Por el contrario, existen evidencias consistentes que muestran que los sujetos con una percepción severa de la enfermedad obtienen mejores niveles de adherencia, incluso si el tratamiento dura un $\operatorname{largo~periodo~}^{146}$.

\subsubsection{Factores Relacionados con el Tratamiento}

En primer lugar, los factores relacionados con el tratamiento no deberían de ningún modo dificultar la adherencia del paciente, sino que deberían ayudarle a cumplir con su tratamiento. Existen numerosos factores relacionados con el tratamiento que inciden en la adherencia, los más importantes son aquellos relacionados con la complejidad del régimen, la polifarmacia, la duración del tratamiento, los frecuentes cambios en el régimen farmacológico, la inmediatez de los efectos y eficacia del tratamiento, los efectos secundarios, la vía de administración, y la disponibilidad de apoyo médico ${ }^{90,141}$.

Un tratamiento de un corto período de duración y con un nivel de complejidad sencillo, ayuda a que el paciente se adhiera a su régimen ${ }^{145}$, mientras que a medida que aumenta la duración del tratamiento, disminuye el porcentaje de cumplimiento ${ }^{109,118,149}$. Del mismo modo, a medida a que aumenta el grado de polifarmacia, las dosis de medicamentos prescritas, y la complejidad del tratamiento, disminuye el porcentaje de cumplimiento $^{24,89,102,113,120,146,150,151}$. Es comprensible, que, a mayor número de medicamentos que el paciente tiene que tomar, más fácil es olvidarse alguna dosis ${ }^{146}$. Por 
ejemplo, Jansa et al. ${ }^{113}$ encontraron diferencias significativas en el número de comprimidos diarios prescritos entre el grupo de pacientes cumplidores de su estudio (5.78 comprimidos/día) y el grupo de no cumplidores (3.20 comprimidos/día), y un mayor porcentaje de incumpliendo en aquellos sujetos con una elevada complejidad de tratamiento.

Una vía de administración no invasiva (como por ejemplo la vía oral), contribuye positivamente a mejorar el cumplimiento del tratamiento ${ }^{141}$. Por ejemplo, se ha observado mejores resultados de adherencia en pacientes asmáticos cuando la medicación es administrada por vía oral en lugar de ser administrada por vía inhalatoria ${ }^{152}$. Asimismo, si la vía de administración requiere personal entrenado o conlleva alguna dificultad, la influencia sobre la adherencia también es negativa. En el estudio de Bender y Bender ${ }^{153}$, la dificultad a la hora de usar los inhaladores contribuyó de manera significativa a una reducida adherencia.

Del mismo modo, un régimen de dosificación simple, como por ejemplo aquel que incluye una dosis diaria o dosis fijas combinadas, mejora la adherencia al tratamiento del paciente pues minimiza la frecuencia de la dosis ${ }^{89}$. Estos hechos han sido demostrados por Dickson y Plauschinat ${ }^{154}$ donde los porcentajes de incumplimiento alcanzaron un $48.1 \%$ en aquellos pacientes con dosis fijas combinadas respecto a un $58.6 \%$ que no presentaron éste tipo de dosis.

Los efectos secundarios, y en menor medida los efectos adversos, también han mostrado comportarse como una barrera negativa en la adherencia al tratamiento del paciente. Esta problemática ha sido ampliamente examinada, encontrándose un mayor nivel de adherencia en aquellos sujetos que no experimentan ningún efecto ${ }^{90,93,141,155-157}$. Por ejemplo, Munro et al. ${ }^{156}$ encontraron los efectos secundarios y los efectos adversos como causas más frecuentes de incumplimiento entre los estudios de su revisión sistemática. 
Hay que señalar, que frecuentes cambios de medicación son realizados en los primeros meses tras el inicio de un nuevo tratamiento ${ }^{158,159}$ hasta que la enfermedad está totalmente estable y controlada. En otras ocasiones, los efectos secundarios, la ineficacia del tratamiento, o las limitaciones económicas de los pacientes, obligan a efectuar cambios en el régimen terapéutico. Estos cambios de medicación al principio del inicio de un tratamiento, repercuten negativamente en la adherencia del paciente.

Por tanto, los profesionales sanitarios deberían considerar los factores relacionados con el tratamiento a la hora de diseñar el tratamiento del paciente, y hacer partícipe al paciente en el proceso para minimizar posibles barreras relacionadas con la adherencia terapéutica.

\subsubsection{Factores Relacionados con el Paciente}

Los factores relacionados con el paciente que inciden en la adherencia terapéutica están ligados a los conocimientos, las actitudes, las creencias, los recursos, las percepciones y las expectaciones que éste tiene ${ }^{90}$.

En primer lugar los conocimientos del paciente sobre su enfermedad y el tratamiento juegan un papel fundamental en la adherencia ${ }^{89,90,141,146}$. En numerosas ocasiones, el paciente carece de algunos conocimientos sobre su enfermedad y desconoce las consecuencias que ocasiona una falta da adherencia al tratamiento. En otras ocasiones, los pacientes no se percatan de la importancia que tiene el régimen farmacológico para su Salud e incluso, frecuentemente, algunos pacientes carecen de la trascendencia que tienen las visitas a consulta ${ }^{141}$. Todos estos factores repercuten de manera negativamente en el cumplimiento, y ponen de manifiesto la necesidad de una educación óptima del paciente, para mejorar la adherencia. 
La percepción de necesidad de un tratamiento está influenciada por los síntomas, las experiencias previas, y las expectaciones del paciente ${ }^{90}$. De acuerdo al Modelo de Creencias de Salud (MCS) ${ }^{160}$, aquellos pacientes que perciben la necesidad de tratar sus condiciones tienen mayor probabilidad de adherirse a las recomendaciones del tratamiento. Además, la predisposición a cumplir el tratamiento aumenta si el paciente percibe que éste va a ser efectivo y puede mejorar su Salud ${ }^{141}$.

La motivación del paciente y sus preocupaciones también desempeñan un papel fundamental en la adherencia ${ }^{89,90,141,146}$. Un aumento de la motivación del paciente como consecuencia de su confianza para cumplir con el tratamiento, se ha asociado a una mejor adherencia, mientras que las preocupaciones del paciente sobre la medicación se han relacionado con un incumplimiento voluntario ${ }^{117,161}$. Por otro lado, una percepción baja de necesidad de tratamiento, de su efectividad, y de confianza, influye de manera negativa en la adherencia del paciente.

El olvido de la toma de medicación es un factor que ha sido ampliamente estudiado en la literatura científica ${ }^{89,90,95,102,141,146}$, siendo la principal causa de incumplimiento en los estudios de adherencia ${ }^{117,161-165}$. La probabilidad de incumplir el régimen de terapéutico por olvido de la medicación, aumenta con la complejidad el régimen, el número de prescripciones, medicamentos, y tomas diarias de dosis. Además, los pacientes con edad avanzada, deterioro cognitivo, y enfermedades relacionadas con éste, tienen mayor facilidad para olvidar la medicación. Para evitar esta causa de incumplimiento, los métodos para recordar la toma de medicación han resultado ser muy efectivos $^{166-168}$.

Hoy en día, existe una gran variedad de métodos y estrategias para ayudar a los pacientes a tomar la medicación y seguir correctamente los tratamientos, mediante el recordatorio de la toma de las dosis y facilitando las indicaciones ${ }^{169}$. Por ejemplo, los instrumentos de organización como pastilleros y organizadores han resultado ser una substancial mejora en determinados estudios de adherencia puesto que estos permiten una organización de las pastillas día por día y el paciente puede apreciar fácilmente si se tomó 
la medicación ${ }^{166}$. Los calendarios y hojas de anotación han resultado ser efectivos para evitar que el paciente se quede sin medicación, especialmente al viajar o irse de vacaciones ${ }^{170}$. Sincronizar alarmas en el reloj o el teléfono móvil es también un método popular y efectivo muy extendido entre la población ${ }^{170}$.

Con el gran desarrollo de las nuevas tecnologías de la información y la comunicación (TIC) experimentado en los últimos, los mensajes de texto y aplicaciones para teléfonos móviles (apps) también han resultado herramientas prácticas a la hora de mejorar la adherencia a medicación en una gran variedad de enfermedades crónicas ${ }^{167,171}$. Del mismo modo, determinados pacientes para no olvidar la toma de medicación asocian su ingesta con actividades cotidianas de la vida diaria como, por ejemplo, el automatismo de preparar un café en la mañana, leer el periódico, o la rutina que realiza algunas personas antes de acostarse como ducharse, levarse los dientes, o ver la televisión ${ }^{172}$. Otras investigaciones han puesto de manifiesto una mejora en la adherencia cuando los pacientes asocian la toma de medicación con las principales comidas del día ${ }^{173}$.

\subsection{Consecuencias y Repercusiones de la Falta de Adherencia al Tratamiento}

La falta de adherencia al tratamiento terapéutico desencadena una serie de consecuencias negativas que van a repercutir, principalmente, en la Calidad de Vida del paciente, así como en la progresión de la enfermedad, y en los costes monetarios para el Sistema y el propio paciente ${ }^{90}$. 
Evidencias clínicas han demostrado que la prescripción farmacológica es un componente esencial para el tratamiento y control de numerosas patologías crónicas. Sin embargo, una pobre adherencia al tratamiento es considerada una de las principales barreras para el control de la enfermedad y la consecución de resultados positivos en Salud. Cuando los pacientes incumplen con el régimen farmacológico, no es posible alcanzar óptimos niveles terapéuticos, obteniendo unos efectos menores. Los efectos terapéuticos reducidos conducen a un incremento en la prescripción de dosis farmacológicas o incluso a una suspensión del tratamiento al creerse que éste es inefectivo. Esta asunción está basada en que el paciente o el sujeto está tomando la medicación según las recomendaciones prescritas, cuando una pobre adherencia puede ser la causa de la falta de efectividad ${ }^{105}$. Por ejemplo, se ha estimado que solamente la mitad de los pacientes que son prescritos con tratamientos farmacológicos toman suficientes dosis de medicación para experimentar efectos terapéuticos ${ }^{105}$.

Una pobre adherencia al tratamiento farmacológico, puede provocar una falta de control de la enfermedad, que resulta en una progresión más acelerada de esta, y consecuentemente puede desencadenar complicaciones, hospitalizaciones, aumento de la morbilidad, discapacidad, e incluso la muerte para el propio paciente ${ }^{97,105}$. Asimismo, la falta de incumplimiento terapéutico provoca un doble gasto económico como consecuencia del ausentismo laboral, pérdida de productividad y muerte prematura consecuencia de los niveles de morbilidad y mortalidad ${ }^{174}$. Por ejemplo, los pacientes incumplidores del tratamiento de diabetes y enfermedad cardíaca presentaron una mayor mortalidad (12.1\%) que los pacientes adherentes al tratamiento $(6.7 \%)^{175}$. Sokol et al. ${ }^{176}$ estudiaron también el riesgo de hospitalización asociado a la adherencia a medicación de cuatro condiciones crónicas (diabetes, hipercolesterolemia, insuficiencia cardíaca, y enfermedad arterial hipertensiva) que presentaban los sujetos de su estudio. Los resultados demostraron que entre los pacientes que padecían diabetes, el porcentaje de hospitalización incrementaba de un $13 \%$ a un $30 \%$ para aquellos sujetos con una pobre adherencia, mientras que para aquellos que padecían enfermedad isquémica el riesgo de hospitalización en pacientes incumplidores aumentaba desde un 19\% hasta un 30\%. 
Osterber y Blaschke ${ }^{97}$ concluyeron, basados en la revisión de múltiples estudios, que entre el 33\% y el 69\% de las hospitalizaciones relacionadas con la medicación en los EEUU son debido a un incumplimiento del tratamiento por parte del paciente.

La falta de adherencia también supone un desembolso económico tanto para los Sistemas de Salud como para el propio paciente. La prescripción de medicamentos es el componente del total de costes sanitarios que más rápido crece en EEUU. Prueba de ellos es el notable incremento producido en gasto de medicación en los últimos años, aumentando desde $9 \%$ hasta un $13 \%$ y se prevé que continúe creciendo a ritmo similar en los próximos años ${ }^{176}$. En el año 2006, 187.5 millones de estadounidenses, lo que representa el $63 \%$ de la población civil no institucionalizada, compró al menos una prescripción médica ${ }^{176}$.

Sin embargo, este importante gasto económico es el resultado, en gran medida, de un aumento en número de prescripciones en personas que no logran niveles eficaces de concentración farmacológica debido a la falta de adherencia a la medicación ${ }^{103}$. El mayor número de prescripciones se traduce para el propio paciente en un mayor gasto económico. De acuerdo con el New England Health Institute (NEHI) ${ }^{175}$ aquellos pacientes incumplidores tienen un gasto considerablemente más elevado que aquellos con niveles adecuados de adherencia, tal y como lo refleja el coste total anual de \$16.498 del paciente incumplidor diabético frente al coste total anual de $\$ 8.846$ del paciente cumplidor diabético.

El elevado gasto económico también es el resultado del aumento del número de visitas clínicas y visitas a centros ambulatorios, salas de urgencias, realización de pruebas diagnósticas complementarias, adición de nuevos fármacos al tratamiento, hospitalizaciones, y reingresos que la falta de adherencia al tratamiento provoca y que podrían evitarse con una correcta adherencia al régimen terapéutico. Por ejemplo, en EEUU se calcula que los costes derivados de la toma incorrecta de medicación alcanzan los 100 billones de dólares, y de estos, 25 billones corresponden a ingresos hospitalarios y 70 billones a pérdida de productividad y muerte prematura ${ }^{174}$. 


\subsection{Métodos de Valoración de la Adherencia al Tratamiento Farmacológico}

Los métodos disponibles para la valoración de la adherencia al tratamiento farmacológico pueden ser clasificados como métodos directos y métodos indirectos. Actualmente, ningún método ha sido considerado como método estándar o de referencia por su falta de fiabilidad y precisión ${ }^{97}$.

El fundamento de los métodos de evaluación directa reside en comprobar si existió o no la ingestión de medicación por el paciente. Por lo general, son objetivos y específicos, pero carecen de utilidad al tener un precio elevado y requerir infraestructura, por lo que se reservan casi exclusivamente a ensayos clínicos ${ }^{92,145}$ (Figura 9). Existen tres métodos directos: observación directa, en los que un profesional sanitario ofrece la medicación al paciente y observa cómo éste se la toma; evaluación de los niveles de fármaco o metabolitos en sangre u orina, realizado por medio de técnicas de laboratorio; y evaluación de marcadores biológicos en sangre, en los que se administra una sustancia inocua junto a la formulación farmacológica para medir posteriormente, las concentraciones de éste marcador en sangre ${ }^{90,97}$.

Los métodos de evaluación indirecta de la adherencia son los más utilizados por tener una buena efectividad de acuerdo a su sencillez, precio, e infraestructura requerida. Son muy útiles en investigación, atención primaria y extrapolables a la farmacia comunitaria $^{92}$ (Figura 9). Los más utilizados en los estudios son: entrevistas de autocomunicado, recuento de comprimidos, evaluación de la eficacia clínica alcanzada, el uso de monitores electrónicos, control de prescripciones retiradas de la base de datos de la farmacia, y el uso de diarios u hojas de registro de medicación ${ }^{90,92,95,97,145}$. 


\begin{tabular}{|c|c|}
\hline Métodos Directos & Métodos Indirectos \\
\hline Objetivos & Menos Objetivos \\
Fiables & Menos Fiables \\
Caros & Baratos \\
Sofisticados & Sencillos \\
Limitados a Ciertos Fármacos & Válidos para Cualquier Fármaco \\
Normalmente Exactos & Sobreestiman el Cumplimiento \\
Útiles en Ensayos Clínicos & Útiles en Atención Primaria \\
\hline
\end{tabular}

Figura 9. Características de los Métodos de Evaluación de Adherencia Directos vs Indirectos.

* Obtenido de Gabarro $1992^{92}$.

Los métodos de auto-cumplimento se fundamentan en preguntar directa o indirectamente al paciente por medio de una entrevista sobre su nivel de incumplimiento $^{92}$. Estos métodos cuando se realizan correctamente constituyen uno de los mejores métodos de valoración indirecta para evaluar la adherencia a medicación, ofreciendo indicadores de validez semejantes a los métodos de evaluación directa ${ }^{92}$.

La entrevista se debe de realizar en un ambiente distendido, agradable para el paciente, y adecuado para la conversación ${ }^{177}$. El entrevistador debe escoger preguntas bien formuladas, evitando cuestiones acusatorias y agresivas ${ }^{92}$. Un factor limitante de estos métodos reside en la identidad del entrevistador, pues las respuestas variarán si el interlocutor es el médico que realizó la prescripción o un profesional sanitario relacionado, como, por ejemplo, otro médico o el farmacéutico ${ }^{92}$. Dentro de estos métodos, los cuestionarios validados de cumplimiento autorreferido de Hayness-Sackett ${ }^{93}$ y Morisky-Green-Levine ${ }^{178}$ son lo más utilizados. 
El Test de Haynes-Sacket ${ }^{93}$ es un cuestionario validado con una sensibilidad del $50 \%$ y una especificidad del $87 \%$, con dos partes diferenciadas para preguntar al enfermo sobre su nivel de cumplimento. En la primera parte del cuestionario se hace ver al paciente la dificultad que entraña el tomar la medicación por medio de la frase: «la mayoría de pacientes tienen dificultades en tomar sus medicamentos», para posteriormente preguntarle en una segunda parte la pregunta: «¿tiene usted dificultades en tomar los suyos?». Si la respuesta es afirmativa, el paciente es clasificado como incumplidor, mientras que si responde negativamente puede que el paciente no diga la verdad y se le insistirá preguntando con la siguiente cuestión: «¿cómo los toma?: todos los días, muchos días, algunos días, pocos días, o raras veces». Se considera incumplidor aquel paciente cuyo porcentaje de incumplimiento es $<80 \%$ ó $>110 \%$. Finalmente, se realiza una tercera pregunta y se recoge lo que el paciente mencione sobre la siguiente reflexión: «muchas personas tienen dificultad en seguir los tratamientos, ¿por qué no me comenta cómo le va a usted».

El cuestionario de adherencia a medicación Morisky-Green-Levine ${ }^{178}$, con una sensibilidad del $81 \%$ y una especificidad del $44 \%$, y validado en su versión española por Val Jimenez et al. ${ }^{179}$ se ha utilizado en numerosos estudios de adherencia en patologías crónicas como enfermedad hipertensiva, diabetes, enfermedades vasculares, asma, EPOC, depresión, Parkinson, y VIH, con resultados satisfactorios.

Este cuestionario, desarrollado originalmente para evaluar la conducta de los pacientes asociado al uso de fármacos antihipertensivos, ha sido el más utilizado a nivel internacional en los estudios de adherencia a medicación en los últimos veinte años y consta de las siguientes cuatro preguntas dicotómicas ${ }^{179}$ : 1) ¿Olvida alguna vez tomar los medicamentos para tratar su enfermedad? 2) ¿Toma los medicamentos a las horas indicadas? 3) Cuando se encuentra bien, ¿deja de tomar la medicación? 4) Si alguna vez le sientan mal, ¿deja de tomarla? 
Morisky et al. ${ }^{178}$ desarrollaron una escala de 0 a 4 para clasificar el grado de incumplimiento del paciente. Cada respuesta afirmativa (sí) dada por el paciente, se le otorga un valor de 0 (cero) puntos, mientras que cada respuesta contestada negativamente (no) se le otorga un valor de 1 (un) punto. De acuerdo a la suma de los valores de cada respuesta, el grado de adherencia del paciente será clasificado como: alto (4 puntos), medio (2-3 puntos), y bajo (0-1) puntos. En adición, la escala permite evaluar la adherencia como variable dicotómica, de modo que un valor de 4 puntos clasifica al paciente como adherente, y un valor $<4$ puntos clasifica al paciente como no adherente ${ }^{178}$.

Las ventajas múltiples del método de Morisky-Green-Levine en cuanto a que es un método sencillo, barato, fiable cuando el paciente asegura no cumplir con su medicación, fácil de comprender independientemente del nivel sociocultural, e informativo sobre el origen del incumplimiento, lo convierten en uno de los métodos más utilizados en investigación ${ }^{92,177}$.

El método de recuento de comprimidos consiste en contar la medicación restante del paciente que queda en el envase dispensado previamente, de manera que conociendo la pauta de administración y los días transcurridos entre la fecha de dispensación y la fecha de recuento, se puede valorar si el paciente se adhiere a su tratamiento o en cambio lo incumple ${ }^{92,95}$. La fórmula para calcular el cumplimiento es la siguiente:

\% cumplimiento $=($ número de comprimidos que previsiblemente ha tomado el paciente/número de comprimidos que han sido prescriptos) x 100 .

Debido a que su aplicación presenta algunas dificultades, como, por ejemplo, saber la fecha exacta del inicio del tratamiento y del envase que se prescribe, disponer de un número superior de comprimidos hasta la fecha control, y mantener el envase en el momento del control, lo convierten en un método de valoración relegado casi exclusivamente a ensayos clínicos. Además, en población general sobreestima la adherencia, ya que no se sabe si los comprimidos que faltan en el envase han sido tomados por el paciente, desechados, o entregados a otra persona. En población de edad avanzada, 
ocurre todo lo contrario, debido a que este método de valoración puede llegar a infravalorar la adherencia ya que este tipo de población tiende a retirar las recetas antes de que se les acabe la medicación, y tiende a acumular en el domicilio más medicación de la que realmente necesitan ${ }^{95}$.

Otro método de valoración es el de la evaluación de la eficacia clínica alcanzada. Este método consiste en detectar el grupo de pacientes con fracaso terapéutico, y analizar el porcentaje que es debido al incumplimiento. Es un método que puede resultar poco fiable, puesto que existen otros factores, independientes de la adherencia al tratamiento, que pueden influir en los resultados, y que por tanto afectan a su eficacia ${ }^{95,145}$.

El uso de monitores electrónicos como por ejemplo Monitores Acoplados al Envase de los Medicamento (MENS) ${ }^{146}$, es otro método indirecto para la valoración de la adherencia. Estos dispositivos registran automáticamente o semi-automáticamente unidades de dosificación de medicamentos (comprimidos, gotas, grageas, etc.) cuando son removidas del envase ${ }^{92,95}$. Es un sistema sofisticado, que registra exactamente el momento en el que se abre el vial, y provee detallada información para calcular el número de dosis correctamente tomadas en la correcta posología. Sin embargo, la apertura del envase no asegura que el medicamento se haya consumido. Además, el alto precio de los monitores electrónicos hace que suelan ser limitados a los ensayos clínicos.

Otro método indirecto de valoración de la adherencia, es el tiempo transcurrido entre dos dispensaciones sucesivas de un mismo medicamento, utilizado frecuentemente en Sistemas de Salud donde el control y retiro de prescripciones queda registrado en la base de datos ${ }^{92,95}$. Para que sea fiable este método, el paciente debe retirar siempre la medicación en la misma farmacia o en la red de farmacias que estén integras en la base de datos. Además, se debe realizar un estricto seguimiento de cada una de las prescripciones dispensadas, y se deberá conocer cualquier modificación en la pauta de administración del medicamento. Este método permite identificar a los pacientes incumplidores, ya que se puede calcular fácilmente si la frecuencia de dispensación no es 
aceptable. Sin embargo, el retiro de la prescripción en la fecha adecuada, no asegura que el paciente vaya a consumir realmente la medicación ${ }^{92}$.

Por último, se puede recabar información acerca de la adherencia al tratamiento del paciente por medio de la recolección de diarios u hojas de registro diario, donde el paciente apunta la medicación tomada cada día ${ }^{146}$. Este método permite recoger información adicional que puede ser relacionada con eventos externos y/o afectos adversos. Es un método que requiere gran colaboración del paciente, dado que la documentación tiene que ser completa y consistente. En general, los pacientes en edad avanzada, tienen dificultades para utilizar este método ya que se olvidan de recoger numerosa información, lo que hace muy difícil la evaluación de la adherencia al tratamiento. Además, existe el riesgo de que la creatividad del paciente supera a la realidad $^{146}$. 


\section{Salud en los Grupos de Población Vulnerables}

Actualmente, la población mundial experimenta en su conjunto los mejores niveles de Salud de la Historia de la Humanidad ${ }^{4}$. Las notables mejoras en Sanidad, higiene, atención prenatal, y el acceso a agua potable han llevado a un acelerado progreso a nivel mundial ${ }^{2}$. Además, el crecimiento de la economía mundial ha permitido una revolución tecnológica que ha multiplicado los recursos disponibles a través de las TIC en materia de Salud como jamás se había experimentado anteriormente.

Sin embargo, existe un hecho que no puede ser ignorado. A medida que el progreso sanitario continúa avanzando, las desigualdades en Salud continúan incrementádose ${ }^{10,180}$. Mientras que una gran parte del mundo continúa avanzando hacia una mejor Salud, otras partes del mundo se han quedado atrás o están perdiendo terreno. Incluso en las naciones que disponen de un elevado nivel sanitario, como por ejemplo EEUU, es habitual observar desigualdades de Salud entre los distintos grupos de población, lo que aumenta la probabilidad de padecer procesos patológicos, como es el caso de las enfermedades crónicas ${ }^{181}$.

Estos grupos de población no están adecuadamente integrados dentro del Sistema de Salud debido a las propias características de los individuos y a las que les rodean, lo que incrementa el riesgo de que no reciban una adecuada asistencia sanitaria, y consecuentemente, vean comprometida su Salud. A menudo, los sujetos que componen 
estos grupos de población, están olvidados dentro del Sistema Sanitario, pues son grupos minoritarios, es decir, grupos socialmente subordinados cuyos miembros tienen un poder o control significativamente menor que otros grupos de la misma sociedad ${ }^{182}$. Estos grupos sociales son vistos con una baja estima por sus rasgos físicos o culturales característicos, y fruentemente son excluidos socialmente ${ }^{182,183}$. Los grupos minoritarios más frecuentes son aquellos pertenecientes a minorías raciales, minorías étnicas, minorías religiosas, y minorías sexuales, aunque no son los únicos grupos ${ }^{184}$.

\subsection{Contexto y Situación de las Desigualdades en los Grupos Sociales de Población Estadounidense}

El siglo XX ha experimentado la transformación de la población de EEUU desde una población predominante blanca con raíces occidentales, hasta una Sociedad formada por una gran variedad de diferentes grupos de población. En una nación cuya reciente historia ha estado caracterizada por las constantes desigualdades sociales y económicas entre sus ciudadanos (como, por ejemplo, violaciones de los derechos humanos y restricciones de sufragio), a día de hoy, las desigualdades en facetas de la vida moderna como educación, empleo, vivienda, y otras necesidades vitales, continúan terriblemente vigentes ${ }^{181}$. Quizá, una de las manifestaciones más notables, se observa en las existentes desigualdades y disparidades de Salud entre los grupos sociales de población.

Las desigualdades en Salud, término comúnmente empleado fuera de las fronteras estadounidenses, se refiere de manera genérica a las diferencias en Salud de los individuos o grupos; mientras que las disparidades o inequidades en Salud, término usado casi exclusivamente en los EEUU, hace referencia a las diferencias innecesarias, evitables, e 
injustas respecto al acceso y utilización de los servicios de Salud, el Estado de Salud, los resultados en Salud, y la calidad de la asistencia entre los diferentes grupos poblacionales ${ }^{185,186}$. Las disparidades de Salud reflejan una distribución injusta de los riesgos y los recursos de Salud ${ }^{186}$. Como consecuencia de estas disparidades, los grupos de población más desfavorecidos, frecuentemente pertenecientes a grupos minoritarios, padecen de una reducida Calidad de Vida como consecuencia de una pobre Salud causada por una acentuada discapacidad, una considerable morbilidad y mortalidad, y las dificultades que presentan para el acceder a los servicios de Salud.

Estos grupos de población desfavorecidos, denominados grupos de población vulnerables, experimentan un mayor riesgo de pobreza y exclusión social que la población general, y engloba a aquellas personas desfavorecidas económicamente, sin seguro médico, pertenecientes a minorías raciales y étnicas, niños de familias de bajos ingresos, ancianos, indigentes, sujetos con VIH, y enfermedades crónicas, incluidas enfermedades mentales ${ }^{187}$. También, incluye aquellas personas viviendo en medio rural que encuentran numerosas barreras para tener acceso a los servicios de Salud ${ }^{187}$.

En EEUU, las disparidades de Salud son más bien sistemáticas que fortuitas, y se observan en las diferencias existentes entre grupos de población a la hora de disponer acceso a seguro médico, asistencia y calidad sanitaria ${ }^{188}$. Las minorías étnicas y las personas con bajo nivel económico tienen más problemas para adquirir un seguro médico que las personas blancas de poder adquisitivo ${ }^{189}$. Este hecho se refleja cuando se compara la proporción del $16.2 \%$ de latinos/hispanos y $11.1 \%$ de afroamericanos existentes en EEUU sin seguro médico, con el de $6.7 \%$ de población blanca no hispánica (año 2015) ${ }^{189}$. Además, las minorías étnicas y raciales y las personas con bajo nivel socioeconómico reciben peor calidad de asistencia sanitaria ${ }^{189}$, y se estima que cerca de 83.000 muertes/año son consecuencia de las disparidades de Salud ${ }^{189}$. Diferentes fuentes, incluyendo el Sistema Sanitario, que no se comporta como un Sistema Social sino como uno económico, los profesionales sanitarios, los pacientes, y los administradores de planes contribuyen a aumentar las disparidades de Salud entre los grupos de población ${ }^{190}$. 


\subsection{Fuentes de Vulnerabilidad}

El ámbito de la Salud de los grupos de población vulnerables puede ser dividido en tres categorías: físico, psicológico, y social ${ }^{187}$. Aquellas personas con necesidades físicas, incluyen embarazos de alto riesgo, enfermos crónicos y discapacitados, y personas infectadas por el VIH. En el campo psicológico, los grupos de población vulnerables incluyen aquellas personas con enfermedades mentales como esquizofrenia, desorden bipolar, depresión severa, y síndrome hipercinético, como también aquellos individuos con una historia de abuso de alcohol, y otras sustancias estupefacientes. En el dominio social, los grupos de población vulnerables incluyen aquellas personas viviendo en familias abusivas, indigentes, inmigrantes, y refugiados.

La vulnerabilidad de estas personas está condicionada y/o determinada por la raza, etnia, edad, sexo, orientación sexual, discapacidad, y otros factores como el nivel de ingresos, lenguaje, cultura, situación de inmigración, seguro médico (o falta del mismo), y ausencia de una Atención Sanitaria continua ${ }^{90,181,185,186,191}$.

La Salud de estas personas y los problemas de asistencia sanitaria, interactúan con otros factores como por ejemplo pobreza, escasez de vivienda, y educación inadecuada. El nivel económico y el área de residencia; la raza y la etnia; la severidad de la enfermedad, la edad, y el estado funcional o de desarrollo del individuo; y las barreras de comunicación son las principales fuentes de vulnerabilidad de estos grupos de población 


\subsubsection{Nivel Económico y Área de Residencia}

Los individuos pueden ser vulnerables en función de sus circunstancias financieras o área de residencia ${ }^{185,186}$. Se considera que los ingresos económicos y la educación son los indicadores más representativos de nivel económico. Junto a estos determinantes el área de residencia y sus características presentan un importante efecto independiente en la Salud.

Estos factores, frecuentemente interrelacionados entre sí, se presentan como obstáculos para estos grupos de población vulnerables a la hora de obtener asistencia sanitaria y resultan en importantes factores de riesgo para la Salud. Susceptibles de estos factores son aquellas personas cuyos niveles de ingresos y/o seguro médico les impide tener acceso a la asistencia sanitaria deseada. Por ejemplo, en 2015, se estimó que cerca de 29 millones de personas carecían de seguro médico en EEUU, lo que resulta en una asistencia médica inadecuada y consecuentemente, un disminuido nivel de Salud de estas personas $^{189}$.

La influencia que genera el área de residencia como fuente de vulnerabilidad es a través de diferentes vías. La primera de ellas es el impacto que general la disponibilidad geográfica, pues en estas áreas la disponibilidad de instituciones de Salud y Atención Sanitaria especializada es menor, independientemente del seguro médico ${ }^{184}$. Otras vías de vulnerabilidad son la exposición a medios ambientes tóxicos y de polución, y la falta de recursos comunitarios en el área.

Cabe señalar que, al referirse al área de residencia, estos grupos vulnerables tienden a concentrarse en determinadas zonas, marcando una separación espacial con otros grupos poblacionales, originando una segregación. Los grupos vulnerables normalmente se sitúan en áreas o zonas caracterizadas por ambientes ruidosos, con tráfico denso, altas tasas de criminalidad y delincuencia, elevada concentración de tiendas de 
licores, y fácil acceso a drogas. Algunos autores ${ }^{182,186}$ señalan que estas segregaciones podrían ser el resultado histórico de discriminaciones económicas, más que de las propias decisiones tomadas por los individuos.

\subsubsection{Raza y Etnia}

La raza y la etnia también son fuentes significativas de vulnerabilidad, y frecuentemente, están asociadas a grupos minoritarios poblacionales. En EEUU, las minorías étnicas y raciales cobran un peso importante pues a día de hoy representan un tercio de la población total ${ }^{192}$. Su vulnerabilidad reside en la mayor morbilidad y mortalidad que padecen con respecto a la población americana blanca no hispánica, como reflejan la prevalencia más elevada de enfermedades como la diabetes, accidentes cerebrovasculares, y enfermedades cardíacas ${ }^{192}$.

Además, estas minorías se ven comprometidas con los problemas que encuentran para tener acceso a una adecuada asistencia sanitaria y de calidad, dado que muchos profesionales sanitarios carecen de los conocimientos, creencias, prácticas, y factores de riesgos asociados a la cultura de las de estos grupos ${ }^{184,192}$. Por ejemplo, los individuos de una determinada raza/etnia requieren pruebas de cribado para enfermedades que son más prevalentes dada su genética, además que pueden reaccionar de una manera diferente a la medicación, y realizar prácticas curativas arraigadas a su cultura que interfieran con el tratamiento tradicional ${ }^{192}$.

Las causas subyacentes de esta vulnerabilidad no están del todo bien entendidas, y se les asocia con estereotipos, estigma, y otras causas diversas ${ }^{184,192,193}$, que pueden tener sus raíces en razones políticas, históricas, y/o filosóficas, incluyendo las experiencias de discriminación vividas recientemente en la historia de EEUU ${ }^{185}$. Por 
ejemplo, según los datos nacionales de EEUU, la población blanca no hispánica posee una percepción más negativa de todas las minorías raciales/étnicas que la percepción de su propia raza, siendo la minoría afroamericana la peor considerada, seguida de la latina/hispana, y la asiática ${ }^{194}$. Es más, un $45 \%$ de la población blanca no hispánica cree que la mayoría de los afroamericanos son "vagos", mientras que un 51\% afirma que la mayoría de afroamericanos son "propensos a la violencia", y un 29\% piensa que la población afroamericana no es "inteligente"194.

\subsubsection{Severidad de la Enfermedad, Edad, y Estado Funcional o de Desarrollo del Individuo}

Las personas pueden ser vulnerables debido a la naturaleza y/o severidad de sus enfermedades o discapacidades. Estas personas, encuentran frecuentemente numerosas dificultades para tener acceso a los servicios de Salud que demandan sus enfermedades o discapacidades. Estas dificultades son, por ejemplo, la falta de continuidad y de coordinación entre los diferentes profesionales sanitarios, inhabilidad de los especialistas para tratar sus condiciones, y dificultad para recibir autorizaciones para tratamientos costosos o especiales. Además, un gran número de sujetos tienen que hacer frente al estigma que conlleva enfermedades como el VIH o las enfermedades mentales ${ }^{184}$.

Los pacientes que padecen múltiples enfermedades crónicas, son un ejemplo de esta fuente de vulnerabilidad. Estos pacientes, como se ha mencionado anteriormente, requieren más visitas anuales al médico ${ }^{66,76-78}$, un mayor uso de prescripciones médicas ${ }^{49,80}$, un elevado riesgo de presentar interacciones medicamentosas, errores médicos en prescripción, duplicidades, sobredosificaciones e infra dosificaciones, y la aparición de efectos adversos ${ }^{81}$. Estas circunstancias requieren de un seguimiento continuo y una coordinación a distintos niveles por parte de los profesionales sanitarios, 
que frecuentemente no se produce, convirtiendo a este grupo de individuos en una población vulnerable.

La edad y el desarrollo funcional del individuo también son fuentes de vulnerabilidad. Los niños requieren de unas necesidades de Salud muy distintas a la de los adultos, y que deben ser apropiadas a su edad. Por otro lado, las personas de edad más avanzada también demandan de unas necesidades únicas debido al incremento de la incidencia de enfermedades, y a la compleja mezcla de interacciones físicas y sociales que se dan con el incremento de la edad ${ }^{184}$. Por ejemplo, los procesos crónicos alcanzan una alta prevalencia en las personas de avanzada edad ${ }^{17-19}$, provocando unas necesidades sociales y de Salud totalmente distintas a personas jóvenes o adultas, debido a su avanzado desarrollo funcional, que en muchos centros y/o clínicas no son atendidas adecuadamente.

\subsubsection{Barreras de Comunicación}

Las personas pueden ser vulnerables en algunos casos debido a las limitaciones en la capacidad de comunicarse con los profesionales que interactúan en el Sistema Sanitario. Las dificultades en la comunicación pueden deberse al nivel de educación de la persona, a las diferencias culturales o lingüísticas, o discapacidad física y/o mental. Las personas con problemas de comunicación pueden experimentar problemas al expresar sus preferencias en el tratamiento, obtener servicios acordes a sus normas culturales, encontrar especialistas que sean sensitivos con sus particulares problemas, y comprender el tratamiento terapéutico ${ }^{184}$. Estas dificultades de comunicación experimentadas repercuten negativamente en la calidad de la Atención Sanitaria ${ }^{187,192}$. 
En EEUU, la fuente de vulnerabilidad de comunicación más común es la dificultad para hablar y/o entender el lenguaje del inglés, experimentada en una importante proporción de inmigrantes ${ }^{188}$. Los adultos con una limitada comunicación en inglés presentan mayor insatisfacción con la Atención Sanitaria recibida y una peor comprensión de su Estado de Salud. La calidad de la comunicación también juega un papel significativo en estos grupos, de modo que la escasez de intérpretes profesionales lleva a una deficiente comunicación ${ }^{188}$. Por ejemplo, muchos hospitales y clínicas carecen de personal entrenado para comunicarse con los pacientes de habla hispana (hay que recordar que la población latina/hispana representa alrededor del $20 \%$ en los EEUU) y utilizan espontáneos intérpretes o traductores como sus propios hijos ${ }^{195}$. Esta circunstancia da a lugar a cuantiosas malinterpretaciones, contribuyendo a un nivel de Salud más pobre, provocado, por ejemplo, por los efectos adversos de una medicación mal empleada. Ante esta situación, no es de extrañar que en ocasiones, estos pacientes prefieran no acudir a un centro para recibir asistencia sanitaria, debido a sus problemas de comunicación, y optan por prácticas de auto-tratamiento ${ }^{188,195}$.

\subsection{La Salud y el Bienestar como Derechos Fundamentales}

La Salud, el Bienestar, y un acceso digno y asequible a servicios de asistencia sanitaria es un Derecho fundamental de todo individuo. El concepto de Salud como Derecho Fundamental fue introducido por primera vez por la OMS en su Constitución en $1946^{196}$, y estipula que, "el goce del grado máximo de salud de que se pueda lograr es uno de los derechos fundamentales de todo ser humano..."(p1). Además, la OMS concreta que el grado máximo de salud sólo puede ser alcanzado por medio de un conjunto de 
criterios sociales entre los que se incluye la disponibilidad de los servicios de Salud, entre otros, mediante las mismas oportunidades para todas las personas ${ }^{196}$.

Unos años más tarde, la Declaración Universal de Derechos Humanos en la Asamblea General de las Naciones Unidas de 1948 declaró la Salud como Derecho Humano en el artículo 25 en el cual expone: "toda persona tiene derecho a un nivel de vida adecuado que le asegure, así como a su familia, la salud y el bienestar, y en especial la alimentación, el vestido, la vivienda, la asistencia médica y los servicios sociales necesarios..."(197,p4).

Desde entonces el Derecho a la Salud se ha reflejado en todas las Constituciones nacionales, en los tratados, leyes, acuerdos, políticas, y programas de todos los países del mundo, y se ha subrayado el valor singular de la Salud en las Sociedades. Con el fin de proteger y garantizar los derechos humanos, la OMS formuló una serie de principios y normas que incluyen la no discriminación, la disponibilidad, la accesibilidad, la aceptabilidad, la calidad, la rendición de cuentas, y las universalidad ${ }^{198}$.

El principio de no discriminación procura asegurar el ejercicio de los derechos sin discriminación alguna por motivos de raza, color, sexo, idioma, religión, opinión política o de otras índoles, origen nacional o social, posición económica, nacimiento o cualquier otra condición como discapacidad, edad, estado civil y familiar, orientación e identidad sexual, Estado de Salud, área de residencia, y situación económica y social.

La disponibilidad asegura contar con un número suficiente de establecimientos, bienes, servicios públicos de Salud, y programas de Salud, que dispongan de una accesibilidad en cuatro dimensiones superpuestas: la no discriminación, la accesibilidad física, la accesibilidad económica, y el acceso a la información. Además, la aceptabilidad implica que los establecimientos, bienes, y servicios de Salud sean respetuosos con la ética médica, culturalmente apropiados, sensibles a la necesidad de cada sexo, y con una buena calidad desde el punto de vida científico y médico. Los Estados y otros garantes 
de los derechos son los responsables de la observancia de los derechos humanos, que deben ser ejercidos en cualquier lugar del mundo por ser universales e inalienables.

Sin embargo, los grupos sociales vulnerables en EEUU no tienen las mismas oportunidades de gozar al Derecho de Salud, ni tampoco de disfrutar de los servicios sanitarios, como se ha explicado y documentado anteriormente. Por tanto, estamos ante una violación de los Derechos Humanos en el ámbito de la Salud, arraigada a las disparidades, prácticas discriminatorias, y relaciones de poder injustas que a lo largo de la historia se han sucedido en la nación.

Las disparidades de Salud entre la población estadounidense ponen al descubierto la existente discriminación de los grupos de población vulnerables, y crea la necesidad imperiosa de unificar esfuerzos para garantizar los Derechos Fundamentales de Salud y Bienestar de estas poblaciones.

A pesar de que la Salud de los individuos y las comunidades está sujeta a la combinación de numerosos factores, los esfuerzos realizados en el pasado a nivel gubernamental, federal, y estatal para disminuir las disparidades en Salud en los EEUU se han centrado casi con exclusividad en el Sistema de Salud, olvidando factores fundamentales como los sociales, económicos, ambientales y las conductas individuales. Por ejemplo, alrededor de 3.0 trillones de dólares han sido empleados en asistencia sanitaria en EEUU (año 2014), sin embargo, los gastos en servicios sociales son desproporcionalmente menores ${ }^{85}$.

Los factores sociales, económicos, ambientales y las conductas individuales son fundamentales para alcanzar la equidad a nivel de Salud puesto que condicionan el acceso a asistencia sanitaria de los individuos, crean importantes barreras para adoptar y mantener una Salud óptima, y son en última estancia los determinantes más importantes de mortalidad prematura ${ }^{199}$ (Figura 10). Estos factores determinan la Salud de los individuos y de las comunidades, y explican la mayor parte de las diferencias respecto a la situación sanitaria. 


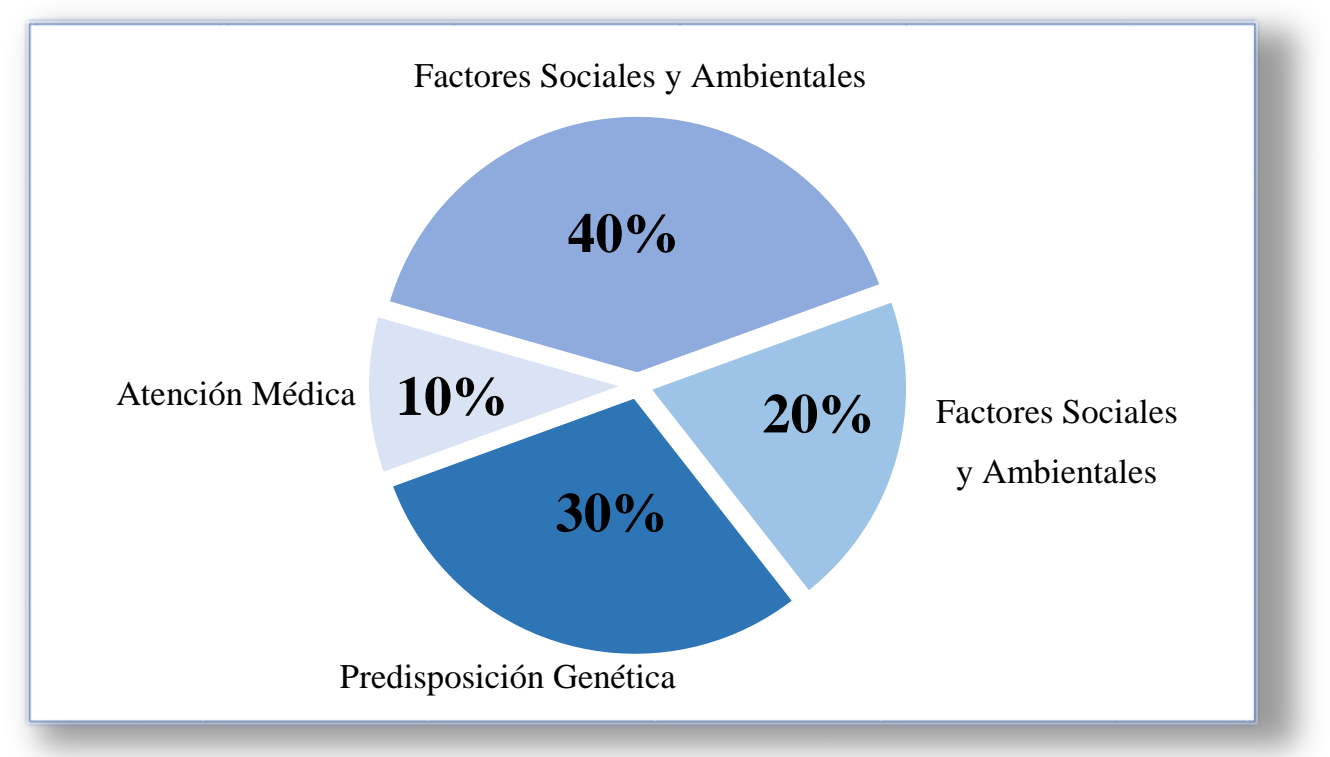

Figura 10. Impacto de los Diferentes Factores de Riesgo de Mortalidad Prematura.

* Obtenido de Schroeder $2007^{199}$, modificado por autor.

\subsection{Determinantes Sociales de la Salud}

La OMS define los determinantes sociales de la Salud como "las circunstancias en que las personas nacen, crecen, viven, trabajan, y envejecen, incluido el sistema de salud"36,p1 y están directamente o indirectamente relacionadas con las enfermedades crónicas en el individuo. También señala que estas circunstancias son "el resultado de la distribución del dinero, el poder, y los recursos a nivel mundial, nacional, y local que depende a su vez de las políticas adoptadas"(36,p1). Factores como por ejemplo acceso a la educación, vivienda, Sanidad, oportunidades de trabajo, y apoyo social, no se distribuyen equitativamente en todas las áreas del planeta y originan desigualdades e inequidades con un mayor riesgo de ser padecidas por las poblaciones más vulnerables $^{36}$. 
Healthy People $2020^{200}$ afirma que las disparidades sociales de Salud afectan negativamente a grupos de población e impiden su acceso a Salud debido a su grupo étnico o racial, religión, situación socioeconómica, sexo, edad, Salud mental, discapacidades cognitivas, físicas, o sensoriales, orientación sexual, área geográfica de vivienda, u otras características vinculadas a discriminación o exclusión social.

En EEUU los determinantes sociales de la Salud han sido objeto de estudio en numerosas ocasiones y han sido bien documentadas. Por ejemplo, el meta-análisis llevado a cabo por Galea et al. ${ }^{201}$ en el que se incluyeron más de 50 estudios, se determinó que los factores sociales, incluyendo la educación, la segregación racial y étnica, los apoyos sociales, y la pobreza eran la causa de un tercio de las muertes totales en los EEUU cada año.

Asimismo, como se ha explicado con anterioridad, un bajo nivel educativo en EEUU está directamente relacionado con un menor nivel de ingresos, una menor esperanza de vida, y una mayor probabilidad de muerte prematura ${ }^{202}$. Es más, los hijos de padres que no han terminado la educación en el instituto tienen mayor probabilidad de vivir en un entorno que presenta numerosas barreras para el acceso de Salud, como son vecindarios insalubres, barrios peligrosos con vandalismo, violencia, y crimen, viviendas deterioradas, y espacios sin parques, sin aceras, sin centros recreativos o bibliotecas ${ }^{203}$. En estos vecindarios o barrios residenciales, las minorías étnicas y raciales tienen una mayor probabilidad de vivir que sus contrapartes de raza blanca ${ }^{204}$.

Otro ejemplo de cómo influyen los determinantes sociales de la Salud en la población estadounidense, queda reflejado en el riesgo más elevado que presentan los niños de las familias desfavorecidas a padecer enfermedades crónicas que los niños de familias con buenos recursos económicos ${ }^{37}$. Cuando el niño desarrolla una condición crónica, las familias desfavorecidas experimentan barreras de acceso a la Salud, debido a que frecuentemente carecen de seguro social, y a menudo no poseen un centro de atención al que acudir regularmente. En adición, los niños de estas familias reciben menos servicios de atención ambulatoria y utilizan más servicios de hospitalización que aquellos 
de familias que disfrutan de mejor situación económica ${ }^{37}$. Estas condiciones tienen un transcendental impacto en el futuro de los niños, que se ve condicionado por el entorno en el que ha crecido ${ }^{205}$.

El abordaje de los determinantes sociales de la Salud ha cobrado más relevancia en las últimas décadas, por la existencia de una mayor concienciación social de la población y del gobierno. En consecuencia, se han producido un creciente número de iniciativas, reformas, y programas que han emergido para desarrollar soluciones dentro del Sistema de Salud, particularmente, para incluir las necesidades sociales dentro de la asistencia sanitaria. A continuación, se abordan las principales iniciativas para abordar los determinantes sociales y reducir las disparidades de Salud.

\subsection{Esfuerzos para Reducir las Disparidades de Salud}

\subsubsection{Ley de Protección al Paciente y Cuidado de Salud Asequible}

En respuesta a las preocupaciones suscitadas por las crecientes, y cada vez mayores disparidades de Salud en los EEUU entre los grupos sociales de la población, en marzo del 2010, el Gobierno de EEUU bajo el mandato del Presidente Barack Obama, promulgó la Ley de Protección al Paciente y Cuidado de Salud Asequible (Patient Protection and Affordable Care Act, PPACA), más conocido como Obamacare ${ }^{206}$. 
La PPACA fue promulgada con el fin de incrementar la calidad y la accesibilidad a los servicios de Salud, y reducir los porcentajes de población sin seguro médico mediante la ampliación de la cobertura de los seguros y la reducción en los costes de Atención Sanitaria ${ }^{206}$. Esta ley tiene la finalidad de otorgar a cualquier persona las mismas oportunidades para comprar un seguro médico incluso para aquellos que disponen de unos ingresos por debajo del nivel de pobreza. El propósito es que nadie deje de recibir asistencia sanitaria debido a la imposibilidad de pago. Es más, la PPACA pretende garantiza que las aseguradoras traten a sus clientes de una manera justa, y que estos puedan tener una serie de derechos.

\subsubsection{Programas Federales Medicare y Medicaid}

Al esfuerzo de la PPACA por reducir las disparidades de Salud en los EEUU, se le suman los Programas Medicare ${ }^{85}$ y Medicaid $^{207}$. Dentro del Departamento de Salud y Servicios Sociales de los EEUU (Department of Health and Human Services, HHS) los Centros para los Servicios de Medicare y Medicaid (Centers for Medicare and Medicaid Services, CMS) administran los programas federales Medicare y Medicaid que proporcionan una parte de cobertura a determinados servicios médicos de específico grupos de población estadounidense ${ }^{85,207}$. A pesar de que Medicare y Medicaid fueron promulgadas en 1965, a lo largo de estas décadas se han realizado reformas, particularmente en los últimos años, con el fin de reducir las disparidades de Salud.

Por un lado, el programa Medicare provee una parte de cobertura de atención médica a través de seguro médico. Financiado a través de los impuestos de las nóminas salariales de la mayoría de trabajadores, empresas, y otros impuestos, las personas de 65 años o mayores, que hayan trabajado y aportado al Sistema con sus impuestos, así como personas con ciertas discapacidades y enfermedades, pueden disfrutar de la cobertura de 
atención médica ofrecida por Medicare ${ }^{85}$. El programa Medicare ayuda con los gastos del cuidado de Salud, pero no cubre todos los gastos médicos, ni la mayor parte de los gastos a largo plazo, aunque se puede comprar pólizas suplementarias para apaliar los gastos que el programa no cubre. Dentro del programa Medicare, existen cuatro pólizas o planes disponibles para los usuarios del programa que cumplan los requisitos: Parte A (Seguro de Hospital), Parte B (Seguro Médico), Parte C (Plan Advantage), y Parte D (Plan de Medicamentos Recetados de Medicare) ${ }^{85}$.

La Parte A (Seguro de Hospital) ${ }^{85}$, ayuda al usuario con los pagos ocasionados por las estancias del hospital, de los centros de enfermería especializados (pero no paga por los servicios del cuidador ni por el cuidado a largo plazo), de los cuidados del hospicio, de los servicios de los cuidados del hogar (atención domiciliaria), y de la estancia en una institución religiosa no médica para servicios de Salud. La mayoría de las personas mayores de 65 años o mayores, que son ciudadanos o residentes permanentes de los Estados Unidos tienen derecho a esta póliza de Seguro de Hospital de manera gratuita.

La Parte B (Seguro Médico) ${ }^{85}$, ayuda al usuario a pagar los servicios del médico, de los cuidados del paciente ambulatorio, del cuidado de Salud en el hogar, del equipo médico a largo plazo y otros servicios necesarios para tratar las enfermedades. Además, la Parte B también cubre muchos servicios preventivos como, por ejemplo, la prueba Papanicolau, la vacuna contra la gripe, y las mamografías. Cualquier persona que tenga derecho al Seguro de Hospital (Parte A), puede inscribirse en el Seguro Médico (Parte B) de Medicare pagando una cuota mensual. A los servicios cubiertos por las Parte A y Parte B, se le denomina Medicare Original.

La Parte C (Plan Advantage) ${ }^{85}$, es ofrecido por compañías privadas aprobadas por Medicare. Este plan ofrece los mismos servicios cubiertos por el Medicare Original, excepto el cuidado de hospicio y la atención durante un ensayo clínico. Además, ayuda a cubrir al usuario numerosos servicios adicionales que el Medicare Original no cubre 
como por ejemplo servicios de vista y servicios dentales, consultas de otorrino, y días adicionales en el hospital que no son cubiertos por el Medicare Original.

La Parte D (Plan de Medicamentos Recetados de Medicare) ${ }^{85}$, proporciona ayuda para cubrir determinados medicamentos que son clasificados en "niveles" o "categorías". Cualquier persona que tiene Seguro de Hospital, Seguro Médico, o el Plan Advantage, tiene derecho al Plan de Medicamentos Recetados de Medicare. Este Plan es voluntario y requiere el pago de una cuota mensual adicional a la cobertura.

Por otro lado, el Programa Medicaid provee protección médica y de hospital por medio de un programa de seguridad social financiado a nivel federal y estatal, para personas y familias con limitados recursos económicos ${ }^{207}$. Actualmente, 64 millones de personas están incluidas en el programa Medicaid. Los propios Estados establecen y administran sus propios programas, y determinan el tipo, la cantidad, la duración, y el alcance dentro de las directrices marcadas a nivel federal. Los Estados están obligados a cubrir ciertos servicios obligatorios y pueden elegir la forma de ofrecer otros servicios opcionales $^{207}$.

Entre los servicios obligatorios se encuentran la hospitalización, atención primaria, atención domiciliaria, test de laboratorio, rayos $\mathrm{X}$, cuidados de enfermería, atención domiciliaria, transporte hospitalario, y pruebas de prevención entre otros. Mientras que los servicios opcionales incluyen la prescripción de medicamentos, servicios clínicos, servicios de terapia física y ocupacional, servicios dentales, servicios quiroprácticos, servicios de podología, y servicios de optometría entre otros ${ }^{207}$. 


\subsubsection{Centros Médicos Comunitarios}

Los centros médicos comunitarios (Community Health Centers, CHCs), juegan un papel fundamental reduciendo las disparidades de Salud por medio de servicios de asistencia sanitaria a poblaciones de grupos de población vulnerables con necesidades muy amplias. Por más de 50 años, la red nacional de centros comunitarios lleva proporcionando servicios de prevención y atención primaria de alta calidad asequibles para las familias y comunidades más desfavorecidas. Estos centros también ofrecen servicios dentales, de Salud mental, de sustancias de abuso, y de farmacia ${ }^{208}$. Actualmente, los CHCs sirven a una población superior a los 24 millones de personas en EEUU ( 1 de cada 14 personas) que viven en más de 9,200 comunidades rurales y urbanas $(\text { año 2015) })^{208}$.

Los CHCs están localizados en áreas en las que la asistencia es muy necesaria, pero escasa, y mejora el acceso a Salud de millones de estadounidenses, independientemente de su estado de seguro médico o capacidad para pagar. Estas áreas son identificadas por el gobierno federal y están caracterizadas por presentar un estado de pobreza muy elevado, una alta mortalidad infantil, y una baja asistencia sanitaria. Los servicios son ofrecidos a todos los residentes, y los costes de asistencia son gratuitos, o mínimos para aquellas personas que puedan hacer frente al pago $^{208}$.

La mayoría de los pacientes que acuden a recibir servicios de los $\mathrm{CHCs}$ pertenecen a familias cuyos ingresos económicos se encuentran en el nivel del umbral de pobreza o muy cercanos a éste. Una gran proporción de estos usuarios corresponde a miembros de grupos raciales y étnicos minoritarios; además, la mitad de ellos se encuentran viviendo en zonas rurales, mientras que la otra mitad viven económicamente deprimidos en áreas urbanas $^{208}$. 
Los CHCs reducen las disparidades sociales de Salud eliminando las barreras más comunes que estos grupos de población se encuentran cuando acceden a asistencia sanitaria. Estos centros ofrecen transporte hasta las clínicas, servicios de traducción, educación de automanejos, educación sanitaria, y visitas a hogares. Además, estos centros adaptan sus servicios a las necesidades especiales y las prioridades de las comunidades, y proporcionan un entorno lingüístico y cultural apropiados. Por ejemplo, aproximadamente un cuarto de los usuarios de los CHCs recibe los servicios en otro lenguaje distinto al inglés, y la mayoría de estos usuarios afirma que su médico habla el mismo lenguaje ${ }^{208}$.

El éxito de los CHCs radica en la participación del paciente en la prestación de servicios. Los órganos de gobierno, cuyos miembros son la mayoría pacientes, gestionan las actuaciones de los centros. Los miembros de los órganos sirven como representantes de la comunidad y toman decisiones sobre los servicios ofrecidos. La gestión activa del paciente respecto a los CHCs asegura la capacidad de respuesta a las necesidades locales, y ayuda a garantizar una mejor Calidad de Vida de millones de pacientes pertenecientes a grupos de población vulnerables. Los CHCs garantizan ${ }^{208}$ :

- Acceso a atención primaria y preventiva, proporcionando ciertos servicios mediante inmunizaciones, educación sanitaria, mamografías, citología vaginal, y otras pruebas de cribado.

- Atención efectiva y rentable, reduciendo los gastos del Sistema Sanitario estadounidense en 24 millones de dólares por medio de una menor utilización de los costosos servicios de urgencias, servicios de especialista, y servicios de hospital.

- Atención de alta calidad, similar o incluso superior a la ofrecida en otros lugares, con una satisfacción por parte de los usuarios del 99\%. 
- Eliminación de las disparidades sociales de Salud, por medio de una mayor sensibilización cultural con las prácticas llevadas a cabo y la participación ciudadana, que otros lugares carecen. Es más, a medida que las poblaciones de grupos vulnerables utilizan los CHCs las disparidades sociales de Salud son reducidas a lo largo de los estados.

- Manejo eficaz de las enfermedades crónicas, a través de estándares que cumplen o superan los criterios aceptados a nivel nacional. Los CHCs han sido reconocidos como modelos para la prevención, diagnóstico, y el manejo de las enfermedades crónicas por mejorar la calidad de sus pacientes con enfermedades crónicas y reducir el coste de los tratamientos relacionados con estas enfermedades.

- Mejorar la Salud relacionado con los partos, proporcionando acceso a una atención prenatal. Las comunidades que son atendidas por los $\mathrm{CHCs}$ tienen una tasa de mortalidad infantil de al menos un $10 \%$ menor que similares comunidades que no son atendidas por estos centros.

- Creación de empleos y estimulación del crecimiento de la economía, mediante la generación de billones de dólares en actividades económicas beneficiándose las comunidades locales, y la creación de más de 230.000 puestos de trabajos en las comunidades más deprimidas económica y socialmente.

Los CCHs son servicios públicos que generan cuantiosos beneficios para pacientes, comunidades, aseguradoras, el Sistema Sanitario, los estados, y el propio gobierno. Su principal magnitud radica, como se ha explicado, en la eliminación de las disparidades sociales de Salud, alcanzando una equidad para el acceso a Salud por parte de los usuarios, y haciendo el Sistema Sanitario más eficiente. 
En un país como EEUU donde el Sistema Sanitario es Privado, la expansión de los CHCs que proporcionan acceso a asistencia sanitaria gratuita, o con mínimos costes, podría ser un significativo avance para asegurar el Derecho a Salud y Bienestar de estas poblaciones que, como se ha mencionado anteriormente, son los olvidados del Sistema, ya que frecuentemente son excluidos.

\subsection{Poblaciones de Grupos de Población Vulnerables en Investigación}

Los grupos de población vulnerables y las minorías poblacionales están infrarrepresentadas en investigación, particularmente en las investigaciones llevadas a cabo en EEUU donde estas poblaciones han alcanzado una importante proporción en la población, lo que conlleva a una serie de problemas ${ }^{209,210}$. Estos problemas incluyen la falta de información sobre la etnia y la Salud de los individuos, una posible falta de aplicabilidad de las evidencias halladas en ensayos clínicos, y una posterior disminución del acceso a intervenciones y a tratamiento. Dadas las tasas más elevadas de morbilidad y mortalidad en estas poblaciones de grupos vulnerables en comparación con la población general, la falta de investigación exacerba todavía más, la vulnerabilidad de estos grupos poblacionales.

Se desconoce las razones y las barreras percibidas por las cuales los investigadores no incluyen a los grupos vulnerables y minoritarios en las investigaciones. Varias investigaciones han excluido específicamente a estos grupos del estudio, o han utilizado métodos de reclutamiento que, tal vez sin darse cuenta, los excluían ${ }^{209}$. Esto es una contradicción si lo comparamos con el esfuerzo llevado a cabo en las últimas dos o tres 
décadas para reducir las disparidades sociales de Salud y mejorar el nivel de Salud de estas poblaciones.

En numerosas ocasiones se ha atribuido a las propias poblaciones la no participación en investigaciones debido a no entender la importancia del estudio, presentar barreras lingüísticas, o simplemente no disponer de la voluntad ${ }^{209}$. Sin embargo, los hallazgos descubiertos en la revisión sistemática de Wender et al. ${ }^{210}$, en la que 18 de los 20 estudios revisados fueron realizados en los EEUU, puso en entredicho estas afirmaciones, al concluir que la no participación en estudios de los individuos de grupos minoritarios raciales y étnicos debía ser debida a otros atributos más allá de la raza y la étnica, puesto que la voluntad de estas minorías no difiere de la de la raza blanca no hispánica.

La necesidad de incrementar la participación de los grupos vulnerables y las minorías en investigaciones ha sido impulsad por diversos autores ${ }^{211,212}$. Estos esfuerzos están completamente justificados por razones éticas y morales, además que la participación de estos grupos asegura la generalización de hallazgos en la población general. Dadas las escasas investigaciones desarrolladas con poblaciones de grupos vulnerables y minorías, y su representación inadecuada en ensayos clínicos aleatorios $^{213,214}$, los esfuerzos en investigación en Salud Pública deben de concentrarse en asegurar iguales oportunidades para la participación en investigaciones. Al mismo tiempo, el número de investigaciones en estos grupos de población debería incrementar para reducir las disparidades de Salud y aumentar la Calidad de Vida de los individuos, pues la Salud, el Bienestar, y un acceso digno y asequible a servicios de asistencia sanitaria es un Derecho fundamental de todo sujeto, como anteriormente se ha explicado. 


\section{Justificación del Estudio}

Hoy en día, la población mundial disfruta de la mayor esperanza de vida en la historia de la humanidad ${ }^{2,3}$. Paralelamente a este hecho, el mundo ha experimentado una transición demográfica que ha dado lugar a un aumento relativo de personas mayores y una reducción de niños y jóvenes en la población mundial ${ }^{2,3,7,13}$. Puesto que el envejecimiento del ser humano está asociado a un mayor riesgo a padecer enfermedades crónicas en el individuo ${ }^{17-19}$, los procesos crónicos adquieren mayor importancia por la elevada proporción de personas mayores existentes en la actualidad a nivel mundial, los nuevos estilos de vida adquiridos, y los actuales procesos de urbanización.

Las enfermedades, patologías, o condiciones crónicas, también conocidas como enfermedades no comunicables, o enfermedades no trasmisibles se caracterizan por su larga duración, y una progresión generalmente lenta $^{26}$, como por ejemplo las enfermedades cardiovasculares, respiratorias, osteomusculares, diabetes, o cáncer. Su alta prevalencia en la Sociedad, la elevada carga de morbilidad y mortalidad que originan, y las consecuencias que desencadenan en materia económica y en recursos de Salud, las convierten en la principal amenaza para las propias personas que padecen las enfermedades, sus familias, los Sistemas de Salud, y la propia Sociedad. 
El fenómeno de las enfermedades crónicas alcanza tal magnitud que la mayoría de los individuos con estas condiciones, las presentan en forma múltiple ${ }^{17,40,41}$, debido a que muchas de estas enfermedades ocurren frecuentemente en combinación ${ }^{39}$, y a la mayor probabilidad de padecer más enfermedades cuando ya se padece una ${ }^{38}$.

Las personas que presentan enfermedades crónicas deben de adquirir una serie de aptitudes y responsabilidades (autocuidados) ${ }^{87}$ para minimizar el impacto de sus enfermedades, mejorar su Salud, y prevenir mayores deterioros, mediante su participación activa en el tratamiento, lo que conlleva la toma diaria de decisiones por parte del paciente (automanejos) ${ }^{86}$, que influyen en su estilo de vida, en la toma de medicación, y en la ejecución de acciones preventivas.

Sin embargo, muchos pacientes con enfermedades crónicas tienen dificultades para alcanzar un eficiente y efectivo control de los autocuidados y automanejos como lo ponen de manifiesto los bajos porcentajes de adherencia al tratamiento existentes entre la población, y las escasas estrategias en la práctica clínica para mejorarlas ${ }^{90}$.

La falta de adherencia terapéutica o el incumplimiento a los tratamientos terapéuticos constituye una problemática a nivel mundial dada su extensión y sus consecuencias clínicas y económicas, repercutiendo, principalmente, en la Calidad de Vida del paciente, en la progresión de la enfermedad, y en los costes monetarios para el Sistema y el propio paciente $e^{90}$.

El incumplimiento a los tratamientos a largo plazo es especialmente preocupante entre los sujetos que padecen enfermedades crónicas ${ }^{98}$. Se estima que aproximadamente un $\mathbf{5 0 \%}$ de los sujetos que padecen enfermedades crónicas en los países desarrollados incumplen el régimen farmacológico con independencia de la patología y el escenario $^{90,105}$, llegándose a producir porcentajes más elevados en personas de edad más avanzada $^{97,106}$, y en los países en desarrollo ${ }^{90}$. La adherencia al tratamiento disminuye incluso hasta niveles del 20-30\% si se le acompañan cambios en el estilo de vida ${ }^{99}$. 
La $\mathrm{OMS}^{90}$ considera la adherencia como un fenómeno multidimensional, e identifica cinco grupos de factores o dimensiones que inciden en la adherencia, como son: factores relacionados con las características socioeconómicas, factores relacionados con el sistema o el equipo de asistencia sanitaria, factores relacionados con la enfermedad, factores relacionados con el tratamiento, y factores relacionados con el paciente.

A pesar de que la población mundial en su conjunto experimenta los mejores niveles de Salud en la historia de la humanidad ${ }^{4}$, especialmente en los países desarrollados como por ejemplo EEUU, algunas poblaciones experimentan desigualdades en Salud que dificultan el acceso a asistencia sanitaria y, por tanto, a una buena Calidad de Vida. Estos grupos de población, denominados grupos de población vulnerables, experimentan un mayor riesgo de pobreza y exclusión social que la población general, y engloba a aquellas personas desfavorecidas económicamente, sin seguro médico, pertenecientes a minorías étnicas y raciales, niños de familias de bajos ingresos, ancianos, indigentes, sujetos con VIH, y enfermedades crónicas y mentales ${ }^{187}$.

Pese a la gran cantidad de estudios surgidos en los últimos años sobre la adherencia al tratamiento, relativamente poco es conocido acerca de este tema en estos grupos de población vulnerables, a excepción de la población perteneciente a los programas Medicare y Medicaid ${ }^{215}$.

Existe una imperiosa necesidad de realizar investigaciones en estos grupos de población para conocer las barreras y dificultades relacionadas con su adherencia al tratamiento. Una mejor comprensión de estos factores permitirá diseñar nuevas estrategias e implementar intervenciones que ayuden a reducir las desigualdades en materia de Salud y mejorar la Calidad de Vida de estos sujetos. No hay que olvidar que toda persona, tiene Derecho a un nivel adecuado de Salud y Bienestar, sea cual sea su condición o clase social (Artículo 25 de la Declaración Universal de los Derechos Humanos) $)^{197}$. 
Según nuestro conocimiento, este es el primer estudio que analiza la adherencia al tratamiento farmacológico y los factores relacionados desde el marco multidimensional propuesto por la OMS en grupos de población vulnerables que padecen enfermedades crónicas. Por tanto, la relevancia de este estudio radica en examinar tres cuestiones de máxima actualidad: enfermedades crónicas, dada su elevada prevalencia en la Sociedad, las cargas de morbilidad y mortalidad que originan, y las consecuencias tan negativas que desencadenan; adherencia desde una perspectiva multidimensional, dado los elevados porcentajes de incumplimiento de los tratamientos a largo plazo; y poblaciones de grupos vulnerables, dada las escasas investigaciones acerca de este tema en estos grupos de población y su frecuente infrarrepresentación en investigaciones de Salud Pública. 



\section{Hipótesis y OBjetivos}





\section{Hipótesis de Trabajo}

Con este trabajo se pueden generar las siguientes hipótesis.

\subsection{Ho: Hipótesis Nula}

Los grupos de población vulnerables presentan la misma tasa de prevalencia de incumplimiento del tratamiento farmacológico de las enfermedades crónicas que la población general de referencia de países desarrollados.

\section{$1.2 \mathrm{H}_{1}$ : Hipótesis Alternativa}

Los grupos de población vulnerables presentan diferente tasa de prevalencia de incumplimiento del tratamiento farmacológico de las enfermedades crónicas que la población general de referencia de países desarrollados. 


\section{Objetivos}

\subsection{Objetivo General}

- Conocer, analizar, y valorar el fenómeno sanitario de incumplimiento al tratamiento farmacológico, sus causas, y factores relacionados en pacientes con enfermedades crónicas de grupos de población vulnerables.

\subsection{Objetivos Específicos}

- Determinar la tasa de prevalencia de incumplimiento del tratamiento farmacológico prescrito y sus principales causas en pacientes de grupos de población vulnerables que padecen enfermedades crónicas tras la inicialización de un nuevo régimen farmacológico para una patología diagnosticada. 
- Caracterizar el grado al tratamiento farmacológico y la conducta de incumplimiento en los pacientes de grupos de población vulnerables que padecen enfermedades crónicas.

- Analizar la evolución del incumplimiento farmacológico en los primeros nueve meses de tratamiento tras la inicialización de un nuevo régimen farmacológico para una nueva patología diagnosticada.

- Identificar los factores relacionados con el incumplimiento al tratamiento farmacológico de acuerdo a los 5 grupos de factores o dimensiones que propone la OMS: i) factores socioeconómicos; ii) factores relacionados con el sistema o el equipo de asistencia médica; iii) factores relacionados con las condiciones del paciente; iv) factores relacionados con el tratamiento y v) factores relacionados con el paciente.

- Valorar las variaciones de los factores relacionados con el incumplimiento en el tiempo.

- Establecer un perfil predictivo de paciente en riesgo de incumplimiento que permitirá a los profesionales sanitarios identificar a estos pacientes más fácilmente y actuar. 

Material y Métodos 



\section{Diseño del Estudio}

El diseño de estudio utilizado para lograr los objetivos propuestos en el presente trabajo es un diseño de investigación epidemiológico observacional y descriptivo. Estos diseños epidemiológicos permiten obtener información de un fenómeno con el objetivo de conocer su origen, evolución y comportamiento a lo largo del tiempo, y la posible asociación a factores que condicionan y/o determinan un fenómeno ${ }^{216}$. El tipo de estudio seleccionado fue un estudio transversal y muestral, con dos momentos de recogida de información en el tiempo: fase I y fase II. La recogida de información se realizó entre los meses de marzo y diciembre del año 2015.

Los estudios observacionales permiten una primera aproximación a un problema de Salud mediante la simple observación, manteniéndose el observador al margen en todo el proceso de estudio y sin ningún tipo de control e intervención ${ }^{217}$. Cuando la información de la temática a investigar es escasa o no se dispone, los estudios observacionales descriptivos son los más adecuados para conocer la situación y describir sus características y frecuencias más importantes de un problema de Salud, para saber su importancia, y para poder establecer medidas de intervención en función de unas determinadas variables de persona, lugar, y tiempo. Es decir, permiten establece una foto sobre el fenómeno estudiado. Son de gran utilidad en clínica, investigación y, sobre todo, 
en Planificación y Programación Sanitaria puesto que proporcionan gran cantidad de información para administradores sanitarios, epidemiólogos, y profesionales clínicos ${ }^{218}$.

Dentro de los estudios observacionales descriptivos, los estudios transversales estudian la exposición y la enfermedad de un grupo de población definida en un momento determinado. Se utilizan para describir la frecuencia y distribución de una enfermedad o factor de riesgo, mediante la prevalencia, razón por la cual, se utilizan para saber la carga e importancia de una enfermedad o evento sanitario ${ }^{218}$, como es el caso de este estudio. Asimismo, los estudios transversales pueden identificar los determinantes de la enfermedad, los grupos de población más vulnerables o de mayor riesgo, y sus necesidades $^{217}$. Estos estudios son de elección cuando no se puede determinar con precisión el momento de inicio del evento que se estudia, como por ejemplo es el caso de las enfermedades crónicas en las cuales es difícil establecer el momento de comienzo de la enfermedad ${ }^{219}$. Estos estudios permiten hallar diferencias significativas y generar una hipótesis útil para posteriores estudios analíticos. Además, son estudios de gran utilidad porque son fáciles de realizar, reproducibles, y muy económicos ${ }^{217}$.

El presente estudio epidemiológico observacional, descriptivo, transversal, permite obtener una primera aproximación de la adherencia en pacientes con enfermedades crónicas en grupos de población vulnerables. El estudio proporciona una valiosa información para determinar las barreras que inciden en la falta adherencia de estos grupos. Además, el presente estudio tiene una componente longitudinal porque se estudian los sujetos a lo largo de un período de tiempo en dos momentos ${ }^{219}$. 


\section{2. Ámbito del Estudio}

El estudio fue realizado en dos CHCs, The St. Mary's Health Center (Centro de Salud Santa María) y The Good Samaritan Clinic (Clínica El Buen Samaritano), de atención totalmente gratuita, localizadas en el condado de Chatham, en el estado de Georgia (GA), en el sureste de EEUU.

Englobadas dentro de la red de la Fundación de St. Joseph's/Candler, una de las principales instituciones sanitarias de la región, el Centro de Salud Santa María y la Clínica El Buen Samaritano ofrecen una amplia gama de servicios a toda la comunidad sin distinción de raza, color, religión, sexo, orientación sexual, nacionalidad o estatus migratorio. El Centro de Salud Santa María y la Clínica El Buen Samaritano son centros sin fines de lucro comprometidos con el Bienestar de aquellos grupos de población más desfavorecidos y sin seguro médico. Su misión es tratar enfermedades, promover la Salud en la comunidad, eliminar las disparidades de Salud entre la población, y reducir los costes en el Sistema Sanitario evitando hospitalizaciones innecesarias. Los servicios ofrecidos en ambas clínicas/centros son servicios de atención primaria, control de enfermedades crónicas, terapia ocupacional, y programas de prevención de enfermedades.

De acuerdo al último registro de información efectuado en marzo del 2015, el Centro de Salud Santa María cuenta aproximadamente con un total de 1237 pacientes, mientras que la Clínica El Buen Samaritano cuenta con un total de 957 pacientes.

Situada en la ciudad de Savannah, GA, cuya población metropolitana asciende a 144.352 habitantes (año 2014) (220 $^{2}$ y en un área que ha sido afectada por una profunda pobreza durante muchos años, el Centro de Salud Santa María atiende a una población mayoritariamente urbana y de raza afroamericana. 
Por otra parte, la clínica El Buen Samaritano, localizada en la parte noroeste del área metropolitana de Savannah, en la pequeña localidad de Garden City, de 8.994 habitantes (año 2015) ${ }^{220}$, atiende a una población mayoritariamente de etnia hispano/latina, ofreciendo sus servicios en ambos idiomas, inglés y español.

La población estimada que se concentra alrededor del área metropolitana de Savannah es de 379,199 habitantes (año 2015) ${ }^{220}$ y está compuesta principalmente por cinco grupos raciales y étnicos ${ }^{220}$ : blancos (49.4\%), afroamericanos (40.2\%), hispano/latinos (6.2\%), asiáticos (2.9\%), e indígenas nativos americanos (0.3\%). Por otra parte, la distribución de estos grupos a nivel nacional estadounidense (año 2015) está compuesta por $^{220}$ : blancos (61.6\%), afroamericanos (13.3\%), hispano/latinos (17.6\%), asiáticos $(5.6 \%)$, e indígenas nativos americanos (1.2\%).

Al comparar la distribución de los grupos poblacionales del área de Savannah con respecto a la distribución a nivel nacional estadounidense, se puede apreciar que el porcentaje de población de raza blanca no hispana es el grupo mayoritario de población en ambas regiones (Figura 11), existiendo un porcentaje mayor en la distribución a nivel nacional estadounidense. Asimismo, en EEUU el grupo de población hispano/latino es la minoría racial/étnica más extensa seguida del grupo de población afroamericana, pero en el área de Savannah, esta distribución se invierte siendo la minoría afroamericana la más voluminosa del área por delante de hispano/latinos, asiáticos, e indígenas nativos americanos (Figura 11).

El elevado porcentaje de la minoría afroamericana en la distribución de la población del área metropolitana de Savannah está relacionado con los episodios de esclavitud experimentados en la ciudad durante el siglo XVIII. La ubicación costera de la ciudad de Savannah hizo convertirse a la ciudad en un punto de referencia para el comercio marítimo y la trata de esclavos importados desde el África Occidental. Las importantes plantaciones de arroz y algodón, demandaron una masiva importación de esclavos, llegando a convertirse en una de las ciudades americanas más importantes de comercio de esclavos $^{221}$. 


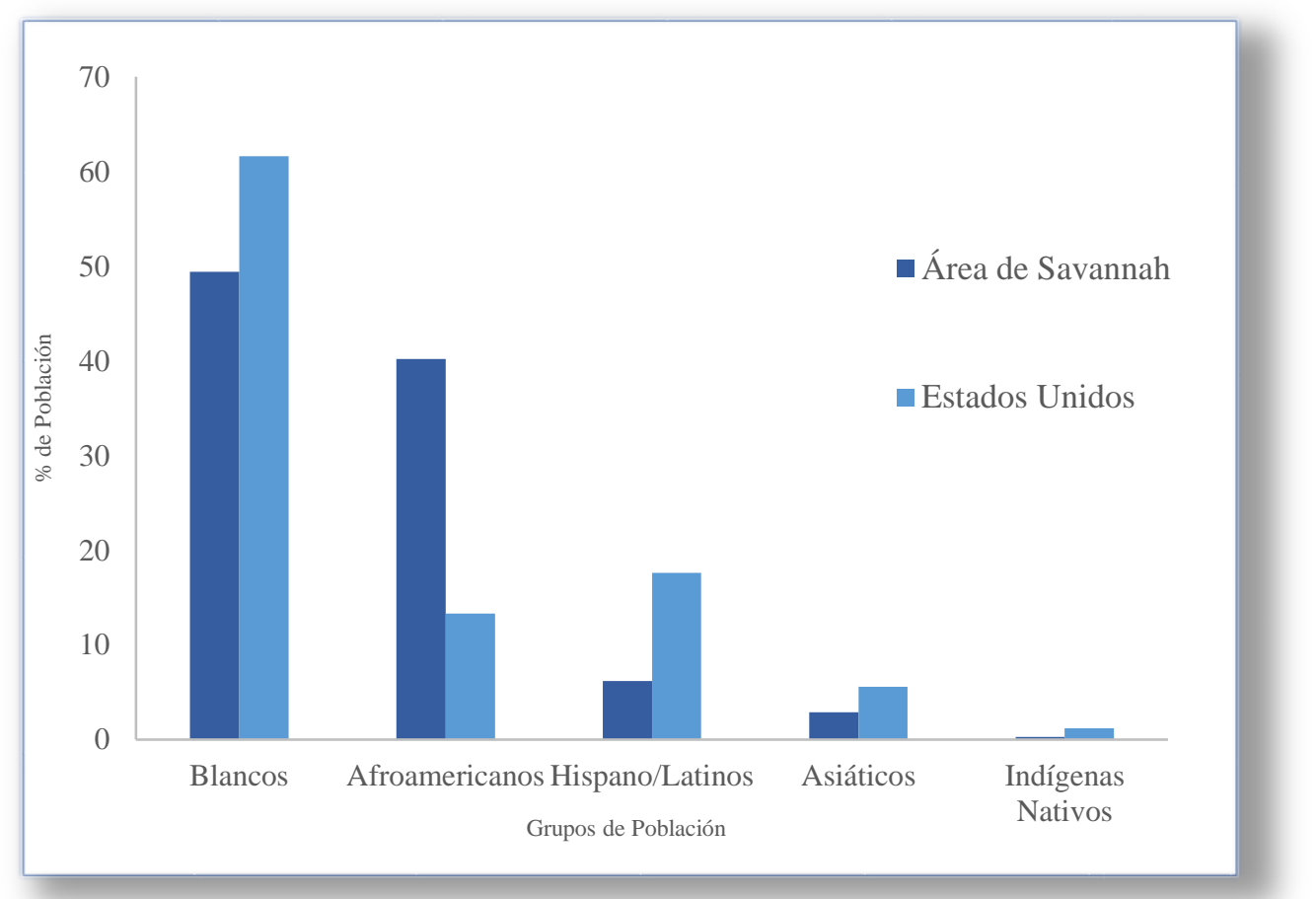

Figura 11. Comparación de la Distribución de los Grupos de Población entre el Área Metropolitana de Savannah y a Nivel Nacional Estadounidense.

* Obtenido de U.S. Census Bureau, Quick Facts $2015^{220}$

Para cuando la Guerra de Secesión terminó en 1865 y la trata de esclavos fue abolida, los esclavos importados desde África se habían integrado en la ciudad, convirtiéndose en un grupo de población numeroso ${ }^{221}$.

Tras la abolición de la esclavitud, los movimientos masivos inmigratorios a la ciudad de Savannah se redujeron, sin embargo, prosiguieron en menor medida en todo el resto del país, y muchas personas continuaron la búsqueda del Sueño Americano (The American Dream). Este término, mundialmente conocido y mencionado por primera vez en 1931 por James Truslow Adams en su libro La Épica Estadounidense (American Epics), hace referencia a la igualdad de oportunidades y libertad que permite a los ciudadanos lograr sus objetivos en la vida con los valores de esfuerzo y determinación ${ }^{222}$. 
La búsqueda de una mayor prosperidad y mayores oportunidades hace que EEUU sea un importante destino de movimientos migratorios como así lo indica el importante porcentaje de población inmigrante residente en EEUU (13.1\%) (período años 2010$2014)^{220}$, mientras que para la ciudad de Savannah este porcentaje es sustancialmente menor, situándose en el $6.6 \%$.

\section{Población de Estudio}

La población del presente estudio está compuesta por los sujetos que acuden a la Clínica Santa María y al Centro El Buen Samaritano. Las personas que acuden a recibir los servicios de ambos centros deben de cumplir con los siguientes requisitos para su aceptación en dichos centros comunitarios ${ }^{223}$ :

$>$ Tener una edad entre 19-64 años*

$>$ Ser ciudadano estadounidense o residente legal en EEUU

$>$ No disponer de seguro médico

$>$ No disfrutar del programa gubernamental de ayudas en Salud Medicaid

$>$ Disponer de unos ingresos familiares por debajo del $400 \%$ de nivel de pobreza federal (Anexo II).

* Nota: aquel paciente que una vez admitido en cualquiera de los dos centros, sobrepase la edad de 64 años y no disfrute del programa federal de ayudas en servicios de Salud Medicare, podrá seguir disfrutando de los servicios ofrecidos en los centros. 
La población del estudio está caracterizada por poseer bajos recursos económicos; pertenecer a grupos étnicos y raciales minoritarios; padecer múltiples enfermedades crónicas, incluidas enfermedades que generan una carga importante de estigma como el VIH; no disponer de seguro médico; y vivir en medios rurales. Todas estas características convierten a la población de estudio en una población vulnerable ${ }^{187}$.

Esta población, frecuentemente, está discriminada o excluida socialmente, no integrada en el Sistema de Salud, y se enfrenta diariamente a cuestiones de Calidad de Vida, como por ejemplo importantes cargas de morbilidad y mortalidad, autocuidados y automanejos de las enfermedades crónicas padecidas, barreras lingüísticas y culturales que dificultan el acceso a los servicios de Salud, y largas distancias recorridas a los centros médicos y lugares donde recogen la medicación.

\section{Selección de Pacientes}

Para conseguir los objetivos del estudio, se estableció que la muestra de población diana del estudio cumpliera los requerimientos exigidos por los centros para el uso de sus servicios y además cumpliera con los criterios de inclusión de este estudio. Los criterios de inclusión del estudio fueron los siguientes:

$>$ Sujetos $\geq 19$ años de edad, con al menos 1 enfermedad crónica* y con régimen farmacológico prescrito, que se encuentren en los primeros seis meses de tratamiento después de haber iniciado un nuevo régimen farmacológico** para una nueva patología diagnosticada. 
Para los objetivos del presente estudio, se definió enfermedad, patología, o condición crónica como aquella de larga duración con una progresión generalmente lenta ${ }^{21}$. Asimismo, se elaboró una lista de 48 condiciones crónicas (Anexo III), las cuales fueron definidas por los códigos CIE-9 y/o frecuencia de prescripción (se utilizó la Clasificación Estadística Internacional de Enfermedades y Problemas Relacionados con la Salud CIE-9, cuyas siglas en inglés $I C D-9$, puesto que era el sistema utilizado en la medicina general en EEUU para registrar los resultados de los pacientes y procedimientos llevados a cabo en la práctica en los sistemas informáticos cuando se realizó el estudio). La clasificación de morbilidades fue elaborada en base a otras investigaciones realizadas por Ollero-Baturone et al. ${ }^{55}$, Barnett et al. ${ }^{40}$, y Hernández et al. ${ }^{224}$.

** Se definió nuevo régimen farmacológico como cualquier inicio de tratamiento que implicara al menos un principio activo para una nueva patología diagnosticada en el paciente, ignorando los ajustes de dosis, modificación en la posología, modo de administración, o cambio de principio activo para la misma patología.

Los criterios de exclusión del estudio fueron los siguientes:

- Sujetos con enfermedades mentales mayores (esquizofrenia, trastornos bipolares, trastornos maníaco-depresivos) que impidieran recordar al paciente la información acerca de su tratamiento farmacológico y cumplimiento.

- Sujetos con cualquier trastorno, enfermedad, o desorden que le incapacitara de responder correctamente a las preguntas del cuestionario utilizado en el estudio.

- $\quad$ Ausencia a la entrevista 3 veces en distintos días. 


\section{Proceso de Estudio}

En la primera fase de recogida de información (fase I), los pacientes que cumplían los criterios de inclusión fueron entrevistados personalmente en una habitación cerrada para mantener la confidencialidad de sus respuestas durante el tiempo de la entrevista. Cada entrevista tuvo un tiempo de duración aproximado entre 30-40 minutos, donde los pacientes respondieron a una serie de preguntas socioeconómicas y relacionadas con su régimen farmacológico que fueron formulados por el entrevistador. El entrevistador, en este caso fue el investigador principal. Éste recibió formación previa a la realización del estudio para minimizar posibles errores y sesgos en la realización de la entrevista. Además, el cuestionario del estudio fue estructurado con la finalidad de que los participantes hablaran y respondieran a las preguntas evitando la influencia del entrevistador. La información proporcionada por los participantes del estudio fue introducida a Microsoft Excel 2016 por el propio investigador principal.

El entrenamiento del investigador principal para realizar las entrevistas del estudio fue adquirido en la asignatura lectiva, Research Methods, correspondiente al período formativo del investigador en Armstrong State University. La formación recibida por parte del entrevistador consistió en 3 fases: 1) estudio de la entrevista, en el que el entrevistador se concentró en el aprendizaje exhaustivo de todas las preguntas, los saltos de pregunta, así como la familiarización con los códigos CIE-9 correspondientes a las 48 condiciones crónicas del estudio; 2) entrevistas de práctica, en las que el entrevistador simuló entrevistas entre sus compañeros sin la presión que supone una situación real y permitió su mejor familiarización con el proceso; 3) entrevistas grabadas, que fueron realizadas con pacientes voluntarios no incluidos en el estudio y posteriormente evaluadas con el objetivo de dar orientación al entrevistador para las entrevistas del estudio. 
En la segunda fase de recogida de información (fase II), sólo los pacientes clasificados como adherentes en la fase I fueron contactados para realizar una segunda entrevista en su noveno mes de tratamiento tras la inicialización de un nuevo régimen farmacológico. Respecto a los pacientes clasificados como no adherentes de la fase I, no se consideró proceder a su entrevista dado que dichos pacientes ya cumplían con los criterios de incumplimiento. En esta segunda entrevista, la recogida de información fue realizada por la misma persona que las entrevistas realizadas en la fase I, el investigador principal.

Debido a las dificultades de algunos participantes en acudir a los centros en el noveno mes de inicio del tratamiento para realizar la entrevista personal, como por ejemplo tener que recorrer largas distancias hasta la clínica, no disponer de medio de transporte, y no encontrarse en la ciudad, algunas de las entrevistas de la fase II del estudio fueron realizadas por teléfono.

Las entrevistas personales de la fase II del estudio tuvieron lugar en la misma habitación cerrada que las entrevistas realizadas en la fase I. Por otro lado, las entrevistas realizadas por teléfono se llevaron a cabo en una sala con acceso telefónico donde sólo se encontraba el entrevistador. Se recomendó a los pacientes que durante la realización de la entrevista por teléfono de la fase II se encontraran en un espacio tranquilo y a poder ser solos. Las entrevistas de la fase II tuvieron un tiempo de duración aproximado de 20-25 minutos. Finalmente, la información proporcionada por los pacientes en la fase II, al igual que la información de la fase I, fue analizada, procesada, e introducida en Microsoft Excel 2016 por el propio investigador principal, con el asesoramiento del Director de la presente Tesis Doctoral y de un estadístico. 


\section{Tamaño de Muestra}

De acuerdo a los objetivos, el diseño, y considerando la población accesible del estudio, se procedió a establecer el cálculo del tamaño de la muestra mediante muestro no probabilístico de acuerdo a las recomendaciones de Casal y Mateu ${ }^{225}$ y Martín ${ }^{226}$. Se utilizó un muestreo intencional o de conveniencia, dado que la población accesible estuvo determinada por consideraciones prácticas como accesibilidad, facilidad, rapidez, y bajo costo. Se estableció un tamaño de muestra de estudio de 130 pacientes, acorde a publicaciones anteriores de la misma temática y similar metodología ${ }^{163,165}$, y se consideró una tasa de no respuesta aproximadamente del $20 \%$, en la que se incluyó pacientes que rehusaran a participar en el estudio, ausencias en las entrevistas, y abandonos del estudio.

De este modo, el valor inicial de la muestra del estudio fue de 156 pacientes (94 pacientes del Centro Santa María y 62 pacientes de la Clínica El Buen Samaritano). Como se explicó anteriormente, la muestra de estudio fue seleccionada según cuestiones prácticas, cuando los pacientes de los centros implicados en el estudio que cumplían los criterios de inclusión acudían a consulta médica durante el período del estudio.

De los 156 sujetos seleccionados en el inicio del estudio, 4 pacientes $(2.6 \%)$ no aceptaron participar en el estudio, y 2 pacientes (1.3\%) fueron excluidos. Las razones de exclusión fueron, ausentarse a la entrevista 3 veces en distintos días (2 pacientes) y presencia de desorden mental mayor tras revisión de la historia clínica (1 paciente).

Los restantes 150 pacientes (90 pacientes del Centro Santa María y 60 pacientes de la Clínica El Buen Samaritano) cumplieron con los criterios de inclusión/exclusión, aceptaron participar en el estudio, firmaron el consentimiento informado, y constituyeron la muestra de estudio. No hubo ningún retiro anticipado de los pacientes a lo largo de las fases que se componía el estudio, por lo que la muestra de 150 individuos del estudio se mantuvo hasta el final de éste. 


\section{Instrumento de Medida}

Debido a que en la práctica médica el concepto de adherencia suele circunscribirse casi exclusivamente al uso de los medicamentos por parte del paciente de una forma acordada con el profesional sanitario ${ }^{91}$, y debido a las dificultades sociales que ya de por sí presenta la población de la muestra a estudiar, se decidió evaluar la adherencia al tratamiento farmacológico o adherencia a medicación ${ }^{97}$, sin valorar las recomendaciones del profesional sanitario en cuanto a régimen alimentario y/o estilo de vida, aunque estos quedaron recogidos, como se explicará posteriormente.

Por tanto, se definió adherencia al tratamiento farmacológico como el grado de comportamiento de los pacientes - respecto a la toma de medicamentos - se corresponde con las recomendaciones acordadas con un prestador de asistencia sanitaria ${ }^{97}$.

Para evaluar la adherencia al tratamiento farmacológico se utilizó el cuestionario validado de adherencia a medicación más utilizado internacionalmente, como es el de Morisky-Green-Levine que tiene una sensibilidad del $81 \%$ y una especificidad del $44 \%{ }^{178}$ (Anexo IV). Para aquellos sujetos que el inglés no era su lengua materna o no eran fluidos en este idioma, se utilizó la versión del cuestionario validada en español por Val Jiménez et al. ${ }^{179}$ (Anexo V). El propio autor del cuestionario, Dr. Donald Morisky, concedió su autorización para su uso en el presente estudio mediante escrito (Anexo VI). 


\section{Recogida de Datos}

La recogida de datos se realizó mediante el diseño de un cuestionario en ambos idiomas, en inglés (Anexo VII) y también en español (Anexo VIII), siguiendo los criterios de calidad de Arribas $^{227}$, Anguita et al. ${ }^{228}$, y Muñoz ${ }^{229}$. El cuestionario fue estructurado en cinco partes y cumple con las siguientes características: es adecuado e intuitivamente razonable a la problemática que se quiere medir, es válido para medir las variables de objeto de estudio, es fiable al existir un mínimo de error en la medida, es capaz de medir cambios en el individuo a través del tiempo, y está basado en los datos generados por el propio paciente.

La primera parte del cuestionario de recogida de datos agrupa variables sociodemográficas específicas, las patologías padecidas por el paciente, su tratamiento farmacológico, y otras observaciones, que fueron rellenados por el propio entrevistador por medio del acceso a la historia de los pacientes. En las restantes partes del cuestionario la recolección de datos se hizo de forma indirecta en la que el entrevistador recogió las contestaciones verbales dadas por los pacientes.

La segunda parte del cuestionario recoge preguntas relacionadas con la demografía, economía, estilo de vida, autocuidados, nivel de dependencia básica y funcional, y autovaloración del Estado de Salud por los pacientes. La tercera parte del cuestionario recoge el cuestionario Morisky-Green-Levine, y a continuación información sobre la medicación, y el acceso.

La cuarta parte del cuestionario de recogida de datos agrupa cuestiones sobre la información recibida por el paciente, la relación del paciente con el profesional sanitario, y la frecuencia de visita al centro o clínica. 
La última parte del cuestionario recoge el test de Barthel, instrumento utilizado ampliamente en Salud Pública para determinar el grado de discapacidad de la persona por medio de la realización de actividades de la vida diaria (AVD) y cuya evaluación proporciona una estimación cuantitativa del grado de dependencia del sujeto ${ }^{230}$.

El cuestionario de recogida de datos ha sido diseñado cuidadosamente de modo que la estructura y disposición de las preguntas es ágil y agradable para la interlocución paciente-entrevistador. Asimismo, las preguntas se han redactado de una manera clara, evadiendo ambigüedades, sin influenciar en la respuesta del sujeto, y agrupando todas las correspondientes a un aspecto del estudio. El orden en que las preguntas son formuladas sigue una sucesión lógica en la que la secuencia psicológica juega un papel esencial para obtener las preguntas más sinceras del sujeto entrevistado. Las preguntas en el inicio del cuestionario son preguntas generales fáciles de responder, evitando preguntas difíciles, embarazosas, y vagas. A medida que el sujeto entrevistado se siente más cómodo con la entrevista y el clima de esta le parece más familiar, las preguntas sucesivas se concretan sobre hechos relacionados con el paciente y su medicación, para finalizar con preguntas sobre opinión. Para evitar la monotonía, la fatiga, y facilitar los cambios de tema, se utilizaron determinadas preguntas de menor transcendencia para dar un cierto respiro a la persona entrevistada.

Una vez redactado el cuestionario de recogida de información, fue revisado por un experto en la materia, el Director de la presente Tesis Doctoral, cuyas aportaciones fueron aplicadas al cuestionario. Posteriormente se procedió a la comprobación del cuestionario en un grupo experimental de 10 personas no incluidas en el estudio, pero representativas de la muestra, con la finalidad de comprobar sus resultados y cotejar el orden y estructura de las preguntas en el cuestionario. Este cuestionario piloto coincidió con la última etapa de formación del entrevistador, por lo que las entrevistas pre-test fueron grabadas para la posterior evaluación de las impresiones creadas en los sujetos del cuestionario piloto, como por ejemplo si existe entusiasmo, aburrimiento, duda, fatiga, y/o posibles incomprensiones. 


\section{Determinación de las Variables}

\subsection{Variable Dependiente}

Para la determinación de la adherencia al tratamiento farmacológico, se consideró la adherencia como una variable dicotómica. Para ello, se evaluaron las respuestas de los pacientes a las preguntas del cuestionario de Morisky-Green-Levine ${ }^{178}$ (Anexo IV). Los pacientes fueron clasificados en adherentes cuando respondieron negativamente (no) a todas las preguntas del cuestionario, mientras que se clasificaron como no adherentes cuando respondieron a una o más preguntas del cuestionario afirmativamente (sí) ${ }^{178}$. Este método fue utilizado para determinar la variable dependiente adherencia en todos los posteriores análisis estadísticos del estudio (análisis descriptivo, análisis bivariado y análisis de regresión logística).

\subsection{Variables Independientes}

Para la determinación de las variables independientes, se consideraron los cinco grupos o dimensiones propuestos por la $\mathrm{OMS}^{90}$ que inciden en la adherencia terapéutica, explicados previamente. Además, se creó un grupo adicional para analizar el posible sesgo ocasionado por el cambio realizado en la metodología de la entrevista en la fase II del estudio. Por tanto, la clasificación atiende a las siguientes categorías: 


\subsubsection{Factores Relacionados con las Características Socioeconómicas}

Sexo, edad, raza/etnia, lugar de nacimiento, nivel de alfabetización, nivel de educación completado, necesidad de intérprete, cohabitación, área geográfica de residencia, situación laboral actual, nivel de ingresos anuales, acceso a la medicación (factor coste y factor transporte).

- Sexo, masculino y femenino.

- Edad, con los siguientes intervalos, 18-44 años, 45-64 años, y $\geq 65$ años.

- Raza/Etnia, blancos, afroamericanos, hispano/latinos, asiáticos, y otras.

- Lugar de nacimiento, Estados Unidos y fuera de Estados Unidos.

- Nivel de alfabetización, alfabetizados (capacidad para leer, escribir, y realizar cálculo numérico), y analfabetizados.

- Nivel de educación completado, ninguno, estudios primarios, estudios secundarios, y universidad.

- Necesidad de intérprete, con necesidad de intérprete y sin necesidad de intérprete para comunicarse en inglés.

- Cohabitación, viviendo solo, viviendo con la familia, y viviendo con pareja/amigos.

- Área geográfica de residencia, urbana y rural.

- Situación laboral actual, trabajando, desempleado, incapacitado, jubilado, y otra.

- Ingresos anuales, con los siguientes intervalos, < \$5000, \$5000-\$9999, \$10000\$14999, \$15000-\$19999 y >\$20000. 
- Acceso a la medicación: factor coste y factor transporte

- Factor coste: se identificaron a todos los sujetos con problemas asociados al factor coste. Para ello, los pacientes que respondieron al menos una pregunta afirmativa de las siguientes cuestiones dicotómicas cerradas, fueron categorizados en "pacientes con problemas de acceso a la medicación debido al factor coste". Las siguientes preguntas registraron las dificultades de acceso a medicación a las que los pacientes se enfrentan respecto al factor coste:

a. ¿Alguna vez ha dejado de estar sin medicación para ahorrar dinero y gastarlo en otras necesidades básicas como agua o comida? (variable dificultades por ahorrar dinero).

b. ¿Alguna vez ha dejado de tomar la medicación debido a su elevado precio? (variable dificultades por precio elevado).

- Factor transporte: se identificaron a todos los sujetos con problemas asociados al factor transporte. Para ello, los pacientes que respondieron al menos una pregunta afirmativa de las siguientes cuestiones dicotómicas, fueron categorizados en "pacientes con problemas de acceso a la medicación debido al factor transporte". Las siguientes preguntas registraron las dificultades de acceso a medicación a las que los pacientes se enfrentan respecto al factor transporte:

a. ¿Ha estado alguna vez sin medicación porque no podía llegar a recogerla a la farmacia/tienda/clínica? (variable dificultades para recoger medicinas).

b. ¿Ha experimentado alguna vez dificultades de desplazamiento de transporte (problemas al ir en coche, coger el autobús, largas distancias de desplazamiento, etc.) para acceder a su medicación? (variable dificultades en el desplazamiento). 


\subsubsection{Factores Relacionados con el Sistema o el Equipo de Asistencia Sanitaria}

Centro de salud/clínica, información general recibida, número de lugares de recogida de la medicación, frecuencia de visita a consulta, y relación con los profesionales sanitarios.

- Centro de salud/clínica, Centro Santa María y Clínica el Buen Samaritano.

- Información general recibida, los pacientes que respondieron al menos una pregunta negativamente de las siguientes cuestiones dicotómicas cerradas fueron categorizados en "pacientes con información general recibida incompleta”. Las siguientes preguntas registraron la percepción del paciente de la información recibida sobre su tratamiento, las condiciones padecidas, y formas adicionales de información.

a. ¿Recibe información individual sobre su medicación actual y efectos secundarios? (variable información individualizada sobre medicación y efectos secundarios).

b. ¿Piensa que su doctor, enfermera, y farmacéutico le han explicado apropiadamente las condiciones que padece y la medicación que debe seguir? (variable información explicada apropiadamente).

c. ¿Fue incluido en un programa de educación individual o recibió información adicional por escrito de páginas web sobre la medicación que toma? (variable información adicional sobre medicación). 
- Número de lugares (farmacias, supermercados, clínicas, etc.) de recogida de la medicación. Estos fueron registrados en, 1 lugar, 2 lugares, y $\geq 3$ lugares.

- Frecuencia de visita a consulta, las respuestas de los participantes fueron abiertas, y posteriormente se categorizaron en la siguiente clasificación: quincenal, mensual, trimestral, semestral, y anual.

- Relación con los profesionales sanitarios, se evaluó la percepción de satisfacción, comunicación, y apoyo social que el paciente recibe por parte de los profesionales sanitarios. Las siguientes preguntas fueron efectuadas:

a. ¿Está satisfecho con la relación que tiene con el personal sanitario, enfermera y/o doctor?, donde se registra una respuesta dicotómica cerrada positiva o negativa (variable satisfacción con profesionales sanitarios).

Los pacientes que respondieron a la pregunta negativamente fueron clasificados como "pacientes no satisfechos con su relación con los profesionales sanitarios".

b. ¿Cómo calificaría su comunicación con el personal sanitario? (variable comunicación), los participantes expresaron su respuesta en una escala de 0 (muy mala) a 10 (muy buena), y las respuestas fueron categorizadas en los siguientes intervalos:

i. Muy buena: [10-9]

ii. Buena: [8-7]

iii. Regular: [6-4]

iv. Mala: [3-2]

v. Muy Mala: [1-0] 
c. ¿Cómo evaluaría el apoyo social recibido por los profesionales sanitarios? (variable apoyo social) los participantes expresaron su respuesta en una escala de 0 (muy mala) a 10 (muy buena), y las respuestas se categorizaron en los siguientes intervalos:

i. Muy buena: [10-9]

ii. Buena: [8-7]

iii. Regular: [6-4]

iv. Mala: [3-2]

v. Muy Mala: [1-0]

\subsubsection{Factores Relacionados con la Enfermedad}

Tipo de condiciones crónicas, número de condiciones crónicas, grupo de riesgo clínico, índice de masa corporal, y hábitos de vida (actividad física, consumo de tabaco, consumo de alcohol, y clase de bebida, y consumo de drogas).

- Tipo de condiciones crónicas, categorizadas por sistema y definidas por frecuencia de prescripción y acorde al sistema CIE-9 (Anexo III), se agruparon en 8 categorías, de la siguiente manera:

a. Categoría A: circulatorio y enfermedad sanguínea

b. Categoría B: respiratorio

c. Categoría C: digestivo

d. Categoría D: nervioso y mental-conducta

e. Categoría E: endocrino-nutricional-metabólico

f. Categoría F: renal, genitourinario, reproductor, y enfermedad congénita

g. Categoría G: musculoesquelético

h. Categoría H: infecciones, cáncer, órganos sensoriales, y enfermedad de la piel 
- Número total de condiciones crónicas, fueron categorizadas de acuerdo a estos intervalos:
a. 1 Condición crónica
b. 2-3 Condiciones crónicas
c. 4-5 Condiciones crónicas
d. 6-7 Condiciones crónicas
e. $\geq 8$ Condiciones crónicas

- Grupo de riesgo clínico: tomando como base de referencia el modelo de atención al paciente crónico de Castilla y León ${ }^{231}$ y la definición de paciente pluripatológico dada por Ollero-Baturone et al. ${ }^{55}$ (Anexo I) los pacientes fueron clasificados en tres grupos de severidad dependiendo de la gravedad de la patología, la multimorbilidad, y el uso de servicios sanitarios.

La clasificación atiende a:

a. G1: pacientes con una patología en estadio estable o inicial, con baja necesidad de atención primaria.

b. G2: pacientes con dos o más patologías estables o con una patología en estadio avanzado, con necesidades de atención sanitaria moderadas.

c. G3: pacientes pluripatológicos ${ }^{55}$ con elevadas necesidades de atención sanitaria y con frecuentes necesidades sociales. 
- Índice de masa corporal, las variables fueron categorizadas de acuerdo a la clasificación realizada por el U.S. Department of Health \& Human Services ${ }^{232}$, los pacientes se clasificaron en:
a. Bajo peso: $\mathrm{IMC}<18.5 \mathrm{~kg} / \mathrm{m}^{2}$
b. Peso normal: IMC [18.5-24.99 kg/m²]
c. Sobrepeso [25-29.99 kg/m²]
d. Obesidad: [30-39.99 kg/m²]
e. Obesidad Mórbida: $\geq 40 \mathrm{~kg} / \mathrm{m}^{2}$

- Hábitos de vida, fueron recogidos del siguiente modo:

a. Actividad física ( $\geq 150$ minutos de ejercicio moderado $\mathrm{o} \geq 75$ minutos de ejercicio intenso a la semana, o una combinación equivalente) de acuerdo a las recomendaciones de actividad física para la Salud ofrecidas por el U.S. Department of Health \& Human Services ${ }^{233}$.
i. Práctica de actividad física
ii. No práctica de actividad física

b. Consumo de Tabaco, de acuerdo a la siguiente clasificación utilizada en numerosos estudios científicos ${ }^{234,235}$.

i. Fumador compulsivo ( $\geq 20$ cigarrillos/día)

ii. Fumador moderado (11-19 cigarrillos/día)

iii. Fumador leve $(\leq 10$ cigarrillos/día)

iv. Exfumador ( $\geq 1$ año sin fumar)

v. No fumador 
c. Consumo de Alcohol, clasificación recogida por el U.S. Department of Health \& Human Services ${ }^{233}$ :

i. Empedernido bebedor: $\geq 15$ bebidas/semana para hombres $\mathrm{y} \geq 8$ bebidas/semana para mujeres)

ii. Moderado bebedor (8-14 bebidas/semana para hombres y 4-7 bebidas/semana para mujeres)

iii. Leve bebedor: ( $\leq 7$ bebidas/semana para hombres $\mathrm{y} \leq 3$ bebidas/semana mujeres)

iv. No bebedor

d. Clase de bebida alcohólica (para aquellos pacientes que toman alcohol):
i. Vino
ii. Cerveza
iii. Bebidas Destiladas
iv. Otras

e. Consumo Drogas:
i. Uso en la actualidad
ii. Uso en el pasado
iii. Nunca 


\subsubsection{Factores Relacionados con el Tratamiento}

Tratamiento farmacológico, tratamiento no-farmacológico, grado de polifarmacia, y cambios en el régimen farmacológico.

- Tratamiento farmacológico, se registraron el número de prescripciones totales de cada paciente, así como el número de "pastillas" (comprimidos, grageas, píldoras, cápsulas, y tabletas), inyecciones, inhaladores, y otras formas medicamentosas, utilizadas por cada paciente/día.

a. Número de prescripciones:

i. $\leq 2$ prescripciones

ii. $\quad 3-5$ prescripciones

iii. $\quad 6-8$ prescripciones

iv. $\geq 9$ prescripciones

b. Número de pastillas:

i. 0-3 pastillas/día

ii. 4-6 pastillas/día

iii. 7-9 pastillas/día

iv. $\quad \geq 10$ pastillas días

\section{c. Inyecciones}

i. Pacientes con inyecciones diarias

ii. Pacientes sin inyecciones diarias 


\section{d. Inhaladores}

i. Pacientes con inhaladores diarios

ii. Pacientes sin inhaladores diarios

e. Otras formas (colirios, enemas, y medicamentos tópicos)

i. Pacientes con uso de otras formas diarias

ii. Pacientes sin uso de otras formas diarias

- Tratamiento no-farmacológico, se registró el número de pacientes que siguen una dieta específica para la condición/es padecida/s, de hipertensión, colesterol, ácido úrico, sobrepeso, diabetes, problemas digestivos, y problemas renales. También se registró el empleo de técnicas de monitorización por los pacientes fuera del entorno clínico, ya bien en su casa, en farmacias, tiendas, o supermercados para el control de la glucosa (para aquellos pacientes insulinodependientes) y para el control de la presión arterial (para todos los pacientes), de acuerdo a las recomendaciones individuales y la frecuencia dada paciente por los profesionales de la Salud como determina el U.S. Department of Health \& Human Services ${ }^{236,237}$.

\section{a. Dieta específica}

i. Pacientes siguiendo una dieta específica

ii. Pacientes no siguiendo una dieta específica

\section{b. Técnicas de monitorización}

i. Uso de técnicas de monitorización

ii. No empleo de técnicas 
- Grado de polifarmacia, se decidió aplicar la siguiente clasificación, ya empleada en anteriores estudios de adherencia a medicación en pacientes con patologías crónicas ${ }^{238}$.

a. Régimen de tratamiento sin ningún grado de polifarmacia: $\leq 2$ fármacos

b. Régimen de tratamiento con pequeño grado de polifarmacia: 3-5 fármacos

c. Régimen de tratamiento con moderado grado de polifarmacia: 6-8 fármacos

d. Régimen de tratamiento con elevado grado de polifarmacia: $\geq 9$ fármacos

- Cambios en el régimen farmacológico, se decidió registrar si los pacientes sufrían algún cambio en el tratamiento farmacológico tras la fase I del estudio, por lo que esta variable sólo fue analizada en la fase II del estudio. Se registró como cambio en el régimen farmacológico del paciente, cualquier variación en la dosificación, posología, principio activo, y/o cambio en la vía de administración, así como la introducción en el régimen de nuevos fármacos:

a. Cambios en el régimen farmacológico

b. Sin cambios en el régimen farmacológico

\subsubsection{Factores Relacionados con el Paciente}

Dificultades sensoriales, dependencia básica y funcional de las AVD valoradas mediante el Índice de Barthel, auto-valoración del Estado de Salud del último año, conocimiento sobre las condiciones que padece cada paciente y su tratamiento farmacológico, apoyo familiar recibido, necesidad de ayuda para el control de la medicación, persona responsable de la toma y control de la medicación, empleo de métodos/estrategias para la toma de medicación, y especificación del método para aquellos pacientes que lo utilicen. 
- Dificultades sensoriales, visual (campo visual $\left.<20^{\circ}\right)^{239}$, auditiva (sordera moderada) $)^{240}$, y comunicativa (dificultad para vocalizar correctamente) ${ }^{241}$.

- Dependencia básica y funcional de las actividades de la vida diaria (Índice de Barthel $)^{230}$, con la siguiente valoración:
a. Independencia: [100]
b. Dependencia leve: [91-99]
c. Dependencia moderada: [61-90]
d. Dependencia severa: [21-60]
e. Dependencia total: [0-20]

- Auto-valoración del Estado de Salud del último año, los participantes expresaron su respuesta en una escala de 0 (muy mala) a 10 (muy buena), y se categorizaron las respuestas en:
a. Muy buena: [9-10]
b. Buena: [7-8]
c. Regular: [4-6]
d. Mala: [2-3]
e. Muy Mala: [0-1]

- Conocimiento sobre las condiciones padecidas y tratamiento farmacológico, los pacientes que respondieron al menos una pregunta negativamente de las siguientes cuestiones dicotómicas cerradas fueron categorizados en "pacientes con conocimiento incompleto sobre las condiciones padecidas". Las siguientes preguntas registraron los conocimientos de los pacientes sobre la razón de la prescripción de los medicamentos, el número total de ellos incluidos en su régimen, y su posología. 
a. ¿Sabe por qué toma cada medicamento? (variable conocer razón por la que toma cada medicamento).

b. ¿Sabe cuántos medicamentos está tomando y a qué hora debe de tomar cada uno de ellos? (variable número de medicamentos y posología).

- Apoyo familiar recibido, se registró la percepción del paciente sobre el apoyo familiar recibido. Se formuló la siguiente pregunta cerrada:

a. ¿Recibe apoyo familiar (financiero, comprensivo, emocional, etc.) respecto a su tratamiento farmacológico?

Los pacientes que respondieron a la pregunta afirmativamente fueron clasificados como "pacientes con apoyo familiar".

- Necesidad de ayuda para el control de la medicación, se recogió la percepción de necesidad de ayuda por parte del paciente para el control de su medicación. La siguiente pregunta cerrada fue efectuada:

a. ¿Necesita ayuda para el control y seguimiento de su medicación?

Los pacientes que respondieron a la pregunta afirmativamente fueron clasificados como "pacientes con necesidad de ayuda para el control de su medicación".

- Persona responsable de la toma y control de medicación, se registró la siguiente pregunta con respuestas cerradas:

a. ¿Quién es el responsable de su seguimiento farmacológico?

i. Usted mismo

ii. Miembro familiar

iii. Cuidador Profesional 
- Métodos usados para la recordar la toma de medicación, se registraron las siguientes preguntas:

a. ¿Utiliza algún método (alarmas, pastilleros, teléfono, etc.) para tomar su medicación a la hora cada día?

i. Utilización de método/estrategia

ii. No Utilización de método/estrategia

Los pacientes que respondieron a la pregunta afirmativamente fueron clasificados como "pacientes que utilizan un método para tomar la medicación".

Por último, los pacientes que respondieron positivamente a la pregunta se les formuló la siguiente cuestión abierta:

b. Explique qué estrategia utiliza para recordar la toma de su medicación a la hora indicada cada día, en caso de que utilice alguno (variable estrategia). Las respuestas abiertas de los pacientes fueron clasificadas en:

i. Métodos e instrumentos de organización y manejo de la medicación (pastilleros, alarmas, calendarios, aplicaciones teléfono móvil, etc.)

ii. Ayuda ofrecida por otra persona (miembro de la familia, amigo, cuidador, etc.)

iii. Asociación con la práctica de actividades cotidianas de la vida diaria que conllevan una misma rutina cada día sobre la misma hora y que sirven como recordatorio para la toma de medicación (al levantarse, antes de asearse, después de cepillarse los dientes, antes de salir de casa en la mañana, antes de empezar a conducir, antes de acostarse, etc.).

iv. Asociación con la toma de alimentos (desayuno, comida, y cena)

v. Otros métodos 


\subsubsection{Metodología de Entrevista}

Dado que las entrevistas de la fase II del estudio se realizaron algunas de ellas vía telefónica ante la imposibilidad de algunos pacientes en acudir a los centros en su noveno mes de tratamiento para realizarlas personalmente, como se ha explicado anteriormente, se procedió a analizar la relación de la variable metodología de entrevista con la variable dependiente adherencia para descartar cualquier tipo de sesgo producido en la metodología de la entrevista. De modo, la variable metodología de entrevista quedó registrada de la siguiente forma:

- Metodología de entrevista, se registró el tipo de entrevista realizado a los pacientes en la fase II del estudio. Por lo tanto, esta variable sólo fue analizada en la fase II del estudio.
a. Entrevista personal
b. Entrevista telefónica 


\section{Análisis Estadístico}

La información proporcionada por los participantes del estudio fue introducida a Microsoft Excel 2016 por el propio investigador principal. Seguidamente, los datos fueron codificados e introducidos en el paquete estadístico para las Ciencias Sociales (SPSS), versión 22.0, para su posterior análisis. En el presente estudio se desarrollaron tres tipos de análisis:

\subsection{Análisis Descriptivo}

El análisis descriptivo permitió realizar una descripción detallada de las características de la muestra del estudio. Los resultados se expresaron en frecuencias (n) y en porcentaje (\%) con su respectivo intervalo de confianza del 95\% (IC). Para las variables cuantitativas, adicionalmente se incluyó la media \pm la desviación estándar (media $\pm \mathrm{DE})$.

\subsection{Análisis Bivariado}

Para determinar la existencia o no de relación entre las variables independientes (variables relacionadas con las características socioeconómicas, variables relacionadas con el sistema o el equipo de asistencia sanitaria, variables relacionadas con la enfermedad, variables relacionadas con el tratamiento, y variables relacionadas con el 
paciente) y la variable dependiente (adherencia), se procedió a comparar la distribución de las variables independientes con la variable cualitativa adherencia (grupo no adherente y grupo adherente). Para la determinación de la posible existencia de asociación entre la variable dependiente y las variables independientes se utilizó el coeficiente estadístico Chi-cuadrado de Pearson, cuando las frecuencias esperadas eran suficientemente grandes, y el test de Fisher, cuando la muestra a estudiar era demasiado pequeña, es decir, los valores esperados de al menos el $80 \%$ de las celdas en las tablas de contingencia eran mayores de 5.

Para determinar la existencia de diferencias estadísticamente significativas de las variables cuantitativas entre los grupos no adherente y el grupo adherente, se recurrió a la prueba T-Student, para cuando las variables se ajustaron a una distribución normal, y la prueba U de Mann Whitney en ausencia de normalidad.

Asimismo, se llevó acabo la determinación de la normalidad de la distribución de dichas variables mediante la prueba de Kolmogorov-Smirnov (K-S), con la condición de que los valores de asimetría $>1$ y de significación de $\mathrm{z}$ de $\mathrm{K}-\mathrm{S}<0.05$ indican una ausencia de normalidad en la distribución de la variable.

Para las pruebas estadísticas en cuestión, si el p-valor asociado al estadístico de contraste resultó menor que el nivel de significación $0.05(\mathbf{p}<\mathbf{0 . 0 5})$ se rechazó la hipótesis nula $\mathrm{H}_{0}$ a un nivel de confianza del $95 \%$, y se aceptó la hipótesis alternativa $\mathrm{H}_{1}$ (asociación entre la adherencia y la variable independiente). Las asociaciones estadísticamente significativas de las variables cualitativas y cuantitativas fueron recogidas en tablas para su mejor visualización.

Posteriormente, se procedió al análisis de las asociaciones significativas mediante los estadísticos Odds Ratio (OR), y V de Cramer (V) (para tablas 2xJ o Ix2), o en su caso $\boldsymbol{P h i}(\boldsymbol{\phi})$ (cuando las dimensiones de las tablas fueron iguales a 2x2). El OR es una medida que muestra el grado de asociación que existe entre un grupo (adherentes o no adherentes) y el factor de interés de adherencia, mientras que la V de Cramer y Phi son 
coeficientes de contingencia usados para cuantificar la asociación de las variables cualitativas cuando sus categorías son de dos $(\phi)$ o tres o más clases (V).

Para aquellas variables cualitativas de más de dos categorías que mostraron una relación significativa asociativa se llevó a cabo el análisis de los residuos tipificados corregidos (ARij) con el correspondiente valor tabular de la normal, para un nivel de significación de 5\% (>1.96). Los residuos tipificados corregidos constituyen la mejor herramienta para poder interpretar con precisión el significado de la asociación detectada.

El grupo tomado de referencia para el análisis fue el grupo no adherente, mientras que el factor tomado de referencia fue aquel que se creía favorable para la ocurrencia del evento de interés (incumplimiento), indicado en cada caso en el análisis estadístico en cursiva. El OR (factor referencia/factor no referencia) fue calculado en todas las tablas de dimensiones 2x2. En adición, se decidió asignar signo negativo al coeficiente Phi y V de Cramer, cuando la relación de asociación entre las variables resultó inversamente proporcional, con el fin de diferenciarla más fácilmente de aquellas asociaciones directamente proporcionales (signo positivo), a pesar de que $P h i$ y $V$ de Cramer teóricamente sólo pueden oscilar entre los valores de 0 y 1 . Por último, se procedió a evaluar la dependencia de las asociaciones según los criterios de Cohen $^{242}$.

Finalmente, para comparar el grado de adherencia al tratamiento farmacológico de los sujetos de la muestra en la fase I del estudio respecto a la fase II, se llevó a cabo la prueba de los rangos con signo de Wilcoxon. Esta prueba es apropiada para comparar dos conjuntos de categorías ordinales que provienen de los mismos sujetos, y da la posibilidad de investigar cualquier cambio en los rangos que se produzca desde un punto en el tiempo hasta otro. La hipótesis nula $\left(\mathrm{H}_{0}\right)$ de la prueba de suma de rangos postula que las muestras proceden de poblaciones con la misma distribución de probabilidad. La hipótesis alternativa $\left(\mathrm{H}_{1}\right)$ establece que hay diferencias respecto a la tendencia central de las poblaciones. 


\subsection{Análisis Multivariante}

Dado que la regresión logística es una de las mejores herramientas para determinar las relaciones de dependencia entre las variables, se realizó un análisis logístico binario para desarrollar el modelo de variables predictoras del incumplimiento al tratamiento farmacológico. El objetivo principal fue identificar el $O R$ de incumplimiento, ajustado por las otras variables que han resultado significativas en el análisis bivariado. En el presente estudio Doctoral, el modelo de regresión se usó con un interés orientativo más que predictivo, usando un conjunto de variables independientes. Se midió la contribución de cada variable independiente al cambio en la variable dependiente. El resultado final fue un modelo del cual los valores de las variables independientes pueden utilizarse para predecir cómo influye en probabilidad de aparición del proceso incumplimiento.

Para aumentar la generalización de los resultados del estudio, se estableció la ratio de sujetos para cada variable independiente inferior a 5:1, y se determinó en 10 observaciones por cada variable independiente en el modelo como tamaño de muestra adecuado $^{243}$. Por lo tanto, con un tamaño de muestra de estudio de 150 individuos, se consideró adecuado para el análisis de regresión incluir 15 variables independientes. En la construcción del modelo se incluyeron todas aquellas variables en estudio que resultaron ser significativas (nivel de confianza 95\%) en el análisis. Previamente a la inclusión de las variables en el modelo de regresión, se realizó un análisis de matriz de correlaciones entre las variables independientes continuas para evitar el fenómeno de multicolinealidad. Se procedió a la realización de modelos donde una de las variables independientes actuó como variable dependiente y las restantes covariables continuas actuaron como variables independientes. Se utilizó el diagnóstico de colinealidad otorgado por SPSS para detectar la correlación alta entre las variables continuas independientes. Se procedió a la identificación de las variables que resultaron presentar multicolinealidad (tolerancia $<0.1$ y FIV >10) y se omitieron aquellas variables correlacionadas que aportaban menor significación al modelo. 


\section{Consideraciones Éticas}

Todos los participantes que aceptaron participar en el estudio firmaron un consentimiento informado (Anexo IX) antes de realizar cualquier recogida de información, en el que dieron su consentimiento después de una explicación de las características del estudio, los objetivos, los métodos del estudio, el proceso y el tratamiento de la información. También los participantes consintieron el acceso a su historial médico y a la divulgación de los resultados finales del estudio si estos fueran de interés científico y/o público. Para garantizar la confidencialidad de la información dada por los pacientes, sus respuestas, e información personal fueron codificadas y depositadas en un lugar bajo llave cuyo acceso fue exclusivo del investigador principal.

El estudio fue aprobado por el Institutional Review Board (IRB) de la Universidad de Armstrong State University (Anexo X), lugar donde el investigador principal realizó la estancia durante su formación. El IRB de la Fundación St. Joseph's/Candler también aprobó el estudio (Anexo XI) tras su evaluación por las comisiones pertinentes.

Todos los investigadores implicados en el estudio, así como la directora de ambos centros, tuvieron que aportar el Certificado de Protecting Human Research Participants (Anexo XII) requerido por el National Institutes of Health (NIH) que justifica haber recibido una formación para diseñar y/o llevar a cabo investigaciones en sujetos humanos, respetando y protegiendo los Derechos y el Bienestar de los sujetos del estudio.

Por último, el investigador principal, el Director y el estadístico declaran no tener más interés que el conseguir la mayor validez y fiabilidad de las observaciones y de los resultados que pretendía este trabajo de investigación clínica o aplicada y de Salud Pública. Es decir, declaran no tener conflicto de interés. 



\section{Resultados}





\section{Fase I del Estudio}

A continuación, se presentan los resultados del análisis descriptivo, análisis bivariado, y análisis de regresión logística múltiple de la fase I del estudio. Cabe recordar que la información de la fase $I$ ha sido recogida a todos los pacientes de la muestra $(n=150)$, los cuales, se encontraba en los seis primeros meses de inicio de un nuevo régimen farmacológico para una nueva patología diagnosticada.

\subsection{Análisis Descriptivo}

\subsubsection{Variables Independientes}

Los resultados del análisis descriptivo de las variables independientes se muestran a continuación, agrupados en los cinco grupos o dimensiones propuestas por la $\mathrm{OMS}^{90}$ que inciden en la adherencia terapéutica, explicados con anterioridad. 


\subsubsection{Factores Relacionados con las Características Socioeconómicas}

De los 150 pacientes que constituyen el total de la muestra del estudio, un $36.7 \%$ (55 sujetos) son hombres, mientras que un 63.3\% (95 sujetos) son mujeres (Figura 12).

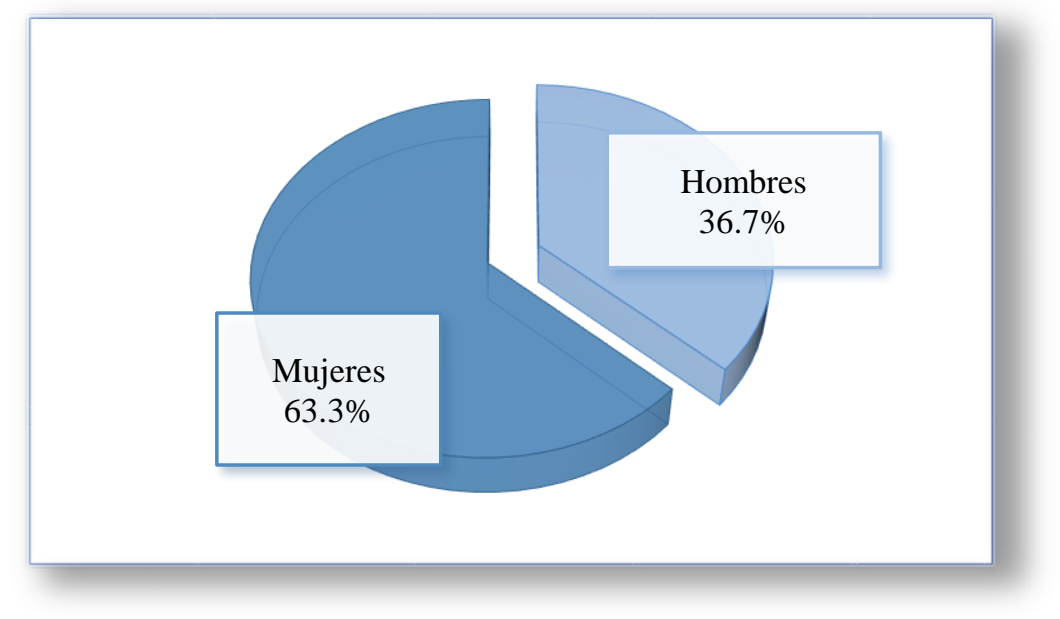

Figura 12. Distribución de los Pacientes del Estudio por Sexo.

La edad media de los pacientes es de 49.81 años y con una $\mathrm{DE} \pm 10.88$. Todos los participantes del estudio se encuentran en el rango de edad (20-78), y su distribución por grupos de edad se muestra a continuación (Figura 13). 


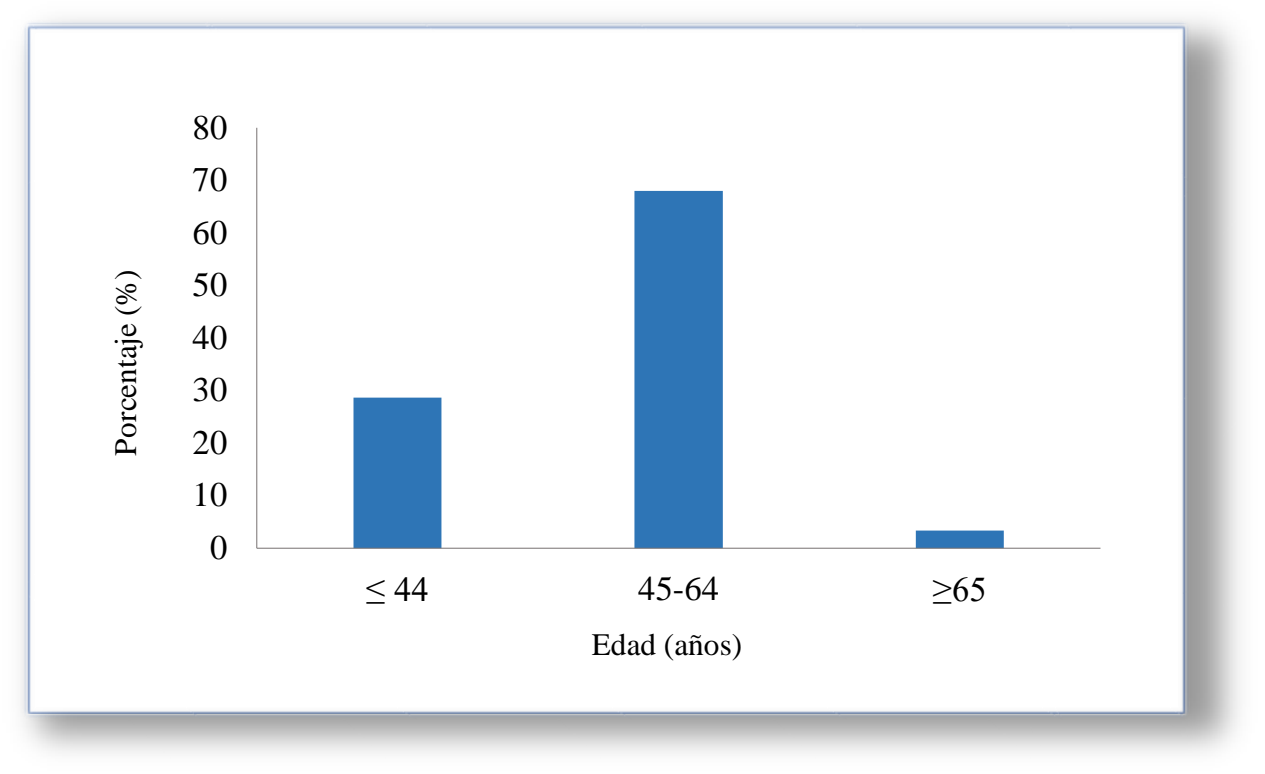

Figura 13. Distribución de los Pacientes del Estudio por Intervalos de Edad.

La distribución de los factores relacionados con las características socioeconómicas de los pacientes se presenta a continuación en la Tablas 1A y 1B. De los factores socioeconómicos, cabe destacar la elevada proporción de los sujetos del estudio pertenecientes a grupos raciales/étnicos minoritarios, así como una elevada proporción de población inmigrante, los bajo niveles de ingresos de los participantes, la difícil situación laboral en la que se encuentra una gran mayoría, y el elevado número de individuos que presentan problemas/dificultades para tener acceso a su medicación y que están relacionados con el factor coste y el factor transporte. También cabe inidcar, que una considerable proporción de sujetos vive en áreas rurales.

A continuación, se recogen los factores relacionados con las características socioeconómicas de los sujetos de la muestra (Tablas 1A y 1B). 
Tabla 1-A. Factores Relacionados con las Características Socioeconómicas.

\begin{tabular}{|c|c|c|c|c|}
\hline & Media \pm DE & Frecuencia (n) & Porcentaje (\%) & IC $(95 \%)$ \\
\hline Sexo & $\mathrm{n}=150$ & & & \\
\hline Masculino & & 55 & 36.7 & $(29.3-44.6)$ \\
\hline Femenino & & 95 & 63.3 & $(55.4-70.7)$ \\
\hline Edad, años $($ media \pm DE $)$ & $49.81 \pm 10.88$ & & & \\
\hline$\leq 44$ & & 43 & 28.7 & $(21.4-36.0)$ \\
\hline $45-64$ & & 102 & 68.0 & $(60.7-75.3)$ \\
\hline$>65$ & & 5 & 3.3 & $(0.7-6.7)$ \\
\hline \multicolumn{5}{|l|}{ Raza/Etnia } \\
\hline Blancos & & 48 & 32.0 & $(24.7-39.3)$ \\
\hline Afroamericanos & & 63 & 42.0 & $(34.0-50.0)$ \\
\hline Hispano/Latinos & & 39 & 26.0 & $(19.3-32.0)$ \\
\hline Otros & & 0 & 0 & -- \\
\hline \multicolumn{5}{|l|}{ Lugar de Nacimiento } \\
\hline Fuera de EEUU & & 44 & 29.3 & $(22.0-36.7)$ \\
\hline EEUU & & 106 & 70.7 & $(63.3-78.0)$ \\
\hline \multicolumn{5}{|l|}{ Nivel de Alfabetización } \\
\hline No alfabetizados & & 15 & 10.0 & $(5.3-15.3)$ \\
\hline Alfabetizados & & 135 & 90.0 & $(84.7-94.7)$ \\
\hline \multicolumn{5}{|l|}{ Nivel de Educación } \\
\hline Ninguno & & 14 & 9.3 & $(4.7-14.7)$ \\
\hline Primarios & & 25 & 16.7 & $(10.7-22.7)$ \\
\hline Secundarios & & 78 & 52.0 & $(44.0-60.7)$ \\
\hline Superiores & & 33 & 22.0 & $(15.3-28.7)$ \\
\hline \multicolumn{5}{|l|}{ Necesidad de Intérprete } \\
\hline Con Necesidad & & 37 & 24.7 & $(18.0-32.0)$ \\
\hline Sin Necesidad & & 113 & 75.3 & $(68.0-82.0)$ \\
\hline \multicolumn{5}{|l|}{ Cohabitación } \\
\hline Sólo & & 46 & 30.7 & $(23.3-38.0)$ \\
\hline Familia & & 85 & 56.7 & $(48.7-65.3)$ \\
\hline Pareja/Amigos & & 19 & 12.7 & \\
\hline \multicolumn{5}{|l|}{$\begin{array}{l}\text { Área Geográfica de } \\
\text { Residencia }\end{array}$} \\
\hline Urbana & & 107 & 71.3 & $(64.0-78.0)$ \\
\hline Rural & & 43 & 28.7 & $(22.0-36.0)$ \\
\hline
\end{tabular}


Tabla 1-B. Continuación de los Factores Relacionados con las Características Socioeconómicas.

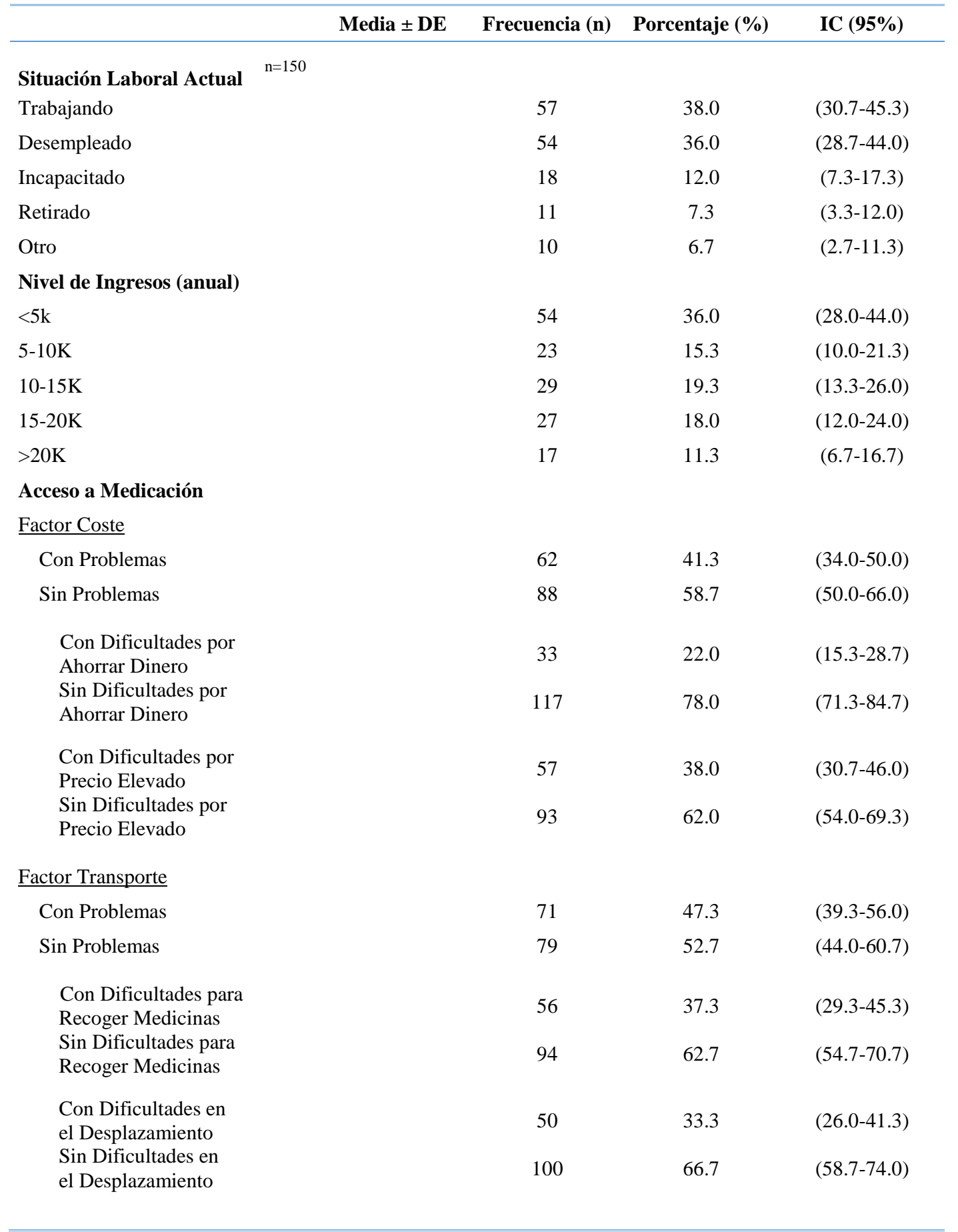


Un $68 \%$ de los participantes del estudio pertenecen a grupos raciales/étnicos minoritarios (42.0\% Afroamericanos y 26.0\% Hispano/Latinos), mientras que un $32 \%$ corresponde a la población mayoritaria estadounidense de raza blanca no Hispánica. No hubo ningún sujeto $(0.0 \%)$ perteneciente a otra raza/etnia (Figura 14$)$.

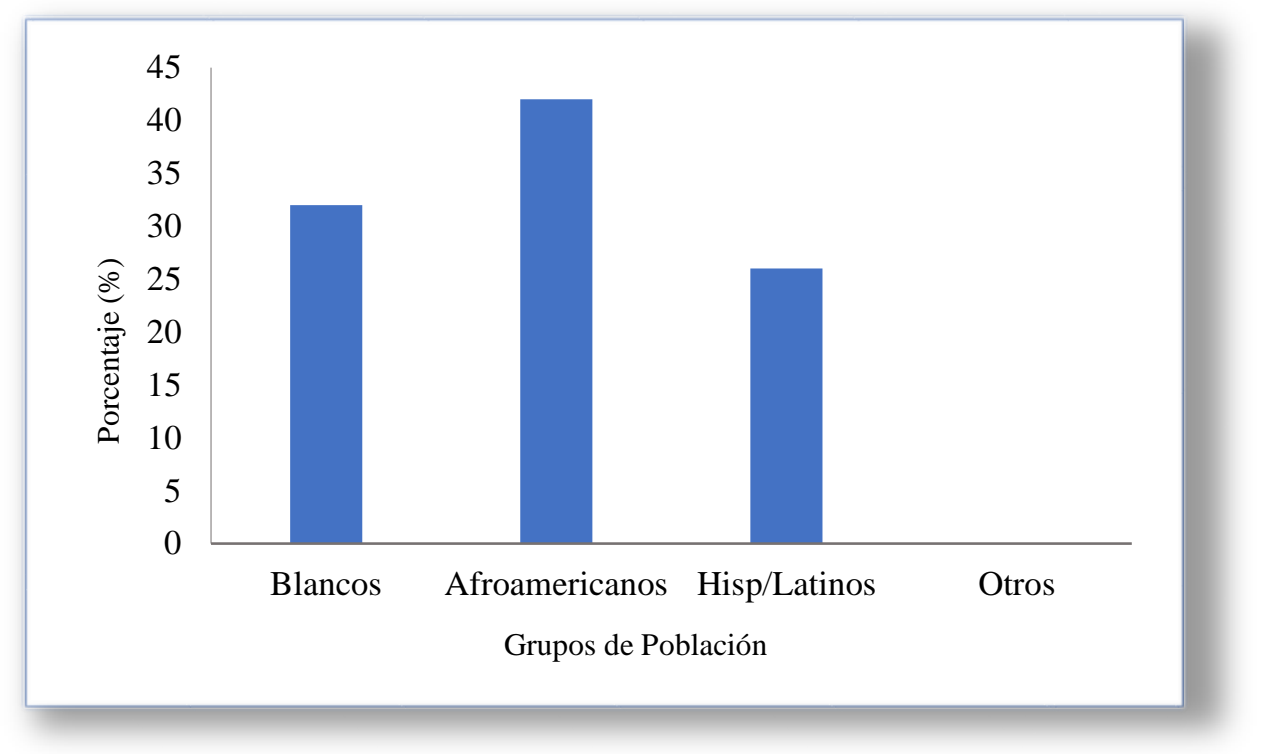

Figura 14. Distribución de los Grupos Raciales/Étnicos de la Población de Estudio.

La población inmigrante participante en el estudio representa el $29.3 \%$ del total de la muestra, frente a la población nacida en EEUU que representa el 70.7\% (Figura 15).

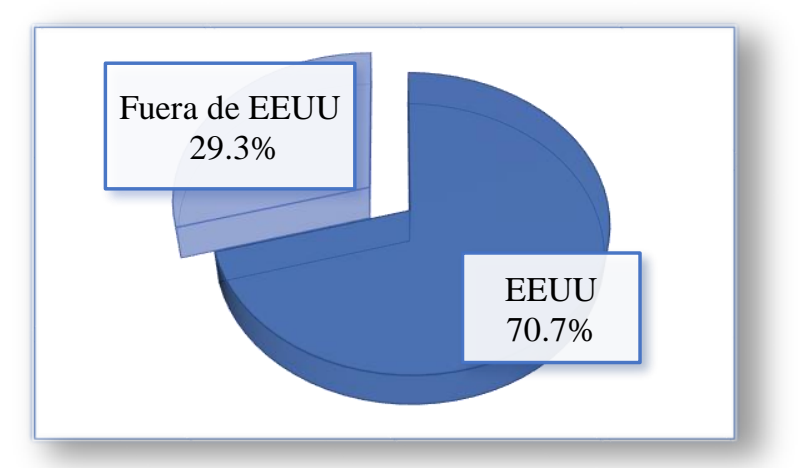

Figura 15. Distribución de los Pacientes del Estudio por Lugar de Nacimiento. 
Los pacientes de la muestra se caracterizan por presentar unos niveles de ingresos familiares muy bajos, concretamente por debajo del $400 \%$ de nivel de pobreza federal (Anexo II), puesto que es un criterio indispensable para ser admitido en los CHCs del estudio, y así poder acceder a los servicios de Salud ofrecidos (Ver Material y Métodos, Apartado 3. Población de Muestra). La distribución de los ingresos anuales de los sujetos se recoge en la Figura 16.

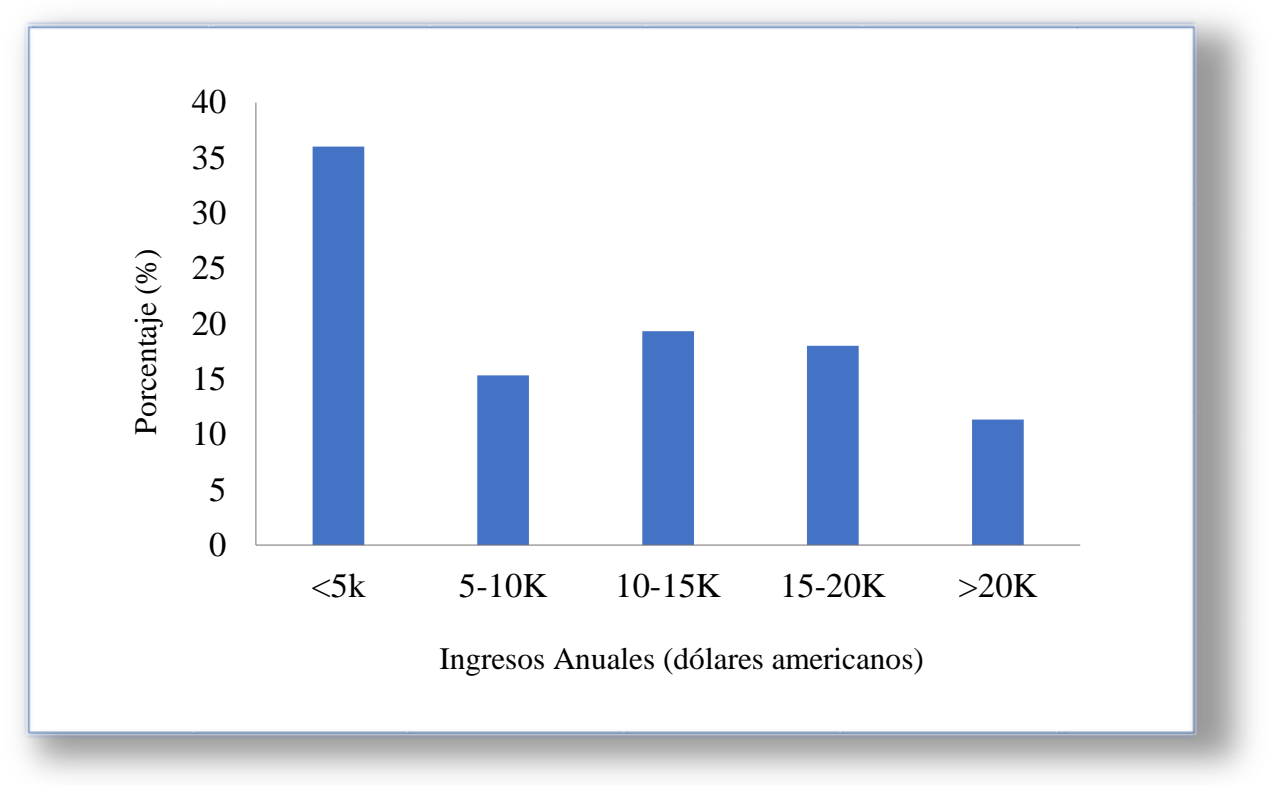

Figura 16. Distribución de los Sujetos del Estudio por Ingresos Anuales (en dólares americanos).

La situación laboral actual de cada paciente puede observarse en la Figura 17. Un $38.0 \%$ de los sujetos del estudio se encuentra trabajando, mientras que un $36.0 \%$ está en situación de desempleo, un $2.0 \%$ se encuentra incapacitado, un $7.3 \%$ está retirado/jubilado, y un $6.7 \%$ se encuentra en otra situación diferente a las anteriores, en las que se engloban por ejemplo, estudiantes y amas de casa. 


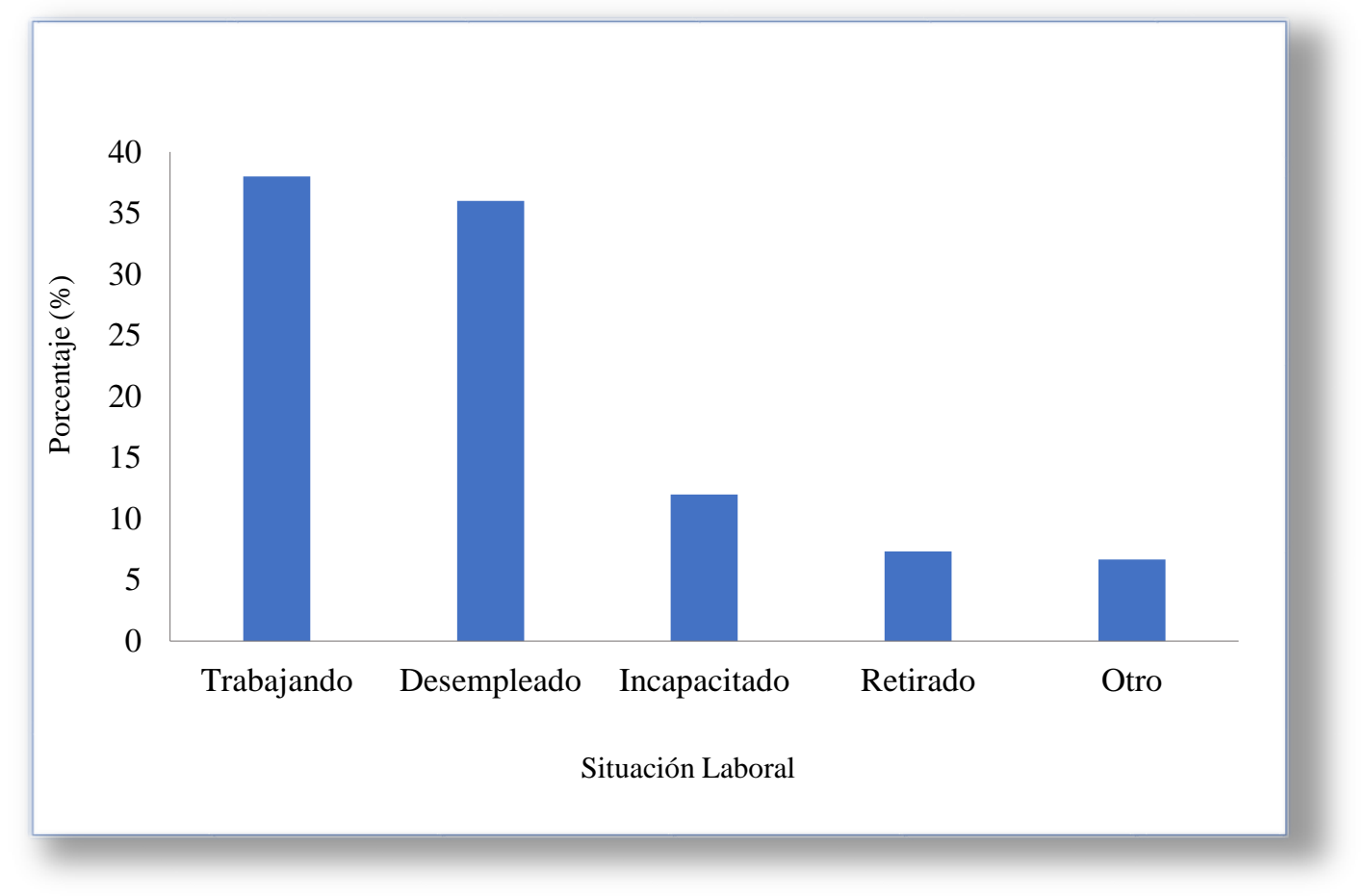

Figura 17. Distribución de los Pacientes del Estudio por Situación Laboral.

A continuación, se muestran los resultados sobre las dificultades de los pacientes para acceder a la medicación (Figura 18). Se observa que un $41.3 \%$ de los pacientes admite tener problemas de acceso a la medicación relacionados con el factor coste. Los problemas relacionados con el factor coste comprenden las dificultades de los pacientes para continuar su régimen prescrito debido a que se ven obligados a ahorrar dinero discontinuando o interrumpiendo su medicación para gastarlo en otras necesidades básicas como agua o comida, y las dificultades debido al precio elevado de los medicamentos que limitan la adquisición de estos. Los resultados muestran que un $22.0 \%$ del total de la muestra de pacientes afirma discontinuar su régimen farmacológico por ahorrar dinero y un $38.0 \%$ manifiesta no tomar la medicación debido a su precio elevado. 


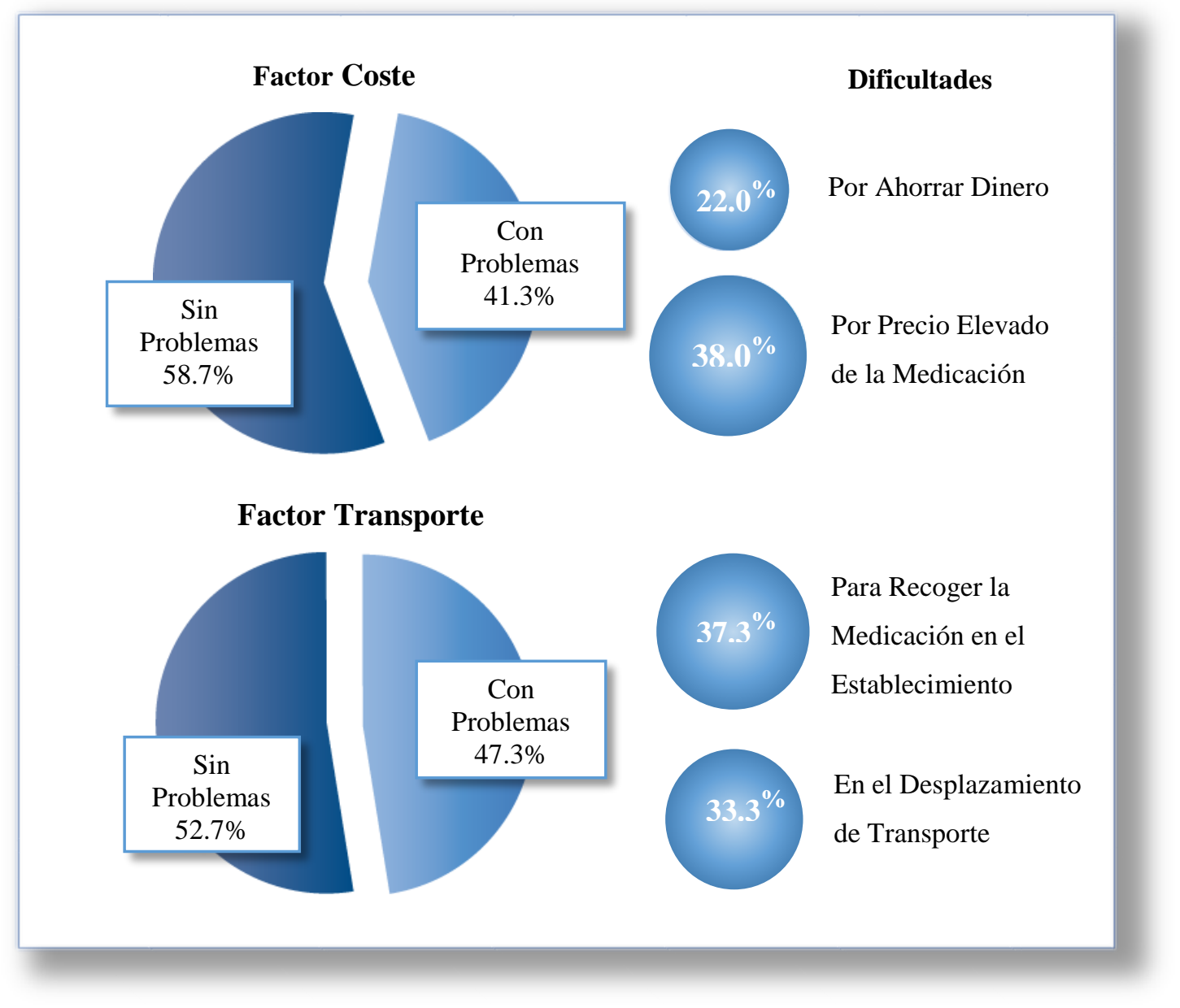

Figura 18. Dificultades de los Pacientes del Estudio para Acceder a la Medicación.

Los resultados sobre los problemas de los pacientes para acceder a la medicación señalan que un $47.3 \%$ de los pacientes presenta problemas relacionados con el factor transporte. Estos problemas engloban las dificultades de los pacientes para recoger la medicación en el establecimiento asignado, y las dificultades experimentadas por los pacientes en materia de desplazamiento para acceder a la medicación, como, por ejemplo, problemas al ir en coche, coger el autobús, y recorrer largas distancias. Los resultados demuestran que un $37.3 \%$ de los individuos del estudio tienen dificultades para recoger la medicación en el establecimiento asignado, y un 33.3\% de los sujetos asegura tener dificultades en el desplazamiento. 


\subsubsection{Factores Relacionados con el Sistema o el Equipo de Asistencia Sanitaria}

A continuación, se presentan los resultados del análisis descriptivo de los factores relacionados con el sistema o el equipo de asistencia sanitaria (Tablas 2-A y 2-B). Las variables más destacadas relacionadas con estos factores son: el alto porcentaje de pacientes que no han recibido una información general completa respecto a su tratamiento, sus condiciones crónicas, e información adicional; la continua regularidad con la que acuden los pacientes a consulta; la satisfacción de los pacientes con el personal sanitario; y la buena comunicación y apoyo social que reciben los pacientes por parte del personal sanitario.

Tabla 2-A. Factores Relacionados con el Sistema o el Equipo de Asistencia Sanitaria.

\begin{tabular}{|c|c|c|c|c|}
\hline & Media $\pm \mathrm{DE}$ & Frecuencia (n) & Porcentaje (\%) & IC $(95 \%)$ \\
\hline Centro de Salud/Clínica & $\mathrm{n}=150$ & & & \\
\hline Clínica Santa María & & 90 & 60.0 & $(52.0-68.7)$ \\
\hline Centro Buen Samaritano & & 60 & 40.0 & $(31.3-48.0)$ \\
\hline \multicolumn{5}{|l|}{ Información Recibida } \\
\hline Información General Incompleta & & 73 & 48.7 & $(40.7-57.3)$ \\
\hline Información General Completa & & 77 & 51.3 & $(42.7-59.3)$ \\
\hline Sin Inf. Individualizada & & 17 & 11.3 & $(6.7-16.7)$ \\
\hline Con Inf. Individualizad & & 133 & 88.7 & $(83.3-93.3)$ \\
\hline Sin Inf. Explicada Apropiadamente & & 9 & 6.0 & $(2.7-10.0)$ \\
\hline Con Inf. Explicada Apropiadamente & & 141 & 94.0 & $(90.0-97.3)$ \\
\hline Sin Inf. Adicional sobre Medicación & & 61 & 40.7 & $(32.7-48.7)$ \\
\hline Con Inf. Adicional sobre Medicación & & 89 & 59.3 & $(51.3-67.3)$ \\
\hline $\begin{array}{l}\text { Número Lugares de Recogida } \\
\text { Medicación }\end{array}$ & $1.73 \pm 0.87$ & & & \\
\hline 1 & & 66 & 44.0 & $(36.0-52.0)$ \\
\hline 2 & & 71 & 47.3 & $(40.0-55.3)$ \\
\hline$\geq 3$ & & 13 & 8.7 & $(4.7-13.3)$ \\
\hline
\end{tabular}


Tabla 2-B. Continuación de los Factores Relacionados el Sistema o el Equipo de Asistencia Sanitaria.

\begin{tabular}{|c|c|c|c|c|c|}
\hline & & Media \pm DE & Frecuencia (n) & Porcentaje (\%) & IC $(95 \%)$ \\
\hline Frecuencia de Consulta & $\mathrm{n}=150$ & & & & \\
\hline Quincenal & & & 14 & 9.3 & $(5.3-14.7)$ \\
\hline Mensual & & & 42 & 28.0 & $(20.7-35.5)$ \\
\hline Trimestral & & & 88 & 58.7 & $(50.7-66.7)$ \\
\hline Semestral & & & 5 & 3.3 & $(0.7-6.6)$ \\
\hline Anual & & & 1 & 0.7 & $(0.0-2.7)$ \\
\hline \multicolumn{6}{|l|}{$\begin{array}{l}\text { Relación con los } \\
\text { Profesionales Sanitarios }\end{array}$} \\
\hline \multicolumn{6}{|l|}{$\underline{\text { Satisfacción }}$} \\
\hline No Satisfecho & & & 4 & 2.7 & $(0.7-5.3)$ \\
\hline Satisfecho & & & 146 & 97.3 & $(94.7-99.3)$ \\
\hline Comunicación & & $9.46 \pm 1.26$ & & & \\
\hline Muy Buena & & & 131 & 87.3 & $(82.0-92.7)$ \\
\hline Buena & & & 12 & 8.0 & $(4.0-12.7)$ \\
\hline Regular & & & 6 & 4.0 & $(0.7-7.3)$ \\
\hline Mala & & & 1 & 0.7 & $(0.0-2.0)$ \\
\hline Muy Mala & & & 0 & 0 & -- \\
\hline Apoyo Social & & $9.35 \pm 1.21$ & & & \\
\hline Muy Buena & & & 126 & 84.0 & $(77.3-90.0)$ \\
\hline Buena & & & 17 & 11.3 & $(6.7-16.7)$ \\
\hline Regular & & & 7 & 4.7 & $(2.0-8.7)$ \\
\hline Mala & & & 0 & 0 & -- \\
\hline Muy Mala & & & 0 & 0 & -- \\
\hline
\end{tabular}

El análisis descriptivo de los factores relacionados con el sistema o el equipo de asistencia sanitaria revelan que un $51.3 \%$ de los pacientes refiere haber recibido información general completa relacionada con su tratamiento, sus condiciones crónicas, e información adicional sobre su medicación; sin embargo, un 48.7\% de los pacientes estima que la información general que han recibido es incompleta. De la muestra total 
de individuos del estudio, un $11.3 \%$ de los sujetos manifiesta no haber recibido información individualizada sobre su medicación actual y efectos secundarios; un 6.0\% considera no haber recibido una información explicada apropiadamente por parte de los profesionales sanitarios en cuanto a las enfermedades o condiciones padecidas y la medicación a seguir; y un $40.7 \%$ asegura no haber recibido ningún tipo de información adicional sobre su medicación actual, como por ejemplo materiales escritos, recomendaciones de páginas web, o no fueron incluidos en ningún programa de educación individual sanitaria (Figura 19).

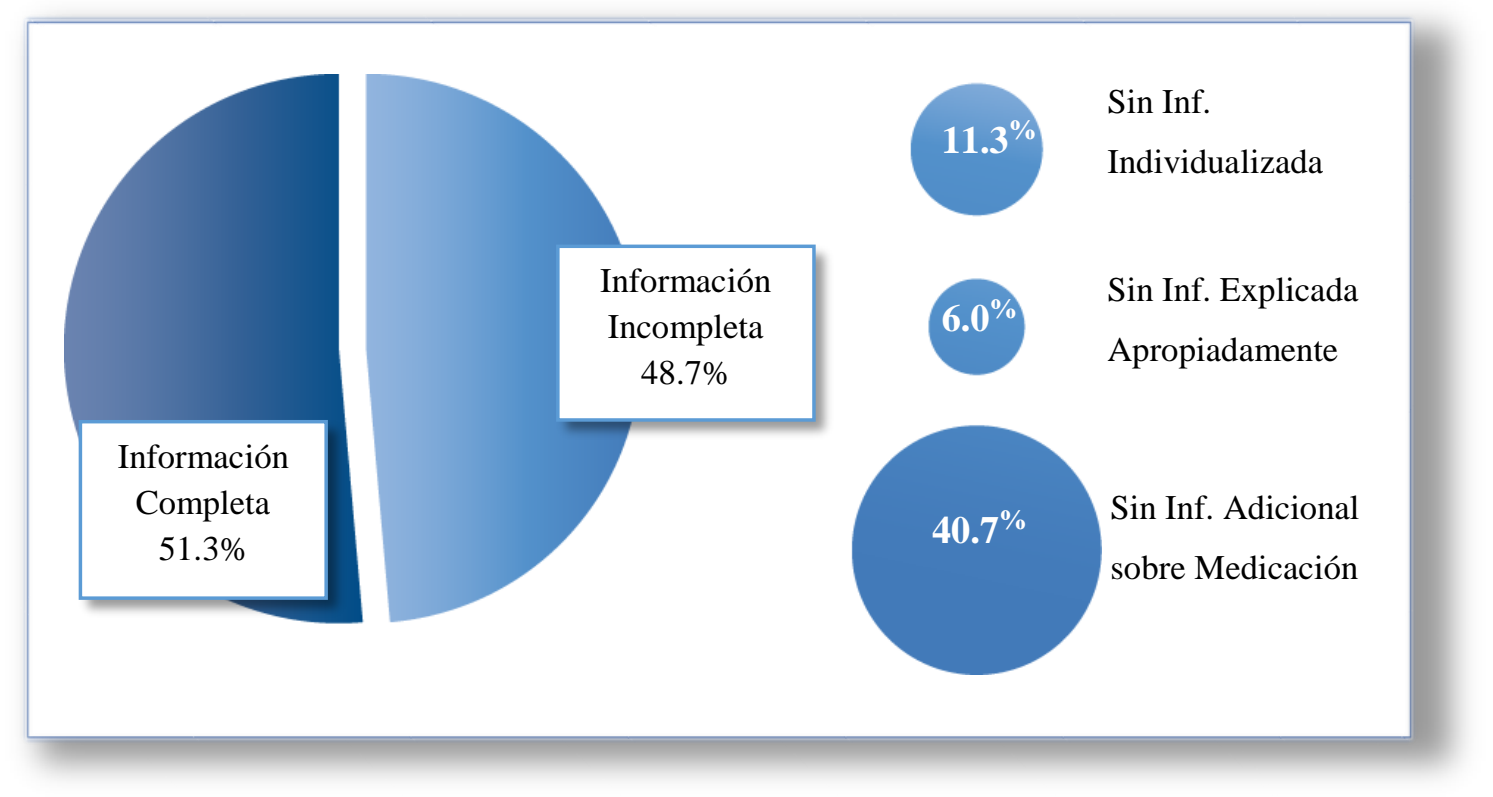

Figura 19. Distribución de los Sujetos del Estudio por la Información Recibida acerca de su Tratamiento, Enfermedades Crónicas, e Información Adicional.

A continuación, se muestran los resultados de la frecuencia con la que los pacientes acuden a consulta (Figura 20). Se puede apreciar que un 9.3\% de los pacientes acude cada dos semanas, un $28.0 \%$ lo hace mensualmente, un $58.7 \%$ acude trimestralmente, un $3.3 \%$ lo hace semestralmente, y un $0.7 \%$ acude a consulta anualmente. 


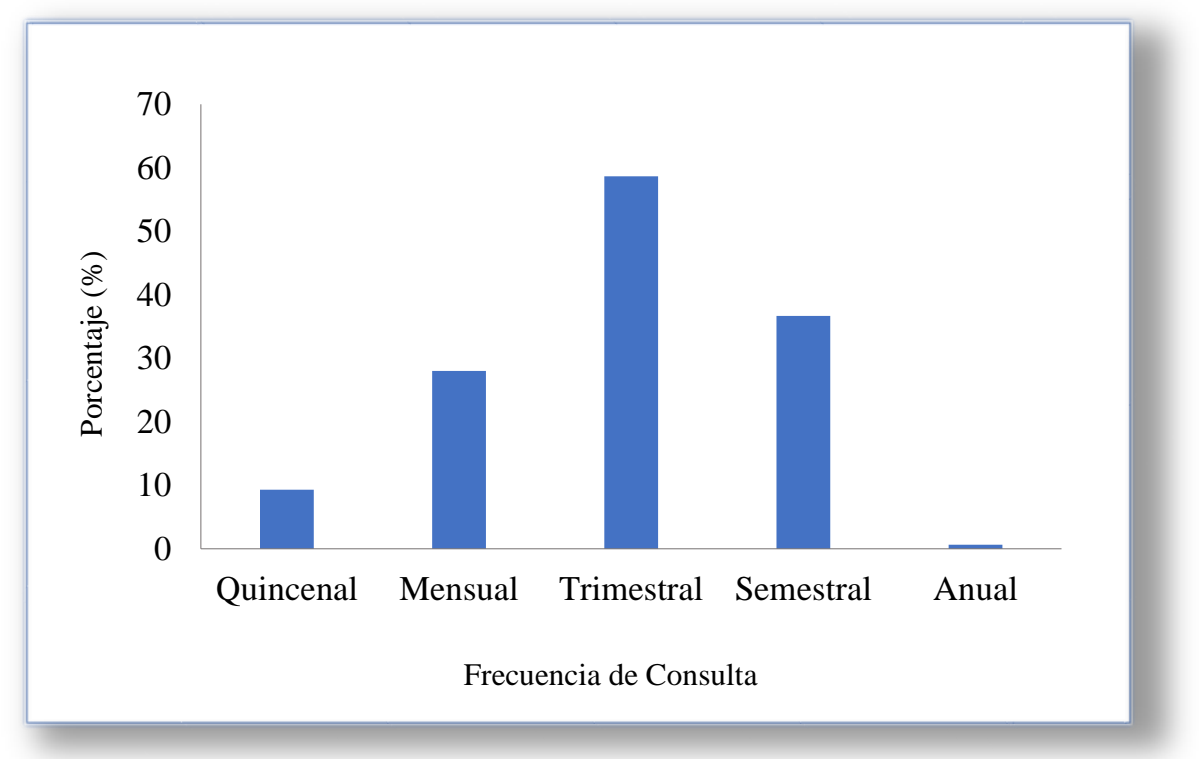

Figura 20. Distribución de los Pacientes del Estudio por Frecuencia de Consulta.

A continuación, se presenta la relación de satisfacción que los pacientes del estudio muestran con los profesionales sanitarios. Un $97.3 \%$ afirma estar satisfecho con su relación con los profesionales sanitarios, mientras que un $2.7 \%$ señala no estar satisfecho (Figura 21).

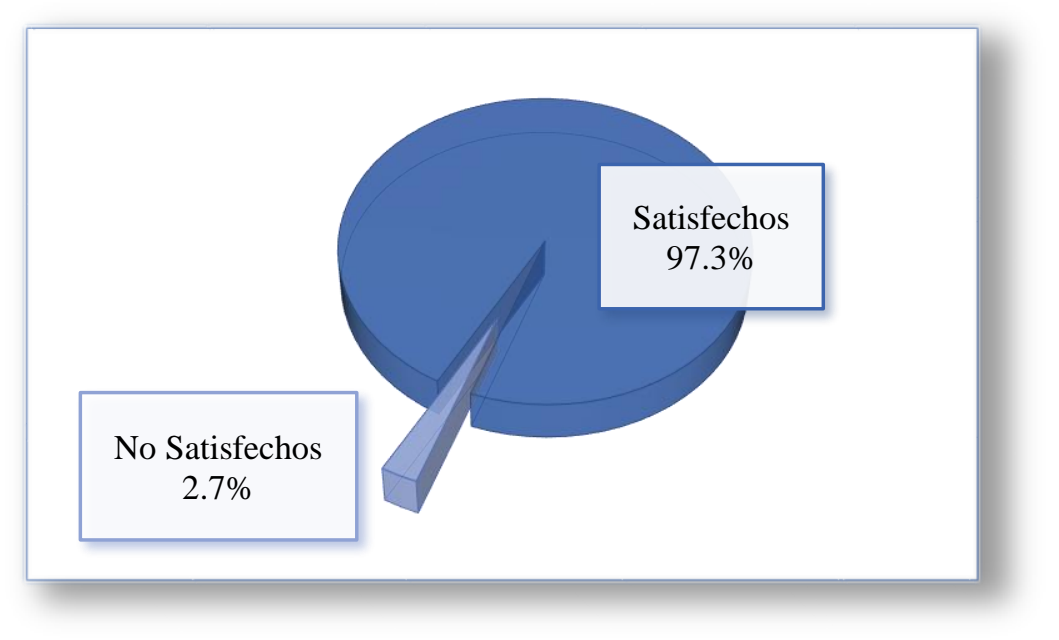

Figura 21. Satisfacción de los Sujetos del Estudio con los Profesionales Sanitarios. 
En cuanto al grado de comunicación, un $87.3 \%$ de los pacientes percibe una relación de comunicación muy buena, un $8.0 \%$ afirma tener una comunicación buena, un $4.0 \%$ señala que su comunicación es regular, un $0.7 \%$ manifiesta tener una mala comunicación, y no existe ningún paciente $(0.0 \%)$ que perciba tener una comunicación muy mala con los profesionales sanitarios (Figura 22).

Respecto al grado de apoyo social, un $84.0 \%$ de los pacientes afirma recibir muy buen apoyo social, un $11.3 \%$ asegura recibir buen apoyo social, un $4.7 \%$ cree que el apoyo social recibido es regular, mientras que no existen pacientes $(0.0 \%)$ que valoren que el apoyo social recibido por parte de los profesionales sanitarios es malo y tampoco muy malo (Figura 22).

Los pacientes califican su comunicación con los profesionales sanitarios en una escala numérica con una nota media de $9.46 \pm 1.26$, mientras que el apoyo social recibido es calificado con una nota media de $9.35 \pm 1.21$.

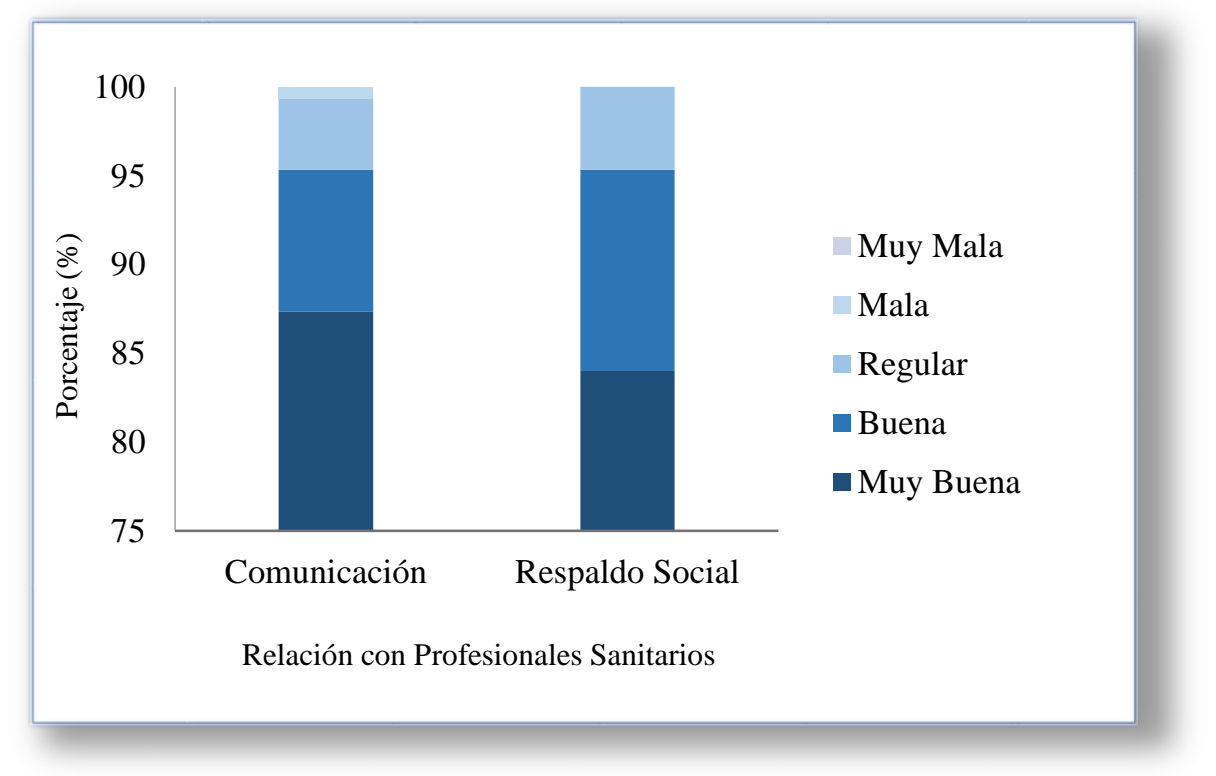

Figura 22. Comunicación y Apoyo Social Percibido por los Pacientes del Estudio con los Profesionales Sanitarios. 


\subsubsection{Factores Relacionados con la Enfermedad}

Los resultados del análisis descriptivo de factores relacionados con la enfermedad del paciente se muestran a continuación. Es importante destacar en este grupo de factores la distribución de las enfermedades crónicas entre los pacientes de la muestra, el número elevado de condiciones crónicas totales padecidas por los pacientes, y la distribución de los pacientes en los grupos de riesgos clínicos.

Tabla 3-A. Factores Relacionados con la Enfermedad.

\begin{tabular}{lcccc}
\hline & $\begin{array}{c}\text { Media } \pm \mathbf{D E} \\
\left(\mathbf{n}^{\mathbf{0}} \text { total) }\right.\end{array}$ & Frecuencia (n) & Porcentaje (\%) & IC (95\%) \\
\hline $\begin{array}{l}\text { Condiciones Crónicas } \\
\text { Enfermedad sanguínea y } \\
\text { circulatorio }\end{array}$ & $\mathrm{n}=150$ & & & \\
Respiratorio & $1.07 \pm 0.77(160)$ & 119 & 79.3 & $(73.3-85.3)$ \\
Digestivo & $0.14 \pm 0.37(21)$ & 20 & 13.3 & $(8.0-19.3)$ \\
Nervioso y mental-conducta & $0.06 \pm 0.27(9)$ & 8 & 5.3 & $(2.0-8.7)$ \\
Endocrino-nutricional-metabólico & $0.69 \pm 0.93(103)$ & 68 & 45.3 & $(37.3-52.7)$ \\
$\begin{array}{l}\text { Renal, genitourinario, reproductor, } \\
\text { y enfermedad congénita }\end{array}$ & $1.56 \pm 0.96(234)$ & 129 & 86.0 & $(80.0-91.3)$ \\
Musculo-esquelético & $0.12 \pm 0.41(18)$ & 18 & 12.0 & $(7.3-17.3)$ \\
$\begin{array}{l}\text { Infecciones, cáncer, órganos } \\
\text { sensoriales, y enfermedad de la } \\
\text { piel }\end{array}$ & $0.19 \pm 0.43(28)$ & 27 & 18.0 & $(12.0-24.0)$ \\
Número Total de Condiciones & $0.13 \pm 0.04(20)$ & 16 & 10.7 & $(6.0-16.0)$ \\
Crónicas & $3.95 \pm 1.90(593)$ & & & \\
1 Condición Crónica & & & & \\
2-3 Condiciones Crónicas & & 12 & 8.0 & $(4.0-12.7)$ \\
4-5 Condiciones Crónicas & & 56 & 37.3 & $(29.3-46.0)$ \\
6-7 Condiciones Crónicas & & 54 & 36.0 & $(28.0-43.3)$ \\
$\geq 8$ Condiciones Crónicas & & 22 & 14.7 & $(9.3-20.7)$ \\
& & 6.0 & $(1.3-7.3)$ \\
\hline \hline
\end{tabular}


Tabla 3-B. Continuación de los Factores Relacionados con la Enfermedad.

\begin{tabular}{|c|c|c|c|c|c|}
\hline & & Media \pm DE & Frecuencia (n) & Porcentaje (\%) & IC $(95 \%)$ \\
\hline Grupo de Riego Clínico & $\mathrm{n}=150$ & & & & \\
\hline G1 & & & 21 & 14.0 & $(8.7-20.0)$ \\
\hline $\mathrm{G} 2$ & & & 110 & 73.3 & $(66.7-80.0)$ \\
\hline G3 & & & 19 & 12.7 & $(8.0-18.7)$ \\
\hline Índice de Masa Corporal & & $33.50 \pm 10.20$ & & & \\
\hline Bajo Peso & & & 2 & 1.3 & $(0.0-3.3)$ \\
\hline Peso Normal & & & 23 & 15.3 & $(9.3-21.3)$ \\
\hline Sobrepeso & & & 39 & 26.0 & $(18.7-33.3)$ \\
\hline Obesidad & & & 54 & 36.0 & $(28.0-44.0)$ \\
\hline Obesidad Mórbida & & & 32 & 21.3 & $(15.3-28.0)$ \\
\hline \multicolumn{6}{|l|}{ Hábitos de Vida } \\
\hline \multicolumn{6}{|l|}{ Actividad Física } \\
\hline Práctica & & & 54 & 36.0 & $(28.0-44.0)$ \\
\hline No Práctica & & & 96 & 64.0 & $(56.0-72.0)$ \\
\hline \multicolumn{6}{|l|}{ Consumo de Tabaco } \\
\hline Fumador Compulsivo & & & 13 & 8.7 & $(4.7-13.3)$ \\
\hline Fumador Moderado & & & 11 & 7.3 & $(3.3-12.0)$ \\
\hline Fumador Leve & & & 24 & 16.0 & $(10.7-22.0)$ \\
\hline Exfumador & & & 33 & 22.0 & $(16.0-29.3)$ \\
\hline No Fumador & & & 69 & 46.0 & $(38.0-54.0)$ \\
\hline \multicolumn{6}{|l|}{ Consumo de Alcohol } \\
\hline Empedernido Bebedor & & & 3 & 2.0 & $(0.0-4.7)$ \\
\hline Moderado Bebedor & & & 7 & 4.7 & $(2.0-8.7)$ \\
\hline Leve Bebedor & & & 62 & 41.3 & $(34.0-49.3)$ \\
\hline No Bebedor & & & 78 & 52.0 & $(44.0-60.0)$ \\
\hline Clase de Bebida & $\mathrm{n}=72$ & & & & \\
\hline Vino & & & 16 & 22.2 & $(13.9-33.3)$ \\
\hline Cerveza & & & 44 & 61.1 & $(50.0-72.2)$ \\
\hline Bebidas Destiladas & & & 11 & 15.3 & $(6.9-23.6)$ \\
\hline Otras & & & 1 & 1.4 & $(0.0-4.2)$ \\
\hline$\underline{\text { Consumo de Drogas }}$ & $\mathrm{n}=150$ & & & & \\
\hline Uso en la Actualidad & & & 5 & 3.3 & $(0.7-6.7)$ \\
\hline Uso en el Pasado & & & 26 & 17.3 & $(11.3-24.0)$ \\
\hline Nunca & & & 119 & 79.3 & $(72.7-85.3)$ \\
\hline
\end{tabular}


La distribución de las enfermedades crónicas se realizó de acuerdo a la clasificación explicada con anterioridad que agrupa a las distintas condiciones crónicas padecidas por los pacientes en ocho categorías diferentes, agrupadas por sistema, y definidas por frecuencia de prescripción y código CIE-9 (Anexo III).

La información acerca de la distribución de las enfermedades crónicas puede ser observada en la Tabla 3-A, donde se muestra el número de pacientes (frecuencias) que padece al menos una enfermedad de un grupo específico, las medias de enfermedades crónicas de un determinado grupo por paciente \pm DE., y el número total de enfermedades que padecen los sujetos del mismo grupo.

Las enfermedades del grupo endocrino-nutricional-metabólico aparecen como las enfermedades más prevalentes entre los pacientes de la muestra (86.0\%), alcanzando una media de $1.56 \pm 0.96$ condiciones crónicas/paciente y un número total de 234 enfermedades padecidas por los sujetos. En segundo lugar de enfermedades más prevalentes se encuentran las enfermedades sanguíneas y del aparato circulatorio (79.3\%), con una media de $1.07 \pm 0.77$ condiciones crónicas/paciente y un número total de 160. A continuación, le siguen las enfermedades del sistema nervioso y mentalconducta $(45.3 \%)$, con una media de $0.69 \pm 0.93$ condiciones crónicas/paciente y un número total de 103 enfermedades. Seguidamente, se sitúan las enfermedades músculoesqueléticas $(18.0 \%)$, con una media de $0.19 \pm 0.43$ condiciones crónicas/paciente y un total de 28. El quinto lugar de enfermedades más prevalentes en los pacientes del estudio corresponde a las enfermedades respiratorias (13.3\%), con una media de $0.14 \pm 0.37$ condiciones crónicas/paciente y un número total de 21 enfermedades. En el sexto lugar se sitúan las enfermedades del aparato renal, genitourinario, reproductor, y enfermedad congénita (12.0\%), con una media de $0.12 \pm 0.41$ condiciones crónicas/paciente y un número total de 18. Seguidamente les siguen las infecciones, cáncer, enfermedades de órganos sensoriales, y enfermedades de la piel (10.7\%) con una media de $0.13 \pm 0.04$ condiciones crónicas/paciente y un total de 20 enfermedades. En el último lugar se 
encuentran las enfermedades digestivas (5.3\%), con una media de $0.06 \pm 0.27$ condiciones crónicas/paciente y un número total de 9 (Figura 23).

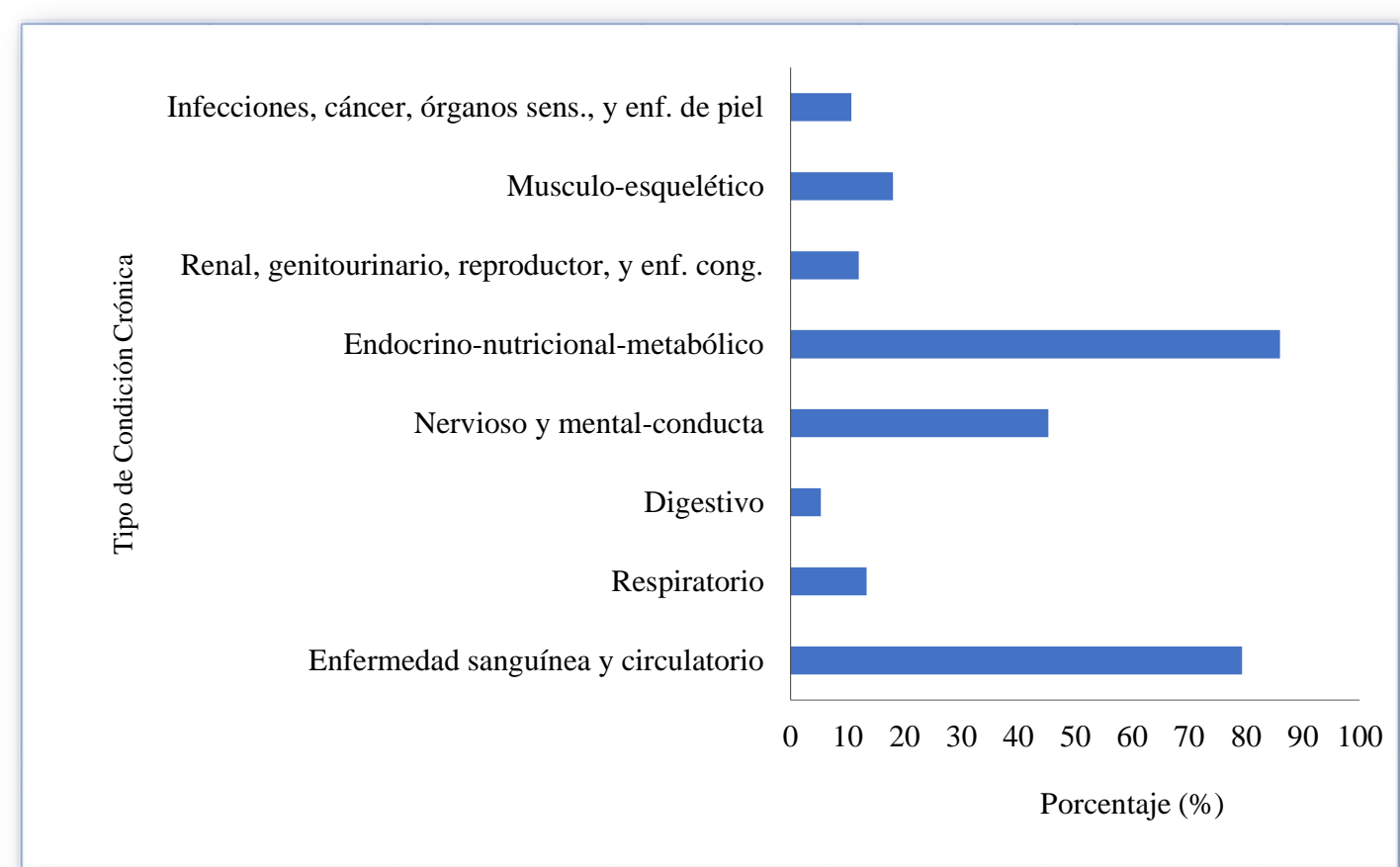

Figura 23. Distribución de las Enfermedades Crónicas de los Pacientes del Estudio.

El número total de condiciones crónicas de los individuos del estudio asciende a 593, con una media de $3.95 \pm 1.90$ condiciones crónicas/paciente. La distribución del número total de condiciones crónicas/paciente corresponde con: un 8.0\% de los pacientes padece una única condición crónica; un 37.3\% padece dos o tres condiciones crónicas; un $36.0 \%$ sufre cuatro o cinco condiciones crónicas; un $14.7 \%$ padece seis o siete condiciones crónicas; y un 4.0\% sufre ocho o más condiciones crónicas (Figura 24). 


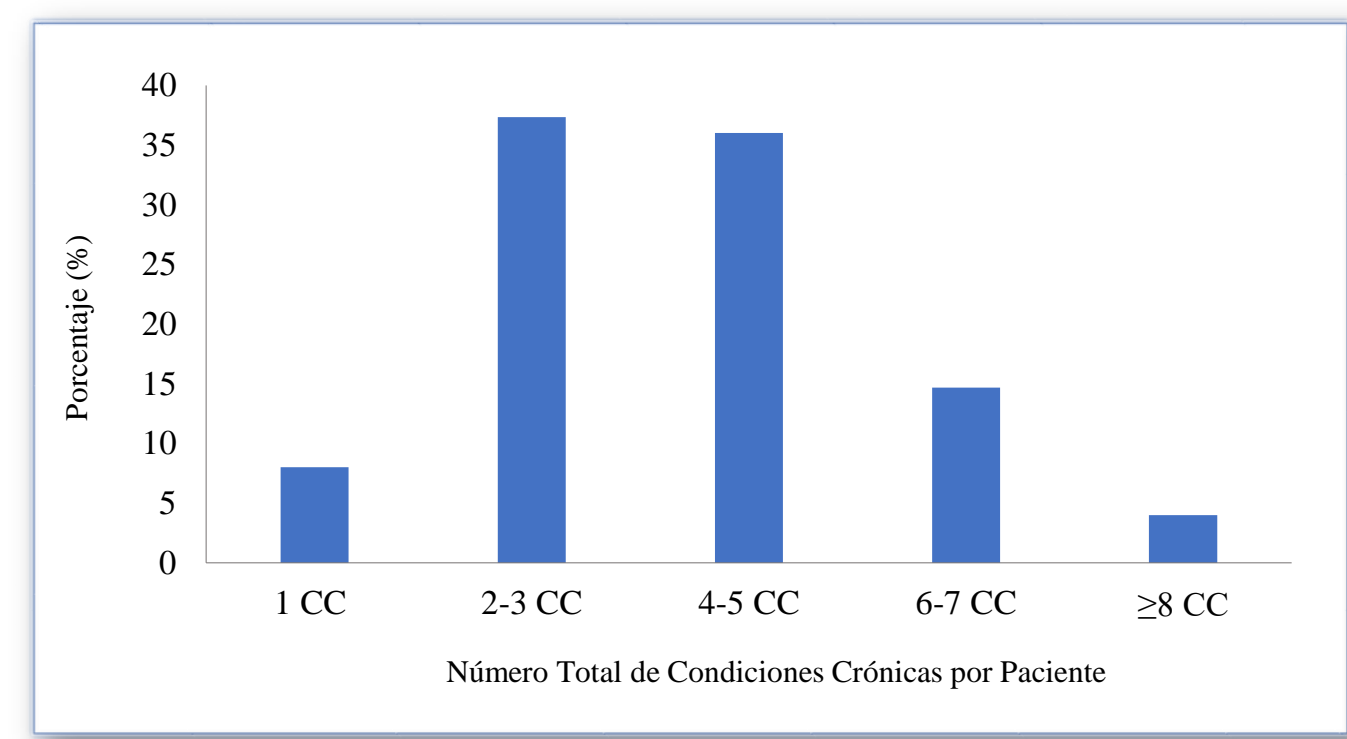

Figura 24. Distribución del Número Total de Condiciones Crónicas/Paciente.

Los resultados de la distribución del número de enfermedades crónicas/paciente indica que un $92.0 \%$ de los sujetos del estudio presenta multimorbilidad, mientras que sólo un $8 \%$ del total de los sujetos no presenta multimorbilidad (Figura 25).

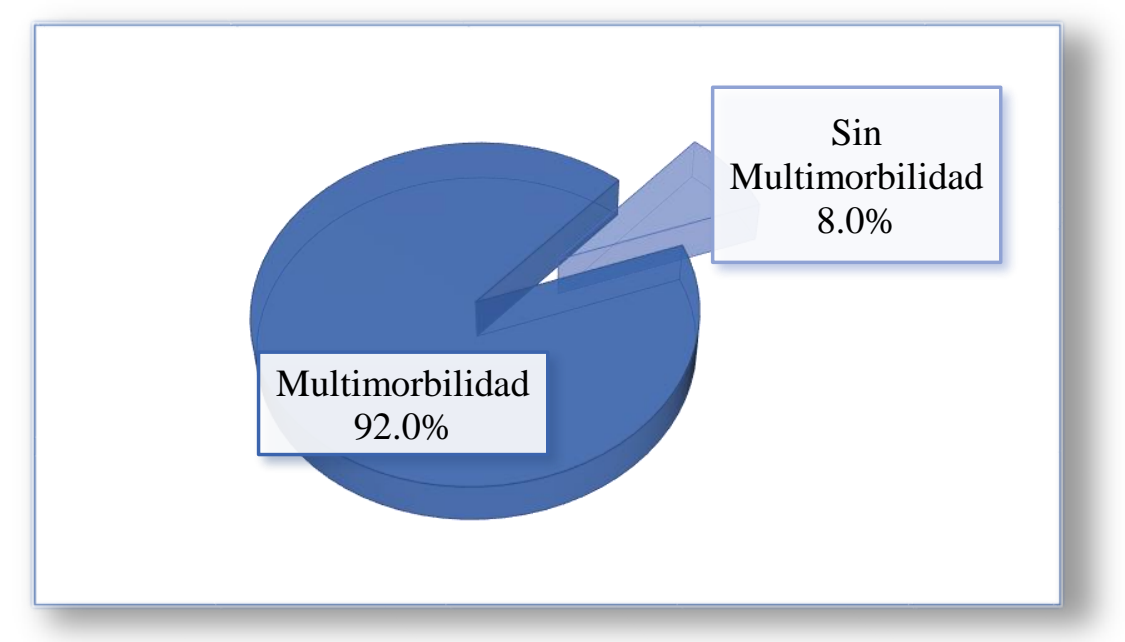

Figura 25. Distribución de los Pacientes del Estudio según Multimorbilidad. 
Como se ha explicado con anterioridad, los pacientes fueron clasificados según el modelo referencia al paciente crónico de Castilla y León ${ }^{231}$ en tres clusters dependiendo de la gravedad de la patología, la multimorbilidad, y el uso de servicios sanitarios, atendiendo a la siguiente clasificación: G1, pacientes con una patología estable o en estadio inicial con baja necesidad de atención primaria; G2, pacientes con dos o más patologías estables o con una en estadio avanzado con necesidades de atención moderadas; G3, pacientes pluripatológicos ${ }^{55}$ con elevadas necesidades de atención sanitaria y con frecuentes necesidades sociales.

Los resultados obtenidos respecto a la distribución de los pacientes por grupo de riesgo clínico, señalan al grupo G2 como el grupo más numeroso del estudio, con un $73.3 \%$ de sujetos, seguidos del grupo G1 con un $14.0 \%$, y del grupo G3 con un $12.7 \%$ de pacientes (Figura 26).

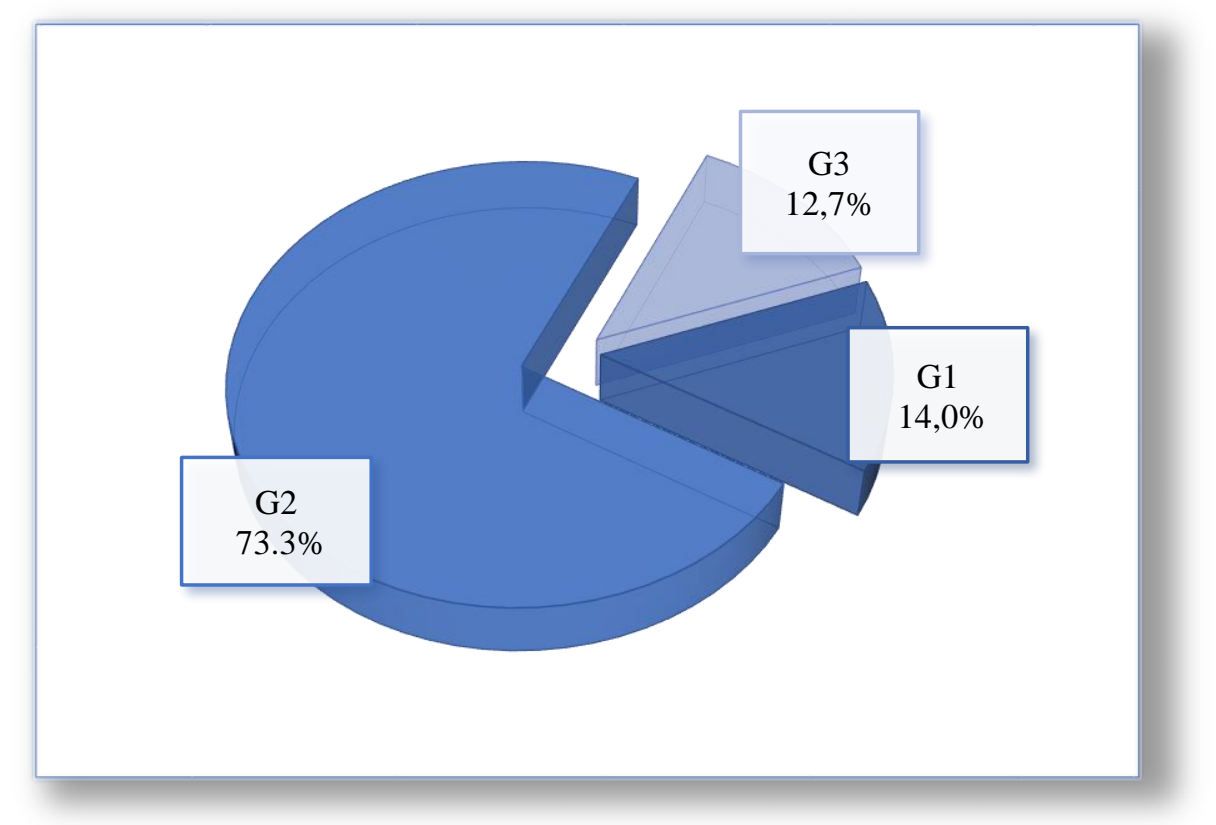

Figura 26. Distribución de los Pacientes del Estudio por Grupo de Riesgo Clínico. 


\subsubsection{Factores Relacionados con el Tratamiento}

Seguidamente se muestran los resultados del análisis descriptivo de los factores relacionados con el tratamiento del paciente. Entre estos factores cabe destacar el elevado número total de prescripciones de cada paciente, así como el elevado número de pastillas, inyecciones, inhaladores, y otras formas medicamentosas incluidas en el régimen farmacológico de los pacientes, y el complejo grado de polifarmacia del tratamiento (Tablas 4-A y 4-B).

Tabla 4-A. Factores Relacionados con el Tratamiento.

\begin{tabular}{|c|c|c|c|c|}
\hline & $\begin{array}{c}\text { Media } \pm D E \\
\left(n^{0} \text { total }\right)\end{array}$ & Frecuencia (n) & Porcentaje (\%) & IC $(95 \%)$ \\
\hline Tratamiento Farmacológico & $\mathrm{n}=150$ & & & \\
\hline Número de Prescripciones & $4.31 \pm 2.58(647)$ & & & \\
\hline$\leq 2$ Prescripciones & & 34 & 22.7 & $(16.0-29.3)$ \\
\hline 3-5 Prescripciones & & 77 & 51.3 & $(43.3-59.3)$ \\
\hline 6-8 Prescripciones & & 32 & 21.3 & $(14.7-28.0)$ \\
\hline$>9$ Prescripciones & & 7 & 4.7 & $(2.0-8.7)$ \\
\hline$\underline{\text { Número de pastillas }}$ & $4.93 \pm 3.61(740)$ & & & \\
\hline 0-3 Pastillas & & 57 & 38.0 & $(30.7-45.3)$ \\
\hline 4-6 Pastillas & & 59 & 39.3 & $(31.3-46.7)$ \\
\hline 7-9 Pastillas & & 19 & 12.7 & $(7.3-18.0)$ \\
\hline$\geq 10$ Pastillas & & 15 & 10.0 & $(5.3-14.7)$ \\
\hline Inyecciones & $0.46 \pm 0.87(69)$ & & & \\
\hline Con inyecciones & & 36 & 24.0 & $(17.3-30.7)$ \\
\hline Sin inyecciones & & 114 & 76.0 & $(69.3-82.7)$ \\
\hline Inhaladores & $0.24 \pm 0.70(36)$ & & & \\
\hline Con Inhaladores & & 20 & 13.3 & $(8.0-19.3)$ \\
\hline Sin Inhaladores & & 130 & 86.7 & $(80.7-92.0)$ \\
\hline$\underline{\text { Otras Formas }}$ & $0.14 \pm 0.59(21)$ & & & \\
\hline Con Otras Formas & & 14 & 9.3 & $(5.3-14.0)$ \\
\hline Sin Otras Formas & & 136 & 90.7 & $(86.0-94.7)$ \\
\hline
\end{tabular}


Tabla 4-B. Continuación de los Factores Relacionados con el Tratamiento.

\begin{tabular}{|c|c|c|c|c|}
\hline & Media \pm DE & Frecuencia (n) & Porcentaje (\%) & IC $(95 \%)$ \\
\hline Tratamiento No Farmacológico & $\mathrm{n}=147$ & & & \\
\hline \multicolumn{5}{|l|}{ Dieta } \\
\hline No Siguiendo Dieta & & 97 & 66.0 & $(58.0-73.3)$ \\
\hline Siguiendo Dieta & & 50 & 34.0 & $(26.7-42.0)$ \\
\hline Técnicas de Monitorización & $\mathrm{n}=150$ & & & \\
\hline No Empleo de Técnicas & & 69 & 46.0 & $(38.7-54.0)$ \\
\hline Empleo de Técnicas & & 81 & 54.0 & $(46.0-61.3)$ \\
\hline \multicolumn{5}{|l|}{ Grado de Polifarmacia } \\
\hline Ningún Grado & & 35 & 23.3 & $(16.7-30.0)$ \\
\hline Pequeño Grado & & 77 & 51.3 & $(43.3-59.3)$ \\
\hline Moderado Grado & & 31 & 20.7 & $(14.0-26.7)$ \\
\hline Elevado Grado & & 7 & 4.7 & $(2.0-8.7)$ \\
\hline
\end{tabular}

El número total de prescripciones de todos los pacientes del estudio asciende a 647 , con una media de $4.31 \pm 2.58$ prescripciones/paciente. La distribución de los pacientes respecto al número total de prescripciones médicas es la siguiente: un $22.7 \%$ de pacientes del total de la muestra requiere una o dos prescripciones; un 51.3\% sujetos de la muestra requiere de tres a cinco prescripciones; un $21.3 \%$ de pacientes requiere de seis a ocho prescripciones; y finalmente, un $4.7 \%$ de los pacientes de la muestra requiere de nueve o más prescripciones médicas (Figura 27). 


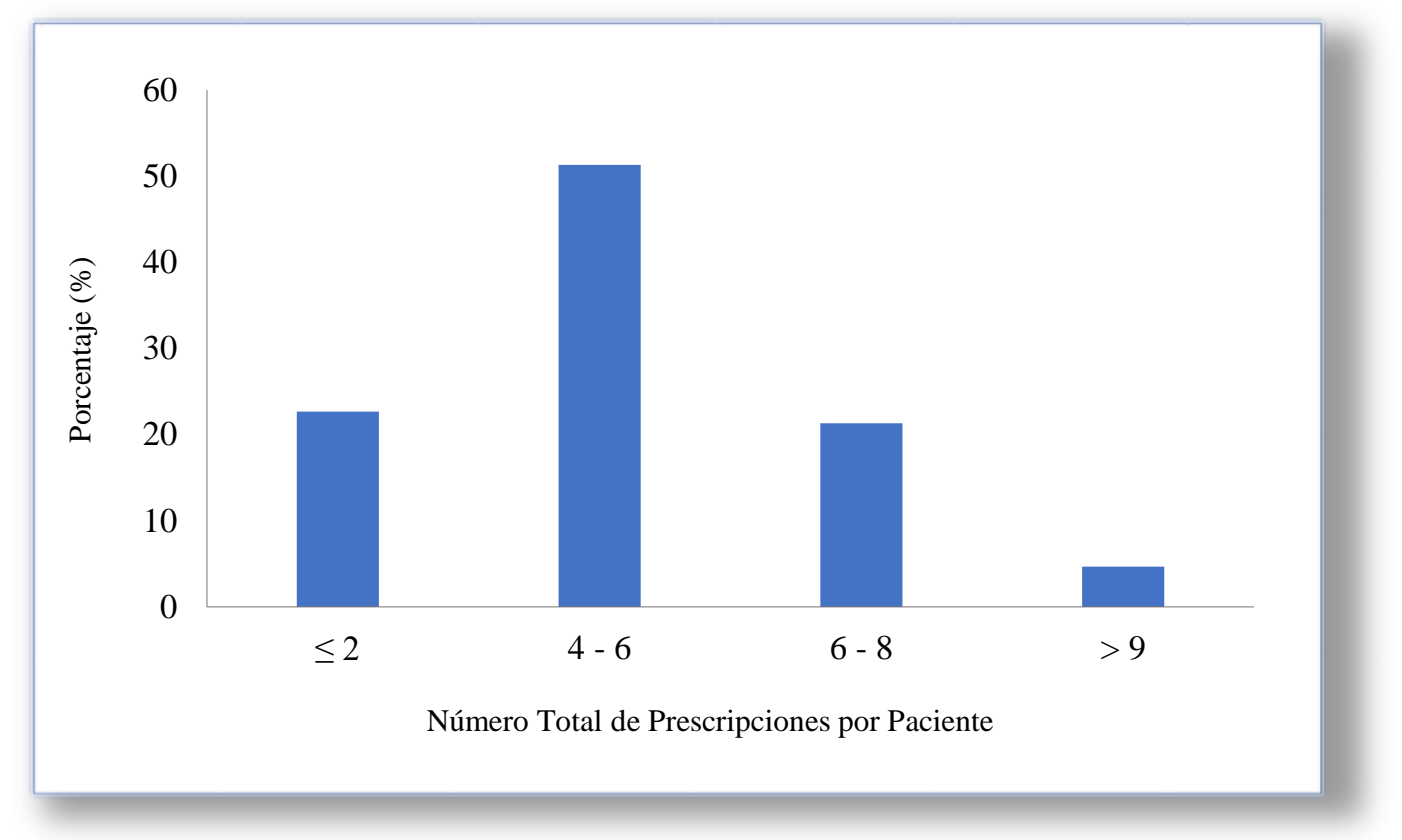

Figura 27. Distribución de los Pacientes del Estudio por el Número Total de Prescripciones.

El número total de "pastillas” (comprimidos, grageas, píldoras, cápsulas, y tabletas) prescritas en los tratamientos farmacológicos del total de los pacientes de la muestra asciende a 740, con un número medio de pastillas/paciente/día de $4.93 \pm 3.61$. La distribución de los pacientes respecto al número total de pastillas incluidas en su tratamiento farmacológico corresponde con la siguiente: un $38.0 \%$ de pacientes del total de la muestra requiere entre cero y tres pastillas/día en su tratamiento farmacológico; un $39.3 \%$ de pacientes requiere entre cuatro y seis pastillas/día; un $12.7 \%$ de pacientes de la muestra requiere entre siete y nueve pastillas/día en su tratamiento farmacológico; y un $10.0 \%$ de pacientes requiere de diez o más pastillas en su tratamiento (Figura 28). 


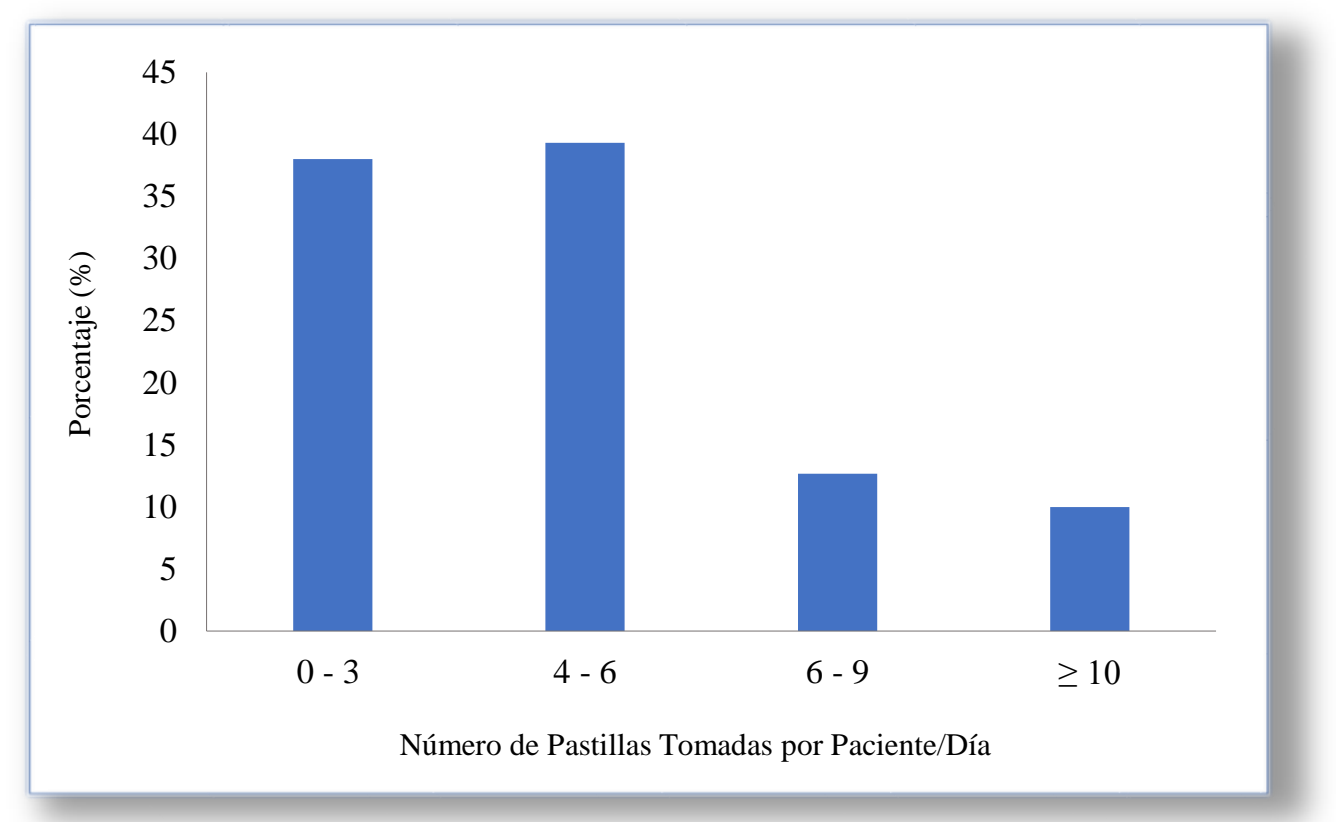

Figura 28. Distribución de los Pacientes del Estudio por el Número de Pastillas/Día Incluidas en sus Tratamientos Farmacológicos.

Los resultados del análisis indican que un $24.0 \%$ de los pacientes del estudio utiliza inyecciones en su régimen farmacológico cada día, mientras que un 13.3\% utiliza inhaladores diariamente, y un $9.3 \%$ utiliza otras formas medicamentosas como son colirios, enemas, y medicamentos tópicos (Figura 29). El número medio de inyecciones/día/paciente usadas por los pacientes asciende a $0.46 \pm 0.87$, mientras que el de inhaladores/día/paciente corresponde a $0.24 \pm 0.70$, y el de otras formas medicamentosas resulta en $0.14 \pm 0.59$. 


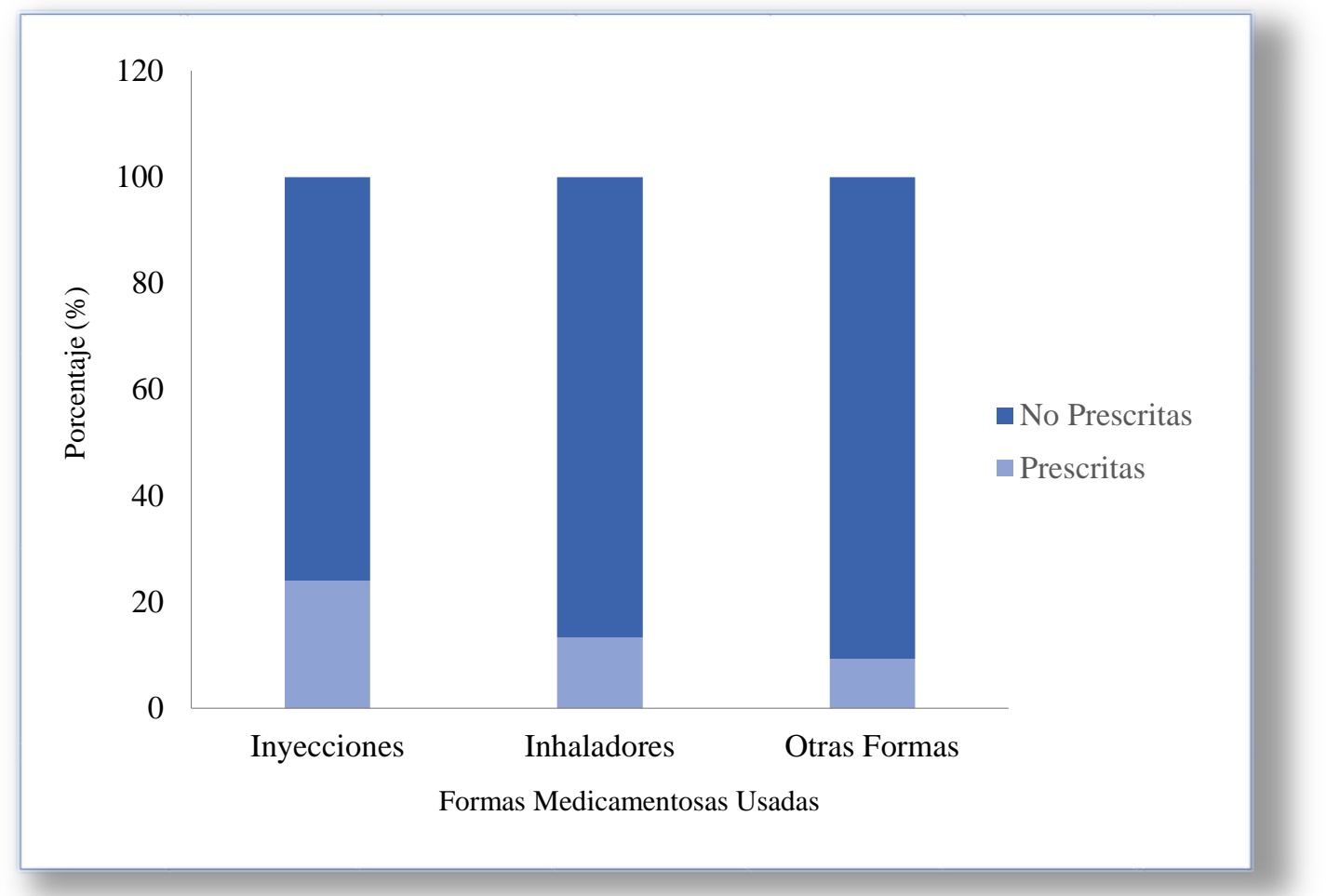

Figura 29. Distribución de los Pacientes del Estudio por la Utilización de Inyecciones/Día, Inhaladores/Día, y otras Formas Medicamentosas Prescritas en sus Tratamientos Farmacológicos.

A los pacientes que se les recomienda seguir una dieta específica padecen patologías relacionadas con problemas de hipertensión, colesterol, ácido úrico, sobrepeso, diabetes, problemas digestivos, y problemas renales. Del total de la muestra del estudio, a 147 pacientes se les recomendó seguir una dieta de acuerdo a la patología/s padecida/s. De estos pacientes, un $34.0 \%$ de los pacientes siguen una dieta específica acorde a las recomendaciones de los profesionales sanitarios, mientras que un $66.0 \%$ no sigue las recomendaciones sugeridas por los profesionales sanitarios y por lo tanto no lleva a cabo ninguna dieta específica para la/s condición/es padecida/s (Figura 30). 


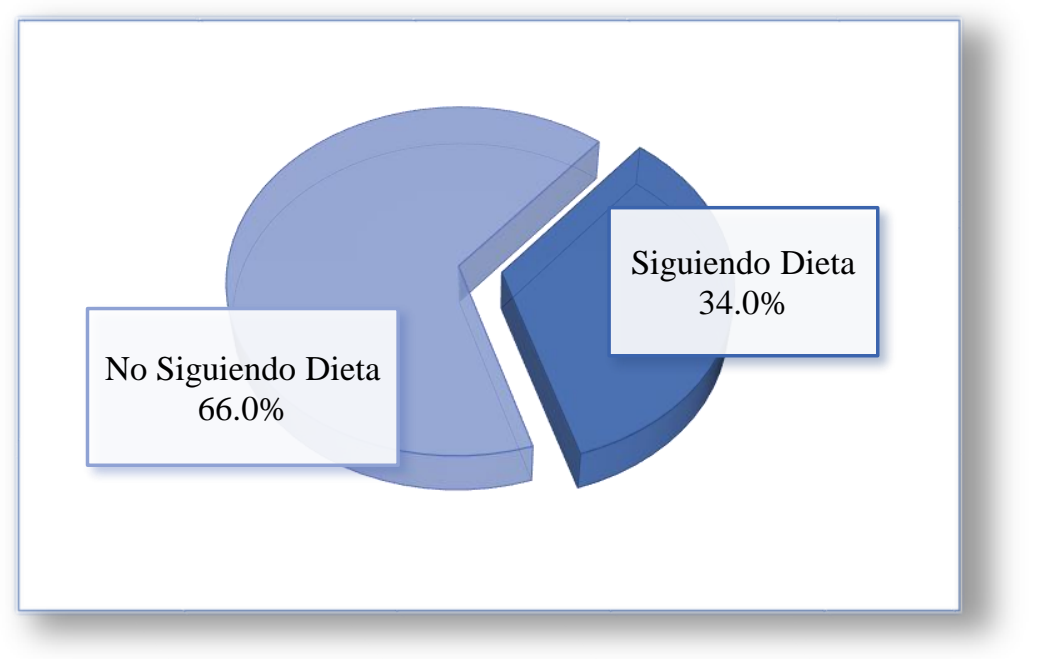

Figura 30. Distribución de los Pacientes del Estudio según las Recomendaciones de Dieta para la/s Patología/s Padecida/s (n=147).

Los pacientes se clasificaron de acuerdo a sus prácticas de monitorización de glucosa y/o presión arterial fuera del entorno clínico, de acuerdo a las recomendaciones sugeridas y establecidas por los profesionales sanitarios. Del total de la muestra, un $54.0 \%$ de sujetos realizaba técnicas de monitorización según las recomendaciones, mientras un $46.0 \%$ las realizaba en menor frecuencia o no las practicaba (Figura 31).

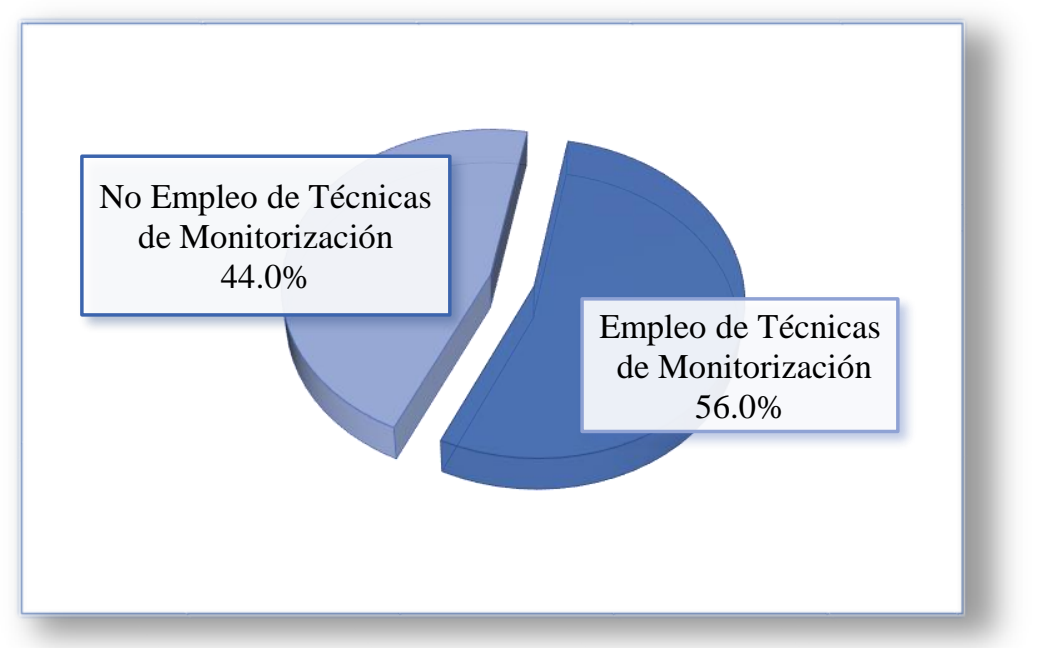

Figura 31. Distribución de los Pacientes del Estudio Según su Empleo de Técnicas de Monitorización fuera del Entorno Clínico. 
Los supermercados, estaciones de policía y bomberos, y centros comerciales son los lugares más frecuentes utilizados por los pacientes para realizar las prácticas de monitorización de presión arterial fuera del entorno clínico, mientras que el domicilio es señalado como el lugar más frecuente para la monitorización de glucosa.

Respecto al grado de polifarmacia del tratamiento farmacológico, los resultados revelan que el tratamiento de un $23.3 \%$ de los pacientes de la muestra no requiere ningún grado de polifarmacia, el tratamiento de un $51.3 \%$ de los pacientes requiere un pequeño grado, el tratamiento de un $20.7 \%$ de los pacientes de la muestra requiere un moderado grado de polifarmacia, y finalmente, el tratamiento del $4.7 \%$ de los pacientes requiere un elevado grado de polifarmacia (Figura 32).

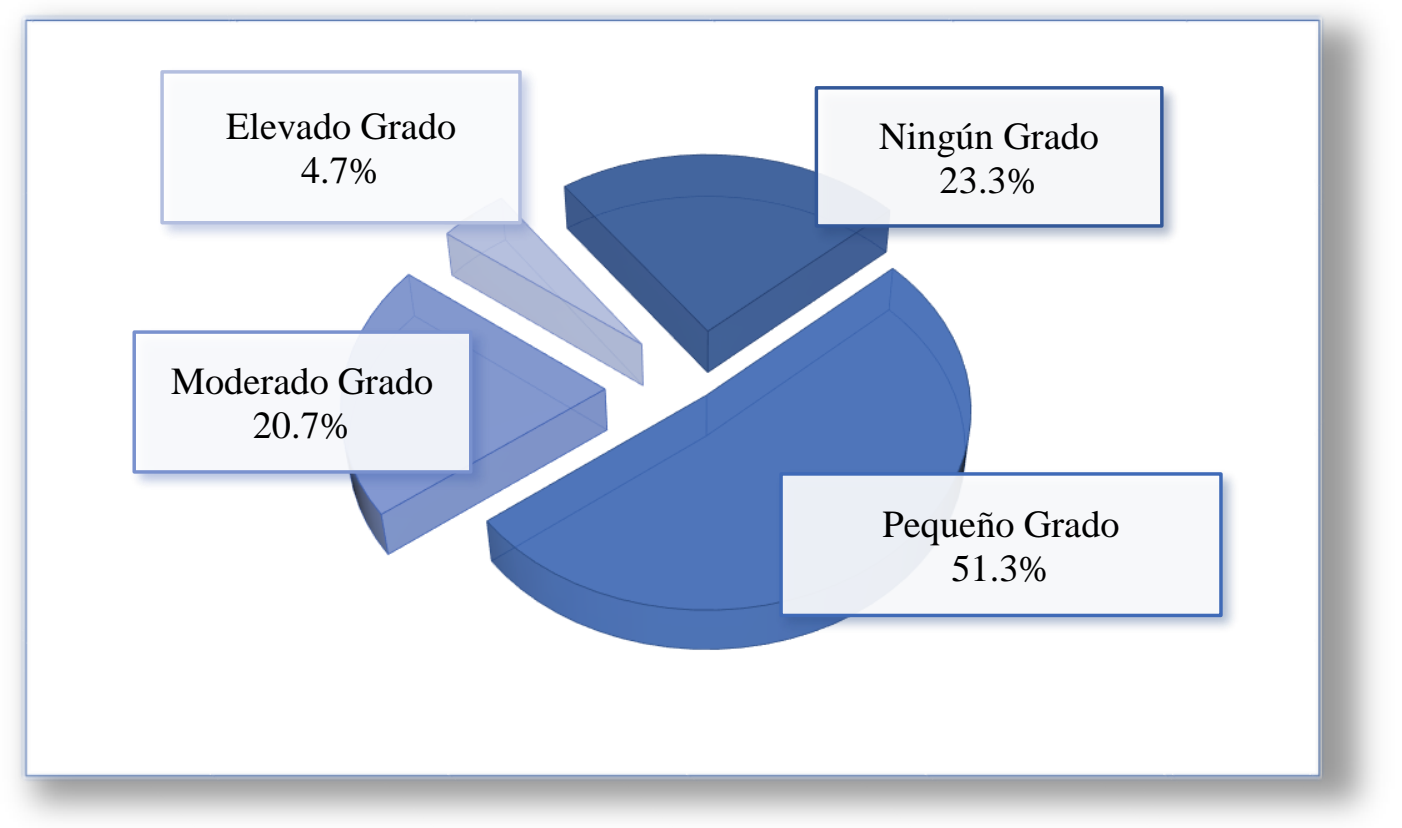

Figura 32. Distribución de los Pacientes del Estudio Según Grado de Polifarmacia Requerido en su Tratamiento. 


\subsubsection{Factores Relacionados con el Paciente}

A continuación, se muestran los resultados del análisis descriptivo de los factores relacionados con el paciente. Las variables más destacables de este grupo de factores son la independencia física y funcional de las AVD que disfrutan la mayoría de los sujetos (valorada con el índice de Barthel), la negativa auto-valoración del Estado de Salud del último año de una gran proporción de individuos, el buen conocimiento sobre las condiciones padecidas y el tratamiento farmacológico, el elevado número de pacientes que son responsables de su propia toma y control de la medicación, y el destacado número de pacientes que utiliza métodos y estrategias para recordar la toma de medicación (Tablas 5-A y 5-B).

Tabla 5-A. Factores Relacionados con el Paciente.

\begin{tabular}{|c|c|c|c|c|c|}
\hline & & Media \pm DE & Frecuencia (n) & Porcentaje (\%) & IC $(95 \%)$ \\
\hline Dificultades Sensoriales & $\mathrm{n}=150$ & & & & \\
\hline Con Dificultades & & & 17 & 11.3 & $(6.7-16.7)$ \\
\hline Sin Dificultades & & & 133 & 88.7 & $(83.3-93.3)$ \\
\hline Índice de Barthel & & $94.63 \pm 9.68$ & & & \\
\hline Independencia & & & 88 & 58.7 & $(50.7-66.7)$ \\
\hline Dependencia Leve & & & 27 & 18.0 & $(12.0-24.7)$ \\
\hline Dependencia Moderada & & & 33 & 22.0 & $(15.4-29.3)$ \\
\hline Dependencia Severa & & & 2 & 1.3 & $(0.0-3.3)$ \\
\hline Dependencia Total & & & 0 & 0 & -- \\
\hline Auto-valoración Estado Salud & & $4.21 \pm 2.63$ & & & \\
\hline Muy Bueno & & & 8 & 5.3 & $(2.0-9.3)$ \\
\hline Bueno & & & 15 & 10.0 & $(6.0-15.3)$ \\
\hline Regular & & & 39 & 26.0 & $(19.3-33.3)$ \\
\hline Malo & & & 55 & 36.7 & $(28.7-44.7)$ \\
\hline Muy Malo & & & 33 & 22.0 & $(15.3-28.0)$ \\
\hline
\end{tabular}


Tabla 5-B. Continuación de los Factores Relacionados con el Paciente.

\begin{tabular}{|c|c|c|c|c|c|}
\hline & & Media \pm DE & Frecuencia (n) & Porcentaje (\%) & IC $(95 \%)$ \\
\hline $\begin{array}{l}\text { Conocimiento Sobre Condiciones } \\
\text { Padecidas y Tratamiento }\end{array}$ & $\mathrm{n}=150$ & & & & \\
\hline Conocimiento Incompleto & & & 10 & 6.7 & $(3.3-10.7)$ \\
\hline Conocimiento Completo & & & 140 & 93.3 & $(89.3-96.7)$ \\
\hline $\begin{array}{l}\text { Desconocer por qué Toma } \\
\text { cada Medicamento }\end{array}$ & & & 5 & 3.3 & $(0.7-6.7)$ \\
\hline $\begin{array}{l}\text { Conocer por qué Toma } \\
\text { cada Medicamento }\end{array}$ & & & 145 & 96.7 & $(93.3-99.3)$ \\
\hline $\begin{array}{l}\text { Desconocer Número de Medicamentos } \\
\text { y Posología }\end{array}$ & & & 7 & 4.7 & $(2.0-8.0)$ \\
\hline $\begin{array}{l}\text { Conocer Número de Medicamentos y } \\
\text { Posología }\end{array}$ & & & 143 & 95.3 & $(92.0-98.0)$ \\
\hline \multicolumn{6}{|l|}{ Apoyo Familiar Recibido } \\
\hline Sin Apoyo Familiar & & & 65 & 43.3 & $(35.3-51.3)$ \\
\hline Con Apoyo Familiar & & & 85 & 56.7 & $(48.7-64.7)$ \\
\hline \multicolumn{6}{|l|}{$\begin{array}{l}\text { Necesidad de Ayuda para Control de } \\
\text { Medicación }\end{array}$} \\
\hline Con Necesidad & & & 46 & 30.7 & $(22.3-39.3)$ \\
\hline Sin Necesidad & & & 104 & 69.3 & $(60.7-76.7)$ \\
\hline \multicolumn{6}{|l|}{$\begin{array}{l}\text { Persona Responsable de la } \\
\text { Medicación }\end{array}$} \\
\hline El Mismo Paciente & & & 127 & 84.7 & $(78.7-90.0)$ \\
\hline Miembro Familiar & & & 23 & 15.3 & $(10.0-21.3)$ \\
\hline \multicolumn{6}{|l|}{$\begin{array}{l}\text { Métodos/Estrategias Usados para } \\
\text { Recordar Medicación }\end{array}$} \\
\hline Ningún Método & & & 44 & 29.3 & $(22.0-36.7)$ \\
\hline Utilización de Estrategias & & & 106 & 70.7 & $(63.3-78.0)$ \\
\hline Estrategias Específicas Usadas & $\mathrm{n}=106$ & & & & \\
\hline Instrumentos de Organización & & & 36 & 34.0 & $(25.5-43.4)$ \\
\hline Ayuda por Otra Persona & & & 13 & 12.3 & $(6.6-18.9)$ \\
\hline Asociación con Actividades & & & 25 & 23.6 & $(16.0-31.1)$ \\
\hline Asociación con Tomar Alimentos & & & 18 & 17.0 & $(10.4-24.5)$ \\
\hline Otras Estrategias & & & 14 & 13.2 & $(6.6-19.8)$ \\
\hline
\end{tabular}


Los resultados obtenidos respecto a la variable dependencia física y funcional de las AVD muestran que un $58.7 \%$ de los pacientes son independientes funcionales; el $18.0 \%$ de los pacientes muestra una leve dependencia física y funcional para realizar las AVD, un $22.0 \%$ manifiesta una dependencia moderada, un $1.3 \%$ muestra dependencia severa, y ningún paciente $(0.0 \%)$ presenta dependencia total física y funcional en la realización de las AVD (Figura 33). El resultado obtenido de la media numérica de la dependencia física y funcional de las AVD de los pacientes de la muestra del estudio corresponde $94.63 \pm 9.68$, lo que equivale a una dependencia física y funcional leve (Figura 33).

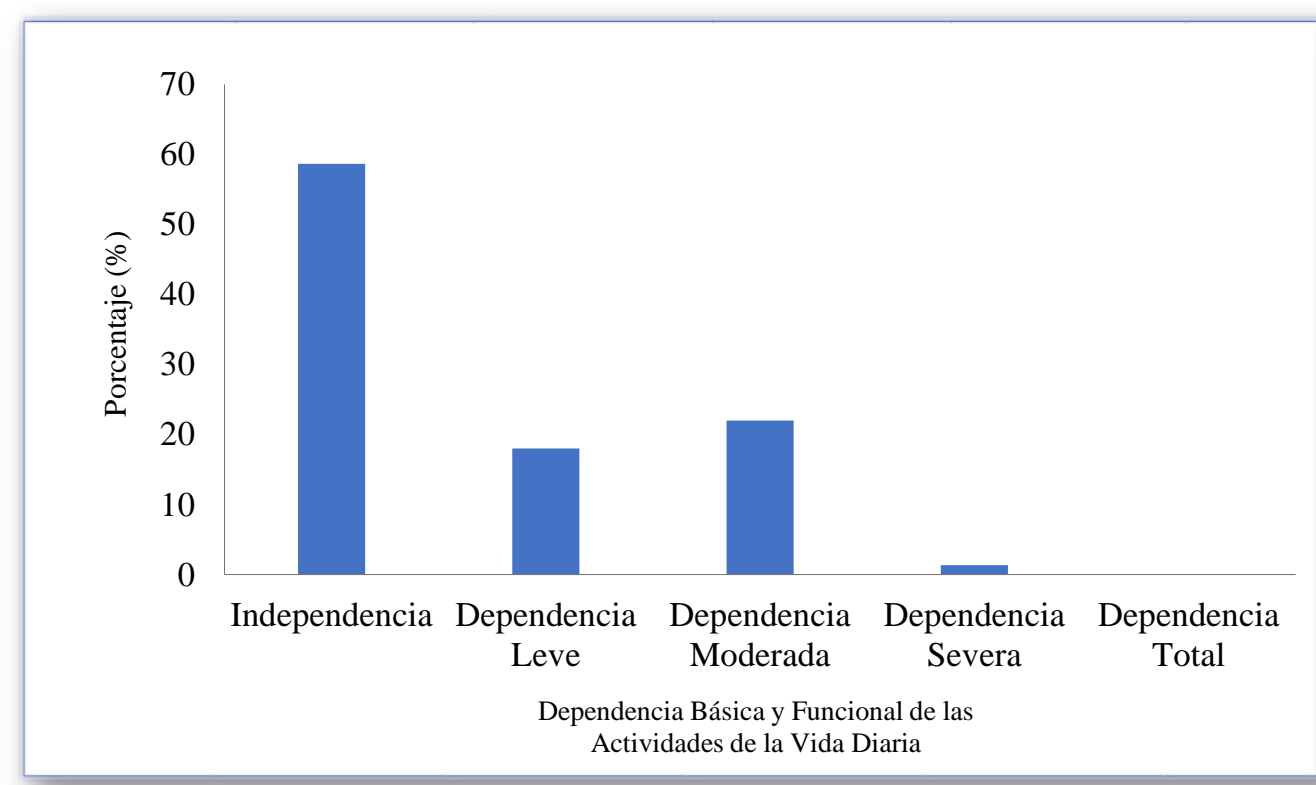

Figura 33. Distribución de los Pacientes del Estudio por su Dependencia Física y Funcional en la Realización de las Actividades de la Vida Diaria. 
Respecto a la valoración que realizó cada paciente sobre su Estado de Salud en el último año, un 5.3\% afirma haber disfrutado de un Estado de Salud muy bueno, un 10.0\% lo califica cono bueno, un $26.0 \%$ considera haber tenido un Estado de Salud regular, un $36.7 \%$ lo califica como malo, y un $22.0 \%$ afirma ser muy malo (Figura 34). La auto-valoración que realizó cada paciente sobre su Estado de Salud en el último año fue calificada en escala numérica con una nota media de $4.21 \pm 2.63$.

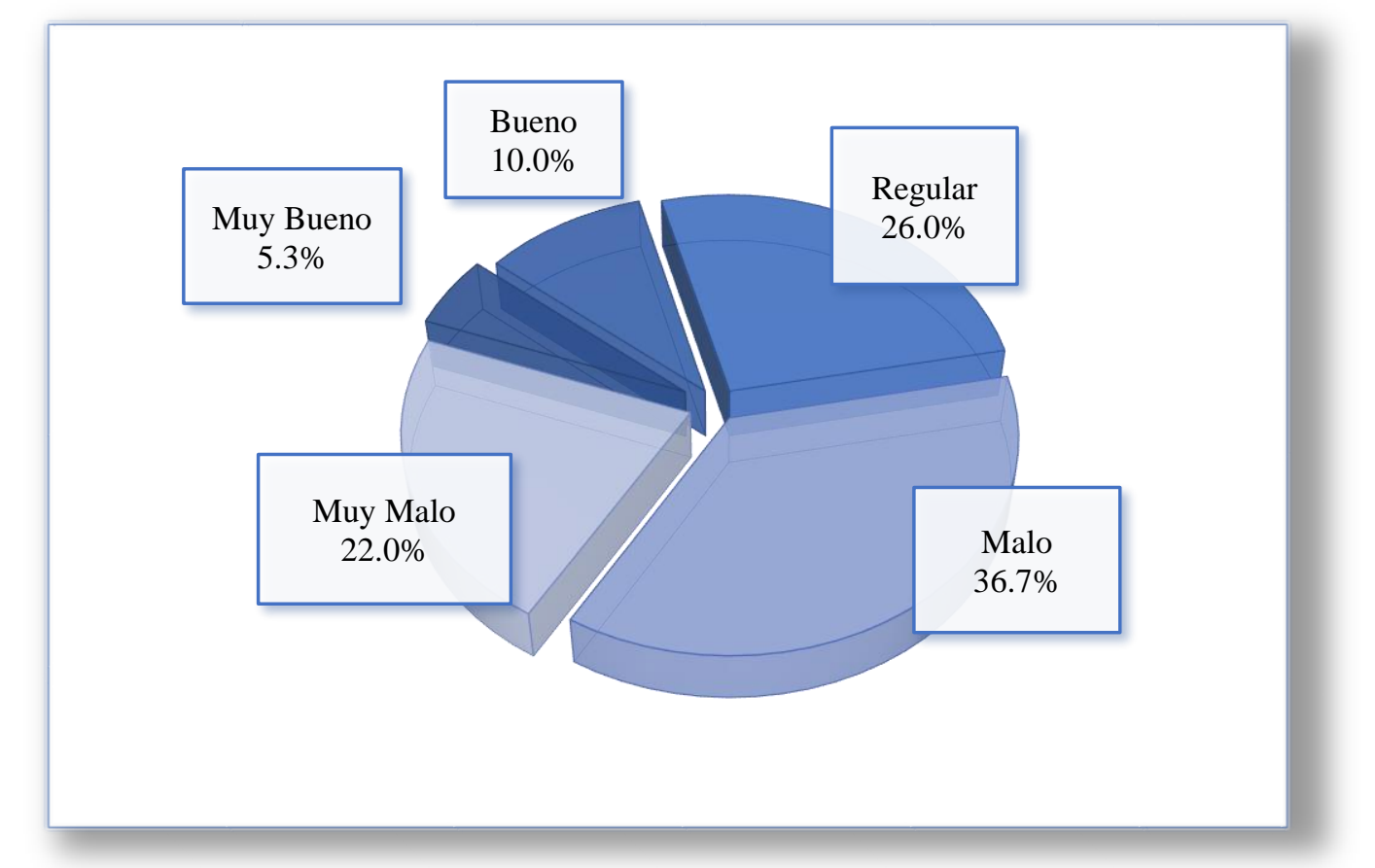

Figura 34. Auto-Valoración del Estado de Salud de los Pacientes en el Último Año.

Los resultados obtenidos sobre el conocimiento completo acerca de las condiciones padecidas por cada paciente y su tratamiento farmacológico reflejan que un $93.3 \%$ de los pacientes posee conocimientos completos sobre las condiciones padecidas, mientras que un $6.7 \%$ de los pacientes posee conocimientos incompletos. Del total de la muestra, un $3.3 \%$ de los individuos desconoce la razón por la que tomaba cada medicamento, y un $4.7 \%$ desconoce el número de medicamentos y posología en su régimen terapéutico (Figura 35). 


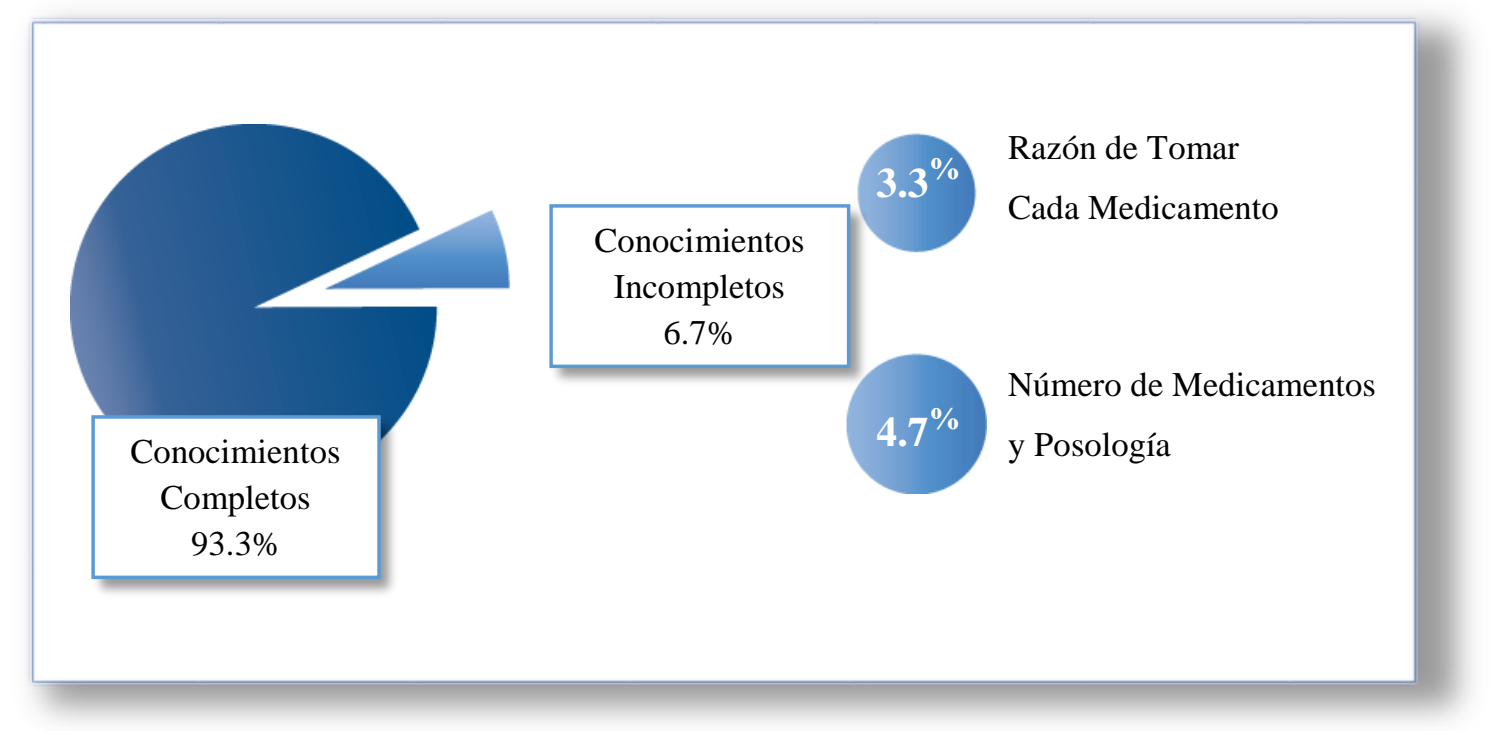

Figura 35. Distribución de los pacientes del Estudio por su Conocimiento acerca de las Condiciones Padecidas y su Tratamiento Farmacológico.

Al preguntar a los pacientes del estudio por la persona responsable para la toma y control de la medicación del paciente, un $84.7 \%$ admite ser "el mismo paciente" la persona responsable y un $15.3 \%$ declara que la responsabilidad para la toma y control de la medicación recae en un miembro de la familia (Figura 36). 


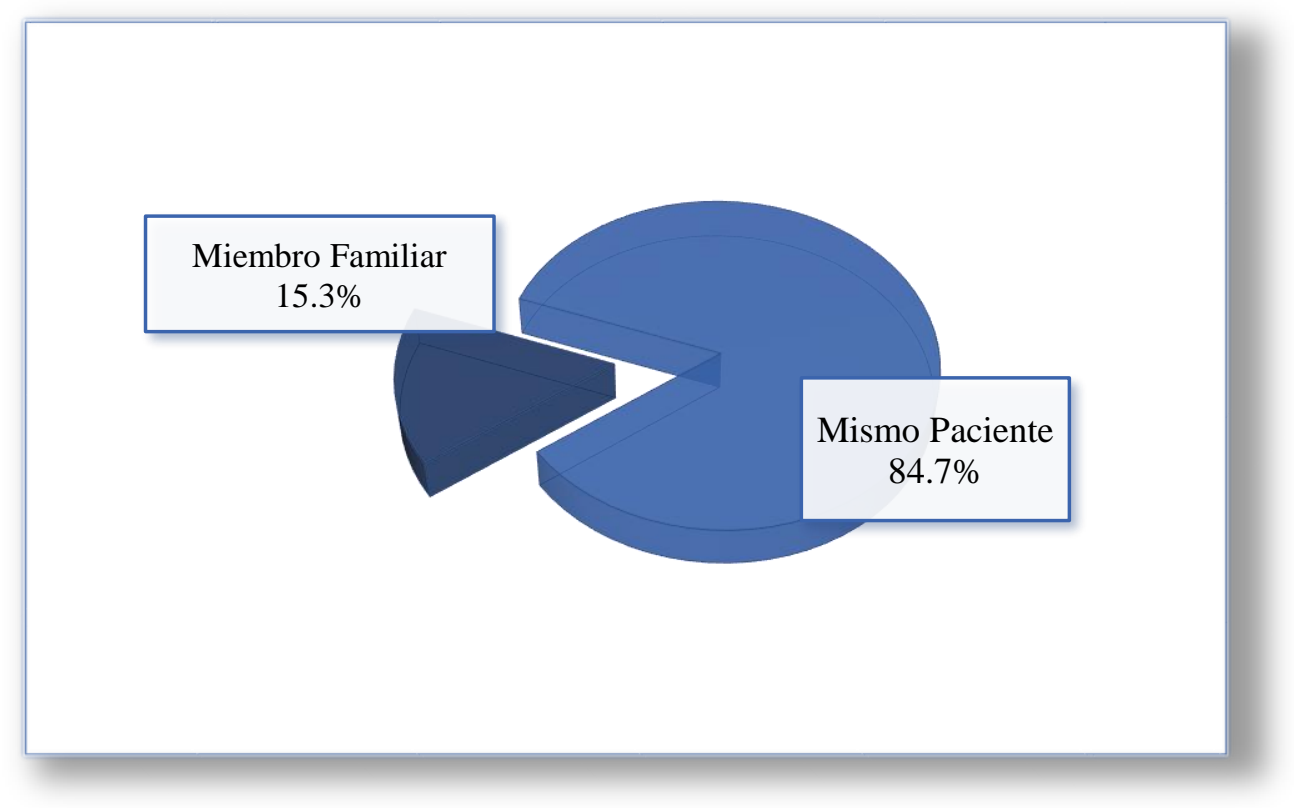

Figura 36. Distribución de los Pacientes del Estudio por la Persona Responsable para la Toma y Control de su Medicación.

Por otro lado, el $70.7 \%$ de los pacientes del estudio admite utilizar un método para recordar la toma de medicación, mientras que un $23.3 \%$ asegura no utilizar ninguno. Las estrategias específicas más utilizadas por los pacientes del estudio para recordar la toma de medicación son: estrategias de organización (34.0\%) como pastilleros, alarmas, o libretas; ayuda ofrecida en forma de recordatorio por otra persona como por ejemplo un familiar, amigo, o cuidador informal (12.3\%); asociación de la toma de medicación con actividades cotidianas de la vida diaria (23.6\%), como por ejemplo levantarse en la mañana, tomar la medicación antes de cepillarse los dientes, o antes de salir de casa; otra estrategia utilizada es asociar la toma de medicación con la toma de alimentos (17.0\%), fundamentalmente con las tres comidas principales, desayuno, comida/almuerzo, y cena; y por último, los individuos del estudio utilizan otras estrategias (13.2\%) que incluyen diferentes acciones y diversos métodos individualizados por el paciente que varían desde situar la medicación en lugares estratégicos hasta llevar la medicación siempre consigo mismo (Figura 37). 


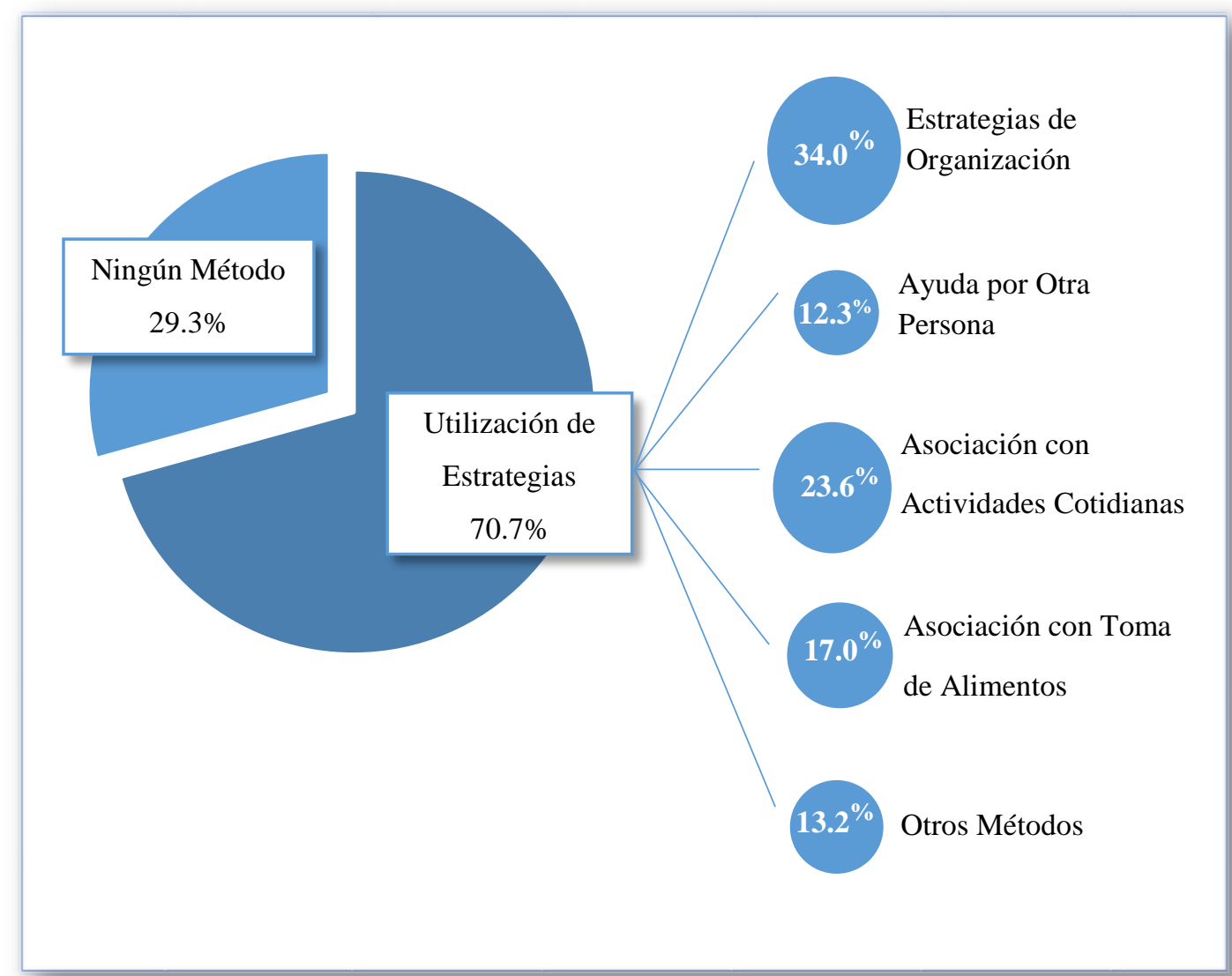

Figura 37. Distribución de los Pacientes del Estudio en Función del Método/Estrategia Utilizada para la Toma de la Medicación. 


\subsubsection{Variable Dependiente: Adherencia}

Debido a que en la práctica médica el concepto de adherencia suele circunscribirse casi exclusivamente al uso de los medicamentos por parte del paciente de una forma acordada con el profesional sanitario, y, debido a las dificultades sociales que ya de por sí presenta la población de la muestra, se decide evaluar la adherencia al tratamiento farmacológico o adherencia a medicación, sin valorar las recomendaciones del profesional sanitario en cuanto a régimen alimentario y/o estilo de vida, aunque estos están recogidos en el estudio.

Por tanto, se ha definido adherencia al tratamiento farmacológico como el grado de comportamiento de los pacientes - respecto a la toma de medicamentos - se corresponde con las recomendaciones acordadas con un prestador de asistencia sanitaria ${ }^{97}$.

Los pacientes son clasificados en dos grupos, "adherentes" y "no adherentes", de acuerdo a su cumplimiento terapéutico. De este modo, los sujetos del estudio son clasificados como adherentes cuando responden negativamente (no) a todas las preguntas del cuestionario de Morisky-Green-Levine ${ }^{178}$ (Anexo IV), mientras que son clasificados como no adherentes cuando responden afirmativamente (sí) a una o más preguntas del cuestionario. A continuación, se muestran los resultados de adherencia al tratamiento farmacológico de los pacientes del estudio en Fase I, es decir, en los primeros seis meses de tratamiento de un nuevo régimen farmacológico (Tabla 6). 
Tabla 6. Distribución de los Pacientes del Estudio en Función de su Adherencia al Tratamiento Farmacológico según el Cuestionario de Morisky-Green-Levine en la Fase I del Estudio (n=150).

\begin{tabular}{cccc}
\hline \hline & Frecuencia (n) & Porcentaje (\%) & IC (95\%) \\
\hline \hline Adherentes & 72 & 48.0 & $(40.0-56.0)$ \\
No Adherentes & 78 & 52.0 & $(44.0-60.0)$ \\
\hline \hline
\end{tabular}

Los resultados de adherencia al tratamiento farmacológico de la Fase I por el método del cuestionario de Morisky-Green-Levine muestran que un 52.0\% de los pacientes del total de la muestra del estudio incumple el tratamiento prescrito (pacientes no adherentes), mientras que un $\mathbf{4 8 . 0 \%}$ del total de pacientes cumple con el tratamiento farmacológico (pacientes adherentes) (Figura 38).

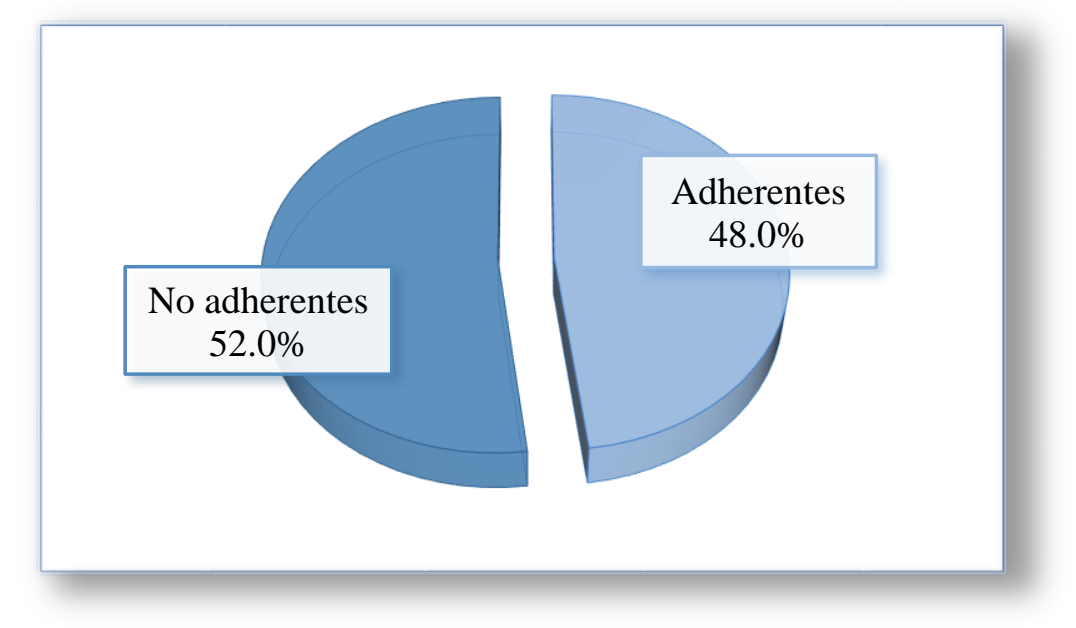

Figura 38. Resultados de Adherencia al Tratamiento Farmacológico en la Fase I del Estudio según el Cuestionario Morisky-Green-Levine $(\mathrm{n}=150)$. 
Asimismo, se procede a la determinación del grado de adherencia al tratamiento farmacológico de los pacientes del estudio en función de sus respuestas al cuestionario de Morisky-Green-Levine ${ }^{178}$. Los pacientes son clasificados en "nivel de adherencia alto" cuando responden negativamente (no) a todas las preguntas de cuestionario, "nivel de adherencia medio", cuando responden positivamente (si) a uno o dos preguntas del cuestionario, y "nivel de adherencia bajo", cuando responden positivamente a tres o cuatro preguntas del cuestionario, con los siguientes resultados (Tabla 7).

Tabla 7. Grado de Adherencia al Tratamiento Farmacológico de los Pacientes del Estudio en la Fase I según el Cuestionario de Adherencia Morisky-Green-Levine.

\begin{tabular}{cccc}
\hline \hline & Frecuencia (n) & Porcentaje (\%) & IC (95\%) \\
\hline \hline Alto & 72 & 48.0 & $(44.0-55.3)$ \\
Medio & 64 & 42.7 & $(34.7-50.7)$ \\
Bajo & 14 & 9.3 & $(4.7-14.7)$ \\
& & & \\
\hline \hline
\end{tabular}

Los resultados muestran que un $48.0 \%$ de los pacientes de la muestra presenta un grado adherencia a la medicación alto, mientras que un $42.7 \%$ muestra un grado de adherencia medio, y un $9.3 \%$ del total de los pacientes del estudio resulta tener un grado de adherencia al tratamiento farmacológico bajo (Figura 39). 


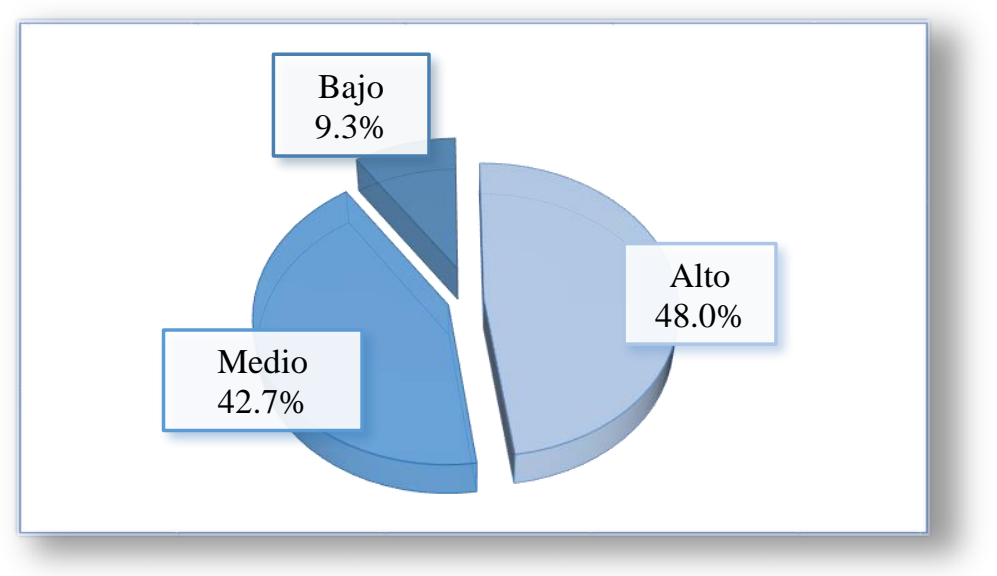

Figura 39. Grado de Adherencia al Tratamiento Farmacológico de los Pacientes del Estudio en la Fase I según el Cuestionario de Adherencia Morisky-Green-Levine.

Seguidamente, se realiza el análisis individualizado (determinación de frecuencia, porcentaje, e IC) de las causas de incumplimiento de los pacientes no adherentes $(\mathrm{n}=78)$ en función de sus respuestas al cuestionario Morisky-Green-Levine. La distribución de las causas de no adherencia se corresponde con los siguientes resultados (Tabla 8).

Tabla 8. Distribución de los Pacientes No Adherentes $(n=78)$ en Función de las Causas de Incumplimiento en la Fase I del Estudio.

\begin{tabular}{|c|c|c|c|c|c|c|}
\hline & $\begin{array}{c}\text { Frecuencia (n) } \\
\text { Sí }\end{array}$ & $\begin{array}{c}\text { Porcentaje } \\
(\%)\end{array}$ & $\underset{(95 \%)}{\text { IC }}$ & $\begin{array}{c}\text { Frecuencia (n) } \\
\text { No }\end{array}$ & $\begin{array}{c}\text { Porcentaje } \\
(\%)\end{array}$ & IC (95\%) \\
\hline $\begin{array}{l}\text { ¿Olvida alguna vez } \\
\text { tomar sus } \\
\text { medicamentos? }\end{array}$ & 65 & 83.3 & (75.3-91.5) & 13 & 16.7 & $(8.5-24.7)$ \\
\hline $\begin{array}{l}\text { ¿Es descuidado con la } \\
\text { hora en que debe } \\
\text { tomar la medicación? }\end{array}$ & 30 & 38.5 & $(28.0-49.3)$ & 48 & 61.5 & $(50.7-72.0)$ \\
\hline $\begin{array}{l}\text { Cuando se encuentra } \\
\text { mejor, ¿deja de } \\
\text { tomar la medicación } \\
\text { vez? }\end{array}$ & 22 & 28.2 & $(17.9-38.2)$ & 56 & 71.8 & $(61.8-82.1)$ \\
\hline $\begin{array}{l}\text { Si alguna vez le } \\
\text { sientan mal los } \\
\text { medicamentos, ¿deja } \\
\text { de tomarlos? }\end{array}$ & 22 & 28.2 & $(17.9-38.2)$ & 56 & 71.8 & $(61.8-82.1)$ \\
\hline
\end{tabular}


Los resultados obtenidos entre los pacientes clasificados como no adherentes de la fase I del estudio son los siguientes: un $83.3 \%$ del grupo de pacientes no adherentes afirma olvidar alguna vez tomar sus medicamentos; un $38.5 \%$ de los pacientes admite ser descuidado con la hora en que debe tomar la medicación; un $28.2 \%$ de los pacientes de la muestra declara dejar de tomar la medicación cuando se encuentra mejor; y finalmente, un $28.2 \%$ de los sujetos reconoce dejar de tomar los medicamentos si le sientan mal (Figura 40).

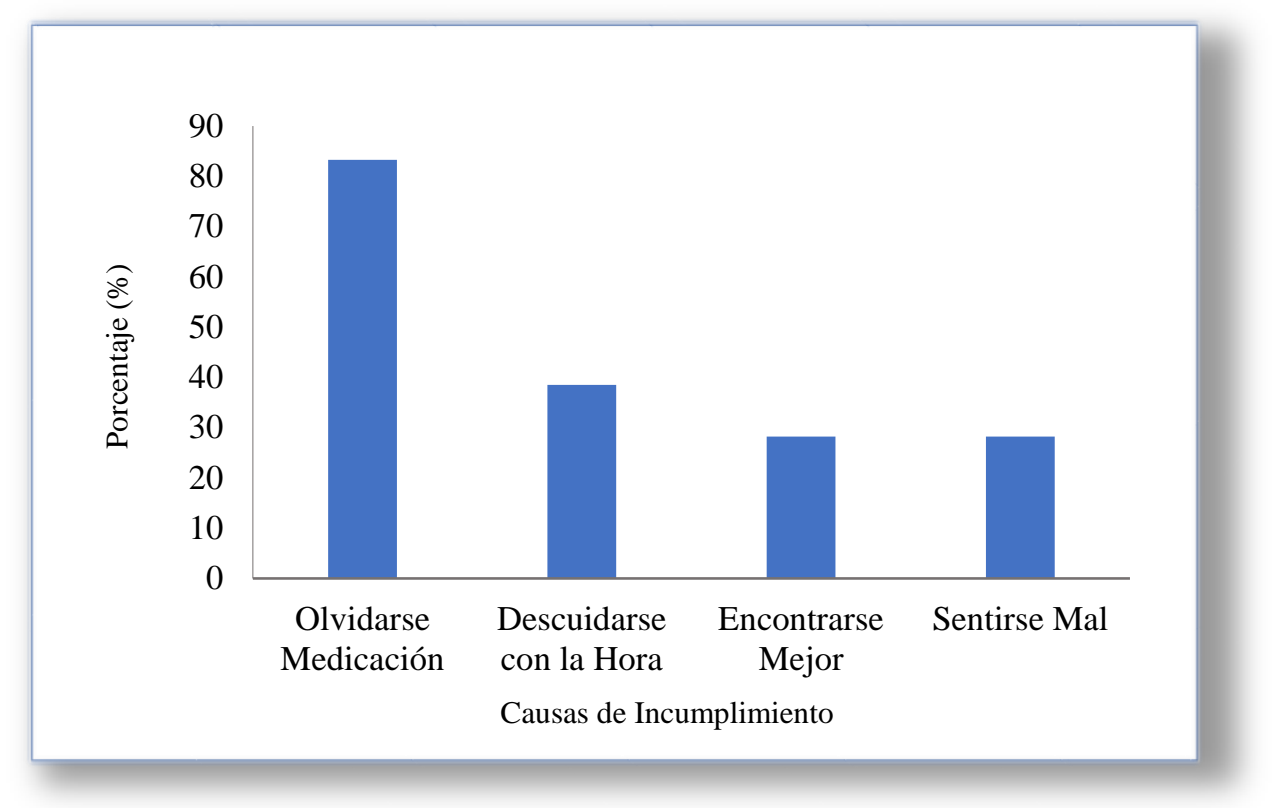

Figura 40. Distribución de los Pacientes No Adherentes $(\mathrm{n}=78)$ en Función de las Causas de su Comportamiento Incumplidor en la Fase I del Estudio.

Entre los pacientes del estudio $(\mathrm{n}=150), 35$ pacientes $(23.3 \%)$ han respondido positivamente (sí) a una pregunta del cuestionario, 29 pacientes $(19.3 \%)$ han contestado positivamente a dos cuestiones, 10 pacientes han respondido positivamente a tres cuestiones $(6.7 \%), 4$ pacientes $(2.7 \%)$ han contestado positivamente a cuatro preguntas, y 72 pacientes $(48.0 \%)$ han respondido negativamente (no) a todas las preguntas del cuestionario de adherencia Morisky-Green-Levine. 
Para determinar la falta de adherencia o el incumplimiento, atendiendo a la voluntad del paciente, han sido analizadas las respuestas de los pacientes dadas en el cuestionario Morisky-Green-Levine de tal forma que los pacientes que responden afirmativamente a la $1^{\mathrm{a}}$ y/o $2^{\mathrm{a}}$ cuestión son clasificados como pacientes que cometen un incumplimiento no intencionado (actos involuntarios); los pacientes que responden afirmativamente a la $3^{\mathrm{a}} \mathrm{y} / \mathrm{o} 4^{\mathrm{a}}$ pregunta, son clasificados como pacientes que cometen un incumplimiento intencionado (actos voluntarios); y los pacientes que responden afirmativamente, al menos a una de las dos primeras preguntas $\left(1^{\mathrm{a}} \mathrm{y} / \mathrm{o} 2^{\mathrm{a}}\right)$ y al menos una de las dos últimas preguntas $\left(3^{\mathrm{a}} \mathrm{y} / \mathrm{o} 4^{\mathrm{a}}\right)$ son clasificados como pacientes que cometen un incumplimiento mixto (incumplimiento no intencionado e incumplimiento intencionado). Los resultados del análisis de adherencia según la conducta de los pacientes del estudio se muestran a continuación (Tabla 9).

Tabla 9. Distribución de los Pacientes No Adherentes $(\mathrm{n}=78)$ por Conducta de Incumplimiento.

\begin{tabular}{cccc}
\hline \hline & Frecuencia (n) & Porcentaje (\%) & IC (95\%) \\
\hline \hline Incumplimiento Involuntario & 73 & 93.6 & $(87.2-98.7)$ \\
Incumplimiento Voluntario & 36 & 46.2 & $(34.6-57.7)$ \\
Incumplimiento Mixto & 31 & 39.7 & $(28.2-50.0)$ \\
& & & \\
\hline \hline
\end{tabular}

La conducta más frecuente manifestada por los pacientes no adherentes del estudio es el incumplimiento involuntario con un $93.6 \%$ de sujetos cometiendo este tipo de incumplimiento; seguido por el incumplimiento voluntario con un $46.2 \%$ de sujetos; y un $39.7 \%$ de sujetos no adherentes muestra un incumplimiento mixto (voluntario e involuntario). 


\subsection{Análisis Bivariado}

Los resultados de las inferencias bivariadas entre la variable dependiente adherencia y las variables independientes de la fase I del estudio agrupados en los cinco grupos o dimensiones propuestas por la $\mathrm{OMS}^{90}$, se presentan a continuación.

\subsubsection{Factores Relacionados con las Características Socioeconómicas}

\subsubsection{Variables Cualitativas}

El resultado del análisis estadístico muestra no existir relación significativa entre las variables cualitativas sexo $(\mathrm{p}=0.839)$, raza/etnia $(\mathrm{p}=0.362)$, lugar de nacimiento $(\mathrm{p}=0.752)$, nivel de alfabetización $(\mathrm{p}=0.913)$, nivel de educación, $(\mathrm{p}=0.951)$, necesidad de intérprete $(\mathrm{p}=0.713)$, área geográfica de residencia $(\mathrm{p}=0.394)$, situación laboral actual $(p=0.951)$, nivel de ingresos $(p=0.182)$, y dificultades para llegar a la farmacia $(\mathrm{p}=0.099)$, con la variable dependiente adherencia.

Las variables cualitativas estadísticamente significativas de las características socioeconómicas asociadas a adherencia se recogen a continuación (Tabla 10). 
Tabla 10. Factores Relacionados con las Características Socioeconómicas Estadísticamente Significativas de la Fase I del Estudio (Variables Cualitativas).

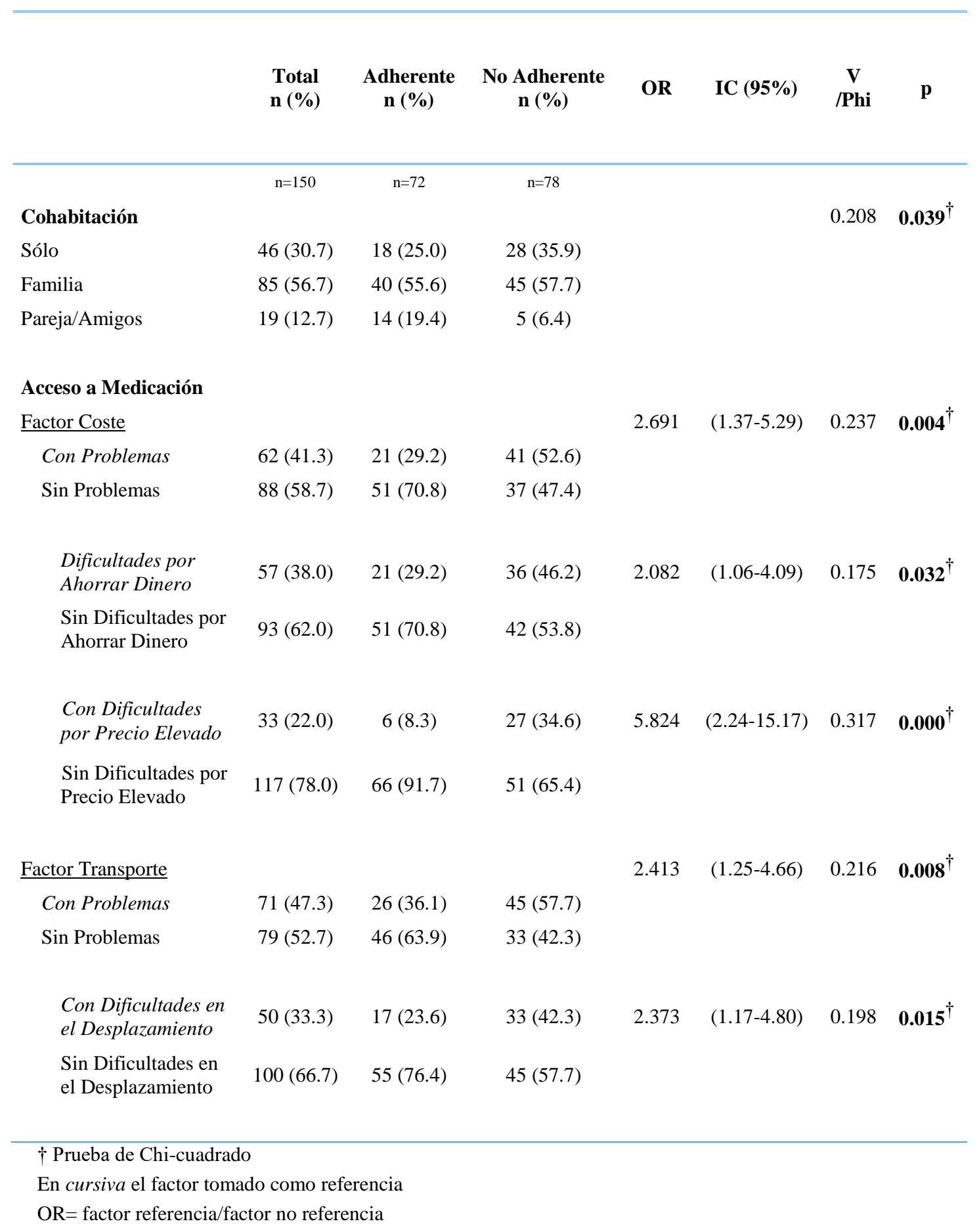


La variable cohabitación presenta una asociación significativa con el incumplimiento $(\mathrm{p}=0.039)$, con una dependencia media $(\mathrm{V}=0.208)$. El análisis de los residuos corregidos demuestra una relación inversa y estadísticamente significativa para la categoría vivir en pareja/amigos (ARij= -2.4) dado que hay más sujetos adherentes al régimen farmacológico que los esperados, mientras que las categorías vivir sólo y vivir en familia no resultan significativas. Analizando estos valores, tanto en sus magnitudes como en sus rangos, se establece el patrón: "Vivir en pareja o con amigos tiene una relación favorable sobre la adherencia al tratamiento farmacológico. De este modo, se evidencia que existe una relación y del tipo que es esta”.

El estudio estadístico de las variables de acceso a la medicación comprende el factor coste y factor transporte. Las dificultades de los pacientes para acceder a la medicación debidas al factor coste están asociadas significativamente $(\mathrm{p}=0.004)$ con el incumplimiento al tratamiento farmacológico, con una dependencia media directa $(\phi=$ 0.237); los pacientes que encuentran problemas relacionados con el coste de la medicación presentan una probabilidad 2.69 veces mayor $(\mathrm{OR}=2.691)$ de incumplir el tratamiento farmacológico. Entre estos problemas, las dificultades de los pacientes por el precio elevado de la medicación muestran una asociación significativa con el incumplimiento del régimen farmacológico $(\mathrm{p}=0.000)$ con una dependencia alta directa $(\phi=0.317)$, y una probabilidad de incumplimiento 5.82 veces mayor $(\mathrm{OR}=5.824)$ de que se produzca el evento. Respecto al hecho de estar sin medicación por ahorrar dinero y gastarlo en otras necesidades básicas, está asociado significativamente con el incumplimiento del tratamiento farmacológico $(\mathrm{p}=0.032)$, con una dependencia media directa $(\phi=0.175)$, y una probabilidad 2.08 veces mayor de que se produzca el suceso de incumplimiento $(\mathrm{OR}=2.082)$. 
Respecto a los problemas de acceso a medicación debidos al factor transporte que presentan los pacientes para tener acceso a su medicación, mantienen una asociación significativa $(\mathrm{p}=0.008)$ con el incumplimiento al régimen farmacológico con una dependencia media directa $(\phi=0.216)$. Los pacientes que encuentran dificultades en el desplazamiento para acceder a su medicación presentan una probabilidad 2.41 veces mayor de incumplir el tratamiento farmacológico $(\mathrm{OR}=2.413)$. En adición, las dificultades para recoger las medicinas resultan también estar asociados significativamente $(\mathrm{p}=0.015)$ con el incumplimiento del régimen con una dependencia media directa $(\phi=0.198)$, y una probabilidad de incumplimiento 2.37 veces mayor $(\mathrm{OR}=2.373)$ de que se produzca el evento.

Como conclusión, del análisis de las variables cualitativas relacionadas con los factores socioeconómicos, tanto en sus magnitudes como en sus rangos, se establece el patrón: "Las dificultades relacionadas con el factor coste y el factor transporte presentan una relación desfavorable sobre la adherencia. De este modo, se evidencia que existe una relación y del tipo que es esta".

\subsubsection{Variables Cuantitativas}

El análisis estadístico de las variables cuantitativas relacionadas con los factores socioeconómicos demuestra no existir relación significativa entre la variable edad $(\mathrm{p}=0.376)$ y la variable dependiente adherencia. Por tanto, no existe ninguna variable cuantitativa estadísticamente significativa de las características socioeconómicas asociada a adherencia en la fase I del estudio. 


\subsubsection{Factores Relacionados con el Sistema o el Equipo de Asistencia Sanitaria}

\subsubsection{Variables Cualitativas}

El resultado del análisis estadístico bivariado muestra no existir relación significativa entre las variables cualitativas centro de salud/clínica $(p=0.350)$, información general recibida $(\mathrm{p}=0.099)$, información apropiadamente explicada $(\mathrm{p}=0.275)$, información adicional sobre medicación $(\mathrm{p}=0.498)$, y satisfacción con la relación con los profesionales sanitarios $(p=0.121)$, con la variable dependiente adherencia.

Las inferencias bivariadas de las variables cualitativas estadísticamente significativas de los factores relacionados con el sistema o el equipo de asistencia sanitaria asociadas a adherencia se recogen en la Tabla 11.

Los resultados revelan una asociación estadísticamente significativa entre la percepción del paciente de no haber recibido información individualizada sobre su medicación y los posibles efectos secundarios con el incumplimiento ( $p=0.032$ ), con una dependencia media directa $(\phi=0.175)$. Los pacientes que percibieron no recibir información individualizada sobre su medicación y sus posibles efectos secundarios presentan una probabilidad 3.40 veces mayor de incumplir el tratamiento $(\mathrm{OR}=3.400)$. Analizando estos valores, tanto en sus magnitudes como en sus rangos, se establece el patrón: "La percepción del paciente de no haber recibido información individualizada sobre su medicación y sus posibles efectos secundarios tiene relación desfavorable sobre la adherencia al tratamiento. De este modo, se evidencia que existe una relación y del tipo que es esta". 
Tabla 11. Factores Relacionados con el Sistema o el Equipo de Asistencia Sanitaria Estadísticamente Significativos de la Fase I del Estudio (Variables Cualitativas).

\begin{tabular}{|c|c|c|c|c|c|c|c|}
\hline & $\begin{array}{l}\text { Total } \\
\text { n }(\%)\end{array}$ & $\begin{array}{c}\text { Adheren } \\
\text { te } \\
\text { n }(\%)\end{array}$ & $\begin{array}{c}\text { No Adherente } \\
\text { n (\%) }\end{array}$ & OR & IC $(95 \%)$ & V /Phi & $\mathbf{p}$ \\
\hline & $\mathrm{n}=150$ & $\mathrm{n}=72$ & $\mathrm{n}=78$ & & & & \\
\hline $\begin{array}{l}\text { Información Individualizada } \\
\text { sobre Medicación }\end{array}$ & & & & 3.400 & $(1.05-10.97)$ & 0.175 & $0.032^{\dagger}$ \\
\hline $\begin{array}{l}\text { Sin Información } \\
\text { Individualizada }\end{array}$ & $17(11.3)$ & $4(5.6)$ & $13(16.7)$ & & & & \\
\hline $\begin{array}{l}\text { Con Información } \\
\text { Individualizada }\end{array}$ & $133(88.7)$ & $68(94.4)$ & $65(83.3)$ & & & & \\
\hline Frecuencia de Consulta & & & & & & 0.287 & $0.008^{\star}$ \\
\hline Quincenal & $14(9.3)$ & $11(15.3)$ & $3(3.8)$ & & & & \\
\hline Mensual & $42(28.0)$ & $25(34.7)$ & $17(21.8)$ & & & & \\
\hline Trimestral & $88(58.7)$ & $35(48.6)$ & $53(67.9)$ & & & & \\
\hline Semestral & $5(3.3)$ & $1(1.4)$ & $4(5.1)$ & & & & \\
\hline Anual & $1(0.7)$ & 0 & $1(1.3)$ & & & & \\
\hline \multicolumn{8}{|l|}{$\dagger$ Prueba de Chi-cuadrado } \\
\hline \multicolumn{8}{|l|}{ - Test de Fisher. } \\
\hline \multicolumn{8}{|c|}{ En cursiva el factor tomado como referencia } \\
\hline $\mathrm{OR}=$ factor referencia/factor & o referencia & & & & & & \\
\hline
\end{tabular}

La variable frecuencia de consulta presenta una relación estadísticamente significativa con el incumplimiento $(\mathrm{p}=0.008)$, con una dependencia relativamente alta $(\mathrm{V}=0.287)$. El análisis de los residuos corregidos muestra una relación significativa para las categorías quincenal (ARij= -2.4), mensual (ARij= -1.9), y trimestral (ARij= 2.4), mientras que las categorías semestral y anual no resultan significativas. La categoría quincenal y mensual mantienen una relación inversa con el incumplimiento, dado que hay más sujetos adherentes que los esperados, mientras que la categoría trimestral mantiene una relación directa al incumplimiento al existir menos sujetos adherentes que los esperados. Analizando estos valores, tanto en sus magnitudes como en sus rangos, se establece el patrón: "Una frecuencia de consulta trimestral tiene relación desfavorable sobre la adherencia al tratamiento farmacológico, mientras que la frecuencia de consulta quincenal y mensual tiene relación favorable. De este modo, se evidencia que existe una relación y del tipo que es esta”. 


\subsubsection{Variables Cuantitativas}

El resultado del análisis estadístico de las variables cuantitativas demuestra no existir diferencias significativas en la variable número de lugares de recogida de la medicación entre los sujetos del grupo no adherente y los del grupo adherente $(\mathrm{p}=0.435)$. Las diferencias estadísticamente significativas entre las variables cuantitativas de los sujetos del grupo no adherente y adherente relacionadas con los factores relacionados con el sistema o el equipo de asistencia sanitaria se recogen a continuación (Tabla 12).

Tabla 12. Diferencias Estadísticamente Significativas de los Factores Relacionados con el Sistema o el Equipo de Asistencia Sanitaria de la Fase I del Estudio (Variables Cuantitativas).

\begin{tabular}{ccccccccc}
\hline & Grupo & $\begin{array}{c}\text { Frecuencia } \\
(\mathbf{n})\end{array}$ & $\begin{array}{c}\text { Media } \pm \\
\text { DE }\end{array}$ & $\begin{array}{c}\text { Rango } \\
\text { Promedio }\end{array}$ & $\begin{array}{c}\text { Suma de } \\
\text { Rangos }\end{array}$ & Mínimo & Máximo & p \\
\hline $\begin{array}{c}\text { Relación de } \\
\text { Comunicación }\end{array}$ & $\begin{array}{c}\text { Adherente } \\
\text { No }\end{array}$ & 72 & $9.69 \pm 0.91$ & 81.57 & 5873.0 & 8 & 10 & \\
& $\begin{array}{c}\text { Adherente } \\
\text { Adherente }\end{array}$ & 72 & $9.24 \pm 1.48$ & 69.90 & 5452.0 & 3 & 10 & $\mathbf{0 . 0 2 8}^{+}$ \\
Apoyo Social & $\begin{array}{c}\text { No } \\
\text { Adherente }\end{array}$ & 78 & $9.19 \pm 1.23$ & 68.38 & 5333.5 & 4 & 10 & \\
\hline \hline
\end{tabular}

+ Prueba U de Mann-Whitney 
Los resultados del análisis revelan diferencias estadísticamente significativas de las variables relación de comunicación $(\mathrm{p}=0.028)$ y apoyo social $(\mathrm{p}=0.012)$ entre los sujetos del grupo no adherente y los del grupo adherente. Se observa que la calificación media otorgada por los pacientes en la comunicación con los profesionales sanitarios del grupo de pacientes adherente es ligeramente superior $(9.69 \pm 0.91)$ a la del grupo no adherente $(9.24 \pm 1.48)$. Asimismo, la calificación media otorgada al apoyo social recibido por los pacientes del estudio por parte del personal sanitario es ligeramente superior en el grupo adherente $(9.53 \pm 1.18)$ que en el grupo no adherente $(9.19 \pm 1.23)$.

\subsubsection{Factores Relacionados con la Enfermedad}

\subsubsection{Variables Cualitativas}

Los resultados del análisis estadístico bivariado de los factores relacionados con la enfermedad establecen que no existe relación estadísticamente significativa entre las variables cualitativas índice de masa corporal $(p=0.837)$, actividad física $(p=0.474)$, consumo de tabaco $(\mathrm{p}=0.694)$, consumo de alcohol $(\mathrm{p}=0.316)$, clase de bebida $(\mathrm{p}=0.672)$, y consumo de drogas $(\mathrm{p}=0.722)$, con la variable dependiente adherencia.

Las variables cualitativas estadísticamente significativas de los factores relacionadas con la enfermedad se muestran a continuación (Tabla 13). 
Tabla 13. Factores Relacionados con la Enfermedad Estadísticamente Significativos Asociados a Adherencia de la Fase I del Estudio (Variables Cualitativas).

\begin{tabular}{|c|c|c|c|c|c|c|c|}
\hline & $\begin{array}{l}\text { Total } \\
\text { n }(\%)\end{array}$ & $\begin{array}{l}\text { Adherente } \\
\text { n (\%) }\end{array}$ & $\begin{array}{c}\text { No Adherente } \\
\text { n (\%) }\end{array}$ & OR & IC (95\%) & V /Phi & $\mathbf{p}$ \\
\hline & $\mathrm{n}=150$ & $\mathrm{n}=72$ & $\mathrm{n}=78$ & & & & \\
\hline $\begin{array}{l}\text { Grupo de Riesgo } \\
\text { Clínico }\end{array}$ & & & & & & 0.388 & $0.000^{\dagger}$ \\
\hline G1 & $21(14.0)$ & $16(22.2)$ & $5(6.4)$ & & & & \\
\hline G2 & $110(73.3)$ & $40(55.6)$ & 70 (89.7) & & & & \\
\hline G3 & $19(12.7)$ & $16(22.2)$ & $3(3.8)$ & & & & \\
\hline
\end{tabular}

El resultado del análisis bivariado de los factores relacionados con la enfermedad de los pacientes revela una asociación significativa $(\mathrm{p}=0.000)$ entre la variable grupo de riesgo clínico y el incumplimiento, con una dependencia alta $(\mathrm{V}=0.388)$. El análisis de los residuos corregidos establece una relación estadísticamente significativa para todas las categorías de la variable: $G 1$ (ARij= -2.8), G2 (ARij= 4.7), y G3 (ARij= -3.4). Los grupos de riesgo clínico $G 1$ y $G 3$ resultan tener una relación inversa con el incumplimiento, dado que hay más sujetos adherentes al régimen farmacológico que los esperados, mientras que la relación del grupo $G 2$ con el incumplimiento es directa, al existir menos sujetos adherentes al tratamiento que los esperados. Analizando estos valores, tanto en sus magnitudes como en sus rangos, se establece el patrón: "Los grupos de riesgo clínico G1 y G3 tienen una relación favorable sobre la adherencia al tratamiento farmacológico, mientras que el grupo de riesgo G2 tiene una relación desfavorable. De este modo, se evidencia que existe una relación y del tipo que es esta”. 


\subsubsection{Variables Cuantitativas}

El resultado del análisis estadístico de las variables cuantitativas establece no existir diferencias significativas entre las variables de las categorías de las condiciones crónicas de enfermedades sanguíneas y del aparato circulatorio $(p=0.361)$; enfermedades del aparato respiratorio $(\mathrm{p}=0.873)$; enfermedades del aparato digestivo $(p=0.179)$; enfermedades nerviosas y mental-conductuales $(p=0.622)$; enfermedades endocrinas-nutricionales-metabólicas $(p=0.060)$; enfermedades del sistema renal, genitourinario, reproductor, y enfermedad congénita $(p=0.748)$; enfermedades músculo-esqueléticas $(\mathrm{p}=0.200)$; enfermedades infecciosas, cáncer, órganos sensoriales, y de la piel $(\mathrm{p}=0.387)$; y número total de condiciones crónicas ( $\mathrm{p}=0.072$ ) entre los sujetos del grupo adherente y los del grupo no adherente. Por tanto, no existió ninguna variable cuantitativa estadísticamente significativa asociada a adherencia relacionada con la enfermedad de los pacientes en la fase I del estudio.

\subsubsection{Factores Relacionados con el Tratamiento}

\subsubsection{Variables Cualitativas}

El resultado del análisis estadístico bivariado demuestra no existir relación significativa entre la variable cualitativa dieta $(p=0.116)$, con la variable dependiente adherencia. Las variables cualitativas estadísticamente significativas asociadas a adherencia de los factores relacionados con el tratamiento se recogen a continuación (Tabla 14). 
Tabla 14. Factores Relacionados con el Tratamiento Estadísticamente Significativos en la Fase I del Estudio (Variables Cualitativas).

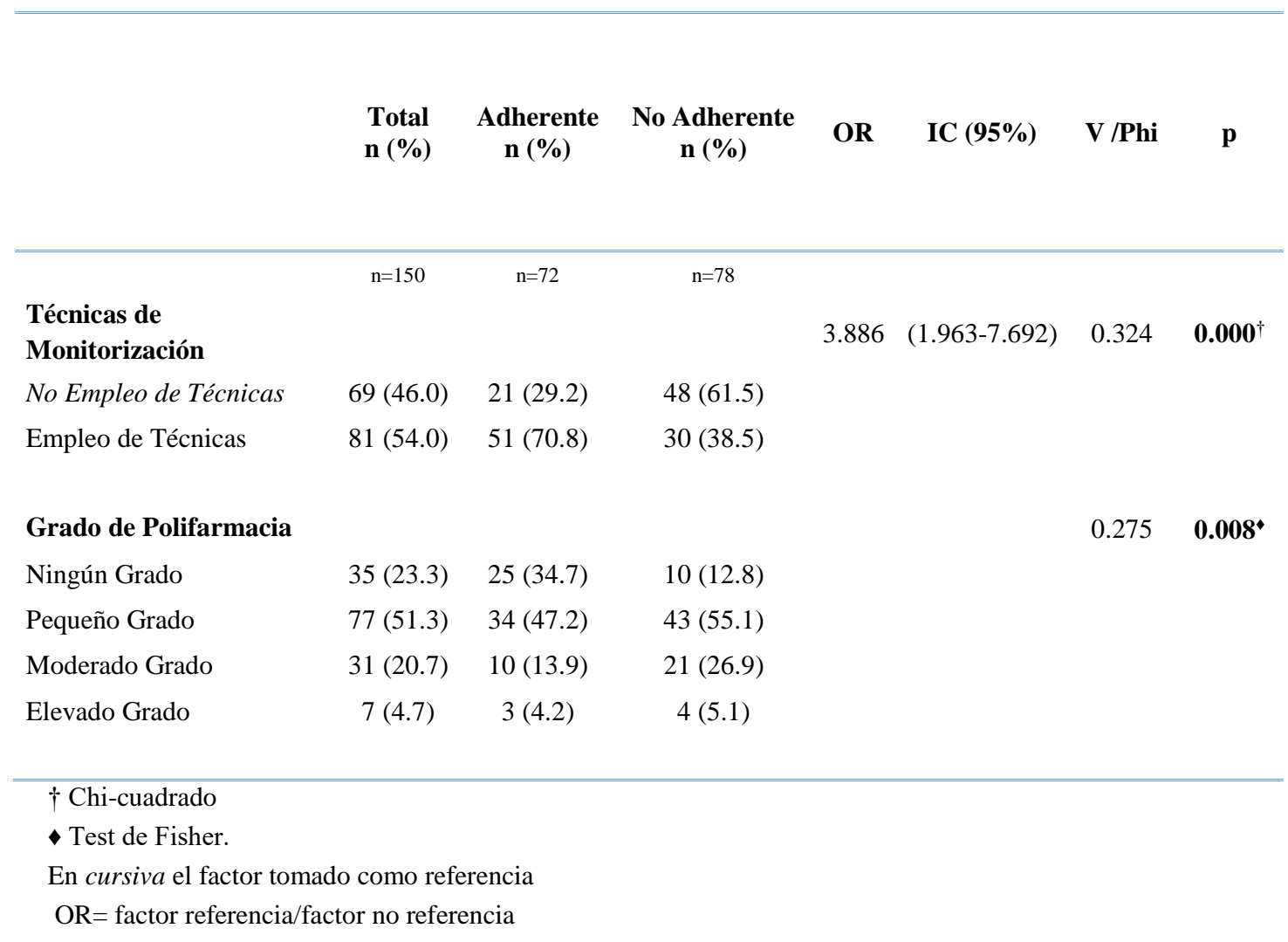

El resultado del análisis bivariado de los factores relacionados con el tratamiento de los pacientes establece una asociación significativa $(\mathrm{p}=0.000)$ entre la variable técnicas de monitorización y el incumplimiento, con una dependencia alta, proporcionalmente directa $(\phi=0.324)$. Los pacientes que no practican técnicas de monitorización fuera del entorno clínico (toma de la presión arterial y/o medición de la glucosa), presentan 3.89 veces mayor de probabilidad incumplir el tratamiento farmacológico $(\mathrm{OR}=3.886)$. Analizando estos valores, tanto en sus magnitudes como en sus rangos, se establece el patrón: "Los pacientes que no practican técnicas de monitorización fuera del entorno clínico tienen una relación desfavorable sobre la adherencia al tratamiento farmacológico. De este modo, se evidencia que existe una relación y del tipo que es esta”. 
Los resultados del análisis estadístico de la variable grado de polifarmacia revelan una asociación significativa $(\mathrm{p}=0.008)$ con una dependencia alta $(\mathrm{V}=0.275)$. El análisis de los residuos corregidos demuestra una relación significativa para la categoría sin polifarmacia (ARij= -3.2), y para la categoría moderada polifarmacia $($ ARij= 2.0), mientras que las categorías pequeña polifarmacia y gran polifarmacia no resultan ser significativas. La categoría sin polifarmacia resulta tener una relación inversa con el incumplimiento, dado que hay más sujetos adherentes al régimen de medicación que los esperados. La categoría moderada polifarmacia establece una relación directa con el incumplimiento, dado que hay menos sujetos adherentes al régimen de medicación que los esperados. Analizando estos valores, tanto en magnitudes como en rangos, se establece el patrón: "El tratamiento sin ningún grado de polifarmacia tiene relación favorable sobre la adherencia al tratamiento, mientras que un tratamiento con un grado moderado de polifarmacia tiene una relación desfavorable. De este modo, se evidencia que existe una relación y del tipo que es esta".

\subsubsection{Variables Cuantitativas}

El resultado del análisis estadístico de las variables cuantitativas establece no existir diferencias significativas entre las variables número de inyecciones/día usadas ( $\mathrm{p}=0.488)$ y número de inhaladores/día usados $(\mathrm{p}=0.493)$ entre los sujetos del grupo adherente y los del grupo no adherente (Tabla 15). 
Tabla 15. Diferencias Estadísticamente Significativas de los Factores Relacionados con el Tratamiento de la Fase I del Estudio (Variables Cuantitativas).

\begin{tabular}{|c|c|c|c|c|c|c|c|c|}
\hline & Grupo & $\begin{array}{c}\text { Frecuencia } \\
\text { (n) }\end{array}$ & Media \pm DE & $\begin{array}{c}\text { Rango } \\
\text { Promedio }\end{array}$ & $\begin{array}{c}\text { Suma de } \\
\text { Rangos }\end{array}$ & Mínimo & Máximo & $\mathbf{p}$ \\
\hline \multirow{2}{*}{$\begin{array}{c}\text { Número de } \\
\text { Prescripciones }\end{array}$} & Adherente & 72 & $3.88 \pm 2.94$ & 64.75 & 4662.0 & 1 & 20 & \multirow{2}{*}{$\mathrm{0.003}^{+}$} \\
\hline & $\begin{array}{c}\text { No } \\
\text { Adherente }\end{array}$ & 78 & $4.72 \pm 2.14$ & 85.42 & 6663.00 & 1 & 10 & \\
\hline \multirow{2}{*}{$\begin{array}{c}\text { Número de } \\
\text { Pastillas }\end{array}$} & Adherente & 72 & $4.11 \pm 3.74$ & 61.23 & 4408.5 & 0 & 24 & \multirow{2}{*}{$0.000^{+}$} \\
\hline & $\begin{array}{c}\text { No } \\
\text { Adherente }\end{array}$ & 78 & $5.69 \pm 3.33$ & 88.67 & 6916.5 & 0 & 18 & \\
\hline \multirow{3}{*}{ Otras Formas } & Adherente & 72 & $0.07 \pm 0.35$ & 71.74 & 5165.5 & 0 & 2 & \multirow{3}{*}{$0.044^{+}$} \\
\hline & & & & & & & & \\
\hline & $\begin{array}{c}\text { No } \\
\text { Adherente }\end{array}$ & 78 & $0.21 \pm 0.74$ & 78.97 & 6159.5 & 1 & 6 & \\
\hline
\end{tabular}

Los resultados demuestran diferencias estadísticamente significativas de las variables número de prescripciones $(\mathrm{p}=0.003)$, número de pastillas/día $(\mathrm{p}=0.000)$, y número de otras formas medicamentosas usadas (colirios, enemas, y medicamentos tópicos) entre los sujetos del grupo no adherente y los del grupo adherente. Se aprecia que el número medio de prescripciones del grupo no adherente $(4.72 \pm 2.14)$ es superior al número medio de prescripciones del grupo adherente (3.88 \pm 2.94$)$. Además, el análisis señala que la media del número total de pastillas/día incluidas en el régimen farmacológico del grupo no adherente $(5.69 \pm 3.33)$ es visiblemente superior a la media del número total de pastillas/día del grupo adherente (4.11 \$3.74). Por último, el número medio de otras formas medicamentosas usadas en el régimen del grupo no adherente $(0.21 \pm 0.074)$ se muestra superior al número medio de otras formas medicamentosas prescritas en el grupo adherente $(0.07 \pm 0.35)$. 


\subsubsection{Factores Relacionados con el Paciente}

\subsubsection{Variables Cualitativas}

El análisis estadístico bivariado de los factores relacionados con el paciente establece no existir relación estadísticamente significativa entre las variables dificultades sensoriales $(p=0.265)$, índice de Barthel $(p=0.149)$, conocimiento de la razón de la toma de cada medicamento $(\mathrm{p}=0.369)$, apoyo familiar recibido $(\mathrm{p}=0.291)$, y la percepción de los pacientes de necesitar ayuda para el control de la medicación $(\mathrm{p}=0.461)$, con la variable dependiente adherencia. Las variables cualitativas estadísticamente significativas asociadas a adherencia se recogen en la Tabla 16.

El resultado del análisis bivariado de la variable conocimiento sobre las condiciones padecidas y el tratamiento farmacológico muestra un grado de asociación estadísticamente significativo con el incumplimiento $(\mathrm{p}=0.018)$ con una dependencia media directa $(\phi=0.203)$. Los pacientes con un conocimiento incompleto sobre las condiciones padecidas y su tratamiento farmacológico presentan una probabilidad 9.26 veces mayor de incumplir el tratamiento farmacológico $(\mathrm{OR}=9.261)$. Además, desconocer el número de medicamentos y posología está asociado significativamente con el incumplimiento del régimen farmacológico $(\mathrm{p}=0.014)$ con una dependencia media directa $(\phi=0.213)$, sin poder calcular el correspondiente OR debido a la inexistencia de individuos en el grupo adherente sin dichos conocimientos $(\mathrm{n}=0)$. Analizando estos valores, tanto en sus magnitudes como en sus rangos, se establece el patrón: "Los pacientes que disponen de un conocimiento incompleto sobre las condiciones padecidas y su régimen farmacológico tienen una relación desfavorable sobre la adherencia al tratamiento farmacológico. De este modo, se evidencia que existe una relación y del tipo que es esta". 
Tabla 16. Factores Relacionados con el Paciente Estadísticamente Significativos en la Fase I del Estudio (Variables Cualitativas).

\begin{tabular}{|c|c|c|c|c|c|c|c|}
\hline & $\begin{array}{l}\text { Total } \\
\text { n }(\%)\end{array}$ & $\begin{array}{l}\text { Adherente } \\
\text { n (\%) }\end{array}$ & $\begin{array}{c}\text { No Adherente } \\
\text { n }(\%)\end{array}$ & OR & IC $(95 \%)$ & $\begin{array}{c}\text { V de } \\
\text { Cramer/ } \\
\text { Phi }\end{array}$ & $\mathbf{p}$ \\
\hline & $\mathrm{n}=150$ & $\mathrm{n}=72$ & $\mathrm{n}=78$ & & & & \\
\hline $\begin{array}{l}\text { Conocimiento Sobre } \\
\text { Condiciones Padecidas y } \\
\text { Tratamiento }\end{array}$ & & & & 9.261 & $(1.14-75.05)$ & 0.203 & $0.018^{\star}$ \\
\hline Conocimiento Incompleto & $10(6.7)$ & $1(1.4)$ & $9(11.5)$ & & & & \\
\hline Conocimiento Completo & $140(93.3)$ & $71(47.3)$ & $69(46.0)$ & & & & \\
\hline $\begin{array}{l}\text { Desconocer Número de } \\
\text { Medicamentos y Posología }\end{array}$ & $7(4.7)$ & $0(0)$ & $7(9.0)$ & -- & -- & 0.213 & $0.014^{\star}$ \\
\hline $\begin{array}{l}\text { Conocer Número de } \\
\text { Medicamentos y Posología }\end{array}$ & $143(95.3)$ & $72(100.0)$ & $71(91.0)$ & & & & \\
\hline $\begin{array}{l}\text { Persona Responsable de la } \\
\text { Medicación }\end{array}$ & & & & 2.898 & $(1.12-7.53)$ & 0.184 & $\mathbf{0 . 0 2 4} 4^{\dagger}$ \\
\hline El Mismo Paciente & $127(84.7)$ & $56(77.8)$ & $71(91.0)$ & & & & \\
\hline Miembro Familiar & $23(15.3)$ & $16(22.2)$ & $7(9.0)$ & & & & \\
\hline $\begin{array}{l}\text { Métodos/Estrategias Usadas } \\
\text { para Recordar la Medicación }\end{array}$ & & & & 6.857 & $(2.90-16.19)$ & 0.385 & $\mathbf{0 . 0 0 0}^{\dagger}$ \\
\hline Ningún Método & $44(29.3)$ & $8(11.1)$ & $36(46.2)$ & & & & \\
\hline $\begin{array}{l}\text { Utilización de } \\
\text { Métodos/Estrategias }\end{array}$ & $106(70.7)$ & $64(88.9)$ & $42(53.8)$ & & & & \\
\hline $\begin{array}{l}\text { Estrategias Específicas } \\
\text { Usadas }\end{array}$ & $\mathrm{n}=106$ & $\mathrm{n}=64$ & $\mathrm{n}=42$ & & & 0.413 & $\mathbf{0 . 0 0 1}^{\dagger}$ \\
\hline Instrumentos de Organización & $36(34.0)$ & $18(28.1)$ & $18(42.9)$ & & & & \\
\hline Ayuda por Otra Persona & $13(12.3)$ & $11(17.2)$ & $2(4.8)$ & & & & \\
\hline Asociación con Actividades & $25(23.6)$ & $22(34.4)$ & $3(7.1)$ & & & & \\
\hline $\begin{array}{l}\text { Asociación con Tomar } \\
\text { Alimentos }\end{array}$ & $18(17.0)$ & $7(10.9)$ & $11(26.2)$ & & & & \\
\hline Otras Estrategias & $14(13.2)$ & $6(9.4)$ & $8(19.0)$ & & & & \\
\hline \multicolumn{8}{|l|}{$\uparrow$ Chi-cuadrado } \\
\hline \multicolumn{8}{|c|}{ - Test de Fisher. En cursiva el factor tomado como referencia. } \\
\hline \multicolumn{8}{|c|}{$\mathrm{OR}=$ factor referencia/factor no referencia } \\
\hline
\end{tabular}


La variable persona responsable de la medicación presenta una asociación estadísticamente significativa con el incumplimiento $(\mathrm{p}=0.024)$ con una dependencia media $(\phi=0.184)$. Los pacientes cuyo control y responsabilidad de la medicación la delegan en ellos mismos, presentan una relación directa con el incumplimiento, resultando en una probabilidad 2.90 veces mayor de incumplir el tratamiento $(\mathrm{OR}=$ 2.898). Analizando estos valores, tanto en sus magnitudes como en sus rangos, se establece el patrón: "Los pacientes que delegan el control y la responsabilidad de la medicación en el mismo paciente, tienen una relación desfavorable sobre la adherencia al tratamiento farmacológico. De este modo, se evidencia que existe una relación y del tipo que es esta".

La utilización de una estrategia o método para recordar la toma de medicación establece una relación estadísticamente significativa asociada a la adherencia $(\mathrm{p}=0.000)$. El análisis estadístico señala que existe una dependencia media proporcionalmente directa entre no usar una estrategia para recordar la toma de medicación y el incumplimiento $(\phi=0.184)$. Aquellos pacientes que no usan una estrategia para recordar la toma de medicación presentan una probabilidad 6.86 veces mayor de incumplimiento $(\mathrm{OR}=6.857)$. Analizando estos valores, tanto en sus magnitudes como en sus rangos, se establece el patrón: "No utilizar una estrategia o método para recordar la toma de medicación tiene una relación desfavorable sobre la adherencia al tratamiento farmacológico. De este modo, se evidencia que existe una relación y del tipo que es esta".

El análisis estadístico de las distintas estrategias específicas que utilizan los individuos del estudio para recordar la toma de medicación revela una asociación significativa $(\mathrm{p}=0.001)$ con el incumplimiento con una dependencia alta $(\mathrm{V}=0.413)$. El análisis de los residuos corregidos muestra una relación significativa para la categoría ayuda por otra persona (ARij= -2.0) y la categoría asociación con actividades cotidianas de la vida diaria (ARij= -3.2), mientras que las categorías asociación con tomar alimentos, instrumentos de organización, y otros métodos no resultan ser significativas. 
Las categorías, ayuda por otra persona y asociación con actividades cotidianas de la vida diaria, presentan una relación inversa con el incumplimiento, dado que hay más sujetos adherentes al régimen farmacológico que los esperados. Analizando estos valores, tanto en sus magnitudes como en sus rangos, se establece el patrón: "La utilización de una estrategia o método para recordar la toma de medicación tiene relación favorable sobre la adherencia al tratamiento farmacológico, siendo las estrategias ayuda por otra persona y asociación de la medicación con la realización de actividades cotidianas de la vida diaria las más favorables para cumplir el tratamiento farmacológico. De este modo, se evidencia que existe una relación y del tipo que es esta".

\subsubsection{Variables Cuantitativas}

El resultado del análisis estadístico de las variables cuantitativas de los factores relacionados con el paciente establece no existir diferencias significativas entre la variable auto-valoración del Estado de Salud $(\mathrm{p}=0.646)$, entre los sujetos pertenecientes al grupo no adherente y los del grupo adherente. Por tanto, no existe ninguna variable cuantitativa estadísticamente significativa asociada a adherencia relacionada con el paciente en la fase I del estudio. 


\subsection{Análisis de Regresión Logística}

Se ha procedido a utilizar la regresión logística binaria para determinar las relaciones de dependencia entre las variables y desarrollar el modelo de variables predictoras de incumplimiento al tratamiento farmacológico.

La construcción del modelo incluye todas las variables del estudio que han resultado estadísticamente significativas en la fase I del estudio (nivel de confianza del 95\%) en el análisis bivariado. Se ha excluido a aquellas variables que no han sido analizadas para todos los sujetos de la muestra. El modelo incluye 15 variables independientes, respetando que la ratio de sujetos para cada variable independiente sea inferior a 5:1 y de 10 observaciones por cada variable independiente.

Se ha procedido a la identificación de las variables que pueden presentar multicolinealidad (tolerancia $<0.1$ y FIV $>10$ ), mediante el diagnóstico de colinealidad por SPSS. Ninguna variable independiente ha demostrado estar afectada por este fenómeno, por lo que no ha sido necesario omitir ninguna variable.

Las 15 variables independientes finales incluidas en el análisis de regresión son:

- Factores Socioeconómicos: cohabitación, dificultades para ahorrar dinero, dificultades por precio elevado, dificultades medio de transporte, relación de comunicación con los profesionales sanitarios, y apoyo social recibido.

- Factores Relacionados con el Sistema o el Equipo de Asistencia Sanitaria: información individualizada sobre medicación y efectos secundarios.

- Factores Relacionados con las Enfermedad: grupo de riesgo clínico. 
- Factores Relacionados con el Tratamiento: técnicas de monitorización, grado de polifarmacia del tratamiento, número de prescripciones, número de pastillas, y otras formas medicamentosas usadas.

- Factores Relacionados con el Paciente: persona responsable de la toma de medicación, y utilización de método/estrategia para recordar la toma de medicación.

Se utiliza el estadístico Wald como criterio de decisión de mantenimiento o retirada de una variable modelo, con un punto de corte para la clasificación de 0.5 y un máximo de 20 iteraciones. Se sigue una modelización "forward" (por pasos hacia adelante), ajustada al modelo máximo con todas las variables, donde se introducen una a una las variables que significativas del test de Wald $(\mathrm{p} \leq 0.05)$, hasta llegar al modelo final, que es el que mejor ajusta. El análisis del modelo resulta en 5 pasos con un total de 6 iteraciones, y $\mathbf{5}$ variables predictoras de incumplimiento al tratamiento farmacológico: dificultades por ahorrar dinero, grupo de riesgo clínico, número de pastillas, técnicas de monitorización, y utilización de métodos/estrategias usados para la toma de medicación.

Se comprueba la validez del ajuste del modelo mediante la prueba de ómnibus sobre los coeficientes del modelo R cuadrado de Cox y Snell, R cuadrado de Nagelkerke como coeficiente de determinación, y la prueba de Hosmer y Lemeshow. La proporción de la variabilidad de "incumplimiento al tratamiento farmacológico" explicada por este modelo se encuentra entre un $\mathbf{3 9 . 9 \%}$ (R cuadrado de Cox) y un $\mathbf{5 3 . 2 \%}$ (R cuadrado de Nagelkerke) (Tabla 18). Los resultados de la bondad del ajuste, proporcionados por el estadístico Chi cuadrado del test de Hosmer y Lemeshow, resultan ser no significativos $(\mathrm{p}=0.182)$, lo que indica que no existe ninguna razón para pensar que los resultados predichos sean diferentes a los observados, y que el modelo puede considerarse adecuado. La significación estadística de la prueba ómnibus indica que, con las cinco variables independientes incluidas en el modelo, el ajuste mejora claramente de forma significativa $(\mathbf{p}=\mathbf{0 . 0 0 0})$. 
Con las 5 variables predictoras de incumplimiento al tratamiento farmacológico, el modelo tiene una capacidad de clasificar correctamente el 82.0\% de los casos analizados (Tabla 17). El modelo tiene una alta sensibilidad del $77.8 \%$ (clasifica correctamente a 56 sujetos de los 72 pacientes adherentes al tratamiento) y una alta especificidad del $85.9 \%$ (clasifica mejor a los sujetos no adherentes al tratamiento farmacológico, es decir, clasifica correctamente 67 sujetos de los 78 pacientes que incumplen el tratamiento).

Tabla 17. Clasificación del Modelo de Regresión Logística Binaria de la Fase I del Estudio.

\begin{tabular}{l|cccc}
\hline & & \multicolumn{2}{c}{ Frecuencias Pronosticadas } & \\
\cline { 3 - 4 } & & Adherente & No Adherente & Porcentaje (\%) \\
\multirow{3}{*}{ Frecuencias Observadas } & Adherente & 56 & 16 & 77.8 \\
& No Adherente & 11 & 67 & 85.9 \\
& & & & $\mathbf{8 2 . 0}$ \\
\hline
\end{tabular}

Los resultados del modelo predictor de adherencia al tratamiento farmacológico se recogen a continuación (Tabla 18). 
Tabla 18. Resultados del Modelo Final Predictor de Incumplimiento al Tratamiento Farmacológico de la Fase I del Estudio por el Método Forward de Wald.

\begin{tabular}{lccccccc}
\hline \hline & Coef. $\boldsymbol{\beta}$ & $\begin{array}{c}\text { Error } \\
\text { Est. }\end{array}$ & $\begin{array}{c}\mathbf{C h i}^{2} \\
\text { Wald }\end{array}$ & $\mathbf{P}$ & OR & \multicolumn{2}{c}{ IC 95\% para OR } \\
Inferior & Superior \\
\hline $\begin{array}{l}\text { Dificultades por Ahorrar Dinero } \\
\text { Grupo de Riesgo Clínico G3 }\end{array}$ & 1.650 & 0.608 & 7.361 & 0.007 & 5.207 & 1.581 & 17.151 \\
Grupo de Riego Clínico G1 & 2.797 & 1.381 & 4.101 & 0.043 & 16.392 & 1.094 & 245.565 \\
Grupo de Riego Clínico G2 & 3.950 & 1.149 & 11.829 & 0.001 & 51.952 & 5.469 & 493.492 \\
Número de Pastillas & 0.267 & 0.085 & 9.939 & 0.002 & 1.306 & 1.106 & 1.541 \\
Técnicas de Monitorización & 0.990 & 0.446 & 4.918 & 0.027 & 2.691 & 1.122 & 6.453 \\
Método/Estrategia para & 2.065 & 0.558 & 13.716 & 0.000 & 7.884 & 2.643 & 23.511 \\
Recordar la toma de Medicación & & & & & & & \\
Constante & -5.911 & 1.431 & 17.058 & 0.000 & 0.003 & & \\
\end{tabular}

OR: OR ajustada que corresponde al exponente $\beta\left(\mathrm{e}^{\text {coef. } \beta}\right)$

$2 \log$ verosimilitud (-2LL): $131.340 \quad \mathrm{R}^{2}$ de Nagelkerke: 0.532

$\mathrm{R}^{2}$ de Cox y Snell: $0.399 \quad$ Test de Hosmer y Lemeshow: 0.182

A continuación, se procede a hallar la ecuación de regresión logística para el incumplimiento, aunque como se ha explicado anteriormente, su finalidad es más orientativa que predictiva, aunque se ajuste a un buen modelo.

Ecuación de regresión logística para el incumplimiento al tratamiento farmacológico:

Logit $(\mathrm{p})=-5.911+1.650 *($ dificultades por ahorrar dinero $)+2.797 *($ grupo de riesgo G1 $)$ $+3.950 *$ (grupo de riesgo G2) + 0.267*(número de pastillas) + 0.990*(técnicas de monitorización) $+2.065^{*}$ (utilización de método/estrategia para recordar toma de medicación)

Siendo logit $(p)=\ln (p /(1-p)=\ln ($ odds $)$ 
En cuanto a la exactitud del modelo, se calcula el área bajo la curva (ROC), con un resultado de poder de discriminación del modelo construido del 87.9\% del máximo posible (Tabla 19). Se observa que el modelo es estadísticamente significativo $(\mathrm{p}=0.000)$, siendo la hipótesis nula la no discriminación, que en la curva ROC corresponde a los puntos que caen sobre la diagonal (Figura 41).

Tabla 19. Resultados del Grado de Exactitud del Modelo de la Fase I del Estudio.

\begin{tabular}{|c|c|c|c|}
\hline \multirow[b]{2}{*}{ Área } & \multirow[b]{2}{*}{ Sig. Asintótica (b) } & \multicolumn{2}{|c|}{$\begin{array}{l}\text { Intervalo de Confianza } \\
\text { Asintótico al } 95 \%\end{array}$} \\
\hline & & Límite Inferior & Límite Superior \\
\hline 0.879 & 0.000 & 0.826 & 0.933 \\
\hline
\end{tabular}

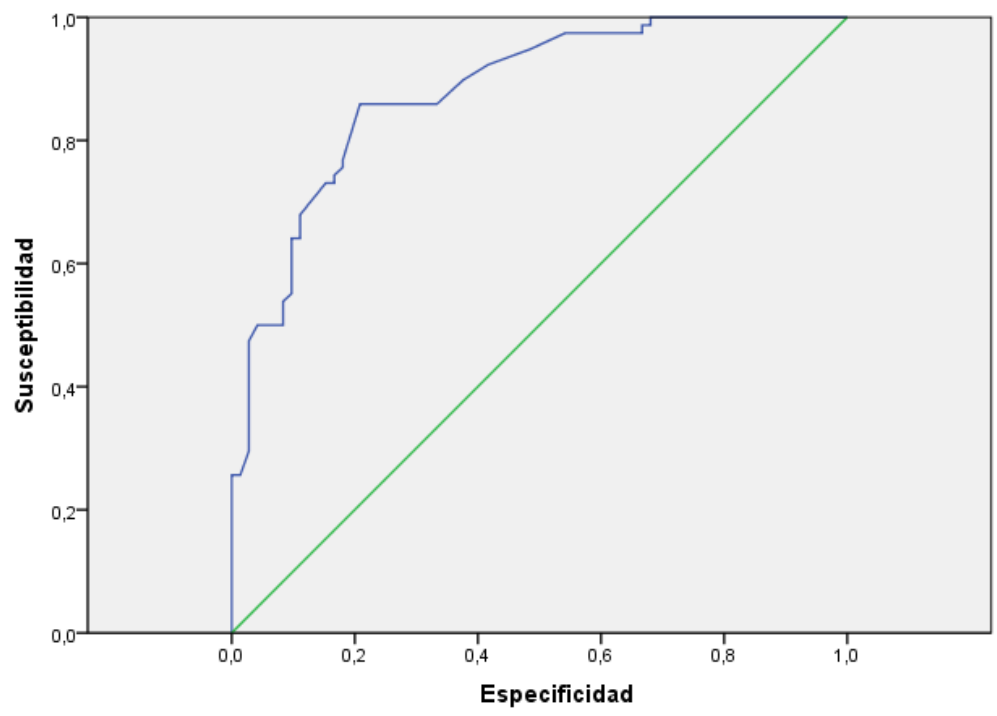

Figura 41. Área Bajo la Curva (ROC) del Modelo de la Fase I del Estudio. 
La Tabla 18 recoge todas las variables predictoras de incumplimiento al tratamiento estadísticamente significativas $(\mathrm{p} \leq 0.05)$. Los respectivos intervalos de confianza de las variables significativas no contienen el 1; por tanto, las variables son de interés para el modelo. Para las variables dicotómicas, la categoría de referencia corresponde con la misma variable elegida en las Tablas del análisis bivariado, mientras que para la categoría grupo de riesgo (grupo con tres categorías) la categoría de referencia elegida es grupo de riesgo $G 3$, que ha sido tomada como referencia dado su mayor significación con respecto a las otras dos categorías.

Al observar la Tabla 18 podemos concluir:

- La variable dificultades para ahorrar dinero, tiene una relación directa al incumplimiento del tratamiento, y los pacientes que ahorran dinero respecto a su medicación presenta una probabilidad 5.21 veces mayor de incumplir el tratamiento.

- Los pacientes del grupo de riesgo clínico G1, tienen una probabilidad 16.39 veces mayor de incumplir el tratamiento que los pacientes del grupo de riesgo clínico G3.

- Los pacientes del grupo de riesgo clínico G2, tienen una probabilidad 51.95 veces mayor de incumplir el tratamiento que los pacientes del grupo de riesgo clínico G3.

- La variable número de pastillas, tiene una relación directamente proporcional al incumplimiento del tratamiento, y aumenta la probabilidad 1.31 veces de incumplir éste, por cada pastilla/día incluida en el régimen de medicación.

- La variable empleo técnicas de monitorización, tiene una relación directa al incumplimiento del tratamiento, y los individuos que no practican técnicas de monitorización fuera del entorno clínico presentan una probabilidad 2.69 veces mayor de incumplir el tratamiento farmacológico. 
- La variable método/estrategia utilizado para recordar la toma de medicación, tiene una relación inversa al incumplimiento del tratamiento, y los individuos que no usan ningún método/estrategia para recordar la toma de medicación presentan una probabilidad 7.88 veces mayor de incumplir el tratamiento. 


\section{Fase II del Estudio}

Se presentan los resultados del análisis bivariado y análisis de regresión logística múltiple de la fase II del estudio. En esta fase II del estudio, todos los individuos del estudio se encontraban en su noveno mes de tratamiento después de haber inicializado su nuevo régimen de medicación.

\subsection{Análisis Descriptivo}

\subsubsection{Variables Independientes}

En la fase II del estudio no se recogió información de las variables independientes puesto que se consideró que esta información no tendría cambios sustanciales durante el período de seguimiento del estudio. Sin embargo, sí se procedió a la recogida de información de la variable dependiente, adherencia, con el propósito de realizar el análisis descriptivo y alcanzar los objetivos planteados en el estudio. 


\subsubsection{Variable Dependiente: Adherencia}

En la fase II del estudio, se procede a determinar la adherencia al tratamiento farmacológico de todos aquellos individuos clasificados como adherentes en la fase I $(n=72)$. Dichos sujetos se encuentran en su noveno mes de tratamiento después de haber iniciado su nuevo régimen farmacológico. Para alcanzar este propósito se realiza una segunda entrevista a dichos pacientes utilizando la misma herramienta de medida que en la fase I, el cuestionario autorreferido Morisky-Green-Levine ${ }^{178}$ (Anexo IV). Se decide no realizar ninguna entrevista a los individuos clasificados no adherentes de la fase $I$, puesto que dichos pacientes mantienen los criterios de paciente incumplidor.

A continuación, se muestran los resultados de adherencia al tratamiento farmacológico de los pacientes en la segunda entrevista del estudio ( $\mathrm{n}=72)$ (Tabla 20).

Tabla 20. Distribución de los Pacientes del Estudio en Función de su Adherencia al Tratamiento Farmacológico según el Cuestionario Morisky-Green-Levine en Fase II del Estudio (n=72).
Frecuencia (n)
Porcentaje (\%)
IC $(95 \%)$

Adherentes


Los resultados de adherencia al tratamiento farmacológico en la segunda entrevista del estudio por el método del cuestionario de Morisky-Green-Levine muestran que un $40.3 \%$ de los sujetos clasificados como adherentes de la fase I, presentan un comportamiento adherente respecto a su régimen farmacológico en su noveno mes de tratamiento; mientras que un $59.7 \%$ de los sujetos presenta un comportamiento incumplidor en su noveno mes de tratamiento. (Figura 42).

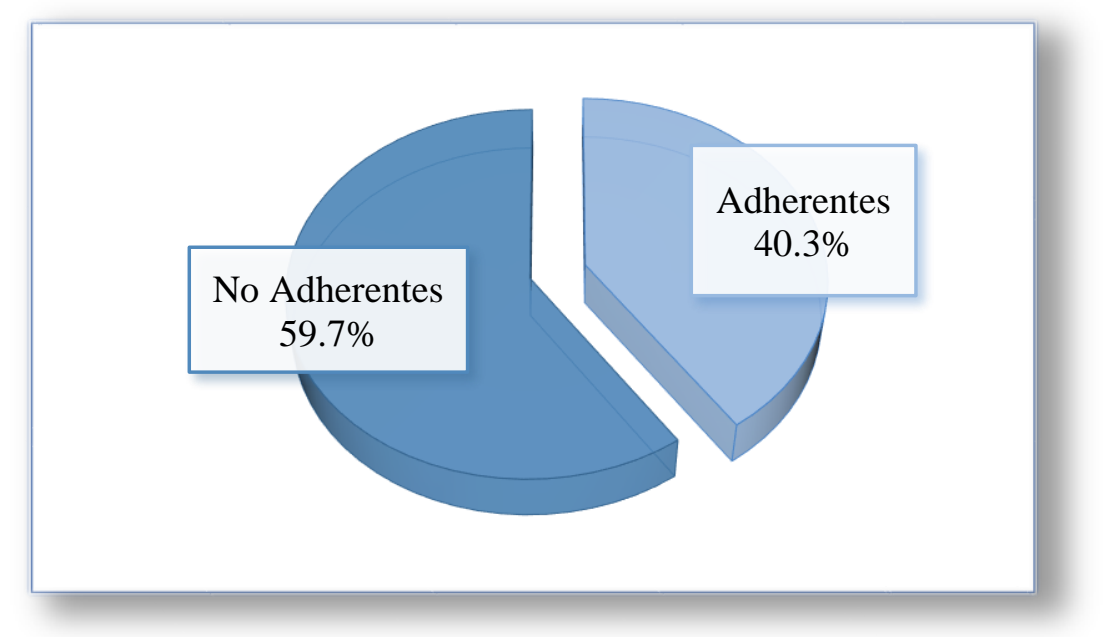

Figura 42. Resultados de Adherencia al Tratamiento Farmacológico según el Cuestionario Morisky-Green-Levine en la Segunda Entrevista del Estudio (n=72).

Con los resultados de la segunda entrevista se procede a llevar a cabo junto con los obtenidos en la primera entrevista, un análisis para determinar el porcentaje total de adherencia al tratamiento farmacológico de todos los pacientes del estudio $(n=150)$, en su noveno mes de tratamiento (fase II el estudio), después de haber inicializado un nuevo régimen de medicación, con los siguientes resultados (Tabla 21). 
Tabla 21. Distribución del Total los Pacientes del Estudio en Función de su Adherencia al Tratamiento Farmacológico según el Cuestionario de Morisky-Green-Levine en la Fase II del Estudio (n=150).

\begin{tabular}{cccc}
\hline \hline & Frecuencia (n) & Porcentaje (\%) & IC (95\%) \\
\hline \hline Adherentes & 29 & 19.3 & $(12.7-26.7)$ \\
No Adherentes & 121 & 80.7 & $(73.3-87.3)$ \\
\hline \hline
\end{tabular}

Los resultados de adherencia al tratamiento farmacológico del total de sujetos de la muestra en la fase II del estudio por el método del cuestionario autorreferido Morisky-Green-Levine muestran que un $\mathbf{8 0 . 7 \%}$ de los sujetos del total de la muestra $(n=150)$ tiene un comportamiento incumplidor en su noveno mes de tratamiento, mientras que un $\mathbf{1 9 . 3 \%}$ de los sujetos presenta un comportamiento adherente o cumplidor al tratamiento farmacológico en su noveno mes. (Figura 43).

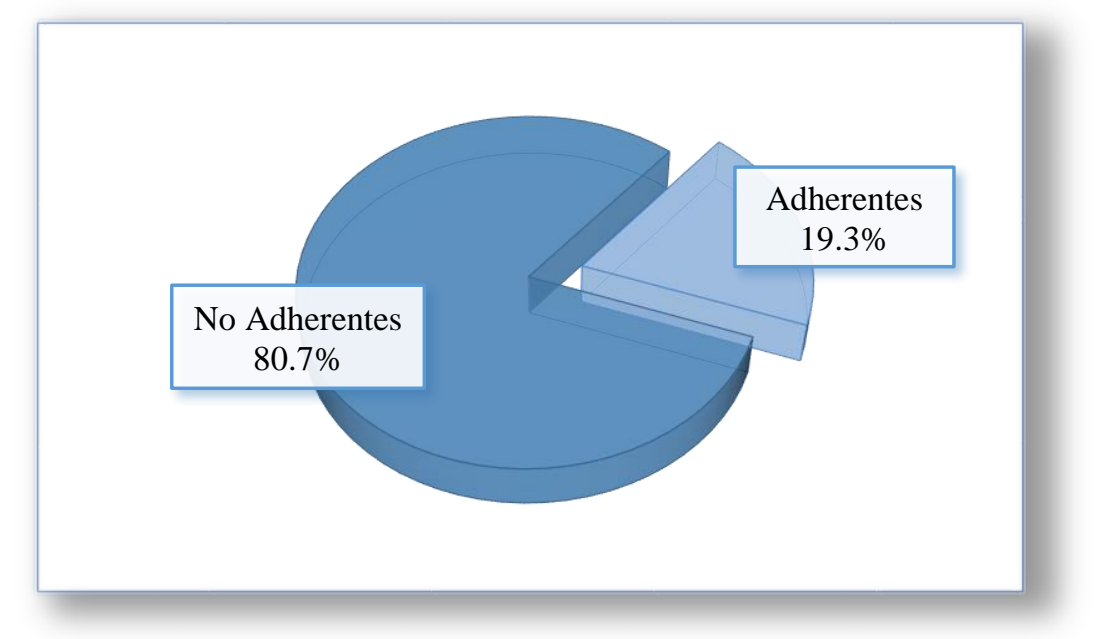

Figura 43. Resultados de Adherencia al Tratamiento Farmacológico en la Fase II del Estudio según el Cuestionario Morisky-Green-Levine ( $\mathrm{n}=150)$. 
Seguidamente se procede a clasificar a todos los pacientes del estudio en función de su grado de adherencia al tratamiento farmacológico en la fase II, del estudio, siguiendo los criterios de Morisky et al. ${ }^{178}$, utilizados ya en la fase I. Los resultados obtenidos se muestran a continuación (Tabla 22).

Tabla 22. Grado de Adherencia al Tratamiento Farmacológico de los Pacientes del Estudio en la Fase II del Estudio.

\begin{tabular}{cccc}
\hline \hline & Frecuencia (n) & Porcentaje & IC (95\%) \\
\hline \hline Alto & 29 & 19.3 & $(13.3-25.3)$ \\
Medio & 105 & 70.0 & $(62.0-77.3)$ \\
Bajo & 16 & 10.7 & $(6.0-15.3)$ \\
\hline \hline
\end{tabular}

Los resultados del grado de adherencia a la medicación del total de la muestra del estudio en su noveno mes de tratamiento muestran que un $19.3 \%$ de los pacientes presenta un grado de adherencia a la medicación alto, mientras que un $70.0 \%$ muestra un grado de adherencia medio, y un $10.7 \%$ presenta un grado de adherencia bajo (Figura 44). 


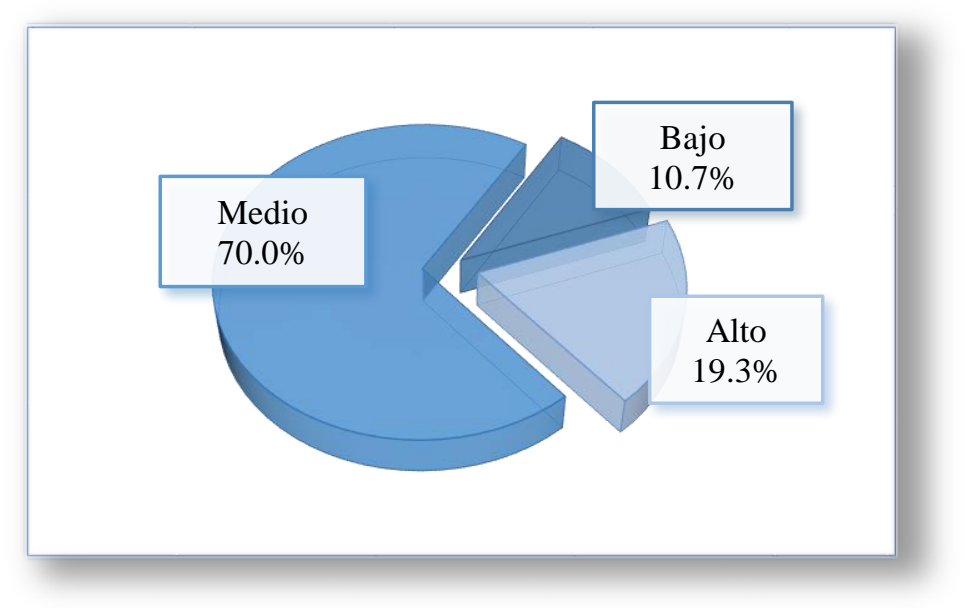

Figura 44. Grado de Adherencia al Tratamiento Farmacológico de los Pacientes del Estudio en la Fase II según el Cuestionario de Adherencia Morisky-Green-Levine

Se realiza el análisis individualizado (determinación de frecuencia, porcentaje, e IC) de las causas de incumplimiento de los pacientes no adherentes $(\mathrm{n}=121)$ en función de sus respuestas al cuestionario Morisky-Green-Levine en la fase II del estudio. La distribución de las causas de incumplimiento se corresponde con (Tabla 23):

Tabla 23. Distribución de los Pacientes No Adherentes $(n=121)$ en Función de las Causas de Incumplimiento en la Fase II del Estudio.

\begin{tabular}{|c|c|c|c|c|c|c|}
\hline & $\begin{array}{c}\text { Frecuencia (n) } \\
\text { Sí }\end{array}$ & $\begin{array}{c}\text { Porcentaje } \\
(\%)\end{array}$ & IC (95\%) & $\begin{array}{c}\text { Frecuencia (n) } \\
\text { No }\end{array}$ & $\begin{array}{c}\text { Porcentaje } \\
(\%)\end{array}$ & IC $(95 \%)$ \\
\hline $\begin{array}{l}\text { ¿Olvida alguna vez } \\
\text { tomar sus } \\
\text { medicamentos? }\end{array}$ & 99 & 81.8 & (74.6-88.8) & 22 & 18.2 & $(11.2-25.4)$ \\
\hline $\begin{array}{l}\text { ¿Es descuidado con la } \\
\text { hora en que debe } \\
\text { tomar la medicación? }\end{array}$ & 51 & 42.1 & $(32.5-51.3)$ & 70 & 57.9 & $(48.8-66.4)$ \\
\hline $\begin{array}{l}\text { Cuando se encuentra } \\
\text { mejor, ¿deja de } \\
\text { tomar la medicación } \\
\text { vez? }\end{array}$ & 31 & 25.6 & $(18.1-33.3)$ & 90 & 74.4 & $(66.1-81.8)$ \\
\hline $\begin{array}{l}\text { Si alguna vez le } \\
\text { sientan mal los } \\
\text { medicamentos, ¿deja } \\
\text { de tomarlos? }\end{array}$ & 29 & 24.0 & $(16.7-31.7)$ & 92 & 76.0 & $(68.3-83.3)$ \\
\hline
\end{tabular}


Las repuestas a las preguntas del cuestionario Morisky-Green-Levine de los pacientes clasificados como no adherentes en su noveno mes de tratamiento corresponden con las siguientes: un $81.8 \%$ de los individuos afirma olvidar alguna vez tomar sus medicamentos durante los nueve meses de duración de su tratamiento; un $42.1 \%$ de los pacientes admite ser descuidado con la hora en que debe tomar la medicación; un $25.6 \%$ de los pacientes de la muestra declara dejar de tomar la medicación cuando se encuentra mejor; y un $24.0 \%$ de los pacientes reconoce dejar de tomar los medicamentos si le sientan mal (Figura 45).

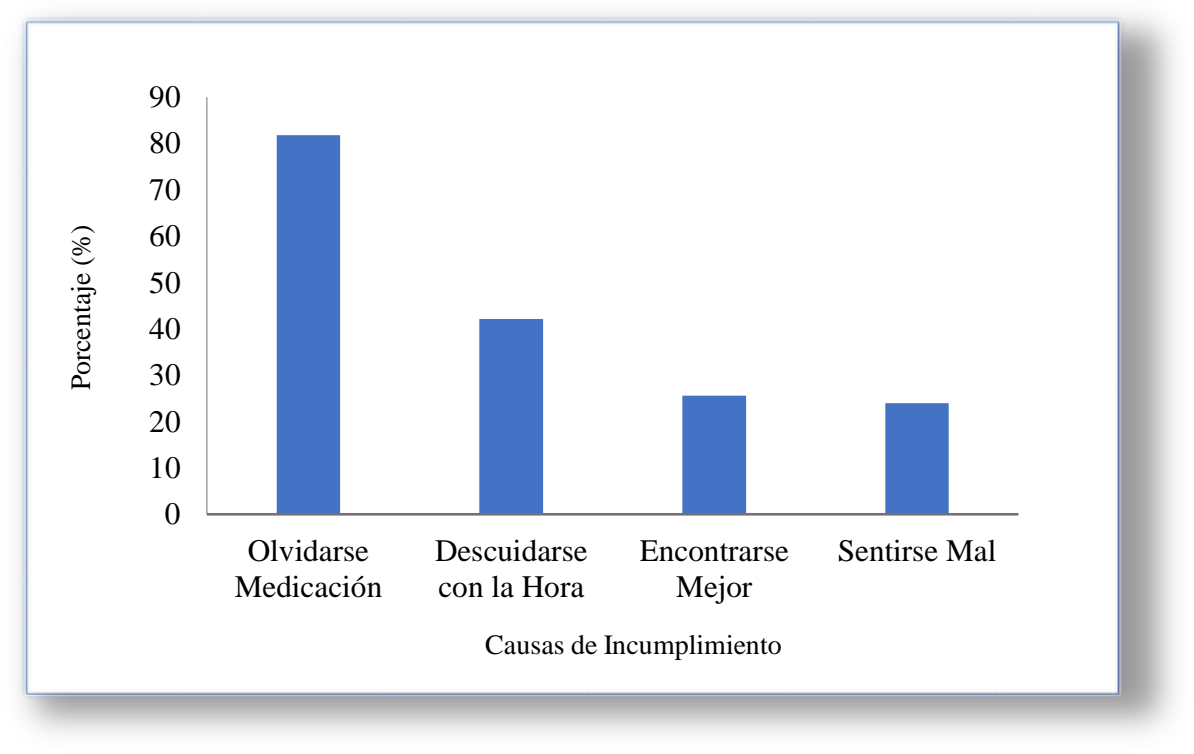

Figura 45. Distribución de los Pacientes No Adherentes $(\mathrm{n}=121)$ en Función de las Causas de su Comportamiento Incumplidor en la Fase II del Estudio.

De entre los pacientes del estudio $(\mathrm{n}=150), 53$ pacientes $(35.3 \%)$ han respondido positivamente (sí) a una pregunta del cuestionario, 52 pacientes (34.7\%) han contestado positivamente a dos cuestiones, 11 pacientes han respondido positivamente a tres cuestiones $(7.3 \%)$, y 5 pacientes $(3.3 \%)$ han contestado positivamente a cuatro preguntas, 
y 29 pacientes $(19.3 \%$ ) han respondido negativamente (no) a todas las preguntas del cuestionario de adherencia Morisky-Green-Levine.

Atendiendo a la voluntad del paciente, se analiza el tipo de incumplimiento que presentan los sujetos en la fase II del estudio. Los resultados del análisis de adherencia según la conducta de los pacientes del estudio se muestran a continuación (Tabla 24).

Tabla 24. Distribución de los Pacientes No Adherentes $(\mathrm{n}=121)$ por

Conducta de Incumplimiento.

\begin{tabular}{cccc}
\hline \hline & Frecuencia (n) & Porcentaje (\%) & IC (95\%) \\
\hline \hline Incumplimiento Involuntario & 112 & 92.6 & $(87.6-96.7)$ \\
Incumplimiento Voluntario & 51 & 42.1 & $(33.9-51.2)$ \\
Incumplimiento Mixto & 42 & 34.7 & $(26.4-43.8)$ \\
\hline \hline
\end{tabular}

La conducta más frecuente manifestada por los pacientes no adherentes del estudio es el incumplimiento involuntario con un $92.6 \%$ de sujetos cometiendo este tipo de incumplimiento; seguido por el incumplimiento voluntario con un $42.1 \%$ de sujetos; y un $34.7 \%$ de pacientes de la muestra cometen un incumplimiento mixto (voluntario e involuntario).

Seguidamente, se procedió a realizar el análisis de la prueba de los rangos con signo de Wilcoxon. La finalidad de esta prueba estadística fue comparar las diferencias en el grado de adherencia de los individuos de fase I con respecto a la fase II del estudio. Los resultados se muestran a continuación (Tabla 25 y Tabla 26). 
Tabla 25. Resultados de la Prueba de Rangos con Signo de Wilcoxon.

\begin{tabular}{ccccc}
\hline \hline & & $\begin{array}{c}\text { Frecuencia } \\
(\mathbf{n})\end{array}$ & $\begin{array}{c}\text { Rango } \\
\text { Promedio }\end{array}$ & $\begin{array}{c}\text { Suma de } \\
\text { Rangos }\end{array}$ \\
\hline \hline & & & & \\
Adherencia Fase II - & Rangos Negativos & 0 & 0.00 & 0.00 \\
Adherencia Fase I & Rangos Positivos & 43 & 22.00 & 946.00 \\
& Empates & 107 & & \\
& Total & 150 & & \\
& & & & \\
& &
\end{tabular}

Los resultados de la prueba de rangos muestran que el grado de adherencia al tratamiento farmacológico de 43 sujetos (28.67\%) difirió desde el punto en el tiempo en que se realizó la entrevista en la fase I hasta el punto en el tiempo que se realizó la entrevista de la fase II del estudio, con un balance positivo en el incumplimiento; mientras que el grado de adherencia de 107 sujetos $(71.33 \%)$ permanece sin diferencias (empates) entre la fase I del estudio y la fase II.

Tabla 26. Resultados de los Estadísticos de Contraste de la Prueba de Rangos con Signo de Wilcoxon.

\begin{tabular}{ccc}
\hline \hline & $\mathbf{Z}$ & $\mathbf{p}$ \\
\hline \hline $\begin{array}{c}\text { Adherencia Fase II - } \\
\text { Adherencia Fase I }\end{array}$ & -6.423 & $\mathbf{0 . 0 0 0}$ \\
\hline \hline
\end{tabular}

Los resultados de los estadísticos de contraste de la prueba de rangos con signo de Wilcoxon demuestran que los sujetos de la fase II del estudio, presentan diferencias estadísticamente significativas en adherencia $(Z=-6.423, p=0.000)$ respecto a los sujetos da la fase I del estudio. 


\subsection{Análisis Bivariado}

Los resultados de las inferencias bivariadas del estudio entre la variable dependiente adherencia y las variables independientes en la fase II del estudio, se presentan a continuación siguiendo el mismo formato de presentación que en la fase $I$. Además de la determinación de las variables independientes en los cinco grupos o dimensiones propuestos por la $\mathrm{OMS}^{90}$ que inciden en la adherencia terapéutica, se incluyó un grupo adicional para analizar el posible sesgo ocasionado por el cambio introducido en la metodología de la entrevista en la fase II (entrevista por teléfono).

\subsubsection{Factores Relacionados con las Características Socioeconómicos}

\subsubsection{Variables Cualitativas}

El resultado del análisis estadístico de los factores relacionados con las características socioeconómicas de los pacientes del estudio demuestra no existir relación significativa entre las variables cualitativas sexo $(p=0.558)$, nivel de alfabetización ( $\mathrm{p}=0.999)$, nivel de educación $(\mathrm{p}=0.493)$, cohabitación $(\mathrm{p}=0.111)$, área geográfica de residencia $(\mathrm{p}=0.754)$, situación laboral actual $(\mathrm{p}=0.407)$, nivel de ingresos $(\mathrm{p}=0.259)$, problemas con el factor coste $(\mathrm{p}=0.996)$, dificultades por precio elevado $(p=0.092)$ y dificultades por ahorrar dinero $(p=0.676)$, con la variable dependiente adherencia. Las variables cualitativas estadísticamente significativas asociadas a adherencia de los factores socioeconómicos de los pacientes se recogen a continuación (Tabla 27). 
Tabla 27. Factores Relacionados con las Características Socioeconómicas Estadísticamente Significativos de la Fase II del Estudio (Variables Cualitativas).

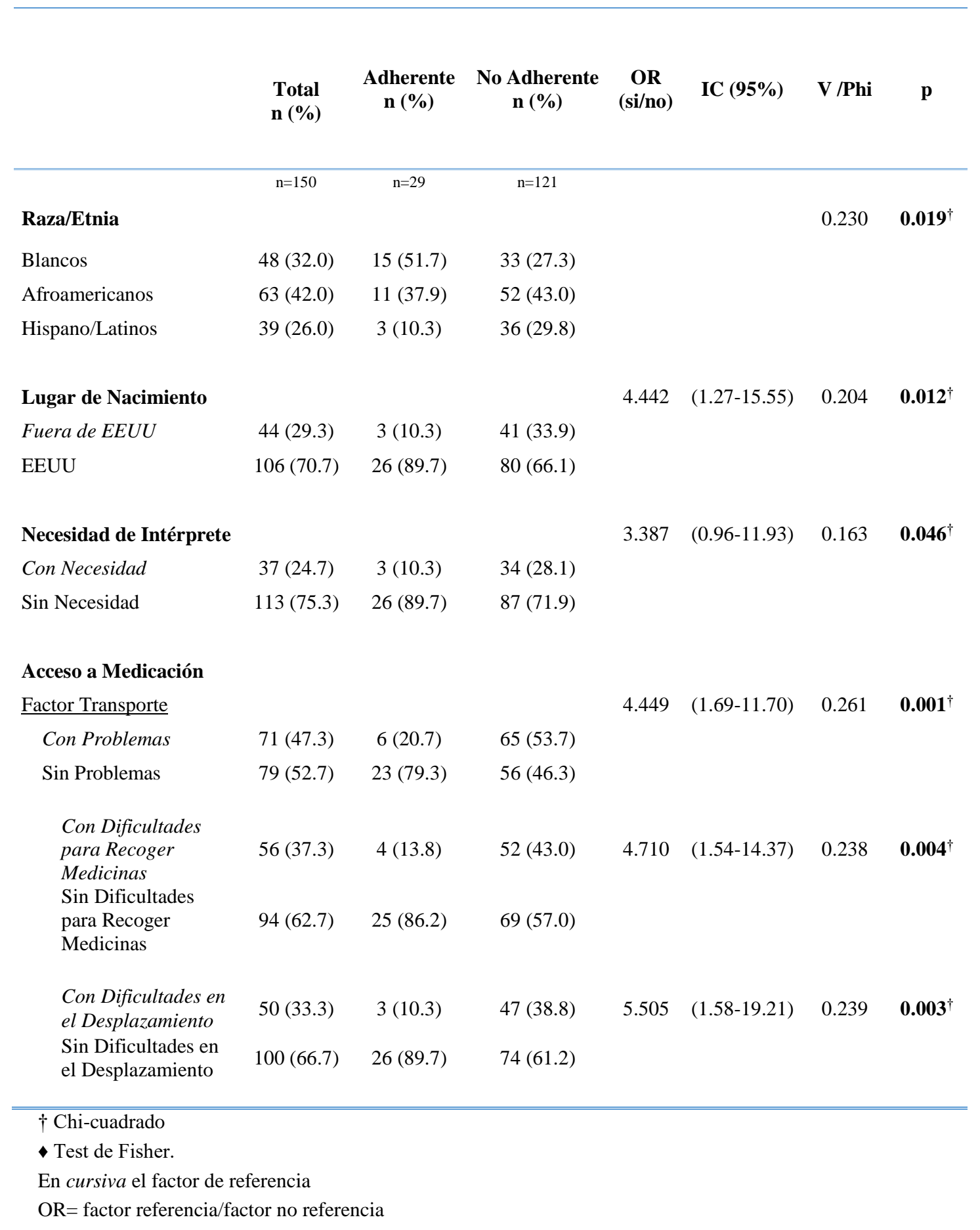


El resultado del análisis revela que la variable raza/etnia está asociada significativamente con el incumplimiento $(\mathrm{p}=0.019)$, con una dependencia relativamente alta $(\mathrm{V}=0.230)$. El análisis de los residuos corregidos demuestra una relación inversa y estadísticamente significativa para la categoría blancos (ARij= -2.5), al existir más sujetos adherentes al tratamiento que los esperados, y una relación directa y estadísticamente significativa para la categoría hispano/latinos (ARij=2.1) al existir más sujetos no adherentes al tratamiento que los esperados. La categoría afroamericanos no resulta significativa (ARij=0.5). Analizando estos valores, tanto en sus magnitudes como en sus rangos, se establece el patrón: "Los sujetos pertenecientes la raza blanca tiene relación favorable sobre la adherencia al tratamiento farmacológico, mientras que pertenecer a la etnia hispana/latina tiene una relación desfavorable con la adherencia. De este modo, se evidencia que existe una relación y del tipo que es esta”.

El resultado del análisis estadístico de la variable lugar de nacimiento establece una asociación significativa $(\mathrm{p}=0.012)$ entre la variable lugar de nacimiento y el incumplimiento, con una dependencia media proporcionalmente directa $(\phi=0.204)$. Los pacientes cuyo lugar de nacimiento no es EEUU presentan una probabilidad 4.44 veces mayor de incumplir el tratamiento farmacológico $(\mathrm{OR}=4.442)$. Analizando estos valores, tanto en sus magnitudes como en sus rangos, se establece el patrón: "Los pacientes que han nacido fuera de EEUU tienen una relación desfavorable sobre la adherencia al tratamiento farmacológico. De este modo, se evidencia que existe una relación y del tipo que es esta".

Posteriormente se procede al análisis de la variable necesidad de intérprete, cuyo resultado establece una asociación significativa $(\mathrm{p}=0.046)$ con el incumplimiento; sin embargo, esta asociación ha sido descartada como significativa porque los límites del IC (95\%) del Odds Ratio (0.96-11.93) contienen al 1, lo que indica que el evento puede ser igualmente presentado tanto en el grupo adherente como en el grupo no adherente.

El estudio estadístico de la variable acceso a la medicación señala que los problemas de los pacientes para acceder a medicación debidas al factor transporte 
resultan estar asociadas significativamente $(\mathrm{p}=0.001)$ con el incumplimiento al tratamiento farmacológico, con una dependencia media directa $(\phi=0.261)$. Los pacientes que encuentran problemas relacionadas con el transporte para acceder a su medicación presentan una probabilidad 4.45 veces mayor $(\mathrm{OR}=4.449)$ de incumplir el tratamiento farmacológico. Dentro de los problemas de transporte, las dificultades para recoger las medicinas resultan estar asociadas significativamente $(p=0.004)$ con el incumplimiento del régimen con una dependencia media directa $(\phi=0.238)$, y una probabilidad de incumplimiento 4.71 veces mayor ( $\mathrm{OR}=4.710$ ). Con respecto a las dificultades en el desplazamiento, también resultan estar asociadas significativamente $(\mathrm{p}=0.003)$ con el incumplimiento del régimen con una dependencia media directa $(\phi=$ $0.239)$, y una probabilidad de incumplimiento 5.51 veces mayor $(\mathrm{OR}=5.505)$.

\subsubsection{Variables Cuantitativas}

El análisis estadístico de las variables cuantitativas relacionadas con los factores socioeconómicos establece no existir relación significativa entre la variable edad $(p=0.359)$ y la variable dependiente adherencia. Por tanto, no existe ninguna variable cuantitativa estadísticamente significativa asociada a adherencia de los factores relacionados con las características socioeconómicas en la fase II del estudio. 


\subsubsection{Factores Relacionados con el Sistema o el Equipo de Asistencia Sanitaria}

\subsubsection{Variables Cualitativas}

El resultado del análisis estadístico bivariado demuestra no existir relación significativa entre las variables cualitativas centro de salud/clínica $(p=0.129)$, información general recibida $(\mathrm{p}=0.382)$, información individualizada sobre la medicación y posibles efectos secundarios $(\mathrm{p}=0.196)$, información apropiadamente explicada $(\mathrm{p}=0.999)$, información adicional sobre medicación $(\mathrm{p}=0.738)$, frecuencia de consulta $(\mathrm{p}=0.160)$ y satisfacción con la relación con los profesionales sanitarios $(\mathrm{p}=0.999)$, con la variable dependiente adherencia. Por tanto, no existe ninguna variable cualitativa estadísticamente significativa asociada a adherencia de los factores relacionados con el sistema o el equipo de asistencia sanitaria en la fase II del estudio.

\subsubsection{Variables Cuantitativas}

El resultado del análisis estadístico de las variables cuantitativas refleja no existir diferencias significativas en la variable número de lugares de recogida de la medicación entre los sujetos del grupo no adherente y los sujetos del grupo adherente $(\mathrm{p}=0.759)$. Las diferencias estadísticamente significativas entre las variables cuantitativas de los sujetos del grupo no adherente y adherente relacionadas con los factores relacionados con el sistema o el equipo de asistencia sanitaria se recogen a continuación (Tabla 28). 
Tabla 28. Diferencias Estadísticamente Significativas de los Factores Relacionados con el Sistema o el Equipo de Asistencia Sanitaria de la Fase II del Estudio (Variables Cuantitativas).

\begin{tabular}{|c|c|c|c|c|c|c|c|c|}
\hline & Grupo & $\begin{array}{l}\text { Frecuencia } \\
\text { (n) }\end{array}$ & Media \pm DE & $\begin{array}{c}\text { Rango } \\
\text { Promedio }\end{array}$ & $\begin{array}{c}\text { Suma de } \\
\text { Rangos }\end{array}$ & Mínimo & Máximo & $\mathbf{P}$ \\
\hline \multirow{2}{*}{$\begin{array}{l}\text { Relación de } \\
\text { Comunicación }\end{array}$} & Adherente & 29 & $9.90 \pm 0.41$ & 88.53 & 2567.5 & 8 & 10 & \multirow{2}{*}{$0.016^{+}$} \\
\hline & $\begin{array}{c}\text { No } \\
\text { Adherente }\end{array}$ & 121 & $9.36 \pm 1.36$ & 72.38 & 8757.5 & 3 & 10 & \\
\hline \multirow{3}{*}{ Apoyo Social } & Adherente & 29 & $9.76 \pm 0.69$ & 90.10 & 2613.0 & 7 & 10 & \multirow{3}{*}{$0.016^{+}$} \\
\hline & & & & & & & & \\
\hline & $\begin{array}{c}\text { No } \\
\text { Adherente }\end{array}$ & 121 & $9.26 \pm 1.29$ & 72.00 & 8712.0 & 4 & 10 & \\
\hline
\end{tabular}

Los resultados estadísticos señálan diferencias estadísticamente significativas de las variables relación de comunicación $(\mathrm{p}=0.016)$ y apoyo social $(\mathrm{p}=0.016)$ entre los sujetos del grupo no adherente y los del grupo adherente. Se observa que la calificación media de la relación de comunicación con los profesionales sanitarios del grupo de pacientes adherente es ligeramente superior $(9.90 \pm 0.41)$ a la del grupo no adherente (9.36 \pm 1.36 ). Asimismo, la calificación media otorgada al apoyo social que han recibido los pacientes por parte del personal sanitario es ligeramente superior en el grupo de pacientes adherente $(9.76 \pm 0.69)$ que en el grupo de pacientes no adherente $(9.26 \pm 1.29)$. 


\subsubsection{Factores Relacionados con la Enfermedad}

\subsubsection{Variables Cualitativas}

El resultado del análisis estadístico bivariado refleja no existir relación significativa entre las variables cualitativas índice de masa corporal $(p=0.149)$ actividad física $(p=0.502)$, consumo de tabaco $(p=0.395)$, consumo de alcohol $(\mathrm{p}=0.357)$, clase de bebida $(\mathrm{p}=0.349)$, y consumo de drogas $(\mathrm{p}=0.999)$, con la variable dependiente adherencia.

Las variables cualitativas estadísticamente significativas asociadas a adherencia de los factores relacionados con la enfermedad se recogen a continuación (Tabla 29).

Tabla 29. Factores Relacionados con la Enfermedad Estadísticamente Significativos Asociados a Adherencia de la Fase II del Estudio (Variables Cualitativas).

\begin{tabular}{|c|c|c|c|c|c|c|c|}
\hline & $\begin{array}{l}\text { Total } \\
\text { n }(\%)\end{array}$ & $\begin{array}{c}\text { Adherente } \\
\text { n (\%) }\end{array}$ & $\begin{array}{c}\text { No Adherente } \\
\text { n }(\%)\end{array}$ & $\underset{(\mathbf{s i} / \mathbf{n o})}{\mathrm{OR}}$ & IC (95\%) & V /Phi & $\mathbf{p}$ \\
\hline & $\mathrm{n}=150$ & $\mathrm{n}=29$ & $\mathrm{n}=121$ & & & & \\
\hline $\begin{array}{l}\text { Grupo de Riesgo } \\
\text { Clínico }\end{array}$ & & & & & & 0.255 & $0.008^{\star}$ \\
\hline G1 & $21(14.0)$ & $6(20.7)$ & $15(12.4)$ & & & & \\
\hline G2 & $110(73.3)$ & $15(51.7)$ & 95 (78.5) & & & & \\
\hline G3 & $19(12.7)$ & $8(27.6)$ & $11(9.1)$ & & & & \\
\hline
\end{tabular}

- Test de Fisher 
El resultado del análisis bivariado de los factores relacionados con la enfermedad establece una asociación significativa $(\mathrm{p}=0.008)$ entre la variable grupo de riesgo clínico y el incumplimiento, con una dependencia relativamente alta $(\mathrm{V}=0.255)$. El análisis de los residuos corregidos demuestra una relación estadísticamente significativa para las categorías $G 2(\mathrm{ARij}=2.9)$ y $G 3(\mathrm{ARij}=-2.7)$, mientras que $G 1$ no resulta significativo (ARij= -1.2). El grupo de riesgo $G 2$ muestra una relación directa al incumplimiento, al existir más sujetos no adherentes al tratamiento que los esperados, mientras que la relación de $G 3$ es inversa al incumplimiento, al existir más sujetos adherentes que los esperados. Analizando estos valores, tanto en sus magnitudes como en sus rangos, se establece el patrón: "El grupo de riesgo G3 tienen una relación favorable sobre la adherencia farmacológica, mientras que la relación del grupo G2 es desfavorable. De este modo, se evidencia que existe una relación el tipo de esta".

\subsubsection{Variables Cuantitativas}

El resultado del análisis estadístico de las variables cuantitativas revela no existir diferencias significativas entre las variables de las condiciones crónicas enfermedades sanguíneas $y$ del aparato circulatorio $(\mathrm{p}=0.123)$; enfermedades del aparato respiratorio $(p=0.205)$; enfermedades del aparato digestivo $(p=0.687)$; enfermedades nerviosas y mental-conductuales $(p=0.379)$; enfermedades endocrinas-nutricionales-metabólicas $(p=0.285)$; enfermedades del sistema renal, genitourinario, reproductor, $y$ enfermedad congénita $(p=0.335)$; enfermedades músculo-esqueléticas $(\mathrm{p}=0.504)$; enfermedades infecciosas, cáncer, órganos sensoriales, y de la piel $(p=0.156)$; y número total de condiciones crónicas $(p=0.615)$ entre los sujetos del grupo no adherente y los del grupo adherente. Por tanto, no existe ninguna variable cuantitativa estadísticamente significativa asociada a adherencia relacionada con la enfermedad en la fase II del estudio. 


\subsubsection{Factores Relacionados con el Tratamiento}

\subsubsection{Variables Cualitativas}

El resultado del análisis estadístico bivariado demuestra no existir relación significativa entre la variable cualitativa dieta $(\mathrm{p}=0.170)$ y grado de polifarmacia del tratamiento farmacológico $(\mathrm{p}=0.725)$, con la variable dependiente adherencia. Las variables cualitativas estadísticamente significativas asociadas a adherencia de los factores relacionados con el tratamiento se recogen a continuación (Tabla 30).

Tabla 30. Factores Relacionados con el Tratamiento Estadísticamente Significativos en la Fase II del Estudio (Variables Cualitativas).

\begin{tabular}{|c|c|c|c|c|c|c|c|}
\hline & $\begin{array}{l}\text { Total } \\
\text { n }(\%)\end{array}$ & $\begin{array}{c}\text { Adherente } \\
\text { n (\%) }\end{array}$ & $\begin{array}{c}\text { No Adherente } \\
\text { n }(\%)\end{array}$ & $\underset{(\mathbf{s i} / \mathbf{n o})}{\mathbf{O R}}$ & IC $(95 \%)$ & V /Phi & $\mathbf{p}$ \\
\hline & $\mathrm{n}=150$ & $\mathrm{n}=29$ & $\mathrm{n}=121$ & & & & \\
\hline $\begin{array}{l}\text { Técnicas de } \\
\text { Monitorización }\end{array}$ & & & & 3.303 & $(1.31-8.31)$ & 0.215 & $0.009 \dagger$ \\
\hline No Empleo de Técnicas & $69(46.0)$ & $7(24.1)$ & $62(51.2)$ & & & & \\
\hline Empleo de Técnicas & $81(54.0)$ & $22(75.9)$ & $59(48.8)$ & & & & \\
\hline $\begin{array}{l}\text { Cambios en el Régimen } \\
\text { Farmacológico }\end{array}$ & $\mathrm{n}=72$ & $\mathrm{n}=29$ & $\mathrm{n}=43$ & & & & \\
\hline Cambios en el Régimen & $43(59.7)$ & $9(31.0)$ & $34(79.1)$ & 8.395 & $(2.86-24.63)$ & 0.480 & $0.000 \dagger$ \\
\hline $\begin{array}{l}\text { Sin Cambios en el } \\
\text { Régimen }\end{array}$ & $29(40.3)$ & $20(69.0)$ & $9(20.9)$ & & & & \\
\hline
\end{tabular}


El resultado del análisis bivariado de los factores relacionados con el tratamiento de los pacientes revela una asociación significativa $(\mathrm{p}=0.009)$ entre la variable técnicas de monitorización y el incumplimiento, con una dependencia media inversa $(\phi=0.215)$. Los pacientes que no realizan técnicas de monitorización fuera del entorno clínico (toma de la presión arterial y/o medición de la glucosa en su caso), presentan una probabilidad 3.30 veces mayor probabilidad de incumplir el tratamiento farmacológico $(\mathrm{OR}=3.303)$. Analizando estos valores, tanto en sus magnitudes como en sus rangos, se establece el patrón: "Los pacientes que no practican técnicas de monitorización fuera del entorno clínico tienen una relación desfavorable sobre la adherencia al tratamiento farmacológico. De este modo, se evidencia que existe una relación y del tipo que es esta".

La variable cambios en el régimen farmacológico (variable que solamente se analizó en la fase II del estudio) presentae una asociación significativa ( $\mathrm{p}=0.000)$ con el incumplimiento, con una dependencia alta proporcionalmente directa $(\phi=0.480)$. Los pacientes que sufren cambios en su régimen farmacológico (variaciones en la dosificación, posología, y/o principio activo), presentan 8.40 veces mayor probabilidad de incumplir el tratamiento farmacológico $(\mathrm{OR}=8.395)$. Analizando estos valores, tanto en sus magnitudes como en sus rangos, se establece el patrón: "Los pacientes que sufren cambios en su régimen farmacológico tienen una relación desfavorable sobre la adherencia al tratamiento farmacológico. De este modo, se evidencia que existe una relación y del tipo que es esta”. 


\subsubsection{Variables Cuantitativas}

El resultado del análisis estadístico de las variables cuantitativas revela no existir diferencias significativas entre las variables número de prescripciones $(p=0.427)$, número de pastillas/día $(\mathrm{p}=0.214)$, número de inyecciones usadas/día $(\mathrm{p}=0.714)$, número de inhaladores usados/día $(\mathrm{p}=0.219)$, y otras formas medicamentosas usadas (colirios, enemas, y medicamentos tópicos) $(\mathrm{p}=0.685)$ entre los sujetos del grupo no adherente y los del grupo adherente. Por tanto, no existe ninguna variable cuantitativa estadísticamente significativa asociada a adherencia relacionada con el tratamiento del paciente en la fase II del estudio.

\subsubsection{Factores Relacionados con el Paciente}

\subsubsection{Variables Cualitativas}

El resultado del análisis estadístico bivariado determina no existir relación significativa entre las variables cualitativas dificultades sensoriales $(p=0.528)$, índice de Barthel $(\mathrm{p}=0.053)$ conocimiento sobre las condiciones padecidas y tratamiento $(\mathrm{p}=0.210)$, conocimiento de la toma de cada medicamento $(\mathrm{p}=0.584)$, conocimiento del número de medicamentos y posología $(\mathrm{p}=0.347)$, apoyo familiar recibido $(\mathrm{p}=0.137)$, percepción de los pacientes de necesitar ayuda para el control de la medicación $(\mathrm{p}=0.397)$, persona responsable de la medicación $(\mathrm{p}=0.156), \mathrm{y}$ estrategias específicas $(\mathrm{p}=0.351)$ con la variable dependiente adherencia. 
Las variables cualitativas estadísticamente significativas asociadas a adherencia de los factores relacionados con el paciente se recogen a continuación (Tabla 31).

Tabla 31. Factores Relacionados con el Paciente Estadísticamente Significativos en la Fase II del Estudio (Variables Cualitativas).

\begin{tabular}{|c|c|c|c|c|c|c|c|}
\hline & $\begin{array}{l}\text { Total } \\
\text { n }(\%)\end{array}$ & $\begin{array}{c}\text { Adherente } \\
\text { n }(\%)\end{array}$ & $\begin{array}{c}\text { No } \\
\text { Adherente } \\
\text { n (\%) }\end{array}$ & $\underset{(\mathbf{s i} / \mathbf{n o})}{\text { OR }}$ & IC $(95 \%)$ & V /Phi & $\mathbf{p}$ \\
\hline & $\mathrm{n}=150$ & $\mathrm{n}=29$ & $\mathrm{n}=121$ & & & & \\
\hline $\begin{array}{l}\text { Métodos/Estrategias } \\
\text { Usadas para Recordar } \\
\text { la Medicación }\end{array}$ & & & & 4.442 & $(1.27-15.55)$ & 0.204 & $\mathbf{0 . 0 1 2}{ }^{\dagger}$ \\
\hline Ningún Método & $44(29.3)$ & $3(10.3)$ & $41(33.9)$ & & & & \\
\hline Utilización de Estrategias & $106(70.7)$ & $26(89.7)$ & $80(66.1)$ & & & & \\
\hline \multicolumn{8}{|l|}{$\uparrow$ Prueba de Chi-cuadrado } \\
\hline \multicolumn{8}{|c|}{ En cursiva el factor tomado como referencia } \\
\hline $\mathrm{OR}=$ factor referencia/fac & tor no referer & & & & & & \\
\hline
\end{tabular}

Los resultados del análisis bivariado de los factores relacionados con el paciente establecen que la variable utilización de una estrategia/método para recordar la toma de medicación presenta una relación estadísticamente significativa asociada al incumplimiento $(\mathrm{p}=0.012)$. El análisis determina que existe una dependencia media proporcionalmente directa entre no usar una estrategia para recordar la toma de medicación y el incumplimiento $(\phi=0.204)$. Aquellos pacientes que no usan una estrategia para la toma de medicación presentan una probabilidad 4.44 veces mayor de incumplimiento $(\mathrm{OR}=4.442)$. Analizando estos valores, tanto en sus magnitudes como en sus rangos, se establece el patrón: "No utilizar una estrategia o método para recordar la toma de medicación tiene una relación desfavorable sobre la adherencia al tratamiento farmacológico. De este modo, se evidencia que existe una relación y del tipo que es esta”. 


\subsubsection{Variables Cuantitativas}

El resultado del análisis estadístico de las variables cuantitativas de los factores relacionados con el paciente, señala no existir diferencias significativas entre la variable auto-valoración del Estado de Salud $(\mathrm{p}=0.646)$, entre los sujetos del grupo no adherente y los del grupo adherente. Por tanto, no existe ninguna variable cuantitativa estadísticamente significativa asociada a adherencia relacionada con el paciente en la fase II del estudio.

\subsubsection{Metodología de Entrevista}

\subsubsection{Variables Cualitativas}

El resultado del análisis estadístico de la variable cualitativa metodología de entrevista se recoge a continuación (Tabla 32). Hay que recordar, que este tipo de análisis solamente se ha llevado a cabo en la fase II del estudio puesto que en la fase I del estudio la metodología de la entrevista a los pacientes fue la misma para todos ellos. 
Tabla 32. Distribución de los Pacientes de la Muestra de la Fase II según Metodología de la Entrevista (Variables Cualitativas).

\begin{tabular}{|c|c|c|c|c|c|c|c|}
\hline & $\begin{array}{l}\text { Total } \\
\text { n }(\%)\end{array}$ & $\begin{array}{c}\text { Adherente } \\
\text { n (\%) }\end{array}$ & $\begin{array}{c}\text { No Adherente } \\
\text { n }(\%)\end{array}$ & $\underset{(\mathbf{s i} / \mathbf{n o})}{\mathbf{O R}}$ & IC $(95 \%)$ & V /Phi & $\mathbf{p}$ \\
\hline & $\mathrm{n}=72$ & $\mathrm{n}=29$ & $\mathrm{n}=43$ & & & & \\
\hline $\begin{array}{l}\text { Metodología de } \\
\text { Entrevista }\end{array}$ & & & & & & & $0.396^{\dagger}$ \\
\hline Entrevista Personal & $28(38.9)$ & $13(44.8)$ & $15(36.4)$ & 0.659 & $(0.25-1.73)$ & -0.100 & \\
\hline Entrevista Telefónica & $44(61.1)$ & $16(55.2)$ & $28(63.6)$ & & & & \\
\hline
\end{tabular}

\footnotetext{
$\uparrow$ Prueba de Chi-cuadrado

En cursiva el factor tomado como referencia

$\mathrm{OR}=$ factor referencia/factor no referencia
}

El resultado del análisis bivariado de la metodología de entrevista muestra que dicha variable no presenta ninguna relación estadísticamente significativa $(\mathrm{p}=0.396)$ con la variable dependencia adherencia. Los límites del IC (95\%) del OR (0.25-1.73) contienen al 1, lo que confirma la no asociación estadísticamente significativa ya que el evento puede ser igualmente presentado tanto en el grupo adherente como en el grupo no adherente. Con ello queda demostrado que la distinta metodología de la fase II del estudio no influye en los resultados del estudio. 


\subsection{Análisis de Regresión Logística}

Se procede a utilizar nuevamente la regresión logística binaria para determinar las relaciones de dependencia entre las variables y desarrollar el modelo de variables predictores de incumplimiento al tratamiento farmacológico, siguiendo los mismos procedimientos que en la fase I del estudio.

La construcción del modelo incluye todas las variables del estudio que han resultado estadísticamente significativas en la fase II del estudio (nivel de confianza del 95\%) en el análisis bivariado. Además, se ha decidido incluir las variables que resultaron más significativas de la fase I con la finalidad de averiguar posibles significaciones. Se ha excluido a aquellas variables que no han sido analizadas para todos los sujetos de la muestra. El modelo incluye 15 variables independientes, respetando que la ratio de sujetos para cada variable independiente sea inferior a 5:1 y de 10 observaciones por cada variable independiente.

Al igual que en la fase $I$, se ha procedido a la identificación de las variables que puedan presentar multicolinealidad (tolerancia $<0.1$ y FIV >10), mediante el diagnóstico de colinealidad por SPSS. Ninguna variable independiente demuestra estar afectada por este fenómeno, por lo que no fue necesaria omitir ninguna variable.

Las 15 finales variables independientes incluidas en el modelo de regresión logística son:

- Factores Socioeconómicos: raza/etnia, lugar de nacimiento, necesidad de intérprete, dificultades por ahorrar dinero, dificultades por precio elevado, dificultades para recoger medicinas, dificultades en el desplazamiento, relación de comunicación con los profesionales sanitarios, y apoyo social recibido. 
- Factores Relacionados con el Sistema o el equipo de Asistencia Sanitaria: información individualizada sobre medicación y efectos secundarios.

- Factores Relacionados con la Enfermedad: grupo de riesgo clínico.

- Factores Relacionados con el Tratamiento: técnicas de monitorización, número de prescripciones, y número de pastillas.

- Factores Relacionados con el Paciente: utilización de método/estrategia para recordar la toma de medicación.

Se utiliza el estadístico Wald como criterio de decisión de mantenimiento o retirada de una variable modelo, con un punto de corte para la clasificación de 0.5 y un máximo de 20 iteraciones. Se siguió una modelización "forward" (por pasos hacia adelante), ajustada al modelo máximo con todas las variables, donde se introducen una a una las variables que resultan significativas en el test de Wald ( $\mathrm{p} \leq 0.05)$, hasta llegar al modelo final, que es el que mejor ajusta.

El análisis del modelo resulta en 6 pasos con un total de 6 iteraciones, y 4 variables predictoras de la adherencia al tratamiento farmacológico: etnia/raza, dificultades para recoger medicinas, grupo de riesgo clínico y utilización de métodos/estrategias usados para recordar la toma de medicación.

La proporción de la variabilidad de "incumplimiento al tratamiento farmacológico" explicada por este modelo se encuentra entre un $\mathbf{2 2 . 0 \%}$ (R cuadrado de Cox) y un 35.2\% (R cuadrado de Nagelkerke) (Tabla 34). Los resultados de la bondad del ajuste, proporcionados por el estadístico Chi cuadrado del test de Hosmer y Lemeshow, resultan ser no significativos $(\mathrm{p}=0.255)$, lo que indica que no existe ninguna razón para pensar que los resultados predichos sean diferentes a los observados, y que el modelo puede considerarse adecuado. 
La significación estadística de la prueba ómnibus indica que, con las cuatro variables independientes incluidas en el modelo, el ajuste mejora claramente de forma significativa $(\mathbf{p}=\mathbf{0 . 0 0 0})$. Con las cuatro variables predictores de la adherencia al tratamiento farmacológico, el modelo tiene una capacidad de clasificar correctamente el 84.7 \% de los casos analizados (Tabla 33). El modelo tiene una baja sensibilidad del $27.6 \%$ (clasifica correctamente a 8 sujetos de los 29 pacientes adherentes al tratamiento) y una alta especificidad del $98.3 \%$ (clasifica mejor a los sujetos no adherentes al tratamiento farmacológico, es decir, clasifica correctamente 119 sujetos de los 121 pacientes que incumplen el tratamiento).

Tabla 33. Clasificación del Modelo de Regresión Logística Binaria de la Fase II del Estudio.

\begin{tabular}{l|cccc}
\hline \multicolumn{4}{c}{} & \multicolumn{3}{c}{ Frecuencias Pronosticadas } \\
\cline { 3 - 4 } & & Adherente & $\begin{array}{c}\text { No } \\
\text { Adherente }\end{array}$ & Porcentaje (\%) \\
\multirow{3}{*}{ Frecuencias Observadas } & Adherente & 8 & 21 & 27.6 \\
& No Adherente & 2 & 119 & 98.3 \\
& & & & $\mathbf{8 4 . 7}$ \\
\hline \hline
\end{tabular}

Los resultados del modelo predictor de adherencia al tratamiento farmacológico se recogen a continuación (Tabla 34). 
Tabla 34. Resultados del Modelo Final Predictor de Incumplimiento al Tratamiento Farmacológico de la Fase II del Estudio por el Método Forward de Wald.

\begin{tabular}{lccccccc}
\hline & Coef. $\beta$ & $\begin{array}{c}\text { Error } \\
\text { Est. }\end{array}$ & $\begin{array}{c}\text { Chi' }^{2} \\
\text { Wald }\end{array}$ & p & OR & $\begin{array}{c}\text { IC 95\% para OR } \\
\text { Inferior }\end{array}$ & Superior \\
\hline \hline Raza/Etnia (Blancos) & & & 9.109 & 0.011 & & & \\
Raza/Etnia (Afroamericanos) & 1.073 & 0.533 & 4.049 & 0.044 & 2.923 & 1.028 & 8.310 \\
Raza/Etnia (Hispano/Latinos) & 2.109 & 0.746 & 7.984 & 0.005 & 8.237 & 1.908 & 35.561 \\
$\begin{array}{l}\text { Dificultades para recoger } \\
\text { medicinas }\end{array}$ & 1.980 & 0.641 & 9.552 & 0.002 & 7.241 & 2.063 & 25.413 \\
Grupo de Riesgo Clínico G3 & & & 7.668 & 0.022 & & & \\
Grupo de Riego Clínico G1 & 0.766 & 0.802 & 0.913 & 0.339 & 2.151 & 0.447 & 10.354 \\
Grupo de Riego Clínico G2 & 1.703 & 0.648 & 6.897 & 0.009 & 5.491 & 1.540 & 19.573 \\
Método/Estrategia para & 1.844 & 0.698 & 6.978 & 0.008 & 6.322 & 1.609 & 24.833 \\
Recordar la toma de Medicación & & & & & & & \\
Constante & -1.587 & 0.714 & 4.936 & 0.026 & 0.205 & & \\
\hline \hline
\end{tabular}

OR: OR ajustada que corresponde al exponente $\beta\left(\mathrm{e}^{\text {coef. }} \beta\right)$

$2 \log$ verosimilitud (-2LL): 109.974

$\mathrm{R}^{2}$ de Nagelkerke: 0.352

$\mathrm{R}^{2}$ de Cox y Snell: 0.220

Test de Hosmer y Lemeshow: 0.255

A continuación, se procede a hallar la ecuación de regresión logística para el incumplimiento, aunque como se ha explicado anteriormente, su finalidad es más orientativa que predictiva, aunque se ajuste a un buen modelo.

Ecuación de regresión logística para el incumplimiento al tratamiento farmacológico:

$\operatorname{Logit}(\mathrm{p})=-1.587+1.073 *($ raza/etnia afroamericana $)+2.109 *($ raza/etnia hispana/latina $)$ $+1.980 *$ (dificultades para recoger medicinas) $+0.766^{*}($ grupo de riesgo G1) + $1.703 *$ (grupo de riesgo G2) + 1.844*(método/estrategia para recordar toma medicación)

Siendo logit $(p)=\ln (p /(1-p)=\ln ($ odds $)$ 
En cuanto a la exactitud del modelo, se calcula el área bajo la curva (ROC), con un resultado de poder de discriminación del modelo construido del $82.7 \%$ del máximo posible (Tabla 35). Se puede apreciar que el modelo es estadísticamente significativo ( $\mathrm{p}=0.000)$, siendo la hipótesis nula la no discriminación, que en la curva ROC corresponde a los puntos que caen sobre la diagonal.

Tabla 35. Resultados del Grado de Exactitud del Modelo de la Fase II del Estudio.

\begin{tabular}{|c|c|c|c|}
\hline \multirow[b]{2}{*}{ Área } & \multirow[b]{2}{*}{ Sig. Asintótica (b) } & \multicolumn{2}{|c|}{$\begin{array}{l}\text { Intervalo de confianza asintótico al } \\
\qquad 95 \%\end{array}$} \\
\hline & & Límite Inferior & Límite Superior \\
\hline 0.827 & 0.000 & 0.756 & 0.898 \\
\hline
\end{tabular}

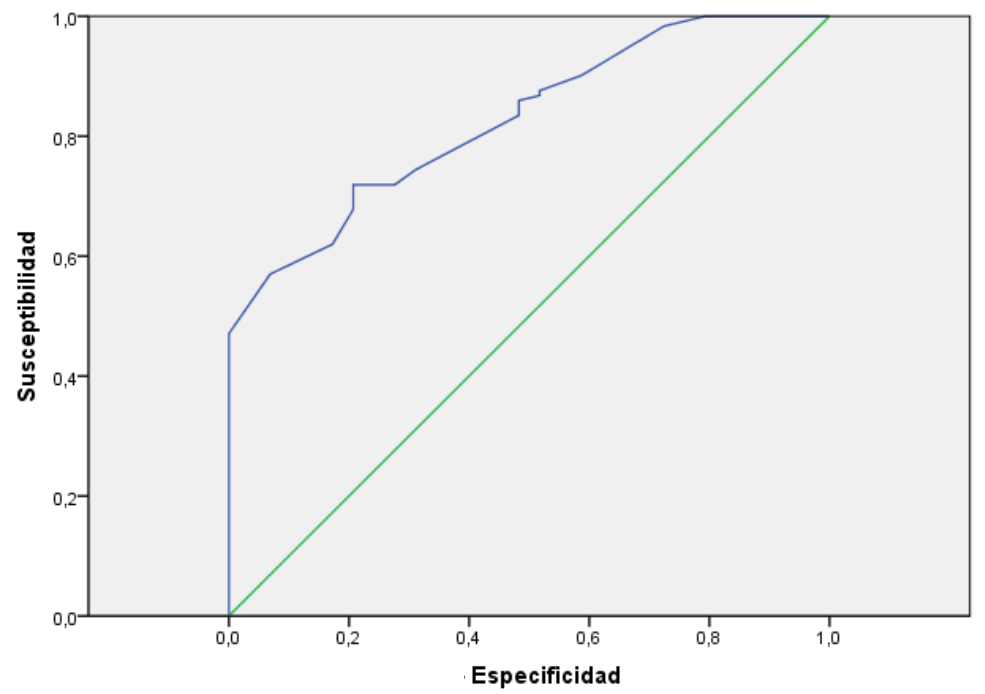

Figura 46. Área Bajo la Curva (ROC) del Modelo de la Fase II del Estudio. 
En la Tabla 34 se recogen todas las variables predictoras de incumplimiento al tratamiento estadísticamente significativas $(\mathrm{p} \leq 0.05)$, a excepción del grupo de riesgo clínico G1, cuya significación no es estadísticamente significativa $(\mathrm{p}=0.339)$. Los intervalos de confianza de las variables significativas, no contienen el 1, excepto la categoría variable grupo de riesgo G1 que su intervalo de confianza contiene el 1, lo que ratifica que la variable no es significativa e indica que el evento puede ser igualmente presentado tanto en el grupo adherente como en el grupo no adherente. Por tanto, el resto de variables son de interés para el modelo.

Para las variables dicotómicas, la categoría de referencia corresponde con la misma variable elegida en las tablas del análisis bivariado, mientras que para la categoría raza/etnia (grupo con tres variables) la categoría de referencia elegida es blancos debido a su mayor significación respecto a las otras dos categorías; del mismo modo, en la categoría grupo de riesgo (grupo con tres categoría) la variable de referencia elegida es grupo de riesgo G3 dada su mayor significación con respecto a las otras dos variables.

Al observar la Tabla 34 podemos concluir:

- Los pacientes de la categoría raza/etnia afroamericana tienen una probabilidad 2.92 veces mayor de incumplir el tratamiento que los pacientes de la categoría raza/etnia blanca.

- Los pacientes de la categoría raza/etnia hispana/latina tienen una probabilidad 8.94 veces mayor de incumplir el tratamiento que los pacientes de la categoría raza/etnia blanca.

- La variable dificultades para recoger medicinas tiene una relación directa al incumplimiento del tratamiento, y los pacientes que manifiestan dificultades para recoger las medicinas en la farmacia, tienda, o clínica, presentan una probabilidad 7.24 veces mayor más de incumplir el tratamiento. 
- Los pacientes del grupo de riesgo clínico G2, tiene una probabilidad 5.49 veces mayor de incumplir el tratamiento que los pacientes del grupo de riesgo clínico G3.

- La variable método/estrategia utilizado para recordar la toma de medicación tiene una relación inversa al incumplimiento del tratamiento, y los individuos que no usan ningún método/estrategia para recordar la toma de medicación presentan una probabilidad 6.32 veces mayor de incumplir el tratamiento. 
Discusión 

A pesar de la creciente evidencia de la capacidad de los tratamientos terapéuticos a largo plazo para mejorar el Bienestar y la CVRS, disminuir la morbilidad y aumentar la supervivencia $^{24}$, los resultados del presente estudio indican que, la efectividad de los tratamientos terapéuticos a medio y largo plazo actuales se ve reducida por el alto incumplimiento existente entre los sujetos que padecen enfermedades crónicas. Nuestro estudio ha permitido establecer el alcance y la magnitud de la problemática del incumplimiento en grupos de población vulnerables, así como el conocimiento y comprensión de las barreras y los factores más significativos relacionadas con los tratamientos terapéuticos de dichas poblaciones.

Los resultados del estudio confirman la hipótesis alternativa del estudio al establecer que la tasa de prevalencia de incumplimiento del tratamiento farmacológico de las enfermedades crónicas en los grupos de población vulnerables, es más elevada que la tasa de incumplimiento farmacológico de la población general de referencia. Los factores relacionados con la adherencia terapéutica encontrados en el estudio, ponen de manifiesto la necesidad de abordar la problemática del incumplimiento desde un punto de vista multidimensional, y no unidimensional como tradicionalmente ha sido asociado.

Además, las observaciones del estudio han permitido establecer notables diferencias de incumplimiento terapéuticos entre los distintos grupos raciales y étnicos, y establecer un perfil predictivo de paciente en riesgo de incumplimiento. 
Según nuestro conocimiento sobre lo publicado en relación al tema de investigación tratado, este es el primer estudio en analizar la adherencia y su evolución en el tiempo, los factores y barreras relacionados con este evento sanitario desde un punto de vista multidimensional, en poblaciones de grupos vulnerables, caracterizadas por ser económicamente desfavorecidos, pertenecer a minorías étnicas y raciales, carecer de seguro médico, y en la mayoría de los sujetos co-existen con múltiples patologías crónicas. 


\section{Discusión sobre las Características de la Muestra}

Los sujetos del estudio pertenecen a grupos de población vulnerables, caracterizados por: poseer escasos recursos económicos, como así lo indican los ingresos familiares inferiores al $400 \%$ del nivel de pobreza federal de cada uno de los pacientes de la muestra (Anexo II); pertenecer a minorías étnicas y raciales, como son el $41 \%$ de sujetos afroamericanos y el $26 \%$ de sujetos hispano/latinos; carecer de seguro médico, sin recibir ningún tipo de cobertura sanitaria (a excepción de los propios servicios de los centros); disponer de unos ingresos económicos muy limitados, como lo demuestra el porcentaje del $89 \%$ de individuos que no supera los 20.000 dólares/año, salario considerablemente reducido al ser comparado con el salario medio del trabajador estadounidense (53,482 dólares/año) (año 2014) ${ }^{244}$, a lo que se le añade las difíciles circunstancias laborales: casi la mitad de los sujetos de la muestra (48\%) se encuentra sin trabajar, bien en situación de desempleo (36\%) o en situación de incapacidad (12\%). Además, los integrantes de la muestra padecen enfermedades crónicas, el $92 \%$ de los individuos del estudio presenta multimorbilidad, porcentaje marcadamente elevado al compararlo con el $20-30 \%$ de multimorbilidad encontrado en la población general que recibe Atención Médica y/o Sanitaria ${ }^{19}$; por último, una proporción considerable del $29 \%$ de sujetos de la muestra reside en medios rurales. 
Los problemas de Salud y la asistencia sanitaria de estos grupos poblacionales se asocian e interaccionan frecuentemente con problemas sociales, incluyendo escasez de recursos como vivienda, situación experimentada por una gran parte de los sujetos, aunque no reflejada en la descriptiva del estudio; inadecuada educación, el 10\% de los individuos del estudio son analfabetos absolutos, un $26 \%$ no llegó a cursar ningún tipo de estudio en el instituto, y un $25 \%$ necesita de un intérprete para acudir a consulta debido a sus dificultades para comprender y/o hablar en inglés; e inmigración, cuyo porcentaje alcanza el $29 \%$ entre los sujetos del estudio.

A pesar de que las condiciones crónicas están relacionadas y asociadas con el aumento de la edad del individuo ${ }^{17-19}$, la población de este estudio está caracterizada por presentar una media de edad adulta joven, de aproximadamente cincuenta años. Este hecho se debe a los propios requisitos establecidos para ser admitido como paciente en los centros (edad menor de sesenta y cinco años en el momento de la aplicación), donde se seleccionó la muestra del estudio.

Cabe destacar la buena relación comunicativa y respaldo social recibidos por los sujetos del estudio por parte de los profesionales sanitarios, con una valoración media, en ambos casos, superior a 9 sobre una escala académica de 1 a 10. Además, el nivel positivo de satisfacción de los pacientes con el personal sanitario de los centros alcanza el 97\%. Estas situaciones pueden explicarse, en primer lugar, por el buen trabajo realizado por los profesionales sanitarios que complementan su profesionalidad con una sensibilidad especial en la comunicación con estas personas, y que lo confirma el elevado porcentaje (89\%) de sujetos que ha recibido información individualizada sobre su medicación actual y efectos secundarios, y el también elevado porcentaje (93\%) de sujetos que presenta conocimientos sobre las condiciones padecidas y el tratamiento. En segundo lugar, por el acceso gratuito a los servicios de los centros que reciben los sujetos del estudio, así como el también acceso gratuito a determinados medicamentos y productos sanitarios suministrados por diversas organizaciones y Fundaciones como 
MedBank. Y en tercer y último lugar, por el apoyo social recibido de todos los profesionales que trabajan en los centros, principalmente, del trabajador social que ayuda a los sujetos a desarrollar destrezas personales e interpersonales que aumentan su poder para enfrentarse a los problemas sociales e incrementar su Bienestar Social y mejorar su Calidad de Vida.

El tratamiento farmacológico de los sujetos del estudio está caracterizado por conllevar un elevado número de prescripciones médicas (cerca de un $75 \%$ de los sujetos dispone de al menos tres prescripciones en su régimen farmacológico), un número considerable de pastillas diarias (más del $75 \%$ de los individuos requiere al menos cuatro pastillas en su régimen farmacológico), incluir inyectables (un $24 \%$ de los pacientes requiere de al menos una inyección en su régimen), incluir inhaladores (un $13 \%$ de los sujetos requiere de al menos un inhalador en su régimen farmacológico), e incluir otras formas medicamentosas (un $9 \%$ de los individuos requiere en su tratamiento de alguna otra forma medicamentosas como son colirios, enemas, y medicamentos tópicos).

La caracterización del tratamiento farmacológico está justificada por el elevado número de patologías crónicas concomitantes que padecen los sujetos (más de la mitad de los sujetos presentan cuatro o más patologías). Por otro lado, los individuos del estudio no siguen unos autocuidados adecuados, ya que el $66 \%$ de los individuos no sigue una dieta específica para la condición/es crónicas padecidas, y el $46 \%$ no practica fuera del entorno clínico las técnicas de monitorización aconsejadas por los profesionales sanitarios para la enfermedad/es específicas padecidas. Estas circunstancias pueden ser comprensibles debido al bajo nivel económico de los sujetos del estudio que limita el acceso a una alimentación sana y equilibrada. El alto coste que supone para estas poblaciones los alimentos saludables en el mercado estadounidense, hace que los sujetos de la muestra se decanten por una alimentación más económica como la comida "rápida" y/o comida "basura". 
Por último, la mayoría de los pacientes que forman parte de la muestra del estudio pertenecen al grupo de riego clínico G2 (73\%), mientras que el resto de participantes corresponde a pacientes del grupo de riesgo G1 (14\%) y grupo G3 (13\%). Es decir, la mayoría de los sujetos son pacientes con dos o más patologías estables o con una patología en estadio avanzado con necesidades de atención sanitaria moderada, con un alto grado de independencia y sin ninguna dificultad para desemplear AVD como lo indica el porcentaje superior al $75 \%$ de los pacientes que poseen una total o leve independencia cuando se analiza y valora con el índice de Barthel. 


\section{Discusión sobre los Resultados de Incumplimiento Terapéutico}

La tasa de incumplimiento terapéutico de los sujetos del estudio se aproxima al $\mathbf{8 1 \%}$ (121/150 pacientes) en el noveno mes de tratamiento (fase II) después de haber inicializado un nuevo régimen farmacológico para una nueva patología diagnosticada. Se trata de un nivel de incumplimiento significativamente más elevado que la tasa general del 50\% aceptada en los estudios de adherencia para el tratamiento a largo plazo de las enfermedades crónicas en los países desarrollados ${ }^{90,105}$.

En este estudio, el $\mathbf{5 2 \%}$ de los sujetos iniciales (78/150) no continuaron su régimen farmacológico en los primeros seis meses de tratamiento (fase I.). De los pacientes adherentes restantes que continuaron su régimen farmacológico, un $\mathbf{6 0 \%}$ de estos sujetos (43/72) no continuan su tratamiento al noveno mes de tratamiento, con un porcentaje total de incumplimiento acumulado del $\mathbf{8 1 \%}(121 / 150)$ al noveno mes de tratamiento, como se ha explicado anteriormente.

Al comparar nuestro estudio con otros realizados y publicados sobre adherencia en relación con las enfermedades crónicas, se aprecian las siguientes observaciones: en primer lugar, los resultados obtenidos en este estudio siguen una progresiva disminución del cumplimiento al tratamiento farmacológico con su transcurso en el tiempo, ya observado en estudios anteriores ${ }^{109,118,149}$. Este suceso es razonable dado la dificultad del 
seguimiento de los tratamientos farmacológicos de las enfermedades crónicas. Segundo, el incumplimiento en los seis primeros meses de tratamiento de este estudio (52\%), es notablemente más elevado que el de otros estudios en el mismo período de seguimiento; por ejemplo, el porcentaje de incumplimiento de los pacientes del estudio de adherencia a medicamentos antihipertensivos presentado por Perreault et al. ${ }^{149}$, alcanzó un $29 \%$ después del sexto mes de tratamiento, mientras que el porcentaje de incumplimiento del estudio de Jackevicius et al. ${ }^{109}$ no sobrepasó el 38\%. Tercero, las diferencias de incumplimiento respecto a otros estudios hacen más notables tras el período de seguimiento de los seis primeros meses ${ }^{109,149}$. Y cuarto, el porcentaje de incumplimiento de estudios con mayor periodo de seguimiento sigue siendo inferior al de este estudio $^{149,245,246}$, como por ejemplo el porcentaje de incumplimiento del $61 \%$ evaluado en el período de seguimiento de 10 años en pacientes hipertensos. Todas estas observaciones se deben, como a continuación se justificará, a que esta investigación se ha realizado en sujetos de grupos poblacionales que por sus características están en situación de exclusión social o discriminación.

El incumplimiento más elevado en esta investigación con respecto a otros estudios con un período de seguimiento igual, similar, o considerablemente más largo, de incluso varios años, es un hallazgo novedoso. Esta situación confirma el alto grado de incumplimiento al tratamiento que se produce en grupos poblacionales vulnerables. Además, cabe mencionar que los porcentajes de cumplimiento de nuestro estudio han sido hallados tras la inicialización de un nuevo régimen farmacológico, donde la probabilidad de incumplimiento es considerablemente menor que en los estudios cuya línea de base de adherencia ha sido hallada cuando el tratamiento lleva inicializado varios años.

Todos estos hallazgos nos llevan a rechazar la hipótesis nula planteada en este estudio, y a aceptar la hipótesis alternativa de que los grupos de población vulnerables presentan tasas de prevalencia diferentes de incumplimiento del tratamiento de las enfermedades crónicas que la población general de referencia de los países desarrollados. 
Las notables diferencias de incumplimiento descritas anteriormente, pueden deberse adicionalmente, a que la mayoría de las investigaciones existentes en la actualidad, se centran en el estudio de una única condición crónica ${ }^{58,59}$, a diferencia de este estudio, que examina la adherencia en una muestra de sujetos que mayoritariamente presentan múltiples patologías crónicas ( $92 \%$ total de la muestra), sin olvidar la dificultad adicional que la multimorbilidad conlleva para el cumplimiento del tratamiento.

Actualmente, existen sólo unos pocos estudios que han analizado la adherencia en individuos que padecen múltiples enfermedades crónicas. Sin embargo, la mayoría de ellos, recogidos en una revisión sistemática ${ }^{247}$, no han profundizado lo suficiente en los factores relacionados y asociados con la adherencia, puesto que han analizado adherencia como resultado intermedio en el desarrollo de intervenciones farmacéuticas para mejorar el cumplimiento.

Hipotéticamente, en dichos estudios ${ }^{247}$ cabría esperar similares porcentajes de incumplimiento que en este trabajo. Sin embargo, en tres de estos estudios ${ }^{248-251}$ los porcentajes de incumplimiento de línea de base y de periodo de seguimiento son significantemente inferiores a este estudio. Otros dos estudios ${ }^{252,253}$ introdujeron como criterio de inclusión ser sujeto incumplidor, por lo que no se pudo comparar con nuestro estudio. Y únicamente dos estudios ${ }^{254,255}$ presentaron un incumplimiento mayor que nuestra investigación a los seis meses de tratamiento, probablemente porque el análisis de adherencia fue determinado en ensayos controlados aleatorios. En dichos estudios la selección de muestra fue muy rigurosa, como por ejemplo sujetos mayores de 65 años de edad, y en pacientes cuyos tratamientos habían sido inicializados hace prolongados períodos de tiempo, lo que puede explicar el bajo incumplimiento. Por lo tanto, las notables diferencias observadas de incumplimiento en nuestro estudio respecto a los estudios anteriores de adherencia terapéutica en pacientes con multimorbilidad radica probablemente, en las diferencias entre la muestra de población de los estudios (población de referencia general vs población vulnerable). 
El siguiente planteamiento del estudio consiste en comparar el incumplimiento de esta investigación con el de otros estudios de adherencia en poblaciones similares. Para ello se ha examinado estudios realizados en usuarios del servicio de atención médica estadounidense Medicaid. Esta población, que supera los 64 millones de usuarios en EEUU ${ }^{207}$, es incluida en estudios epidemiológicos por el buen registro llevado a cabo por la Administración sobre la utilización de medicación y servicios, que queda registrado en las bases de datos de cada Estado. La mayor parte de los usuarios del servicio Medicaid tiene unos niveles económicos inferiores a los de la muestra de nuestro estudio, y todos ellos reciben servicios de asistencia sanitaria principalmente de proveedores del sector privado sanitarios como médicos, hospitales, y farmacias.

El primer estudio de adherencia en población Medicaid sometido a comparación ha sido el de Kyanko et al. ${ }^{215}$. Estos autores encontraron, un $37 \%$ de incumplimiento a medicación de enfermedades crónicas, en las que se encontraban dislipidemias, hipertensión, y/o diabetes, entre los sujetos del Departamento de Salud Medicaid de Nueva York. Los sujetos del citado estudio se caracterizaban por pertenecer a poblaciones raciales y étnicas minoritarias (alrededor del 75\%), presentar multimorbilidad (en torno al 50\%), y presentar tres o más prescripciones en su régimen farmacológico (en torno al $40 \%$ ), características muy similares a la población de este estudio.

En el estudio de Dickson et al. ${ }^{154}$, la adherencia a medicación antihipertensiva fue evaluada en sujetos de una muestra de usuarios del servicio Medicaid de población afroamericana (alrededor del 75\%) y urbana (aproximadamente del 90\%). El incumplimiento del estudio osciló entre un $52 \%$ (en aquellos sujetos con un régimen de dos fármacos) y un $41 \%$ (en aquellos sujetos con un tratamiento de un solo fármaco con dos principios activos).

En el estudio realizado por Avorn et al. ${ }^{256}$ el incumplimiento a medicación antilipídica de los sujetos del estudio fue también inferior al de nuestro estudio, situándose alrededor del $65 \%$. Los sujetos del estudio se asemejaban a la población de la muestra de nuestro estudio puesto que eran usuarios de Medicaid o pertenecían a un programa de 
Asistencia Farmacéutica con cobertura para aquellos individuos de edad avanzada y discapacidades.

A pesar de la similitud de la población de usuarios Medicaid con la de nuestro estudio, las diferencias en los niveles de adherencia continúan siendo notablemente inferiores en nuestro estudio. Este hecho puede ser debido a que todos los Estados estadounidenses brindan una cobertura de asistencia médica para pacientes ambulatorios que están amparados bajo el programa Medicaid ${ }^{207}$, eliminando numerosas barreras a las que potencialmente deben de superar la población del presente estudio, como por ejemplo el coste de la medicación, coste del transporte a los centros de salud, ausencia de servicios clínicos rurales, servicios de hospital, y de tratamientos de fisioterapia.

Según nuestro conocimiento, el único estudio actualmente en la literatura con unos niveles de incumplimiento similares al de nuestro estudio, y que tiene como objetivo analizar las tasas de adherencia y sus factores relacionados en una muestra de población de sujetos con múltiples enfermedades crónicas es el de Jansa et al. ${ }^{113}$. En dicho estudio, el método empleado para determinar el incumplimiento fue el cuestionario de adherencia Morisky-Green-Levine. El incumplimiento se determinó en una población con elevada proporción de multimobilidad $(75 \%$ de los sujetos presentaban dos o más condiciones crónicas), y que registraban episodios de hospitalización. El incumplimiento del estudio presentado por Jansa et al. ${ }^{113}$, valorado entre seis y doce meses tras recibir el alta hospitalaria, resultó del $82 \%$, porcentaje muy análogo al obtenido en este estudio.

La semejanza en el porcentaje de incumplimiento con nuestro estudio puede explicarse, en primer lugar, a que se ha utilizado el mismo instrumento de medida. En segundo lugar, por el similar período de análisis de las observaciones en el que se produjeron las valoraciones de adherencia. Y, en tercer y último lugar, debido a la similitud de las poblaciones de los estudios, en cuanto a multimorbilidad y riesgo de incumplimiento, debido al nivel elevado de hospitalización en la población del estudio de Jansa et al. ${ }^{113}$, y a la vulnerabilidad que presenta la población del presente estudio. 
Posteriormente a la discusión sobre la tasa de prevalencia de incumplimiento de este estudio, se ha procedido a abordar los resultados de los pacientes sobre la conducta de incumplimiento terapéutico. Los hallazgos del análisis señalan que la proporción de sujetos no adherentes que cometen incumplimiento no intencionado, incumplimiento intencionado, e incumplimiento mixto es similar en los seis primeros meses ( $94 \%$ vs $46 \%$ vs $40 \%$ ) respecto al noveno mes (93\% vs $42 \%$ vs $35 \%$ ) (Tabla 9 y Tabla 24 ).

Además, se puede apreciar que la principal conducta de incumplimiento entre los pacientes no adherentes, es, destacadamente, el incumplimiento no intencionado. El olvido de la medicación ( $83 \%$ y $82 \%$ ) y el descuido con la hora de la toma de medicación (39\% y $42 \%$ ) son las causas del incumplimiento no intencionado en los seis primeros meses y en el noveno mes de tratamiento respectivamente (Tabla 8 y Tabla 23).

Estas observaciones son similares a los resultados de otros estudios donde confirman que el olvido de la toma de medicación es la causa más frecuente de incumplimiento $^{102}$. Sin embargo, en este estudio, el incumplimiento no intencionado y sus causas alcanzan porcentajes más elevados que el de otros estudios ${ }^{117,161-165}$. Por ejemplo, Gadkari y McHorney ${ }^{117}$ encontraron entre los sujetos de su estudio de enfermedades crónicas un porcentaje de incumplimiento no intencionado del 70\%. Estos autores observaron como causa principal de incumplimiento el olvido de la medicación $(62 \%)$ y como tercera causa más frecuente de incumplimiento el descuido con la hora de la toma de la medicación (23\%). Los resultados más elevados de incumplimiento entre los sujetos de este estudio pueden deberse al menor nivel de instrucción y educación al ser comparados con los sujetos del estudio de Gadkari y $\mathrm{McHorney}^{117}$, y por tanto, presentan una menor comprensión y concienciación del valor y la importancia del seguimiento y continuidad de los tratamientos. Estos resultados confirman la necesidad del paciente de mejorar sus autocuidados y su participación activa en el proceso terapéutico ejecutando acciones para no olvidar y no descuidarse con la toma de la medicación en el régimen prescrito, pues el paciente, en última instancia, es el mayor responsable de su Salud y sus autocuidados. 
Las causas de incumplimiento intencionado y sus correspondientes porcentajes corresponden a las circunstancias de encontrarse mejor (28\% y 26\%) y sentirse mal al tomar los medicamentos ( $28 \%$ y $24 \%$ ) en los seis primeros meses y en el noveno mes de tratamiento respectivamente (Tabla 8 y Tabla 23). Estos resultados se asemejan más a los resultados observados en otras investigaciones publicadas, en las que la tasa de prevalencia de incumplimiento intencionado tiene un rango de variación aproximadamente entre el $30 \%$ y el $40 \%{ }^{163,165}$.

Seguidamente, se ha procedido a comparar el grado de adherencia de los pacientes de la muestra en los seis primeros meses de tratamiento (Tabla 7) con el grado de adherencia al noveno mes de tratamiento (Tabla 22). Se observa que los porcentajes del grado bajo de adherencia se mantienen prácticamente iguales durante el período de seguimiento (9\% vs 11\%). Sin embargo, el grado alto de adherencia desciende drásticamente (48\% vs 19\%), mientras que el grado medio de adherencia se incrementa notablemente ( $43 \%$ vs $70 \%)$.

Estos sucesos representan una falta de continuidad en la toma de medicación por parte de los pacientes del estudio; pero esta falta de continuidad, sin embargo, no es total, puesto que la proporción de pacientes con un grado bajo de adherencia se mantiene prácticamente igual (se produjo un aumento de dos sujetos más). Por lo tanto, son los pacientes con un grado alto de adherencia los que disminuyen su cumplimiento hasta presentar un grado medio de adherencia (41 pacientes). Las diferencias en el grado de adherencia de los pacientes entre los primeros seis meses de tratamiento y el noveno mes de tratamiento resultan ser estadísticamente significativas (prueba con signo de Wilcoxon, $\mathrm{p}=0.000$ ) (Tabla 25 y Tabla 26), lo que indica que esta observación no se debe azar.

Estos resultados son consistentes con las observaciones de otros estudios en los cuales la falta de continuidad al tratamiento farmacológico para tratamientos de enfermedades crónicas disminuye significativamente después de los seis primeros meses de tratamiento ${ }^{109,118,257}$. Por ejemplo, los resultados del estudio de Barber et al. ${ }^{163}$ siguen la misma línea que los del presente estudio, puesto que estos autores observaron 
una falta de continuidad en el tratamiento a muy corto plazo tras la introducción de un nuevo fármaco para una condición crónica. Estos hechos pueden tener una explicación en los cambios que se producen en el régimen del paciente respecto a la dosificación, principio activo, posología, y/o vía de administración, hasta que el médico puede controlar y estabilizar la patología, y que habitualmente ocurren en los primeros meses de instauración de un régimen terapéutico definitivo. Los resultados de nuestro estudio confirman este razonamiento, al encontrar una asociación estadísticamente significativa $(\mathrm{p}=0.000)$ entre la adherencia y los cambios producidos en los regímenes farmacológicos después de la entrevista de la fase I (Tabla 30). 


\section{Discusión sobre los Resultados de los Factores que Inciden en la Adherencia}

\subsection{Factores Relacionados con la Características Socioeconómicas}

Los resultados del análisis estadístico bivariado de los factores relacionados con las características socioeconómicas no han establecido ningún tipo de asociación estadísticamente significativa entre las variables cualitativas sexo, nivel de alfabetización, necesidad de interprete, nivel de educación, área geográfica de residencia, situación laboral actual, y nivel de ingresos, con la variable dependiente adherencia en ninguna fase del estudio. Respecto a la variable cuantitativa edad, los resultados del análisis estadístico no han determinado diferencias estadísticamente significativas entre los sujetos del grupo adherente y los sujetos del grupo no adherente.

Los factores demográficos como sexo, nivel educación, y raza son, por lo general, desempeñan un papel minoritario como variables predictoras de adherencia, puesto que las asociaciones realizadas en los diferentes estudios han sido inconsistentes, o no se ha podido establecer una dirección precisa de las asociaciones ${ }^{98,122,126}$. Sin embargo, en este estudio se observan algunas variables demográficas con relevante información que se explican a continuación. 
Primeramente, cabe señalar que la edad es un factor demográfico particular en los estudios de adherencia al tratamiento farmacológico. Niveles de adherencia más elevados han sido asociados a un aumento de la edad del individuo, hasta que, aproximadamente, alcanza los 70 años, momento en el que generalmente el nivel de adherencia farmacológico empieza a disminuir, debido a otros procesos asociados con el aumento de la edad como, por ejemplo, la demencia y la reducción de la movilidad ${ }^{122}$. En este estudio, la edad no ha resultado asociada a adherencia en ningún análisis, debido, probablemente, por la inequidad en la distribución de los pacientes del estudio por grupos edad, ya que alrededor del 70\% de estos corresponden al grupo de edad 45-64 años y a esta edad no es frecuente que existan pérdidas cognitivas o de memoria.

Las variables cohabitación $\left(\mathrm{p}_{1}=0.039\right)\left(p_{1}\right.$ se referirá de aquí en adelante a la significación encontrada en la fase $I$, mientras que $p_{2}$ se referirá a la significación encontrada en la fase II), acceso a medicación factor coste $\left(\mathrm{p}_{1}=0.004\right)$, dificultades por ahorrar dinero $\left(\mathrm{p}_{1}=0.032\right)$, dificultades por precio elevado de los medicamentos $\left(\mathrm{p}_{1}=0.000\right)$, acceso a medicación relacionado con el factor transporte $\left(\mathrm{p}_{1}=0.008\right), \mathrm{y}$ dificultades en el desplazamiento $\left(\mathrm{p}_{1}=0.015\right)$ resultan estar asociadas significativamente con la adherencia en la fase I del estudio (Tabla 10); mientras que las variables raza/etnia $\left(\mathrm{p}_{2}=0.019\right)$, lugar de nacimiento $\left(\mathrm{p}_{2}=0.012\right)$, acceso a medicación factor transporte $\left(\mathrm{p}_{2}=0.001\right)$, dificultades para recoger las medicinas $\left(\mathrm{p}_{2}=0.004\right)$, y dificultades en el desplazamiento $\left(\mathrm{p}_{2}=0.003\right)$ resultan estar asociadas significativamente con la adherencia en la fase II del estudio (Tabla 27).

La variable cohabitación resulta estadísticamente significativa en la fase I del estudio $\left(\mathrm{p}_{1}=0.039\right)$, con una relación inversa y estadísticamente significativa con el incumplimiento para la categoría vivir en pareja/amigos (ARijpareja/amigos $=-2.4)$. Estos hallazgos son consistentes con los resultados de otros estudios que confirman que la ayuda y el apoyo de una esposa, pareja, compañero, o amigo, favorece y mejora el cumplimiento $^{107,126,258}$, probablemente porque estos sujetos tienen una rutina diaria más estructurada y organizada que aquellos que viven solos. Sin embargo, algunos estudios 
de adherencia no han encontrado ningún tipo de relación entre la variable cohabitación y cumplimiento $^{259,260}$ si la han encontrado no es consistente en el tiempo ${ }^{98,122,126}$. Esta inconsistencia de la variable cohabitación también ha sido observada en este estudio como queda reflejado en la ausencia de significación en la fase II del estudio ( $\mathrm{p}=0.111)$, debido probablemente, a los continuos cambios de vivienda que experimentan los sujetos de la muestra de este estudio debido a su difícil situación social.

Respecto a la variable raza/etnia, el análisis bivariado del estudio establece una relación estadísticamente significativa asociada al incumplimiento en la fase II del estudio $\left(\mathrm{p}_{2}=0.019\right)$. La población hispana/latina presenta una relación directa con el incumplimiento (ARijhispana/latina $=2.1$ ), mientras que la relación de la población blanca es inversa y significativa (ARijblanca $=-2.5$ ). Estos resultados se asemejan a los hallazgos de otros estudios en los que los grupos minoritarios raciales y étnicos han sido asociados a una menor adherencia que la población blanca o caucásica ${ }^{122,258,261,262}$. La población afroamericana no muestra ninguna relación estadísticamente significativa con el incumplimiento en este estudio.

Al comparar los resultados de las variables raza/etnia y lugar de nacimiento en fase I del estudio, se observa que ninguna variable es estadísticamente significativa. Este hecho puede estar relacionado con lo apuntado anteriormente, y ya observado en otros estudios décadas atrás ${ }^{263}$, de que las creencias culturales y populares de estos grupos poblacionales acerca de la medicación, la patología, y el tratamiento, influyen señaladamente sobre la adherencia al tratamiento, y se hacen más notables con el transcurso del período de tratamiento. Por ejemplo, Risser y Mazur ${ }^{264}$ encontraron entre la población hispana de su estudio creencias culturales de Salud muy extendidas como remedios "caseros" a base de zumos y combinaciones de hierbas que, en ocasiones, sustituían a la medicación prescrita. Pascal et al. ${ }^{265}$ encontraron las creencias en determinados "remedios" a base de hierbas y el asesoramiento dado por líderes espirituales como las causas más significativas de incumplimiento al tratamiento farmacológico en una clínica de atención primaria en Nigeria. 
El lugar de nacimiento también mantiene una relación estadísticamente significativa asociada al incumplimiento $\left(\mathrm{p}_{2}=0.012\right)$ en la fase II del estudio. Los pacientes nacidos fuera de EEUU presentan una probabilidad 4.44 veces mayor de incumplir el tratamiento que aquellos pacientes nacidos en EEUU $\left(\mathrm{OR}_{2}=4.44\right)\left(\mathrm{OR}_{2} \mathrm{se}\right.$ referirá de aquí en adelante al Odss Ratio encontrado en la fase II, mientras que $O R_{1}$, se referirá al Odss Ratio encontrado en la fase I). Una explicación plausible por la que esta variable resulta significativa puede tener el fundamento de que el lugar de nacimiento se ve influenciado por la raza o etnia al que pertenece cada sujeto. Sin embargo, la mayor parte de los individuos de este estudio pertenecientes a grupos minoritarios corresponde a segundas generaciones nacidas en EEUU, como lo demuestra la proporción de población minoritaria vs lugar de nacimiento fuera de EEUU (44 vs 106) (Tabla 1-A). Por consiguiente, el lugar de nacimiento o la condición de inmigrante se comporta como un factor asociado al incumplimiento que no está influenciado por el grupo racial/étnico del paciente. Estas observaciones son semejantes a los resultados encontrados en otros estudios $^{266,267}$ donde la condición de inmigrante se asocia al incumplimiento terapéutico de manera independiente.

Respecto al acceso a medicación, los problemas que experimentan los pacientes relacionados con el factor coste en la fase I del estudio están relacionados significativamente con el incumplimiento $\left(\mathrm{p}_{1}=0.004 ; \mathrm{OR}_{1}=2.69\right)$, ejerciendo un valor positivo sobre el incumplimiento las dificultades para ahorrar dinero $\left(\mathrm{p}_{1}=0.032\right.$; $\left.\mathrm{OR}_{1}=2.08\right)$ y las dificultades por el precio elevado de los medicamentos $\left(\mathrm{p}_{1}=0.000\right.$; $\mathrm{OR}_{1}=5.82$ ). En la fase II del estudio, ninguna variable relacionada con el factor coste resulta asociada. Esta circunstancia puede explicarse, principalmente, por la inestabilidad económica que estos grupos de población experimentan en la vida diaria, lo que provoca periodos en los que el acceso a su medicación es muy complicado, y otros en los que no lo es tanto. Hay que tener en cuenta que una gran proporción de dichos individuos se encuentra en situación de desempleo (36\%) y que la mayor parte de la proporción de individuos que se encuentra trabajando (38\%) lo hace de manera temporal y en ocasiones irregular, por lo que la remuneración recibida es reducida. 
A pesar de las ayudas que reciben los pacientes en ambos centros para el acceso a determinados medicamentos, las circunstancias explicadas anteriormente hacen que estas poblaciones dependan económicamente en numerosas ocasiones de familiares, o en menor medida de amigos, no sólo para tener acceso a su medicación, sino también para otras necesidades básicas como la alimentación o vivienda. Además, las características del Sistema de Salud estadounidense, es decir, la falta de financiación de los tratamientos terapéuticos debido al actual Sistema Sanitario liberal, el cual se plantea básica y fundamentalmente como un sistema económico, contribuye a empeorar la situación que sufren los pacientes.

A diferencia de otros Sistemas de Salud que tienen un carácter más social, como por ejemplo el Sistema Nacional de Salud Español donde los medicamentos para los grupos vulnerables llegan a estar cubiertos por una financiación de hasta el 100\%, el coste en medicamentos en EEUU representa una gran parte de los gastos de la vida diaria de los pacientes con enfermedades crónicas. Esta situación convierte el nivel económico del paciente en un factor que condiciona y/o determina el acceso a medicación, especialmente en las poblaciones que no tienen seguro médico como las del presente estudio. Por esta razón, la proporción de pacientes del estudio con dificultades debidas al factor coste $(41 \%)$ es notablemente más elevada que los resultados de otras investigaciones en las que el rango de pacientes con dificultades relacionadas con los costes de medicación se sitúa entre un $10 \%$ y un $20 \%{ }^{134,135,138}$. Por este motivo, la Administración de los EEUU viene planteando permanentemente reformas en el Sistema Sanitario y Social.

La asociación entre incumplimiento y el factor coste establecida en este estudio es consistente con otros estudios publicados. El elevado precio de los medicamentos repercute negativamente en el cumplimiento terapéutico ${ }^{90,98,129,131,132,134,137,265}$, al igual que la necesidad del propio paciente de ahorrar dinero a costa de la medicación ${ }^{128,131,268}$, especialmente en pacientes con patologías crónicas en los que el tratamiento puede llegar a durar toda la vida. El bajo nivel económico de los pacientes es sin duda una importante barrera en la adherencia al tratamiento en este estudio, pero no 
es la única, como se demostrará en el trascurso de esta discusión. Es más, algunos estudios como el de Avorn et al. ${ }^{256}$ han encontrado niveles de incumplimiento menores en aquellos sujetos de la muestra con mayores ingresos, justificando esta circunstancia por las posibles diferencias en el nivel de educación o conocimiento general sobre la Salud de los individuos.

Respecto al factor transporte, los resultados de la fase II y fase I del estudio han establecido una asociación estadísticamente significativa con el incumplimiento $\left(\mathrm{p}_{2}=0.001\right.$ y $\mathrm{p}_{1}=0.008 ; \mathrm{OR}_{2}=4.45$ y $\left.\mathrm{OR}_{1}=2.41\right)$ respectivamente, ejerciendo un valor positivo sobre el incumplimiento las dificultades para recoger las medicinas en la farmacia, tienda, y/o clínica $\left(\mathrm{p}_{2}=0.004 ; \mathrm{OR}_{2}=4.71\right)$, y las dificultades en el desplazamiento que los pacientes tienen que superar para acceder a su medicación $\left(\mathrm{p}_{2}=0.003\right.$ y $\mathrm{p}_{1}=0.015 ; \mathrm{OR}_{2}=5.50$ y $\left.\mathrm{OR}_{1}=2.37\right)$. A pesar de que las probabilidades de incumplimiento son más elevadas en la fase II del estudio, los resultados son similares en ambas fases a excepción de la variable dificultades para recoger las medicinas que no resulta significativa en la fase $I$. El motivo por el que las probabilidades de incumplimiento en la fase II son significativas puede ser fácilmente explicable, ya que un período de tratamiento más prolongado aumenta el número de ocasiones en la que el paciente tiene que desplazarse a retirar las medicinas, y con ello, aumenta la probabilidad de encontrar un número mayor de dificultades. Hay que recordar que el $29 \%$ de los pacientes del estudio vive en medio rural.

De igual forma, las observaciones de este estudio sobre las dificultades en el transporte, son consistentes con los hallazgos de otras investigaciones en las que confirman a estas como una importante barrera en el cumplimiento del tratamiento terapéutico ${ }^{130,139}$. Las dificultades en los costes del transporte (incluyendo gastos directos como gasolina, billete de transporte, el coste de pasar horas e incluso días viajando), así como las dificultades para recoger la medicación (como por ejemplo recorrer largas distancias), han resultado en una falta de continuidad de adherencia al tratamiento por parte de los pacientes en otros estudios ${ }^{130,139}$. Por ejemplo, Tuller et al. ${ }^{139}$ llevó a cabo un 
estudio donde examinaba con profundidad la relación entre adherencia y los costes relacionados con el transporte. En dicho estudio, los sujetos de la muestra manifestaron como razón principal de incumplimiento los problemas que estos encontraban para costearse el transporte; mientras que, en otras ocasiones, el motivo de incumplimiento se debió a la falta de transporte para llegar al lugar a retirar la medicación.

En adición, los problemas de transporte causan en los pacientes de este estudio preocupaciones y un estado de ansiedad, puesto que representan un desafío constante, circunstancia ya observada en previos estudios ${ }^{139}$, debido a que tienen que recoger la medicación semanal o mensualmente al tratarse de enfermedades crónicas que requieren de un tratamiento continuo. En adición, a los pacientes de este estudio les surge el dilema de si gastar el dinero en transporte para recoger las medicinas, o utilizarlo en otras necesidades básicas como es comida, vivienda, o educación, debido a su bajo nivel económico.

Por otra parte, el análisis multivariante de la fase II confirma a las variables razas/etnia y dificultades para recoger las medicinas del estudio como variables independientes asociadas al incumplimiento tras el control del resto de variables. Así, la población afroamericana del estudio presentó 1.07 (95\% IC, [1.03-8.31], p= 0.044, ajustado $\mathrm{OR}=1.07$ ) veces mayor de incumplir el tratamiento prescrito que la población blanca del estudio; para la población hispana/latina, la probabilidad de incumplir el tratamiento se elevó a 2.11 (95\% IC, [1.91-35.56], $\mathrm{p}=0.005$, ajustado $\mathrm{OR}=2.11$ ) veces mayor que la población blanca. Los sujetos que experimentan dificultades para recoger las medicinas presentaron 1.98 (95\% IC, [2.06-25.41], $\mathrm{p}=0.002$, ajustado $\mathrm{OR}=1.98)$ veces mayor de incumplir el tratamiento prescrito que la población que no tiene ninguna dificultad, probabilidad más reducida que la del análisis bivariado $\left(\mathrm{OR}_{2}=4.71\right)$, y que sugiere una causa subyacente como pueden ser la falta de recursos económicos y/o sociales para cumplir los tratamientos farmacológicos. 
En adición, el análisis multivariante en la fase I revela que los sujetos que experimentan dificultades para continuar su régimen prescrito debido a que se ven obligados a ahorrar dinero respecto a su medicación presenta 1.65 (95\% IC, [1.5817.15], $\mathrm{p}=0.007$, ajustado $\mathrm{OR}=1.65$ ) veces mayor de incumplir el tratamiento que la población que no tiene ninguna dificultad, probabilidad semejante a la del análisis bivariado $\left(\mathrm{OR}_{1}=2.08\right)$. Sin embargo, este factor no ha resultado predictivo de incumplimiento en la fase II, debido probablemente, a las razones apuntadas anteriormente sobre la inestabilidad económica de la muestra.

Al igual que en este estudio, las variables raza y etnia han sido independientemente asociadas a una mayor probabilidad de incumplir el tratamiento en estudios previos ${ }^{126}$. Algunas investigaciones han demostrado que la población afroamericana tiene un elevado incumplimiento a medicación relacionado con la hipertensión, hipercolesterolemia, enfermedad cardíaca, VIH, diabetes y esquizofrenia cuando se compara con pacientes de otros grupos raciales/étnicos ${ }^{114,258,269-272}$. Esta falta de adherencia a medicación también ha sido demostrada en la población hispano/latina en estudios de medicación relacionados con hipercolesterolemia, enfermedad cardíaca, VIH, y antidepresivos $258,273,274$. 


\subsection{Factores Relacionados con el Sistema o el Equipo de Asistencia Sanitaria}

Los resultados del análisis estadístico bivariado de los factores relacionados con el sistema o el equipo de asistencia sanitaria no han establecido ningún tipo de asociación entre las variables cualitativas centro de salud/clínica, información general recibida, información apropiadamente explicada, información adicional sobre medicación, y satisfacción con la relación con los profesionales sanitarios con la variable dependiente adherencia en ninguna fase del estudio. Asimismo, el análisis estadístico no ha determinado diferencias estadísticamente significativas de la variable cuantitativa número de lugares de recogida de la medicación entre los sujetos del grupo no adherente y los del grupo adherente.

Las variables información individualizada sobre medicación y posibles efectos secundarios $\left(\mathrm{p}_{1}=0.032\right)$ y frecuencia de consulta $\left(\mathrm{p}_{1}=0.008\right)$, resultan estar asociadas significativamente con la adherencia en la fase I del estudio (Tabla 11), mientras que en la fase II no muestran ningún tipo de asociación.

Numerosas investigaciones han puesto especial atención a la información recibida por los pacientes con respecto a su medicación y posibles efectos secundarios. Dicha información desempeña un papel fundamental en la mejora de la adherencia terapéutica para la Calidad de Vida del propio paciente ${ }^{98}$.

En la fase I de este estudio, la percepción del paciente de no recibir información individualizada sobre la medicación actual y sus efectos secundarios se comporta con una relación directa y estadísticamente significativa con el incumplimiento $\left(\mathrm{p}_{1}=0.032\right)$. Las personas que perciben no recibir una información individualizada sobre su medicación actual y sus efectos secundarios tienen una probabilidad 3.40 veces mayor de incumplir el tratamiento que las personas que perciben recibirlo $\left(\mathrm{OR}_{1}=3.40\right)($ Tabla 11). 
Estos resultados sugieren que un apropiado conocimiento de la medicación y de los posibles efectos secundarios, pueden reducir el incumplimiento intencionado del paciente, puesto que el paciente ya es consciente de lo que puede sucederle y sabría cómo actuar. Además, la información personalizada hace comprender al paciente el proceso patológico padecido y la influencia que puede ejercer el tratamiento en su sintomatología y pronóstico a medio y largo plazo. Por ejemplo, Lorenc y Branthwaite ${ }^{157}$ hallaron en su estudio mejores niveles de cumplimiento en aquellos pacientes que conocían con mejor exactitud su régimen de medicación. En la revisión sistemática sobre adherencia a los tratamientos antituberculosos, Munro et al. ${ }^{156}$, señalaron a los efectos secundarios y a los efectos adversos como frecuentes causas de incumplimiento. En la mayoría de los estudios de dicha revisión, el paciente manifestó no haber recibido información previa sobre los efectos secundarios y posibles efectos adversos, ni tampoco sabía cómo actuar en caso de padecerlos.

En esta misma línea, en la investigación llevada a cabo por Barber et al. ${ }^{163}$ sobre nueva medicación para pacientes con enfermedades crónicas, más de la mitad de los pacientes incumplidores al tratamiento (57\%) expresaron su insatisfacción con la información recibida y declararon la necesidad de recibir más información. Es más, para algunos autores como Tebbi ${ }^{275}$, materiales escritos con las recomendaciones del médico e información sobre la/s condición/es padecida/s, la medicación, y los efectos secundarios, son más efectivos que las recomendaciones orales dadas por los médicos, pues estas generalmente se olvidan rápidamente. Sin embargo, en nuestra investigación no se ha establecido ningún resultado estadísticamente significativo respecto a la información adicional escrita recibida por los pacientes.

Las anteriores observaciones junto con las de nuestro estudio, ponen de manifiesto la necesidad de que el paciente reciba una información comprehensiva y personalizada que le haga comprender la necesidad de su medicación actual y los posibles efectos secundarios, junto con materiales adicionales escritos que le sirvan para recordar la conversación de la entrevista médica y para mejorar dicha información. 
Por otra parte, cabe destacar que no se ha determinado ningún tipo de asociación significativa entre la información recibida y la adherencia en la fase II del estudio. Esta circunstancia puede ser debida tal y como Barber et al. ${ }^{163}$ apuntan, a que el paciente solamente se percata de la necesidad de información acerca de su medicación y efectos secundarios una vez que ha experimentado la toma de medicación. Una vez experimentada la toma de medicación, al paciente le surgen nuevas preguntas y preocupaciones que son respondidas en posteriores consultas médicas, cuando el paciente ya ha experimentado una falta de continuidad en su tratamiento. En algunas ocasiones, el paciente no recurre al profesional sanitario para obtener respuesta a sus nuevas preguntas, ya sea bien por falta de confianza o lejanía de la próxima consulta, sino que recurre a amigos, familiares, o a sus propias creencias ${ }^{163}$. Este hecho puede dar lugar a la obtención de una información errónea o inapropiada en la mayoría de las ocasiones, que contribuye a aumentar el incumplimiento terapéutico, aspecto que hay que tener presente para incidir en la importancia de la instrucción sanitaria y cultural del grupo social y de iguales al que el individuo pertenece.

La variable frecuencia de consulta en la fase I mantiene una asociación estadísticamente significativa con el incumplimiento $\left(\mathrm{p}_{1}=0.008\right)$ (Tabla 11). Los pacientes que acuden quincenal y mensualmente a consulta tienen una relación inversa y estadísticamente significativa con el incumplimiento terapéutico $\left(A R i j_{q u i n c e n a l ~}=-2.4 \mathrm{y}\right.$ $A R i j_{\text {mensual }}=-1.9$ ), mientras que la relación de los pacientes que acuden con una frecuencia trimestral con el incumplimiento es directa (ARijtrimestral=2.4). Las categorías semestral y anual no resultan significativas, aunque la tendencia observada con el incumplimiento es directa.

Los resultados de este estudio sugieren que una consulta más frecuente en el tiempo favorece un mejor cumplimiento, probablemente, debido al establecimiento de una relación más sólida paciente-doctor, que provoca en el primero una mayor confianza para cumplir los objetivos de su tratamiento. Los hallazgos son consistentes con estudios anteriores, que han relacionado una frecuencia de consulta más corta en el tiempo, o un número mayor de consultas, con mejores resultados en la adherencia ${ }^{276,277}$ y con un 
control más rápido y adecuado, de los niveles de hemoglobina $\mathrm{A} 1_{\mathrm{c}}$, presión arterial, y colesterol $^{278,279}$. Es más, basados en los resultados de su estudio, Patel et al. ${ }^{276}$ sugieren que, un aumento en la frecuencia de consulta pueden ser una buena estrategia para mejorar la adherencia de aquellas personas que son incumplidores con su tratamiento farmacológico.

No obstante, tal y cómo apuntan algunos autores como Plantinga et $\mathrm{al}^{277}$, un incremento en la frecuencia de consulta conllevaría un mayor aumento de costes, de utilización de recursos, y de consultas de pacientes, en un Sistema que ya de por sí está saturado. En cambio, para Patel et al. ${ }^{276}$ estos inconvenientes pueden ser minimizados por otros profesionales sanitarios, como por ejemplo enfermeras o farmacéuticos, que pueden ofrecer apoyo clínico a estos pacientes para mantener un apropiado nivel de adherencia. Es más, dichos autores señalan que no todas las consultas requerirían ser cara a cara, y se podría utilizar nuevas estrategias como por ejemplo realizar visitas de grupo y utilizar las TIC para realizar comunicaciones vía telefónica o vía videoconferencia. Estas estrategias, según Patel et al. ${ }^{276}$ mejorarían la adherencia a cualquier tratamiento farmacológico y reforzarían la educación del paciente acerca de su enfermedad, tratamiento, y efectos secundarios. Futuras líneas de investigación serán necesarias para valorar las influencias de las TIC, particularmente internet, redes sociales, y apps, que actualmente están a disposición del paciente para mejorar la comunicación efectiva y, por tanto, mejorar la adherencia y el proceso asistencial en su conjunto como se contempla en las Estrategias de Atención al Paciente Crónico desarrolladas en algunos Sistemas Sanitarios, como el Sistema Nacional de Salud Español ${ }^{231}$.

En la fase II del estudio, la variable frecuencia de consulta no muestra ningún tipo de asociación. Es frecuente que los pacientes de este estudio acudan con mayor regularidad a consulta durante los primeros meses de tratamiento después de haber inicializado un nuevo régimen farmacológico hasta que el médico puede controlar la patología y el paciente consiga adquirir un estadio estable. Una vez que la patología está 
totalmente controlada, las sucesivas consultas se producen con menor frecuencia. Este hecho puede explicar la ausencia de significación de la variable en fase II del estudio.

Los análisis del estudio también han permitido hallar diferencias estadísticamente significativas en ambas fases del estudio entre los grupos de pacientes no adherentes y adherentes, de las variables relación de comunicación $\left(\mathrm{p}_{1}=0.028\right.$ y $\left.\mathrm{p}_{2}=0.016\right)$ y apoyo social $\left(\mathrm{p}_{1}=0.012\right.$ y $\left.\mathrm{p}_{2}=0.016\right)$. Los resultados muestran una valoración media del grupo adherente ligeramente superior, a la valoración media del grupo no adherente en ambas fases del estudio y para ambas variables, siendo mínimamente superiores las valoraciones de la fase II (Tablas 12 y Tabla 28).

Estos resultados sugieren que el grupo adherente percibe recibir una mejor comunicación y respaldo social que el grupo no adherente. Estos hallazgos son comparables a los encontrados en otros estudios de adherencia centrados en la relación médico-paciente. En estos estudios ha quedado demostrado que una pobre comunicación tiene un efecto negativo sobre la adherencia al tratamiento farmacológico, mientras que una comunicación clara, eficaz, y directa ha sido asociada con mejores niveles de adherencia $^{90,98,141,143}$. Un descontento en la comunicación hace que el paciente no siga los consejos dados por el médico y, en consecuencia, no se adhiera el tratamiento. Sin embargo, un paciente que mantiene una comunicación de calidad y al que se le hace partícipe en las decisiones de su régimen, alcanza mejores niveles de adherencia ${ }^{90,98,141,143}$. Análogos resultados han sido demostrados con respecto al apoyo social por Jin et al. ${ }^{141}$. Estos autores observaron en los artículos de su revisión sistemática que los pacientes que reciben apoyo social, ya sea bien de la familia, de los amigos, o del médico obtienen mejores resultados de adherencia al tratamiento. Manteniendo una buena comunicación con el médico y recibiendo apoyo social, el paciente reduce las actitudes negativas hacia el tratamiento, e incrementa la motivación y la responsabilidad de implementar correctamente el tratamiento ${ }^{141}$.

Como se ha mencionado anteriormente, las valoraciones medias de todos los sujetos en ambas fases del estudio en comunicación y apoyo social han sido muy elevadas. En ambos casos se han obtenido calificaciones por encima de 9 sobre una escala 
académica de 10, lo que explica las diferencias mínimas entre las valoraciones medias de ambos grupos. Dichas valoraciones, han sido posibles gracias al acceso gratuito a los servicios de Salud, así como a determinados medicamentos y productos sanitarios que los pacientes disfrutan, y también al apoyo social recibido de todos los profesionales que trabajan en los centros que ponen una motivación y una especial sensibilidad con la población que acude a los centros, particularmente del trabajador social que cumple una función más que destacada.

\subsection{Factores Relacionados con la Enfermedad}

Los resultados del análisis estadístico bivariante de los factores relacionados con la enfermedad del paciente no han establecido ninguna asociación estadísticamente significativa entre las variables cualitativas índice de masa corporal, actividad física, consumo de tabaco, consumo de alcohol, clase de bebida, y drogas, con la variable dependiente adherencia en ninguna fase del estudio. Respecto a las variables cuantitativas, no se han determinado diferencias estadísticamente significativas entre los sujetos del grupo no adherente y los sujetos del grupo adherente de ninguna variable de los factores relacionados con la enfermedad del paciente.

La variable cualitativa grupo de riesgo clínico ha resultado estar asociada significativamente con la adherencia en ambas fases del estudio $\left(\mathrm{p}_{1}=0.000\right.$ y $\left.\mathrm{p}_{2}=0.008\right)$ (Tabla 13 y Tabla 29). El análisis de los residuos tipificados corregidos del grupo de riesgo clínico G3, es decir, los pacientes pluripatológicos con elevadas necesidades de atención sanitaria y con frecuentes necesidades sociales, revela una relación inversa y estadísticamente significativa de este grupo de pacientes con el incumplimiento en fase I 
del estudio (ARij $\mathrm{G}_{\mathrm{G}}=-3.4$ ) y en la fase II (ARij $\mathrm{G} 3=-2.7$ ). Esta relación puede explicarse en primer lugar, debido a que la mayoría de los sujetos categorizados en este grupo tienen a un familiar como "cuidador informal", que, al mismo tiempo, es el responsable del control y la toma de medicación del paciente debido a la severa o moderada dependencia física y funcional ante las AVD que presentan este tipo de pacientes. El papel que desempeña un cuidador familiar respecto a la adherencia ha sido asociado en otros estudios como un factor fundamental en el cumplimiento ${ }^{280}$ puesto que además de ser los responsables de la toma de medicación del paciente, proporcionan un apoyo comprensivo y emocional en todo momento al paciente ${ }^{141}$. En segundo lugar, los episodios de hospitalización sufridos por este grupo de pacientes les han impulsado a conseguir una mayor concienciación de la gravedad del Estado de su Salud, repercutiendo de forma positiva en su adherencia, hecho observado en estudios anteriores ${ }^{146,281}$.

El grupo de riesgo clínico más numeroso con un total de 110 pacientes es el grupo de riesgo clínico G2, (Tabla 3-B), es decir, los sujetos con dos o más patologías estables o con una en estadio avanzado y con una necesidad de atención sanitaria moderada. Los análisis de los residuos tipificados corregidos del grupo de riesgo clínico G2 muestran una relación directa y significativa de este grupo de pacientes con el incumplimiento en la fase $I\left(\mathrm{ARij}_{\mathrm{G} 2}=4.7\right)$ y en la fase $I I\left(\mathrm{ARij}_{\mathrm{G} 2}=2.9\right)$. La relación directa con el incumplimiento puede ser explicada por las diferentes circunstancias a continuación se proceden a examinar.

En primer lugar, la mayoría de estos pacientes están asociados a un mayor uso de prescripciones médicas para tratar su multimorbilidad. El uso de múltiples prescripciones para tratar enfermedades crónicas da lugar a interacciones medicamentosas, errores médicos en prescripción, duplicidades, sobredosificaciones e infradosificaciones, uso inapropiado de los medicamentos por parte del paciente, baja adherencia a la medicación, y la aparición de efectos adversos ${ }^{81}$ lo que aumenta la probabilidad de que el paciente incumpla su tratamiento (hay que recordar que en torno al $25 \%$ de los pacientes del estudio dejaron de tomar la medicación porque le sentaron mal los medicamentos) (Tabla 8 y Tabla 23). 
Además, el uso de múltiples prescripciones médicas genera un grado de polifarmacia en el régimen terapéutico ${ }^{78,97}$ (como posteriormente será analizado), caracterizado por un mayor número de pastillas, inyecciones, inhaladores y/u otras formas medicamentosas, con horarios complejos para la toma de medicación, lo que incrementa la probabilidad de incumplimiento no intencionado (hay que recordar que en torno al $95 \%$ de los sujetos no adherentes del estudio cometen un incumplimiento no intencionado) (Tabla 8 y Tabla 23). Por último, hay que añadir a estas circunstancias el alto coste monetario asociado al uso de múltiples prescripciones médicas ${ }^{80,82,238}$ en una población de estudio cuyo nivel socioeconómico es bajo de por sí (el $40 \%$ de los pacientes del estudio tienen problemas de acceso a la medicación por el factor coste). Estos hechos explican la asociación directa del grupo de riesgo clínico G2 con el incumplimiento.

El análisis de los residuos tipificados corregidos del grupo de riesgo G1, es decir, los pacientes que sufren una patología estable o en estadio inicial y con baja necesidad de atención sanitaria, establece existir una relación inversa y estadísticamente significativa de este grupo de pacientes con el cumplimiento en la fase I del estudio (ARijG1= -2.8) y con la misma relación inversa, pero en ausencia de significación estadística en la fase II. Estos pacientes habitualmente están caracterizados por no presentar ningún grado de polifarmacia o presentar un grado pequeño, un número mínimo de formas medicamentosas prescritas, generalmente con una vía de administración, y con horarios de administración sencillos, que hacen más fácil la toma de medicación, y consecuentemente, disminuir el riesgo de incumplimiento no intencionado. Estas características explican la relación directa de este grupo de riesgo con el cumplimiento. Al mismo tiempo, un régimen farmacológico cuya complejidad sea nula o muy pequeña, es también más fácil de olvidar a largo plazo, pues la concienciación sobre el Estado de Salud y los autocuidados disminuyen ${ }^{146,281}$, circunstancia que puede explicar la ausencia de significación en la fase II del estudio.

El análisis multivariante de la fase II confirma las diferencias significativas en el incumplimiento entre los distintos grupos de riesgo clínico al controlar el resto de 
variables. De este modo, los pacientes del grupo de riesgo G2 presentan 5.49 (95\% IC, [1.54-19.57], $\mathrm{p}=0.009$, ajustado $\mathrm{OR}=5.49$ ) veces mayor de incumplir el tratamiento prescrito que los pacientes del grupo de riesgo G3. Los pacientes del grupo de riesgo G1 presentan una tendencia similar pero no existe ningún tipo de asociación estadísticamente significativa $(\mathrm{p}=0.339)$. En ambas fases del estudio los resultados del análisis multivariante han revelado tendencias similares para los mismos grupos de riesgo clínico, pero las probabilidades de incumplir el tratamiento en la fase I son más elevadas para el grupo de riesgo G1 $(\mathrm{OR}=16.39$, 95\% $\mathrm{IC}$, [1.09-245.57], $\mathrm{p}=0.043)$ y son significativas para el grupo de riesgo G2 ( $\mathrm{OR}=51.92,95 \% \mathrm{IC},[5.47-493.49], \mathrm{p}=0.001)$ con respecto al grupo de riesgo G3.

Estos resultados son consistentes con los del análisis bivariado y confirman la mayor probabilidad de incumplir el tratamiento de los pacientes del grupo G1 y G2 con respecto a los sujetos que componen el grupo de riesgo G3. Las diferencias en la probabilidad del incumplimiento entre las dos fases del estudio pueden estar justificadas debido a la mayor consistencia con el cumplimiento terapéutico a largo plazo de los pacientes del grupo de riesgo G3 (cuidador familiar de apoyo y mayor concienciación por patologías y multimorbilidad) y las mayores barreras que presentan los grupos G1 y G2 con el transcurso del período del tratamiento, por los argumentos anteriormente explicados.

No han sido encontrados resultados de otros estudios de adherencia a medicación respecto a la variable grupo de riesgo para compararlos con nuestro estudio. El motivo de la ausencia de estudios en éste área en la actualidad puede ser debido a la reciente implantación de la Estrategia de Atención al Paciente Crónico, introducida en determinadas comunidades autónomas de España, como por ejemplo la de Castilla y León, Andalucía, Madrid, País Vasco, Cataluña, Comunidad Valenciana, Murcia, Comunidad de Madrid, y Comunidad Foral de Navarra; y al hecho de que se trata de una estrategia a nivel nacional, aunque tomada como referencia de dos modelos internacionales como son The Chronic Care Model (CCM) y The Kaiser-Permanente Pyramid. 


\subsection{Factores Relacionados con el Tratamiento}

Los resultados del análisis estadístico bivariado de los factores relacionados con el tratamiento del paciente no han establecido ninguna relación estadísticamente significativa entre la variable cualitativa dieta con la variable dependiente adherencia. Respecto a las variables cuantitativas, no se han determinado diferencias estadísticamente significativas entre los sujetos del grupo no adherente y los sujetos del grupo adherente de ninguna variable de los factores relacionados con el tratamiento del paciente.

La variable cualitativa técnicas de monitorización muestra una asociación estadísticamente significativa con la adherencia en ambas fases del estudio $\left(\mathrm{p}_{1}=0.000 \mathrm{y}\right.$ $\left.\mathrm{p}_{2}=0.009\right)$ mientras que la variable grado de polifarmacia del tratamiento sólo ha resultado significativa en la fase $I\left(\mathrm{p}_{1}=0.008\right)$ (Tabla 14 y Tabla 30$)$.

El control de la presión arterial y la glucosa fuera del entorno clínico es un componente esencial de los autocuidados para que el paciente pueda prevenir mayores trastornos, limitar la enfermedad, y restaurar la Salud ${ }^{143}$. Los resultados del estudio señalan que los pacientes que no realizan prácticas de monitorización fuera del entorno clínico tienen una relación directa y estadísticamente significativa con el incumplimiento $\left(\mathrm{p}_{1}=0.000, \mathrm{OR}_{1}=3.89\right.$ y $\left.\mathrm{p}_{2}=0.009, \mathrm{OR}_{2}=3.30\right)$. Estos resultados sugieren una asociación importante y consistente en el tiempo (fase I y fase II) entre el incumplimiento y el no emplear técnicas de monitorización fuera del entorno clínico, de acuerdo a las recomendaciones individualizadas dadas por los profesionales sanitarios a cada paciente. 
Los resultados del análisis multivariado confirman la importancia de la práctica de las técnicas de monitorización fuera del entorno clínico como una variable predictora de incumplimiento en la fase $I$, con una probabilidad levemente inferior a la obtenida en el análisis bivariado $(\mathrm{OR}=2.69,95 \%$ IC, [1.12-6.45], p=0.027). Sin embargo, en el periodo de seguimiento (fase II) la contribución de las técnicas de monitorización como variable predictora con respecto a la contribución de las otras variables pasa a ocupar un segundo plano, sin resultar significativa en el análisis multivariado.

Si comparamos los hallazgos de este estudio con los existentes en la literatura científica publicada, encontramos que las prácticas de monitorización han sido ampliamente recomendadas para el manejo de la hipertensión y de la diabetes ${ }^{143}$. Además, estas han sido objeto de numerosas intervenciones para mejorar el control de los niveles de presión arterial y glucosa en sangre ${ }^{282,283}$. Sin embargo, existen limitados estudios donde pongan de manifiesto la monitorización como mejora para la adherencia al tratamiento. Entre estos, los más significativos fueron recogidos por Ogedegbe y Schoenthaler ${ }^{284}$ en una revisión sistemática donde observaron en seis de los once ensayos aleatorios controlados, una mejoría significativa de la adherencia con la monitorización de la presión arterial, consistente con los hallazgos de este estudio.

La única diferencia de esta investigación con respecto al empleo de técnicas de monitorización de otros estudios, es que los pacientes de este estudio controlan su presión arterial frecuentemente en supermercados, estaciones de bomberos, y centros comerciales; mientras que los pacientes de otros estudios lo realizan en el domicilio. La razón de estas diferencias radica en que una gran proporción de los sujetos de este estudio, no dispone de equipos de monitorización de presión arterial en su vivienda. En EEUU, en lugares como centros comerciales o supermercados, es frecuente encontrar estaciones para la toma de la presión arterial totalmente gratuitas. En estas estaciones, adicionalmente a la toma de la presión arterial, el paciente puede controlar su peso, frecuencia cardíaca, índice de masa corporal, e índice de grasa, con la posibilidad de crear una ficha automáticamente donde se registran los valores obtenidos, además de la fecha, 
y la hora, y se envía automáticamente por email al individuo. De este modo, el sujeto puede llevar un seguimiento más fácil de su presión arterial y sin ningún coste.

Las estaciones de presión arterial son muy recomendadas por los profesionales sanitarios de los centros, ante la imposibilidad de muchos pacientes de adquirir equipos de presión arterial y de carecer de las destrezas y entrenamiento necesario para una correcta utilización y funcionamiento de estos. Para la monitorización de la glucosa en sangre, los centros suministran equipos específicos para aquellos pacientes diabéticos que no pueden acudir a al centro con regularidad para el seguimiento de sus niveles. Estos pacientes son educados en los propios centros para una correcta medición y valoración de los niveles de glucosa.

No es un hecho sorprendente que aquellos pacientes que cumplen con las recomendaciones de los profesionales sanitarios respecto a prácticas de monitorización, cumplan también las recomendaciones de la toma de medicación. De acuerdo con Delamater ${ }^{143}$ los autocuidados con monitorización suponen un componente fundamental en el cambio de conducta que refuerza la concienciación sobre el cumplimiento y permite un seguimiento en el tiempo, particularmente para los regímenes más complejos.

Por otro lado, la variable grado de polifarmacia en la fase I muestra una asociación estadísticamente significativa con el incumplimiento $\left(\mathrm{p}_{1}=0.008\right)$. El resultado del análisis de los residuos tipificados corregidos del grado de polifarmacia revela una relación directa y estadísticamente significativa de un moderado grado de polifarmacia con el incumplimiento, mientras que la relación de un régimen sin ningún grado de polifarmacia con el incumplimiento resulta inversa y significativa. Las categorías pequeño grado y elevado grado de polifarmacia no resultaron significativas, aunque la tendencia observada es directa al incumplimiento.

Estos resultados se suman a las extensas investigaciones de adherencia al tratamiento existentes en la actualidad que señalan el fenómeno de polifarmacia, definido como el uso de cinco o más prescripciones médicas ${ }^{49,81}$, como una importante barrera 
en el cumplimiento del tratamiento farmacológico $24,78,89,102,113,120,146,150,151,285$. Este estudio ha querido profundizar más allá de la mera asociación de adherencia con el fenómeno de polifarmacia, y ha examinado su grado. Los hallazgos indican que sólo un moderado grado de polifarmacia es significativo con respeto al incumplimiento. A priori cabría pensar que a mayor grado de polifarmacia mayor grado de asociación con el incumplimiento. Sin embargo, los pacientes con un elevado grado de polifarmacia son generalmente los pacientes con riesgo clínico más elevado (pacientes pertenecientes al grupo G3). Estos pacientes, como se ha explicado anteriormente, tienen más conciencia de la importancia del cumplimiento farmacológico debido a su precario Estado de Salud, su mayor demanda y utilización de los servicios de urgencia, y su mayor riesgo de hospitalizaciones. Estos motivos son las causas por las que no existe significación con el alto grado de polifarmacia. Por otro lado, un pequeño grado de polifarmacia no ha sido asociado significativamente con el incumplimiento ya que el número de prescripciones en este grado (entre tres y cinco) todavía no es lo suficiente como para apreciar las consecuencias de la polifarmacia.

Respecto a las variables cuantitativas, los resultados del análisis estadístico han establecido diferencias estadísticamente significativas en la fase I del estudio entre los grupos de pacientes no adherentes y adherentes, de las variables número de prescripciones $\left(\mathrm{p}_{1}=0.003\right)$, número de pastillas/día $\left(\mathrm{p}_{1}=0.000\right)$, y otras formas medicamentosas, como colirios, enemas, y medicamentos tópicos $\left(\mathrm{p}_{1}=0.044\right)$. Los resultados muestran un número medio por paciente de prescripciones, pastillas/día, y otras formas medicamentosas superior en el régimen de medicación de los pacientes no adherentes respecto al régimen de medicación de los pacientes adherentes (Tabla 15). Estas diferencias apuntan a que el incumplimiento es más frecuente a media que aumenta el número de medicinas en el régimen farmacológico.

Estos hallazgos se suman a las evidencias de otros estudios que sostienen que la adherencia al tratamiento disminuye al aumentar el número de prescripciones, número de pastillas, otras formas medicamentosas, y frecuencia de dosis $\mathrm{s}^{24,89,102,113,120,146,150,151}$. Por ejemplo, un incremento en el número de dosis diarias de 1 pastilla a 4 pastillas en el 
régimen farmacológico de pacientes epilépticos, produjo una reducción de la adherencia de los pacientes de la muestra desde, el $81 \%$ hasta el $39 \%$. Estos datos son muy llamativos si se comparan con nuestro estudio, pues el $62 \%$ de los sujetos de la muestra presenta al menos 4 pastillas diarias en su régimen farmacológico.

Dada la multimorbilidad del grupo de sujetos de la muestra, los pacientes tienen que hacer frente a distintas patologías mediante un número elevado de medicamentos, que, generalmente, van acompañados de regímenes de dosificación complejos, que incluyen varias tomas de medicación al día, y que consecuentemente, dificultan la adherencia al tratamiento $^{146}$. Además, al número elevado de medicamentos está asociado a numerosos factores (brevemente explicados anteriormente) que dificultan la adherencia, como por ejemplo, un mayor coste económico, que supone un gran esfuerzo para los sujetos de la muestra debido a su reducido nivel económico; una mayor complejidad para recordar la toma de medicación, especialmente en los pacientes del estudio donde el olvido de la medicación ocurre en más del $80 \%$ de las situaciones de incumplimiento; una excelente habilidad para el control de los automanejos para no confundir entre sí los medicamentos y seguir la posología indicada; y un mayor número de efectos adversos, importante causa de incumplimiento entre los pacientes de este estudio donde alrededor del $25 \%$ de las situaciones de incumplimiento se deben a que al paciente le "sentaron mal los medicamentos".

El hecho de que en la fase II del estudio, dejen de ser significativas las variables grado de polifarmacia $\left(\mathrm{p}_{2}=0.725\right)$, número de prescripciones $\left(\mathrm{p}_{2}=0.427\right)$, número de pastillas/dia $\left(\mathrm{p}_{2}=0.214\right)$, y otras formas medicamentosas usadas $\left(\mathrm{p}_{2}=0.685\right)$, sugiere que estas variables tienen un papel secundario con el trascurso del tratamiento, fundamentalmente, porque el paciente se va familiarizando con el régimen terapéutico, y va consiguiendo una mayor práctica y manejo de las medicaciones. En los primeros meses de tratamiento después de la inicialización de un nuevo régimen farmacológico, como es el caso de los pacientes de este estudio, es frecuente que el paciente tarde en "habituarse" a su nueva medicación, especialmente, si el horario de la toma de medicación 
coincide con ciertas ocupaciones relacionados con el trabajo. Además, hasta que la patología está totalmente controlada, en los primeros meses de tratamiento se producen continuos cambios en el régimen farmacológico, dificultando si cabe aún más la familiarización del paciente con su régimen.

Estos continuos cambios repercuten negativamente en el cumplimiento del paciente, como así ha quedado demostrado en el resultado del análisis bivariado. Los cambios producidos en el régimen farmacológico de los pacientes tras la fase I del estudio resultan estar asociados significativamente con el incumplimiento $\left(\mathrm{p}_{2}=0.000\right)$. Los pacientes a los que se les introduce cambios en el régimen farmacológico respecto a dosificación, principio activo, posología, y/o vía de administración tras la fase I tienen una probabilidad 8.40 veces mayor de incumplir el tratamiento que a los pacientes que no se les introduce ningún tipo de cambio en su tratamiento $\left(\mathrm{OR}_{2}=8.40\right)$ (Tabla 30).

\subsection{Factores Relacionados con el Paciente}

Los resultados del análisis estadístico bivariado de los factores relacionados con el paciente no han establecido ninguna relación estadísticamente significativa entre las variables cualitativas dificultades sensoriales, índice de Barthel, conocimiento de la toma de cada medicamento, apoyo familiar recibido, y percepción de los pacientes de necesitar ayuda para el control de la medicación. Respecto a las variables cuantitativas, no se han determinado diferencias estadísticamente significativas entre los sujetos del grupo no adherente y los sujetos del grupo adherente de ninguna variable de los factores relacionados con el paciente. 
En la fase I del estudio, el conocimiento sobre las condiciones padecidas y el tratamiento farmacológico ha resultado estar relacionado significativamente con el incumplimiento $\left(\mathrm{p}_{1}=0.018\right)$ con una probabilidad 9.26 veces mayor de incumplir el tratamiento aquellos pacientes con un conocimiento incompleto de las condiciones que padecen y su tratamiento farmacológico $(\mathrm{OR}=9.26)$, ejerciendo un valor positivo sobre el incumplimiento el desconocer el número de medicamentos del régimen y la posología de éste $\left(\mathrm{p}_{1}=0.014\right)$, sin poder calcular el OR al no existir pacientes del grupo adherente que desconozcan el número de medicamentos y la posología de su tratamiento (Tabla 16).

Los hallazgos de este estudio confirman lo propuesto en previas investigaciones las cuales destacan el papel fundamental que desempeña el conocimiento de las patologías padecidas y el tratamiento farmacológico sobre el incumplimiento ${ }^{90,98,102,103,120,143,162}$. Un ejemplo de la importancia del papel fundamental que juega el conocimiento lo demuestra el estudio llevado a cabo por Kim et al. ${ }^{162}$, donde el desconocimiento que poseían los pacientes del estudio sobre la hipertensión arterial resultó ser un factor predictivo en el incumplimiento voluntario. Estos resultados junto con los de nuestro estudio, ponen de evidencia la necesidad de que el paciente posea un adecuado conocimiento sobre las enfermedades padecidas y sobre el tratamiento farmacológico de las mismas.

Sin embargo, algunos autores han enfatizado en que el conocimiento no es suficiente para garantizar el cumplimiento, sino que debe de ir acompañado de una comunicación médico-paciente apropiada para promover la adherencia ${ }^{98,141,143}$, y de una participación activa del paciente en las decisiones relacionadas con las patologías sufridas, y los objetivos de su tratamiento ${ }^{146}$. Cuando el paciente es consciente de su problema de Salud, aumenta su responsabilidad y compromiso, colabora de manera más activa y eficiente en su tratamiento, y consigue un mayor nivel del cumplimiento terapéutico $^{287}$. En este estudio el conocimiento sobre las condiciones padecidas y el tratamiento farmacológico de las mismas se acompaña en todo momento de una comunicación médico-paciente excelente (como así lo afirma cerca del 90\% de los 
pacientes de la muestra) y de un papel activo del paciente en las decisiones que respecta a su Salud (debido a las dificultades sociales de estas poblaciones, los médicos hacen especialmente partícipe al paciente, en la medida de lo posible, en las decisiones acerca de su tratamiento).

En la fase II del estudio, ninguna variable sobre el conocimiento resulta significativa. Esta circunstancia puede ser debida a que una gran parte de los pacientes de nuestro estudio buscan, por iniciativa propia, información en internet relacionada con la/s patología/s padecida/s, los medicamentos de su régimen, así como los posibles efectos secundarios de estos, sino han recibido información tras varias consultas médicas. El avance de las TIC, especialmente de las redes sociales y de internet, ha permitido un acceso a la información más rápido, fácil, y accesible ${ }^{288,289}$. Sin embargo, la gran cantidad de información existente en la red hoy en día, puede jugar como un papel negativo al ofrecer información errónea, engañosa, o de pobre calidad ${ }^{290}$. Los pacientes necesitan ser orientados para realizar una búsqueda de información acorde a sus necesidades y capacidades, que se presente de una manera que pueda ser entendida, independientemente de su educación o contexto cultural ${ }^{290}$. Los profesionales sanitarios deben de desempeñar un papel fundamental orientando al paciente en su búsqueda por internet mediante la recomendación de páginas Web de información clara, completa, y oportuna, con la finalidad de aumentar el conocimiento del paciente.

La variable persona responsable de la medicación ha resultado estar asociada significativamente con el incumplimiento $(\mathrm{p}=0.024)$, en la fase $I$ del estudio. Los pacientes cuyos responsables de la toma de medicación son ellos mismos tienen una probabilidad 2.90 veces mayor de incumplir el tratamiento que los pacientes que tienen a un miembro familiar como responsable $(\mathrm{OR}=2.90)$ (Tabla 16). Los hallazgos de este estudio son consistentes con previas investigaciones que asocian el papel favorecedor de un "cuidador profesional" o un "cuidador informal" sobre el cumplimiento del tratamiento $^{262,280}$. 
Todos los pacientes de este estudio que relegan la responsabilidad de la toma de medicación en otra persona lo realizan sobre un familiar, y generalmente, éste suele ser un familiar de primer grado. Tal y como indica Fredriksen-Goldsen et al. ${ }^{280}$ los cuidadores familiares desempeñan un papel trascendental, mejorando el cumplimiento del paciente y cimentando los principales factores relacionados con la adherencia, como por ejemplo acceso a medicación, conocimiento sobre el tratamiento y las enfermedades padecidas, y la motivación. Estas observaciones se corroboran completamente con las observadas en esta investigación. Los cuidadores familiares de los pacientes de este estudio facilitan el acceso a la medicación ayudando económicamente a los pacientes para hacer frente al coste de los medicamentos. Además, los cuidadores facilitan el transporte al centro y a los lugares para recoger las medicinas. También, facilitan información sobre las condiciones padecidas, el régimen farmacológico, y sus posibles efectos secundarios, que han ido adquiriendo tras acompañar a los propios pacientes a las visitas clínicas. Asimismo, aumentan la motivación por medio del apoyo y respaldo que ofrecen, haciendo sentir al paciente querido y valioso. Del mismo modo, monitorizan los niveles de glucosa y presión arterial de los pacientes, además que les cocinan o ayudan a cocinar de acuerdo al régimen alimenticio requerido para la condición/es padecida/s. En adición, promueven la actividad física para aquellos pacientes que no estén impedidos físicamente. Y, por último, los cuidadores familiares de los pacientes de nuestro estudio, mejoran la adherencia directa a medicación por medio del recuerdo de la toma de medicación.

A pesar del demostrado papel favorecedor del cuidador familiar asociado a la mejora de la adherencia, como ha sido explicado, la falta de educación y formación de estos puede contribuir en algunas ocasiones al incumplimiento ${ }^{262}$, causa probable de la ausencia de significación en la fase II del estudio. Por ejemplo, en el estudio de Buetow et al. ${ }^{291}$ se observó que la falta de conocimientos profesionales por parte de los cuidadores familiares influyó negativamente en el cumplimiento terapéutico, y ocasionó en algunos casos errores en la posología. Mejores niveles de adherencia han sido observados cuando el cuidador es un profesional dado el buen nivel de instrucción y/o educación y formación 
de éste ${ }^{262}$. Sin embargo, la situación económica de los sujetos de este estudio y las pocas ayudas sociales recibidas, les imposibilitan la contratación de un cuidador profesional por estos.

\section{Por otro lado, la variable métodos/estrategias utilizados para recordar la toma} de medicación ha resultado estar asociada significativamente con el incumplimiento en ambas fases del estudio $\left(\mathrm{p}_{1}=0.000\right.$ y $\left.\mathrm{p}_{2}=0.012\right)$ (Tabla 16 y Tabla 31). En la fase II del estudio, las personas que no utilizan ningún método/estrategia para recordar la toma de medicación tienen una probabilidad 4.44 veces mayor de incumplir el tratamiento que aquellas personas que si utilizan métodos o estrategias $\left(\mathrm{OR}_{2}=4.44\right)$; ligeramente inferior a la obtenida en la fase $I$ del estudio $\left(\mathrm{OR}_{1}=6.86\right)$. Estos hallazgos se suman a los de otras investigaciones de adherencia al tratamiento que sugieren que los métodos/estrategias para recordar la toma de medicación son una potente herramienta para mejorar la adherencia $^{98,166,172,275,292,293}$. Dado los elevados porcentajes de incumplimiento no intencionado existentes en la actualidad en los estudios de adherencia ${ }^{102,117,161-165}$, las últimas líneas de investigación se han centrado en la búsqueda de la "mejor" o "más efectiva" herramientas que permita al paciente recordar la toma de medicación a la misma hora cada día.

En nuestro estudio, los métodos o estrategias más efectivas para favorecer el cumplimiento terapéutico son la ayuda ofrecida por otra persona y la asociación de la toma de medicación con actividades cotidianas de la vida diaria, ambas con una relación inversa y estadísticamente significativa con el incumplimiento (ARijpersona $=-2.0$ )

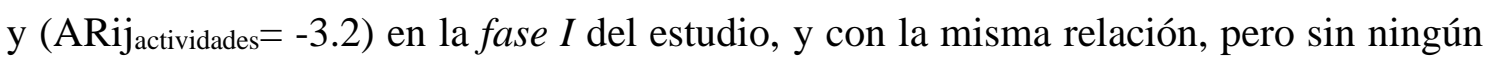
tipo de significación en la fase II.

El papel efectivo que desempeña la ayuda ofrecida por otra persona para recordar la toma de medicación confirma la argumentación debatida anteriormente del rol fundamental que desempeña el cuidador familiar en el cumplimiento del tratamiento. Por otro lado, la asociación de la toma de medicación con actividades cotidianas de la vida diaria resulta para algunos autores una medida más efectiva que asociar la toma de medicación con determinadas horas del día ${ }^{90}$, puesto que el paciente puede estar ocupado 
con otras actividades. Para Tebbi ${ }^{275}$ la falta de un horario sistemático es la raíz del problema del incumplimiento. Los pacientes de este estudio que utilizan dicha estrategia manifiestan asociar la toma de medicación con eventos específicos que ocurren a diario a la misma hora en su vida y que forman parte una "mini-rutina", como pueden ser el ver un determinado programa de televisión, escuchar una emisión radiofónica o hechos más concretos como usar el baño a primera hora de la mañana y/o cepillarse los dientes. La eficacia de esta estrategia para alcanzar un grado óptimo de adherencia ha sido demostrada en estudios previos en aquellos pacientes que tienen integrada de manera estable la toma de medicación en su vida como una "rutina"293. Los resultados de este estudio confirman estos hechos, y sitúan a las actividades cotidianas de la vida diaria como la estrategia más favorecedora para recordar la toma de medicación en los pacientes de este estudio.

A pesar de que en algunos estudios la estrategia de asociar la toma de medicación con las comidas ha resultado favorable con el cumplimiento ${ }^{173}$, en nuestro estudio no ha resultado significativa. Este hecho puede ser debido a que una parte de los pacientes posee un régimen de alimentación inconsistente y con gran variabilidad de una, dos, o tres comidas al día, dependiendo de sus ingresos económicos bisemanales. Esta situación, se corresponde al mismo tiempo con los hallazgos del propio Okuno et al. ${ }^{173}$, que encontraron un grado de cumplimiento bajo en los pacientes de su estudio que realizaban menos de tres comidas al día.

De la misma manera, los instrumentos de organización como pastilleros han resultado ser herramientas efectivas para mejorar el cumplimiento en otros estudios ${ }^{166}$. Sin embargo, en este estudio no han resultado poseer una significación asociada al cumplimiento, debido, probablemente, a que la mayor parte de los pacientes admiten olvidarse tomar la medicación cuando se encuentran fuera de casa "haciendo recados", acudiendo a citas, entrevistas o reuniones, a pesar de haberse llevado la medicación con ellos en el pastillero. 
Además, numerosos pacientes de este estudio afirman una falta de continuidad en su régimen farmacológico en determinadas épocas del año como por ejemplo Navidad y Semana Santa, cuando toman unos días de vacaciones, o cuando duermen fuera de casa, períodos de tiempo y circunstancias que les fuerzan a interrumpir sus rutinas diarias, y que podrían explicar la ausencia de significación en la fase II del estudio.

Con el continuo desarrollo de las TIC en los últimos años, las intervenciones más efectivas para mejorar la adherencia terapéutica mediante el recordatorio de la toma de medicación, se han centrado en mensajes de texto, dispositivos electrónicos, y apps ${ }^{292}$. Por ejemplo, los mensajes de texto han resultado ser una herramienta práctica en la mejora de la adherencia a inmunosupresores en pacientes adolescentes y en la adherencia a medicación antidiabética en pacientes adultos ${ }^{168}$. Estas evidencias confirman la necesidad de introducir las TIC en futuras prácticas clínicas y procesos asistenciales como el cumplimiento del tratamiento.

La asociación entre la utilización de métodos/estrategias para recordar la toma de medicación y el cumplimiento ha sido evaluada en análisis multivariante con modelo de regresión logística tras ajustar el resto de variables. Los resultados de la fase II revelan que los pacientes que no utilizan ninguna estrategia/método para recordar la toma de medicación presentan una probabilidad 6.32 veces mayor (95\% IC, [1.61-24.83], $\mathrm{p}=0.008$, ajustado $\mathrm{OR}=6.32$ ) de incumplir el tratamiento que aquellos pacientes que sí las utilizan. Esta probabilidad es ligeramente inferior a la probabilidad obtenida en fase I del estudio cuyo valor fue 7.88 (95\% IC, [2.64-23.51], p=0.000, ajustado OR=7.88). Las probabilidades que han resultado del análisis multivariado son más elevadas que las obtenidas en el análisis bivariado, lo que subraya la importancia de la utilización de métodos o estrategias para cumplir con el tratamiento.

Además, teniendo en cuenta el gran número de medicamentos y prescripciones utilizadas por los pacientes de la muestra, así como el alto porcentaje de incumplimiento no intencionado (olvido de la medicación y descuido con la hora de la toma de medicación), la utilización de un método/estrategia se hace prácticamente indispensable para los pacientes con enfermedades crónicas. 


\section{Limitaciones del Estudio}

El estudio presenta varias limitaciones en las observaciones y resultados obtenidos que se pasan a describir por ser conscientes de las mismas. Primeramente, todos los estudios de análisis de adherencia están condicionados por la ausencia de un método estándar de medida. En este estudio, se utilizó el cuestionario Morisky-Green-Levine ${ }^{178}$ como único método para evaluar la adherencia al tratamiento farmacológico del paciente. A pesar de que los métodos de auto-cuestionarios pueden infravalorar el verdadero incumplimiento en un $20 \%{ }^{294}$, el cuestionario Morisky-Green-Levine ha sido utilizado y evaluado de manera satisfactoria para un gran número de patologías crónicas como por ejemplo hipertensión, diabetes, enfermedades cardiovasculares, asma, EPOC, y depresión. Por ejemplo, en pacientes con depresión el test de Morisky-Green-Levine ha resultado tener una sensibilidad del $72 \%$ y una especificidad del $74 \%$ para detectar el incumplimiento $^{295}$.

Al mismo tiempo, el cuestionario Morisky-Green-Levine se ha mostrado como un método con mayor sensibilidad para detectar el incumplimiento que el método de recuento de los comprimidos no tomados ${ }^{296}$, con las ventajas de ser un método económico y fácil de usar. Además, para minimizar sesgos de información ante la posibilidad de que el paciente se sienta presionado en la entrevista por su médico y no responda honestamente a sus respuestas sobre el cumplimiento del tratamiento, las entrevistas no 
se han realizado por ningún personal de los centros, sino que han sido realizadas por el investigador principal del estudio, que se encontraba totalmente ajeno al entorno clínico antes de llevarse a cabo este estudio. Esta circunstancia minimiza el posible sesgo relacionado con la complacencia entre el entrevistador y el entrevistado o con la autoaplicación del cuestionario.

En adición, es generalmente aceptado que los pacientes dicen la verdad cuando afirman no haber tomado la medicación ${ }^{294}$. Finalmente, cabe reseñar que el director de este Trabajo Doctoral ha dirigido previamente dos Tesis Doctorales basadas en esta metodología 297,298 , por lo que su experiencia previa ha sido utilizada para reducir y/o evitar estas limitaciones. Todos estos hechos, unidos al alto porcentaje de incumplimiento hallado en el estudio, hacen minimizar el posible sesgo relacionado con el autocuestionario.

La segunda limitación del estudio radica en la selección de las enfermedades crónicas del estudio. La definición ofrecida por la OMS de enfermedad crónica como aquella de larga duración con una progresión generalmente lenta ${ }^{26}$, convierte al proceso de selección de las patologías crónicas como un proceso arbitrario, limitado generalmente a patologías tratadas con prescripciones de fármacos tomados de forma regular y diaria ${ }^{110}$. La selección de las condiciones crónicas de este estudio ha sido elaborada en base a otros estudios de morbilidad realizados por Ollero-Baturone et al. ${ }^{55}$, Barnett et al. ${ }^{40}$, y Hernández et al. ${ }^{224}$. Un total de 48 condiciones crónicas han sido incluidas en el estudio, definidas por los códigos CIE-9 y/o frecuencia de prescripción. De este modo, se ha definido específicamente cada condición crónica sin dar lugar a una interpretación vaga de las enfermedades.

Finalmente, la tercera y última limitación del estudio radica en la introducción de una nueva metodología en la entrevista tras el periodo de seguimiento en fase II. La metodología empleada en la fase II del estudio incluye entrevista personal y telefónica, a diferencia de la fase I que incluye exclusivamente entrevista personal. El motivo del cambio de metodología se ha debido a la imposibilidad de algunos pacientes de acudir a los centros para realizar la entrevista en el noveno mes de su tratamiento. Dentro de las 
diferencias existentes en ambas metodologías, se tomaron una serie de medidas para que ambas metodologías fueran lo más parecidas posibles, Además, se ha descartado cualquier asociación entre el incumplimiento y la metodología de la entrevista. Por lo tanto, el posible sesgo relacionado con la metodología de la entrevista de la fase II ha quedado muy reducido o prácticamente descartado. 


\section{Próximas Líneas de Trabajo}

El presente estudio refuerza la necesidad de reconocer el incumplimiento como un grave a problema del proceso asistencial en relación con las enfermedades crónicas y los pacientes pluripatológicos, que se acentúa en las poblaciones de grupos vulnerables, al reducir las posibilidades de mejora en el Bienestar y la CVRS de los pacientes. El primer paso a tomar debería ser la identificación de aquellos individuos que tienen dificultades o están en riesgo para adherirse al régimen farmacológico, considerando la naturaleza multidimensional de la adherencia al tratamiento.

Nuevas intervenciones deberían ser diseñadas específicamente para dichos grupos de poblaciones en base a los resultados de este estudio para minimizar el incumplimiento y mejorar la CVRS y los resultados clínicos. Son necesarias futuras investigaciones en estos grupos de población que permitan realizar nuevos hallazgos, particularmente en aquellos Sistemas Sanitarios donde los grupos de población vulnerables reciben un mayor apoyo social y las disparidades sociales de Salud son reducidas, como por ejemplo los Sistemas Nacionales de Salud. Por último, será necesario explorar el papel que pueden desempeñar las TIC en el proceso asistencial de los pacientes crónicos y pluripatológicos dentro de la Estrategia de Atención al Paciente Crónico y la Atención Sanitaria. 

Conclusiones 

Primera. - El incumplimiento del tratamiento farmacológico de las enfermedades crónicas en grupos de población vulnerables es más elevado que en la población general de referencia de países desarrollados.

Segunda. - El incumplimiento del tratamiento farmacológico evaluado en pacientes de grupos de población vulnerables alcanza una tasa de prevalencia del $81 \%$ en el noveno mes de tratamiento tras haber inicializado un nuevo régimen farmacológico para una nueva patología diagnosticada; el olvido y el descuido con la hora de la toma de medicación son las principales causas de incumplimiento.

Tercera. - El grado de adherencia al tratamiento farmacológico de sujetos de grupos de población vulnerables se caracteriza por ser un grado de adherencia medio, con una conducta de incumplimiento principalmente involuntaria.

Cuarta. - La adherencia al tratamiento farmacológico disminuye significativamente después de los primeros meses tras el inicio de un nuevo tratamiento. Este hecho es debido fundamentalmente, a los continuos cambios introducidos en el régimen farmacológico hasta que la enfermedad se da por controlada. 
Quinta. - Los factores más significativos asociados con la adherencia al tratamiento farmacológico de acuerdo al marco conceptual de la OMS son: la raza/etnia del sujeto, las dificultades para recoger las medicinas en el lugar asignado, el grupo de riesgo clínico al que pertenece el paciente, y los métodos y estrategias utilizadas para recordar la toma de medicación.

Sexta. - Los factores significativos hallados en cada una de las dimensiones que inciden en la adherencia, reafirma el manifiesto de la OMS de abordar la problemática del incumplimiento desde un punto de vista multidimensional.

Séptima. - Las variaciones en el tiempo de los factores relacionados con la adherencia están relacionadas principalmente con problema sociales, especialmente con la inestabilidad económica y la falta de recursos, creencias culturales y/o populares, y la rápida familiarización y manejo de la medicación que se hacen más importantes con el transcurso del tratamiento.

Octava. - Se ha establecido un perfil de paciente en riesgo de incumplimiento para aquellos individuos de grupos de población vulnerables con enfermedades crónicas como aquel caracterizado por pertenecer a un raza afroamericana o etnia hispana/latina, tener dificultades de transporte para llegar al lugar establecido para recoger las prescripciones, pertenecer a un grupo de riesgo clínico G2, y la falta de utilización de un método o estrategia para recordar la toma de medicación. 


\section{APLICACIONES DE LOS HALLAZGOS}

Primera. - El perfil predictivo del paciente en riesgo de incumplimiento permitirá a los profesionales sanitarios identificar a aquellos pacientes de grupos de población vulnerables que tengan dificultades para adherirse al tratamiento farmacológico, y proporcionarles recomendaciones para evitar el incumplimiento.

Segunda. - La mayor apreciación de los factores relacionados con el incumplimiento al tratamiento permitirá a los profesionales diseñar diferentes planteamientos para realizar intervenciones que mejoren la adherencia del paciente.

Tercera. - El estudio deja abierto líneas de investigación entre los grupos de población de diferentes sanitarios, con el fin de obtener nuevas observaciones, mejorar el acceso a la atención Sanitaria y la Calidad de Vida relacionada con la Salud de estas poblaciones. 

ONCLUSIONS 

First. - Medication non-adherence to chronic diseases among vulnerable populations is more prevalent than among reference population in developed countries.

Second. - Medication non-adherence prevalence rate among vulnerable populations reaches $81 \%$, at the ninth month after starting a new medication regimen for a newly diagnosed disease; forgetfulness followed by careless in taking medicines, are the main reasons for non-adherence.

Third. - The degree of adherence to medication treatment that presents subjects from vulnerable populations is a medium-level and the predominant non-adherence behavior reported was unintentional-behavior.

Fourth. - Medication adherence decreases significantly after the first months of starting a new treatment. This is mainly due to changes in medication that are continuously introduced until the disease is totally controlled.

Fifth. - The most significant factors related to medication adherence according to the conceptual framework proposed by the WHO are: race/ethnicity, issues related to pick up the medicines at the designated facility, clinical risk group, and methods/strategies to remind the medication intake. 
Sixth. - The significant adherence-related factors found in each of the five dimension that interplay with adherence reaffirms the manifesto made by the WHO of addressing the non-adherence problem from a multidimensional perspective.

Seventh. - The variations over time of the adherence-related factors are primarily associated with social problems, particularly financial instability and lack of resources, cultural and popular beliefs, and quick familiarization and managing with the medication regimen that increasingly become more important over time.

Eighth. - A non-adherence predictive risk profile has been constructed for individuals with chronic conditions from vulnerable populations as the one characterized by being Afro-American or Hispanic/Latin, having transportation problems to get the location to pick up the prescriptions, being a G2 clinical risk group patient, and lack of any methods or strategies to remember the intake of medicines.

\section{APPLICATION OF THESE FINDIDINGS}

First. - The non-adherence predictive risk profile will allow healthcare professionals to identify those patients from vulnerable populations that have adherences issues related to the agreed medication treatment, and provide them with recommendations to reduce non-adherence.

Second. - A major appreciation of the related factors to medication adherence will allow clinicians to design and perform different interventions to improve patient adherence.

Third. - The study opens up new research avenues among vulnerable populations from different healthcare systems, with the purpose of obtaining new findings, improvement of access to care and health-related quality of life of these populations. 



\section{Bibliografía}



1. Caldwell JC. Population health in transition. Bulletin of the World Health Organization. 2001;79(2):159-60.

2. World Health Organization. Report on Ageing and Health. [Internet]. Geneva, Switerzaladnd: WHO. 2015. [consultado el 11-9-2014]. Disponible en: http://apps.who.int/iris/bitstream/10665/186463/1/9789240694811_eng.pdf?ua=1

3. 3. United Nations, Department of Economic and Social Affairs, Population Division. [Internet]. World Population Ageing 2013. New York: 2013. [consultado el 10-4 2014]. Disponible en: http://www.un.org/en/development/desa/population/publications/pdf/ageing/WorldPopulationAgei $\underline{\text { ng2013.pdf }}$

4. United Nations, Department of Economic and Social Affairs, Population Division. World Population Prospects: The 2015 Revision, Methodology of the United Nations Population Estimates and Projections. [Internet]. New York: UN. 2015. Working Paper No. ESA/P/WP.242. Disponible en: https://esa.un.org/unpd/wpp/Publications/Files/WPP2015_Methodology.pdf

5. Leeson GW. Increasing Longevity and the New Demography of Death. International Journal of Population Research. 2014;2014.

6. Leeson GW. Future prospects for longevity. Post reproductive health. 2014;20(1):11-5.

7. Wilmoth JR. Demography of longevity: past, present, and future trends. Experimental gerontology. 2000 Dec;35(9-10):1111-29. PubMed PMID: 11113596.

8. Wilmoth JR. Increase of human longevity: Past, present and future. The Japanese Journal of Population. 2011;9(1):155-61.

9. World Health Organization. Global Health Risks: Mortality and Burden Attributable to selected Major Risks. [Internet]. Geneva, Switerzaladnd: WHO. 2009.[consultado el 12-4-2014].Disponible en: http://www.who.int/healthinfo/global_burden_disease/GlobalHealthRisks_report_full.pdf

10. World Health Organization. The World Health Report 2003: Shaping the Future. [Internet]. Geneva, Switerzaladnd: WHO. 2003. [consultado el 27-5-2014]. Disponible en: http://www.who.int/whr/2003/en/whr03 en.pdf

11. Christensen K, Doblhammer G, Rau R, Vaupel JW. Ageing populations: the challenges ahead. Lancet. 2009 Oct 3;374(9696):1196-208. PubMed PMID: 19801098. Pubmed Central PMCID: PMC2810516.

12. Goklany IM. The improving state of the world: why we're living longer, healthier, more comfortable lives on a cleaner planet. Cato Institute; 2007.

13. Lee R. The demographic transition: three centuries of fundamental change. The journal of economic perspectives. 2003;17(4):167-90.

14. Bongaarts J. How long will we live? Population and Development Review. 2006;32(4):605-28.

15. Díaz JP. La demografía y el envejecimiento de las poblaciones. Enfermería Gerontológica. 1998.

16. Vinuesa J. Análisis del envejecimiento demográfico. Revista de Encuentros Multidisciplinares de la Universidad Autónoma de Madrid. 2003.

17. Anderson G, Horvath J. The growing burden of chronic disease in America. Public Health Rep. 2004 May-Jun;119(3):263-70. PubMed PMID: 15158105. Pubmed Central PMCID: PMC1497638.

18. Gijsen R, Hoeymans N, Schellevis FG, Ruwaard D, Satariano WA, van den Bos GA. Causes and consequences of comorbidity: a review. Journal of clinical epidemiology. 2001;54(7):661-74.

19. Marengoni A, Angleman S, Melis R, Mangialasche F, Karp A, Garmen A, et al. Aging with multimorbidity: a systematic review of the literature. Ageing Research Reviews. 2011 Sep;10(4):430-9. PubMed PMID: 21402176. 
20. Fortin M, Lapointe L, Hudon C, Vanasse A, Ntetu AL, Maltais D. Multimorbidity and quality of life in primary care: a systematic review. Health and Quality of life Outcomes. 2004;2(1):1.

21. World Health Organization. Noncommunicable Diseases[Internet]. WHO, 2016. [consultado el 15-2014].Disponible en: http://www.who.int/topics/noncommunicable_diseases/en/

22. Noncommunicable Diseases and Mental Health, World Health Organization. Innovative Care for Chronic Conditions: Building Blocks for Action: Global Report.[Internet]. WHO, 2002. [consultado el 3-3-2014].Disponible en: http://www.who.int/chp/knowledge/publications/icccglobalreport.pdf

23. Alwan A. Global status report on noncommunicable diseases 2010. [Internet]. Geneva, Switerzaladnd: WHO. 2011. [consultado el 22-2-2014]. Disponible en: http://www.who.int/nmh/publications/ncd_report_full_en.pdf

24. Pan American Health Organization, Department of Noncommunicable Diseases and Mental Health. Noncommunicable Disease Risk. Factors in the Americas: Considerations on the Strenthening of Regulatory Capacity [Internet].Washington, D.C.: PAHO. 2015. [consultado el 7-3-2015]. Disponible en: http://iris.paho.org/xmlui/handle/123456789/10024

25. Gerteis J, Izrael D, Deitz D, LeRoy L, Ricciardi R, Miller T, et al. Multiple chronic conditions chartbook. AHRQ Publications; 2014.

26. World Health Organization. Global status report on noncommunicable diseases 2014. [Internet]. Geneva, Switerzaladnd: WHO. 2014. [consultado el 1-5-2014]. Disponible en: http://apps.who.int/iris/bitstream/10665/148114/1/9789241564854_eng.pdf?ua=1

27. Mathers C, Fat DM, Boerma JT. The global burden of disease: 2004 update: World Health Organization; 2008.

28. Bloom DE, Cafiero E, Jané-Llopis E, Abrahams-Gessel S, Bloom LR, Fathima S, et al. The global economic burden of noncommunicable diseases. Program on the Global Demography of Aging,2012.

29. Salomon JA. New disability weights for the global burden of disease. Bulletin of the World Health Organization. 2010;88(12):879-.

30. Nolte E, McKee M. Caring for people with chronic conditions: a health system perspective: McGraw-Hill Education (UK); 2008.

31. Suhrcke M, Nugent RA, Stuckler D, Rocco L. Chronic disease: an economic perspective. London: Oxford Health Alliance, 2006. 2010.

32. Barro RJ. Sala-I-Martin, X.(1995), Economic Growth. En: Suhrcke M, Nugent RA, Stuckler D, Rocco L. Chronic disease: an economic perspective. London: Oxford Health Alliance, 2006. 2010.

33. Danaei G, Finucane MM, Lin JK, Singh GM, Paciorek CJ, Cowan MJ, et al. National, regional, and global trends in systolic blood pressure since 1980: systematic analysis of health examination surveys and epidemiological studies with 786 country-years and 5.4 million participants. The Lancet. 2011;377(9765):568-77.

34. Finucane MM, Stevens GA, Cowan MJ, Danaei G, Lin JK, Paciorek CJ, et al. National, regional, and global trends in body-mass index since 1980: systematic analysis of health examination surveys and epidemiological studies with 960 country-years and 9. 1 million participants. The Lancet. 2011;377(9765):557-67.

35. World Health Organization. Urbanization and health. Bulletin of the World Health Organization. 2010;88(4):241-320.

36. World Health Organization. Social determinants of health. [Internet]. WHO, 2016. [consultado el 27-6-2015].Disponible en: http://www.who.int/social_determinants/en/

37. Newacheck PW. Poverty and childhood chronic illness. Archives of pediatrics \& adolescent medicine. 1994;148(11):1143-9. 
38. Wolff JL, Starfield B, Anderson G. Prevalence, expenditures, and complications of multiple chronic conditions in the elderly. Archives of internal medicine. 2002;162(20):2269-76.

39. Boyd CM, Martin Fortin M. Future of multimorbidity research: how should understanding of multimorbidity inform health system design? Public Health Reviews. 2010;32(2):1.

40. Barnett K, Mercer SW, Norbury M, Watt G, Wyke S, Guthrie B. Epidemiology of multimorbidity and implications for health care, research, and medical education: a cross-sectional study. The Lancet. 2012;380(9836):37-43.

41. Pati S, Swain S, Hussain MA, Kadam S, Salisbury C. Prevalence, correlates, and outcomes of multimorbidity among patients attending primary care in Odisha, India. The Annals of Family Medicine. 2015;13(5):446-50.

42. Tinetti ME, Fried TR, Boyd CM. Designing health care for the most common chronic conditionmultimorbidity. JAMA. 2012;307(23):2493-4.

43. van den Akker M, Buntinx F, Knottnerus JA. Comorbidity or multimorbidity: what's in a name? A review of literature. The European Journal of General Practice. 1996;2(2):65-70.

44. Yancik R, Ershler W, Satariano W, Hazzard W, Cohen HJ, Ferrucci L. Report of the national institute on aging task force on comorbidity. The journals of gerontology Series A, Biological sciences and medical sciences. 2007 Mar;62(3):275-80. PubMed PMID: 17389724. Pubmed Central PMCID: 2645628.

45. Almirall J, Fortin M. The coexistence of terms to describe the presence of multiple concurrent diseases. Journal of Comorbidity. 2013;3(1):4-9.

46. García-Morillo JS, Bernabeu-Wittel M, Ollero-Baturone M, Aguilar-Guisad M, Ramírez-Duque N, de la Puente MAG, et al. Incidencia y características clínicas de los pacientes con pluripatología ingresados en una unidad de medicina interna. Medicina clínica. 2005;125(1):5-9.

47. Rodríguez ÁS. El enfermo con pluripatología: la necesidad de una atención integral coordinada. Medicina clínica. 2005;125(1):12-3.

48. Bernabeu-Wittel M, Alonso-Coello P, Rico-Blázquez M, del Campo RR, Gómez SS, Vales EC. Desarrollo de guías de práctica clínica en pacientes con comorbilidad y pluripatología. Revista Clínica Española. 2014;214(6):328-35.

49. Bernabeu-Wittel M, Barón-Franco B, Murcia-Zaragoza J, Fuertes-Martín A, Ramos-Cantos C, Fernández-Moyano A, et al. A multi-institutional, hospital-based assessment of clinical, functional, sociofamilial and health-care characteristics of polypathological patients (PP). Archives of gerontology and geriatrics. 2011;53(3):284-91.

50. Ramírez-Duque N, Mora-Rufete A, Nieto-Martín MD, Bernabeu-Wittel M, Escalera-Zalvide A, Sánchez-Ledesma M, et al. Riesgo cardiovascular y prescripción farmacológica en pacientes pluripatológicos. Hipertensión y riesgo vascular. 2011;28(2):39-47.

51. Feinstein AR. The pre-therapeutic classification of co-morbidity in chronic disease. Journal of chronic diseases. 1970;23(7):455-68.

52. Valderas JM, Starfield B, Sibbald B, Salisbury C, Roland M. Defining comorbidity: implications for understanding health and health services. The Annals of Family Medicine. 2009;7(4):357-63.

53. Davies SJ. Peritoneal dialysis - current status and future challenges. Nature Reviews Nephrology. 2013;9(7):399-408.

54. Social MdSyP. Unidad de Pacientes Pluripatológicos. Estándares y recomendaciones. Ministerio de Sanidad y Política Social Madrid; 2009.

55. Ollero-Baturone M, Alvarez M, Barón-Franco B, Bernabéu-Wittel M, Codina A, FernándezMoyano A. Atención al paciente pluripatológico. Proceso Asistencial Integrado Atención a Pacientes Pluripatológicos 2a Edición Consejería de Salud Andalucía. 2007. 
56. Marengoni A, Rizzuto D, Wang HX, Winblad B, Fratiglioni L. Patterns of chronic multimorbidity in the elderly population. Journal of the American Geriatrics Society. 2009;57(2):225-30.

57. Lim SS, Vos T, Flaxman AD, Danaei G, Shibuya K, Adair-Rohani H, et al. A comparative risk assessment of burden of disease and injury attributable to 67 risk factors and risk factor clusters in 21 regions, 1990-2010: a systematic analysis for the Global Burden of Disease Study 2010. The lancet. 2013;380(9859):2224-60.

58. Fortin M, Lapointe L, Hudon C, Vanasse A. Multimorbidity is common to family practice: is it commonly researched? Canadian Family Physician. 2005;51(2):244-5.

59. Martínez Velilla N. El desafío terapéutico de la multimorbilidad. Boletín de Información Farmacoterapéutica de Navarra. 2013;21(3):1-12.

60. Marengoni A, Winblad B, Karp A, Fratiglioni L. Prevalence of chronic diseases and multimorbidity among the elderly population in Sweden. American journal of public health. 2008;98(7):1198-200.

61. Garin N, Olaya B, Perales J, Moneta MV, Miret M, Ayuso-Mateos JL, et al. Multimorbidity patterns in a national representative sample of the Spanish adult population. PLoS One. 2014;9(1):e84794.

62. Noel PH, Parchman ML, Williams JW, Jr., Cornell JE, Shuko L, Zeber JE, et al. The challenges of multimorbidity from the patient perspective. J Gen Intern Med. 2007 Dec;22 Suppl 3:419-24. PubMed PMID: 18026811. Pubmed Central PMCID: 2150619.

63. Uijen AA, van de Lisdonk EH. Multimorbidity in primary care: prevalence and trend over the last 20 years. The European journal of general practice. 2008;14(sup1):28-32.

64. Fortin M, Stewart M, Poitras M-E, Almirall J, Maddocks H. A systematic review of prevalence studies on multimorbidity: toward a more uniform methodology. The Annals of Family Medicine. 2012;10(2):142-51.

65. Taylor AW, Price K, Gill TK, Adams R, Pilkington R, Carrangis N, et al. Multimorbidity-not just an older person's issue. Results from an Australian biomedical study. BMC public health. 2010;10(1):1.

66. Rapoport J, Jacobs P, Bell NR, Klarenbach S. Refining the measurement of the economic burden of chronic diseases in Canada. Chronic Diseases and Injuries in Canada. 2004;25(1):13.

67. Fortin M, Bravo G, Hudon C, Vanasse A, Lapointe L. Prevalence of multimorbidity among adults seen in family practice. The Annals of Family Medicine. 2005;3(3):223-8.

68. Mathur R, Hull SA, Badrick E, Robson J. Cardiovascular multimorbidity: the effect of ethnicity on prevalence and risk factor management. Br J Gen Pract. 2011;61(586):e262-e70.

69. Quiñones AR, Liang J, Bennett JM, Xu X, Ye W. How does the trajectory of multimorbidity vary across Black, White, and Mexican Americans in middle and old age? The Journals of Gerontology Series B: Psychological Sciences and Social Sciences. 2011;66(6):739-49.

70. Garcia-Olmos L, Salvador CH, Alberquilla A, Lora D, Carmona M, Garcia-Sagredo P, et al. Comorbidity patterns in patients with chronic diseases in general practice. PLoS One. 2012;7(2):e32141. PubMed PMID: 22359665. Pubmed Central PMCID: 3281110.

71. Ward BW. Prevalence of multiple chronic conditions among US adults: estimates from the National Health Interview Survey, 2010. Preventing chronic disease. 2013;10.

72. Ashman JJ. Multiple chronic conditions among US adults who visited physician offices: data from the National Ambulatory Medical Care Survey, 2009. Preventing chronic disease. 2013;10.

73. Afshar S, Roderick PJ, Kowal P, Dimitrov BD, Hill AG. Multimorbidity and the inequalities of global ageing: a cross-sectional study of 28 countries using the World Health Surveys. BMC public health. 2015;15(1):1.

74. Wu S-Y, Green A. Projection of chronic illness prevalence and cost inflation. Santa Monica, CA: RAND Health. 2000:2000. 
75. Salisbury C, Johnson L, Purdy S, Valderas JM, Montgomery AA. Epidemiology and impact of multimorbidity in primary care: a retrospective cohort study. Br J Gen Pract. 2011;61(582):e12-e21.

76. Schneider KM, O'Donnell BE, Dean D. Prevalence of multiple chronic conditions in the United States' Medicare population. Health and quality of life outcomes. 2009;7(1):1.

77. Starfield B, Lemke KW, Herbert R, Pavlovich WD, Anderson G. Comorbidity and the use of primary care and specialist care in the elderly. The Annals of Family Medicine. 2005;3(3):215-22.

78. Calderón-Larrañaga A, Poblador-Plou B, González-Rubio F, Gimeno-Feliu LA, Abad-Díez JM, Prados-Torres A. Multimorbidity, polypharmacy, referrals, and adverse drug events: are we doing things well? Br J Gen Pract. 2012;62(605):e821-e6.

79. Burgers JS, Voerman GE, Grol R, Faber MJ, Schneider EC. Quality and coordination of care for patients with multiple conditions: results from an international survey of patient experience. Evaluation \& the health professions. 2010;33(3):343-64.

80. Lehnert T, Heider D, Leicht H, Heinrich S, Corrieri S, Luppa M, et al. Review: health care utilization and costs of elderly persons with multiple chronic conditions. Medical Care Research and Review. 2011;68(4):387-420.

81. Ramage-Morin PL. Medication use among senior Canadians. Health Reports. 2009;20(1):37.

82. Moxey ED, O'Connor JP, Novielli KD, Teutsch S, Nash DB. Prescription drug use in the elderly: a descriptive analysis. Health care financing review. 2003;24(4):127.

83. Anderson GF. Chronic care: making the case for ongoing care: Robert Wood Johnson Foundation;2010.

84. Wikman A, Wardle J, Steptoe A. Quality of life and affective well-being in middle-aged and older people with chronic medical illnesses: a cross-sectional population based study. PLoS One. 2011;6(4):e18952.

85. Centers for Medicare and Medicaid Services. National Health Expenditure Data. [Internet]. Baltimore, MD: U.S. Department of Health and Human Services.[consultado el 4-2-2016]. Disponible en: https://www.cms.gov/

86. Grady PA, Gough LL. El automanejo de las enfermedades crónicas: un método integral de atención. Rev panam salud pública. 2015;37(3):187-94.

87. Barlow J, Wright C, Sheasby J, Turner A, Hainsworth J. Self-management approaches for people with chronic conditions: a review. Patient education and counseling. 2002;48(2):177-87.

88. Newman S, Steed L, Mulligan K. Self-management interventions for chronic illness. The Lancet. 2004;364(9444):1523-37.

89. Brown MT, Bussell JK. Medication adherence: WHO cares? Mayo Clinic proceedings. 2011 Apr;86(4):304-14. PubMed PMID: 21389250. Pubmed Central PMCID: 3068890.

90. Sabaté E. Adherence to long-term therapies: evidence for action: World Health Organization; 2003.

91. Martín Alfonso L. Acerca del concepto de adherencia terapéutica. Revista cubana de salud pública. 2004;30(4):0.

92. Gabarro MB. El cumplimiento terapéutico. Pharm care esp. 1999;1:97-106.

93. Haynes R, Taylor D, Sackett D. Compliance in Health Care Baltimore Johns Hopkins University Press. As seen in DiMatteo et al(1993) Health Psychology. 1979;12:93-102.

94. Donovan JL. Patient decision making: the missing ingredient in compliance research. International journal of technology assessment in health care. 1995;11(03):443-55.

95. Mir FM, Larrea VP. Adherencia al tratamiento en el paciente anciano. Información terapéutica del Sistema nacional de Salud. 2004;28(5):113-20.

96. Cramer JA, Roy A, Burrell A, Fairchild CJ, Fuldeore MJ, Ollendorf DA, et al. Medication compliance and persistence: terminology and definitions. Value in health. 2008;11(1):44-7. 
97. Osterberg L, Blaschke T. Adherence to medication. The New England journal of medicine. 2005 Aug 4;353(5):487-97. PubMed PMID: 16079372.

98. Vermeire E, Hearnshaw H, Van Royen P, Denekens J. Patient adherence to treatment: three decades of research. A comprehensive review. Journal of clinical pharmacy and therapeutics. 2001;26(5):331-42.

99. DiMatteo MR. Variations in patients' adherence to medical recommendations: a quantitative review of 50 years of research. Medical care. 2004;42(3):200-9.

100. Morris LS, Schulz R. Patient compliance-an overview. Journal of clinical pharmacy and therapeutics. 1992;17(5):283-95.

101. Choudhry NK, Shrank WH, Levin RL, Lee JL, Jan SA, Brookhart MA, et al. Measuring concurrent adherence to multiple related medications. The American journal of managed care. 2009;15(7):457.

102. Contreras EM, Martínez JC, Cabeza JM. Estrategias para mejorar el cumplimiento terapéutico. FMC-Formación Médica Continuada en Atención Primaria. 2001;8(8):558-73.

103. Gellad WF, Grenard J, McGlynn EA. A review of barriers to medication adherence: a framework for driving policy options: RAND; 2009.

104. Kripalani S, Yao X, Haynes RB. Interventions to enhance medication adherence in chronic medical conditions: a systematic review. Archives of internal medicine. 2007;167(6):540-9.

105. Dunbar-Jacob J, Mortimer-Stephens MK. Treatment adherence in chronic disease. J Clin Epidemiol. 2001 Dec;54 Suppl 1:S57-60. PubMed PMID: 11750211.

106. MacLaughlin EJ, Raehl CL, Treadway AK, Sterling TL, Zoller DP, Bond CA. Assessing medication adherence in the elderly. Drugs \& aging. 2005;22(3):231-55.

107. DiMatteo MR. Social support and patient adherence to medical treatment: A meta-analysis. Health Psychol. 2004;23.

108. Conthe P, Contreras EM, Pérez AA, García BB, de Cano Martín MF, Jurado MG, et al. Treatment compliance in chronic illness: Current situation and future perspectives. Revista Clínica Española (English Edition). 2014;214(6):336-44.

109. Jackevicius CA, Mamdani M, Tu JV. Adherence with statin therapy in elderly patients with and without acute coronary syndromes. Jama. 2002;288(4):462-7.

110. Briesacher BA, Andrade SE, Fouayzi H, Chan KA. Comparison of drug adherence rates among patients with seven different medical conditions. Pharmacotherapy: The Journal of Human Pharmacology and Drug Therapy. 2008;28(4):437-43.

111. Yeaw J, Benner JS, Walt JG, Sian S, Smith DB. Comparing adherence and persistence across 6 chronic medication classes. Journal of managed care pharmacy : JMCP. 2009 Nov-Dec;15(9):72840. PubMed PMID: 19954264.

112. Basak R, McCaffrey Iii DJ, Bentley JP, Przybyla SM, West-Strum D, Banahan BF. Adherence to multiple medications prescribed for a chronic disease: a methodological investigation. Journal of managed care pharmacy : JMCP. 2014 Aug;20(8):815-23. PubMed PMID: 25062075.

113. Jansa M, Hernandez C, Vidal M, Nunez M, Bertran MJ, Sanz S, et al. Multidimensional analysis of treatment adherence in patients with multiple chronic conditions. A cross-sectional study in a tertiary hospital. Patient Educ Couns. 2010 Nov;81(2):161-8. PubMed PMID: 20167450.

114. Ho PM, Bryson CL, Rumsfeld JS. Medication adherence its importance in cardiovascular outcomes. Circulation. 2009;119(23):3028-35.

115. Mäkelä MJ, Backer V, Hedegaard M, Larsson K. Adherence to inhaled therapies, health outcomes and costs in patients with asthma and COPD. Respiratory medicine. 2013;107(10):1481-90. 
116. García F. Metodología de estudios del incumplimiento terapéutico. Sacristán JA, García FM, Martínez-Mir I, Palop V, Amado E, coords Cumplimiento Terapéutico Madrid: Fundación Lilly. 2001:39-41.

117. Gadkari AS, McHorney CA. Unintentional non-adherence to chronic prescription medications: How unintentional is it really? BMC Health Services Research. 2012;12(1):1-12.

118. Benner JS, Glynn RJ, Mogun H, Neumann PJ, Weinstein MC, Avorn J. Long-term persistence in use of statin therapy in elderly patients. Jama. 2002;288(4):455-61.

119. Dilla T, Valladares A, Lizán L, Sacristán JA. Adherencia y persistencia terapéutica: causas, consecuencias y estrategias de mejora. Atención primaria. 2009;41(6):342-8.

120. Cooper LA. A 41-year-old African American man with poorly controlled hypertension: review of patient and physician factors related to hypertension treatment adherence. Jama. 2009;301(12):1260-72.

121. Piette JD. Perceived access problems among patients with diabetes in two public systems of care. Journal of general internal medicine. 2000;15(11):797-804.

122. Krueger KP, Berger BA, Felkey B. Medication adherence and persistence: a comprehensive review. Advances in therapy. 2005;22(4):313-56.

123. Madden JM, Graves AJ, Zhang F, Adams AS, Briesacher BA, Ross-Degnan D, et al. Cost-related medication nonadherence and spending on basic needs following implementation of Medicare Part D. JAMA. 2008 Apr 23;299(16):1922-8. PubMed PMID: 18430911. Pubmed Central PMCID: 3781951 .

124. de Arenas VdAN. Polifarmacia e incumplimiento terapéutico en el anciano pluripatológico. Actuación de los profesionales sanitarios. Cuidados, aspectos psicológicos y actividad física en relación con la salud del mayor Volumen I.125.

125. Doggrell SA. Adherence to medicines in the older-aged with chronic conditions. Drugs \& aging. 2010;27(3):239-54.

126. Larsen J, Stovring H, Kragstrup J, Hansen DG. Can differences in medical drug compliance between European countries be explained by social factors: analyses based on data from the European Social Survey, round 2. BMC public health. 2009;9(1):1.

127. Ferguson T, Stewart K, Funkhouser E, Tolson J, Westfall A, Saag M. Patient-perceived barriers to antiretroviral adherence: associations with race. AIDS care. 2002;14(5):607-17.

128. Piette JD. Cost-Related Medication Underuse: A Window Into Patients' Medication-Related Concerns. Diabetes Spectrum. 2009 2009-03-20 00:00:00;22(2):77-80.

129. Briesacher BA, Gurwitz JH, Soumerai SB. Patients at-risk for cost-related medication nonadherence: a review of the literature. Journal of general internal medicine. 2007;22(6):864-71.

130. Hardon AP, Akurut D, Comoro C, Ekezie C, Irunde HF, Gerrits T, et al. Hunger, waiting time and transport costs: time to confront challenges to ART adherence in Africa. AIDS Care. 2007;19(5):658-65.

131. Choudhry NK, Saya UY, Shrank WH, Greenberg JO, Melia C, Bilodeau A, et al. Cost-related medication underuse: Prevalence among hospitalized managed care patients. Journal of hospital medicine. 2012;7(2):104-9.

132. Popa-Lisseanu MGG, Greisinger A, Richardson M, O'Malley KJ, Janssen NM, Marcus DM, et al. Determinants of treatment adherence in ethnically diverse, economically disadvantaged patients with rheumatic disease. The Journal of Rheumatology. 2005;32(5):913-9.

133. Piette JD, Heisler M, Wagner TH. Cost-related medication underuse: Do patients with chronic illnesses tell their doctors? Archives of Internal Medicine. 2004;164(16):1749-55. 
134. Piette JD, Heisler M, Wagner TH. Problems Paying Out-of-Pocket Medication Costs Among Older Adults With Diabetes. Diabetes Care. 2004 2004-02-01 00:00:00;27(2):384-91.

135. Reed M, Brand R, Newhouse JP, Selby JV, Hsu J. Coping with prescription drug cost sharing: knowledge, adherence, and financial burden. Health services research. 2008;43(2):785-97.

136. Stankuniene A, Stankunas M, Avery M, Lindert J, Mikalauskiene R, Melchiorre MG, et al. The prevalence of self-reported underuse of medications due to cost for the elderly: results from seven European urban communities. BMC health services research. 2015;15(1):1.

137. Steinman MA, Sands LP, Covinsky KE. Self-restriction of Medications Due to Cost in Seniors without Prescription Coverage. Journal of General Internal Medicine. 2001;16(12):793-9.

138. Zivin K, Ratliff S, Heisler MM, Langa KM, Piette JD. Factors Influencing Cost-Related Nonadherence to Medication in Older Adults: A Conceptually Based Approach. Value in Health. 2010;13(4):338-45.

139. Tuller DM, Bangsberg DR, Senkungu J, Ware NC, Emenyonu N, Weiser SD. Transportation Costs Impede Sustained Adherence and Access to HAART in a Clinic Population in Southwestern Uganda: A Qualitative Study. AIDS and Behavior. 2010;14(4):778-84.

140. Rosen S, Ketlhapile M, Sanne I, DeSilva MB. Cost to patients of obtaining treatment for HIV/AIDS in South Africa. South African Medical Journal. 2007;97(7):524-9.

141. Jin J, Sklar GE, Oh VMS, Li SC. Factors affecting therapeutic compliance: A review from the patient's perspective. Therapeutics and clinical risk management. 2008;4(1):269.

142. Ingersoll KS, Cohen J. The impact of medication regimen factors on adherence to chronic treatment: a review of literature. Journal of behavioral medicine. 2008;31(3):213-24.

143. Delamater AM. Improving patient adherence. Clinical diabetes. 2006;24(2):71-7.

144. Carpenter DM, DeVellis RF, Fisher EB, DeVellis BM, Hogan SL, Jordan JM. The effect of conflicting medication information and physician support on medication adherence for chronically ill patients. Patient Educ Couns. 2010 Nov;81(2):169-76. PubMed PMID: 20044230. Pubmed Central PMCID: 2891323.

145. Peralta ML, Carbajal P. Adherencia a tratamiento. Rev Cent Dermatol Pascua. 2008;17(3):84-8.

146. Silva NLd, Ribeiro E, Navarro JL, Zanini AC. Compliance with treatment: related-issues and insights for pharmacist intervention. Brazilian Journal of Pharm Sciences. 2011;47(1):1-12.

147. Kyngäs H, Lahdenperä T. Compliance of patients with hypertension and associated factors. En: Jin J, Sklar GE, Oh VMS, Li SC. Factors affecting therapeutic compliance: A review from the patient's perspective. Therapeutics and clinical risk management. 2008;4(1):269.

148. Lim TO, Ngah BA. The Mentakab Hypertension Study project. Part II-Why do hypertensives drop out of treatment? Singapore medical journal. 1991 Aug;32(4):249-51. PubMed PMID: 1776004.

149. Perreault S, Lamarre D, Blais L, Dragomir A, Berbiche D, Lalonde L, et al. Persistence with treatment in newly treated middle-aged patients with essential hypertension. Ann Pharmacother. 2005;39.

150. Marcum ZA, Gellad WF. Medication adherence to multi-drug regimens. Clinics in geriatric medicine. 2012;28(2):287.

151. Gerber BS, Cho YI, Arozullah AM, Lee SY. Racial differences in medication adherence: A crosssectional study of Medicare enrollees. The American journal of geriatric pharmacotherapy. 2010 Apr;8(2):136-45. PubMed PMID: 20439063. Pubmed Central PMCID: 3740123.

152. Nichols-English G, Poirier S. Optimizing adherence to pharmaceutical care plans. En: Jin J, Sklar GE, Oh VMS, Li SC. Factors affecting therapeutic compliance: A review from the patient's perspective. Therapeutics and clinical risk management. 2008;4(1):269. 
153. Bender BG, Bender SE. Patient-identified barriers to asthma treatment adherence: responses to interviews, focus groups, and questionnaires. En: Jin J, Sklar GE, Oh VMS, Li SC. Factors affecting therapeutic compliance: A review from the patient's perspective. Therapeutics and clinical risk management. 2008;4(1):269.

154. Dickson M, Plauschinat CA. Racial differences in medication compliance and healthcare utilization among hypertensive Medicaid recipients: fixed-dose vs free-combination treatment. Ethnicity \& disease. 2008 Spring;18(2):204-9. PubMed PMID: 18507275. Epub 2008/05/30. eng.

155. Mayer KH, Stone VE. Strategies for optimizing adherence to highly active antiretroviral therapy: lessons from research and clinical practice. Clinical Infectious Diseases. 2001;33(6):865-72.

156. Munro SA, Lewin SA, Smith HJ, Engel ME, Fretheim A, Volmink J. Patient adherence to tuberculosis treatment: a systematic review of qualitative research. PLoS Med. 2007;4(7):e238.

157. Lorenc L, Branthwaite A. Are older adults less compliant with prescribed medication than younger adults? British Journal of Clinical Psychology. 1993;32(4):485-92.

158. Donnan P, Steinke D, Newton R, Morris A. Changes in treatment after the start of oral hypoglycaemic therapy in Type 2 diabetes: a population-based study. Diabetic medicine. 2002;19(7):606-10.

159. Gore M, Sadosky AB, Leslie DL, Tai KS, Emery P. Therapy switching, augmentation, and discontinuation in patients with osteoarthritis and chronic low back pain. Pain Practice. 2012;12(6):457-68.

160. Rosenstock IM, Strecher VJ, Becker MH. Social learning theory and the health belief model. Health Education \& Behavior. 1988;15(2):175-83.

161. Unni EJ, Farris KB. Unintentional non-adherence and belief in medicines in older adults. Patient education and counseling. 2011;83(2):265-8.

162. Kim E-Y, Han H-R, Jeong S, Kim KB, Park H, Kang E, et al. Does knowledge matter?: intentional medication nonadherence among middle-aged Korean Americans with high blood pressure. Journal of Cardiovascular Nursing. 2007;22(5):397-404.

163. Barber N, Parsons J, Clifford S, Darracott R, Horne R. Patients' problems with new medication for chronic conditions. Quality and Safety in health care. 2004;13(3):172-5.

164. Sewitch MJ, Abrahamowicz M, Barkun A, Bitton A, Wild GE, Cohen A, et al. Patient nonadherence to medication in inflammatory bowel disease. The American journal of gastroenterology. 2003;98(7):1535-44.

165. Sewitch MJ, Dobkin PL, Bernatsky S, Baron M, Starr M, Cohen M, et al. Medication non-adherence in women with fibromyalgia. Rheumatology. 2004;43.

166. Petersen ML, Wang Y, Van Der Laan MJ, Guzman D, Riley E, Bangsberg DR. Pillbox organizers are associated with improved adherence to HIV antiretroviral therapy and viral suppression: a marginal structural model analysis. Clinical Infectious Diseases. 2007;45(7):908-15.

167. Pop-Eleches C, Thirumurthy H, Habyarimana JP, Zivin JG, Goldstein MP, De Walque D, et al. Mobile phone technologies improve adherence to antiretroviral treatment in a resource-limited setting: a randomized controlled trial of text message reminders. AIDS (London, England). 2011;25(6):825.

168. Vervloet M, van Dijk L, Santen-Reestman J, Van Vlijmen B, Van Wingerden P, Bouvy ML, et al. SMS reminders improve adherence to oral medication in type 2 diabetes patients who are real time electronically monitored. International journal of medical informatics. 2012;81(9):594-604.

169. Gujral SS, Raheja I, Gupta A. Patient's compliance: An overview. parameters. 2013;1(2):3.

170. Schneider SM, Hess K, Gosselin T, editors. Interventions to promote adherence with oral agents. Seminars in oncology nursing; 2011: Elsevier. 
171. Miloh T, Annunziato R, Arnon R, Warshaw J, Parkar S, Suchy FJ, et al. Improved adherence and outcomes for pediatric liver transplant recipients by using text messaging. Pediatrics. 2009;124(5):e844-e50.

172. Palen L, Aaløkke S, editors. Of pill boxes and piano benches: home-made methods for managing medication. Proceedings of the 2006 20th anniversary conference on Computer supported cooperative work; 2006: ACM.

173. Okuno J, Yanagi H, Tomura S, Oka M, Hara S, Hirano C, et al. Compliance and medication knowledge among elderly Japanese home-care recipients. European journal of clinical pharmacology. 1999;55(2):145-9.

174. Dezii C. Medication noncompliance: what is the problem? Managed care (Langhorne, Pa). 2000;9 (9 Suppl):7.

175. New England Health Institute. Thinking outside the pillbox: a system-wide approach to improving patient medication adherence for chronic disease. New England Health Care Institute; 2009.

176. Sokol MC, McGuigan KA, Verbrugge RR, Epstein RS. Impact of medication adherence on hospitalization risk and healthcare cost. Med Care. 2005 Jun;43(6):521-30. PubMed PMID: 15908846.

177. Rodríguez Chamorro MÁ, García-Jiménez E, Amariles P, Rodríguez Chamorro A, José Faus M. Revisión de tests de medición del cumplimiento terapéutico utilizados en la práctica clínica. Atención primaria. 2008;40(8):413-7.

178. Morisky DE, Green LW, Levine DM. Concurrent and predictive validity of a self-reported measure of medication adherence. Medical care. 1986;24(1):67-74.

179. Val Jiménez A, Amorós Ballestero G, Martínez Visa P, Fernández Ferré M, León Sanromà M. Estudio descriptivo del cumplimiento del tratamiento farmacológico antihipertensivo y validación del test de Morisky y Green. Atención primaria. 1992;10(5):767-70.

180. World Health Organization. A conceptual framework for action on the social determinants of health. [Internet]. Geneva, Switerzaladnd: WHO. 2010. [consultado el 7-7-2015]. Disponible en: http://www.who.int/social_determinants/publications/9789241500852/en/

181. Shi L, Stevens GD, Faed P, Tsai J. Rethinking vulnerable populations in the United States: an introduction to a general model of vulnerability. Harvard Health Policy Rev. 2008;9(1):43-8.

182. Kintgen ER, Kroll BM, Rose M. Perspectives on literacy: SIU Press; 1988.

183. Schaefer RT. Racial and ethnic groups: Pearson Higher Ed; 2011.

184. Alliance. Covering Health Issues, 6th Ed. (Updated 2012).

185. Urrutia M-T, Cianelli R. Disparidad en Salud: Un Fenómeno Multidimensional. Hispanic Health Care International. 2010;8(1):23-35.

186. Arcaya MC, Arcaya AL, Subramanian S. Desigualdades en salud: definiciones, conceptos y teorías.2015.

187. The American Journal of Managed Care. Vulnerable populations: Who are they?AJMC. Report. Nov 2006; 12(13):S348-S352

188. The Henry J. Kaiser Family Foundation. Disparities in health and health care: five key questions and answers. [Internet]. Kaiser Family. Dec 2012. .[consultado el 22-12-2015]. Washington Disponible en: https://kaiserfamilyfoundation.files.wordpress.com/2013/01/8396.pdf

189. Barnett, Jessica C. and Marina S. Vornovitsky, Current Population Reports, P60-257(RV), Health Insurance Coverage in the United States: 2015, U.S. Government Printing Office, Washington, DC, 2016.

190. Nelson A. Unequal treatment: confronting racial and ethnic disparities in health care. Journal of the National Medical Association. 2002;94(8):666. 
191. Chang BL, Bakken S, Brown SS, Houston TK, Kreps GL, Kukafka R, et al. Bridging the digital divide: reaching vulnerable populations. Journal of the American Medical Informatics Association. 2004;11(6):448-57.

192. Bahls C. Health policy brief: achieving equity in health. Health Affairs Brief. 2011:1-6.

193. Williams DR. Race, socioeconomic status, and health the added effects of racism and discrimination. Annals of the New York Academy of Sciences. 1999;896(1):173-88.

194. Davis JA, Smith TW. General social surveys, 1972-1991: Cumulative codebook: National Opinion Research Center (NORC); 1991.

195. Juckett G. Caring for Latino patients. American family physician. 2013;87(1).

196. World Health Organization. World Health Organization Constitution. [Internet]. Basic documents. 1948;1. .[consultado el 11-10-2015]. Disponible en: http://www.who.int/governance/eb/who_constitution_en.pdf

197. United Nations Assembly. Universal Declaration of Human Rights. UN General Assembly. 1948 Dec 10.

198. World Health Organization. Health and human rights. Fact Sheet of the World Health Organization. Dec, 2015; No. 323

199. Schroeder SA. We can do better-improving the health of the American people. New England Journal of Medicine. 2007;357(12):1221-8.

200. Healthy People, Office of Disease Prevention and Health Promotion. Disparities. [Internet]. Washington, D.C.: U.S. Department of Health and Human Services. Disponible en: https://www.healthypeople.gov/2020/about/foundation-health-measures/Disparities

201. Galea S, Tracy M, Hoggatt KJ, DiMaggio C, Karpati A. Estimated deaths attributable to social factors in the United States. American Journal of Public Health. 2011;101(8):1456-65.

202. Marmot M, Friel S, Bell R, Houweling TA, Taylor S, Health CoSDo. Closing the gap in a generation: Health equity through action on the social determinants of health. The Lancet. 2008;372(9650):1661-9.

203. Singh GK, Siahpush M, Kogan MD. Neighborhood socioeconomic conditions, built environments, and childhood obesity. Health affairs. 2010;29(3):503-12.

204. Jargowsky PA. Architecture of segregation: Civil unrest, the concentration of poverty, and public policy. The Century Foundation, New York, and the Center for Urban Research and Education, Rutgers-Camden. 2015.

205. Chetty R, Hendren N, Kline P, Saez E. Where is the land of opportunity? The geography of intergenerational mobility in the United States. National Bureau of Economic Research, 2014

206. Centers for Medicare and Medicaid Services. Affordable Care Act. [Internet]. Baltimore, MD: U.S. Department of Health and Human Services.[consultado el 19-7-2015]. Disponible en: https://www.cms.gov/

207. Centers for Medicare and Medicaid Services. Medicaid. [Internet]. Baltimore, MD: U.S. Department of Health and Human Services. [consultado el 24-1-2016]. Disponible en: https://www.medicaid.gov/

208. National Association of Community Health Centers I. America's Health Centers. Fact Sheet. March,2016.

209. Rogers W, Lange MM. Rethinking the vulnerability of minority populations in research. American journal of public health. 2013;103(12):2141-6.

210. Wendler D, Kington R, Madans J, Van Wye G, Christ-Schmidt H, Pratt LA, et al. Are racial and ethnic minorities less willing to participate in health research? PLoS Med. 2005;3(2):e19. 
211. King Jr TE. Racial disparities in clinical trials. New England Journal of Medicine. 2002;346(18):1400-2.

212. Underwood SM. Participation of minorities and women in clinical cancer research. Annals of Epidemiology. 2000;10(8):S1-S2.

213. Allmark P. Should research samples reflect the diversity of the population? Journal of medical ethics. 2004;30(2):185-9.

214. Hussain-Gambles M. Ethnic minority under-representation in clinical trials: whose responsibility is it anyway? Journal of health organization and management. 2003;17(2):138-43.

215. Kyanko KA, Franklin RH, Angell SY. Adherence to chronic disease medications among New York City Medicaid participants. Journal of Urban Health. 2013;90(2):323-8.

216. Gómez BP. Método epidemiológico: manual docente de la Escuela Nacional de Sanidad. 2009.

217. Mirón Canelo J, Alonso Sardón M, Iglesias de Sena H. Research methodology in occupational health. Medicina y Seguridad del Trabajo. 2010;56(221):347-65.

218. Fernández P. Tipos de estudios clínico epidemiológicos. Epidemiología Conceptos básicos en: Tratado de epidemiología clínica Madrid DuPont Pharma, SA. 2001.

219. Sánchez-Lara K, Méndez-Sánchez N. Breve revisión de los diseños de investigación observacionales. Médica Sur. 2008;15(3):219-24.

220. United States Census Bureau. Quick Facts [Internet]. Wasington, U.S.: U.S. Department of Commerce [consultado el 10-2-2015]. Disponible en: http://www.census.gov

221. Bell K. Atlantic Slave Trade to Savannah. New Georgia Encyclopedia [Internet]. 2002, Sept. [consultado el 15-3-2015]. Disponible en: http://www.georgiaencyclopedia.org/

222. Cullen J. The American dream: A short history of an idea that shaped a nation: Oxford University Press, USA; 2004.

223. St. Joseph's Candler. In the Community [Internet]. Savannah, GA: St. Joseph's Candler [consultado el 1-2-2015].Disponible en: http://www.sjchs.org/in-the-community/in-the-community

224. Hernandez C, Jansa M, Vidal M, Nunez M, Bertran M, Garcia-Aymerich J, et al. The burden of chronic disorders on hospital admissions prompts the need for new modalities of care: a crosssectional analysis in a tertiary hospital. Qjm. 2009;102(3):193-202.

225. Casal J, Mateu E. Tipos de muestreo. Rev Epidem Med Prev. 2003;1(1):3-7.

226. Martín JR. Población de estudio y muestreo en la investigación epidemiológica. NURE Investigación. 2004;1(10).

227. Arribas M. Diseño y validación de cuestionarios. Matronas profesión. 2004;5(17):23-9.

228. Anguita JC, Labrador JR, Campos JD. La encuesta como técnica de investigación. Elaboración de cuestionarios y tratamiento estadístico de los datos (I). Atención primaria. 2003;31(8):527-38.

229. Muñoz TG. El cuestionario como instrumento de investigación/evaluación. España: Almendralejo. Marzo, 2003. Disponible en: http://www.univsantana.com/sociologia/El_Cuestionario.pdf

230. Cid-Ruzafa J, Damián-Moreno J. Valoración de la discapacidad física: el índice de Barthel. Revista española de salud pública. 1997;71(2):127-37.

231. Conserjería de Sanidad de la Junta de Castila y León. Estrategia de Atención al Paciente Crónico en Castilla y León. [Internet].Valladolid: Conserjería de Sanidad Junta de Castilla y León. 2013. [consultado el 4-1-2015]. Disponible en: http://www.saludcastillayleon.es/institucion/es/planesestrategias/estrategia-atencion-paciente-cronico-castilla-leon

232. National Institutse of Health, Classification of Overweight, Obesity by BMI, Waist Circumference, and Associated Disease Risks. [Internet]. Bethesda, MD: U.S. Department of Health \& Human Services. [consultado el 22-8-2015]. Disponible en: https://www.nhlbi.nih.gov/health/educational/lose_wt/BMI/bmi_dis.htm 
233. U.S. Department of Health and Human Services and U.S. Department of Agriculture. 2015-2020 Dietary Guidelines for Americans. [internet]. 8th Edition. December 2015. Disponible en http://health.gov/dietaryguidelines/2015/guidelines/

234. Gasperin LdOF, Neuberger M, Tichy A, Moshammer H. Cross-sectional association between cigarette smoking and abdominal obesity among Austrian bank employees. BMJ open. 2014;4(7):e004899.

235. Husten CG. How should we define light or intermittent smoking? Does it matter? Nicotine \& Tobacco Research. 2009;11(2):111-21.

236. National Institute of Health. Living With High Blood Pressure [Internet]. Bethesda, MD: U.S. Department of Health \& Human Services [consultado el 31-9-2015]. Disponible en: http://www.nhlbi.nih.gov/health/health-topics/topics/hbp/livingwith

237. National Institute of Health. Know Your Blood Sugar Numbers: Use Them to Manage Your Diabetes. [Internet]. Bethesda, MD: U.S. Department of Health \& Human Services [consultado el 1-9-2015]. Disponible en: https://www.niddk.nih.gov/health-information/diabetes/managemonitoring-diabetes/know-blood-sugar-numbers-manage-diabetes

238. Chen S, Alas V, Lee Y, Greene M, Oderda G. Evaluation Of Polypharmacy In Patients With Type 2 Diabetes Mellitus And Its Association With Medication Adherence And Health Care Costs. Value in Health. 2013;16(3):A173.

239. American Optometric Association. Low Vision. [Internet]. St. Louis, MO: American Optometric Association [consultado el 12-10-2015]. Disponible en: http://www.aoa.org/patients-and-public/caring-for-your-vision/low-vision?sso=y

240. Disabled World. Hearing Impairment: Deaf \& Hearing Loss Information. [Internet]. [consultado el 09-10-2015]. Disponible en: http://www.disabled-world.com/disability/types/hearing/

241. American Speech-Language-Hearing Association. Definitions of communication disorders and variations [Internet]. Rockville, MD: ASHA. [consultado el 20-10-2015]. Disponible en: http://www.asha.org/policy/RP1993-00208/

242. Cohen J. Statistical power analysis for the behavior science. Lawrance Eribaum Association. 1988.

243. Ortega Calvo M, Cayuela Domínguez A. Regresión logística no condicionada y tamaño de muestra: una revisión bibliográfica. Revista Española de Salud Pública. 2002;76(2):85-93.

244. United States Census Bureau. United States Median Household Income. [Internet]. Washington,DC: U.S. Department of Commerce [consultado el 10-10-2016]. Disponible en: http://www.census.gov

245. Conlin PR, Gerth WC, Fox J, Roehm JB, Boccuzzi SJ. Four-year persistence patterns among patients initiating therapy with the angiotensin II receptor antagonist losartan versus other antihypertensive drug classes. Clinical therapeutics. 2001;23(12):1999-2010.

246. Breekveldt-Postma NS, Penning-van Beest FJ, Siiskonen SJ, Falvey H, Vincze G, Klungel OH, et al. The effect of discontinuation of antihypertensives on the risk of acute myocardial infarction and stroke. Current medical research and opinion. 2008;24(1):121-7.

247. Williams A, Manias E, Walker R. Interventions to improve medication adherence in people with multiple chronic conditions: a systematic review. Journal of Advance Nursing.2008;63(2):132-43.

248. Nazareth I, Burton A, Shulman S, Smith P, Haines A, Timberall H. A pharmacy discharge plan for hospitalized elderly patients, a randomized controlled trial. Age and ageing. 2001;30(1):33-40.

249. Grant RW, Devita NG, Singer DE, Meigs JB. Improving adherence and reducing medication discrepancies in patients with diabetes. Annals of Pharmacotherapy. 2003;37(7-8):962-9.

250. Ponnusankar S, Surulivelrajan M, Anandamoorthy N, Suresh B. Assessment of impact of medication counseling on patients' medication knowledge and compliance in an outpatient clinic in South India. Patient education and counseling. 2004;54(1):55-60. 
251. Lee JK, Grace KA, Taylor AJ. Effect of a pharmacy care program on medication adherence and persistence, blood pressure, and low-density lipoprotein cholesterol: a randomized controlled trial. Jama. 2006;296(21):2563-71.

252. De Geest S, Schäfer-Keller P, Denhaerynck K, Thannberger N, Köfer S, Bock A, et al. Supporting medication adherence in renal transplantation (SMART): a pilot RCT to improve adherence to immunosuppressive regimens. Clinical transplantation. 2006;20(3):359-68.

253. Wu JY, Leung WY, Chang S, Lee B, Zee B, Tong PC, et al. Effectiveness of telephone counselling by a pharmacist in reducing mortality in patients receiving polypharmacy: randomised controlled trial. Bmj. 2006;333(7567):522.

254. Bernsten C, Björkman I, Caramona M, Crealey G, Frøkjær B, Grundberger E, et al. Improving the well-being of elderly patients via community pharmacy-based provision of pharmaceutical care. Drugs \& aging. 2001;18(1):63-77.

255. Sturgess IK, McElnay JC, Hughes CM, Crealey G. Community pharmacy based provision of pharmaceutical care to older patients. Pharmacy World and Science. 2003;25(5):218-26.

256. Avorn J, Monette J, Lacour A, Bohn RL, Monane M, Mogun H, et al. Persistence of use of lipidlowering medications: a cross-national study. Jama. 1998;279(18):1458-62.

257. Cramer J, Rosenheck R, Kirk G, Krol W, Krystal J. Medication compliance feedback and monitoring in a clinical trial: predictors and outcomes. Value in Health. 2003;6(5):566-73.

258. Kaplan RC, Bhalodkar NC, Brown EJ, Jr., White J, Brown DL. Race, ethnicity, and sociocultural characteristics predict noncompliance with lipid-lowering medications. Preventive medicine. 2004 Dec;39(6):1249-55. PubMed PMID: 15539064.

259. Stilley CS, Sereika S, Muldoon MF, Ryan CM, Dunbar-Jacob J. Psychological and cognitive function: predictors of adherence with cholesterol lowering treatment. Annals of Behavioral Medicine. 2004;27(2):117-24.

260. Ghods A, Nasrollahzadeh D. Noncompliance with immunnosuppressive medications after renal transplantation. Experimental and clinical transplantation: official journal of the Middle East Society for Organ Transplantation. 2003;1(1):39-47.

261. Shenolikar RA, Balkrishnan R, Camacho FT, Whitmire JT, Anderson RT. Race and medication adherence in Medicaid enrollees with type-2 diabetes. Journal of the National Medical Association. 2006;98(7):1071.

262. Aggarwal B, Liao M, Mosca L. Medication adherence is associated with having a caregiver among cardiac patients. Annals of Behavioral Medicine. 2013;46(2):237-42.

263. Morgan M, Watkins C. Managing hypertension: beliefs and responses to medication among cultural groups. Sociology of Health \& Illness. 1988;10(4):561-78.

264. Risser AL, Mazur LJ. Use of folk remedies in a Hispanic population. Archives of pediatrics \& adolescent medicine. 1995;149(9):978-81.

265. Pascal IG, Ofoedu JN, Uchenna NP, Nkwa AA, Uchamma G-UE. Blood glucose control and medication adherence among adult type 2 diabetic Nigerians attending a primary care clinic in under-resourced environment of eastern Nigeria. North American journal of medical sciences. 2012;4(7):310.

266. Tubiana-Rufi N, Moret L, Czernichow P, Chwalow J. Risk factors for poor glycemic control in diabetic children in France. Diabetes Care. 1995;18(11):1479-82.

267. White MC, Tulsky JP, Menendez E, Goldenson J, Kawamura LM. Incidence of TB in inmates with latent TB infection: 5-year follow-up. American Journal of Preventive Medicine.2005;29(4)295 301. 
268. Piette JD, Heisler M, Wagner TH. Cost-related medication underuse among chronically III adults: the treatments people forgo, how often, and who is at risk. American Journal of Public Health. 2004;94(10):1782-7.

269. Charles H, Good CB, Hanusa BH, Chang C-CH, Whittle J. Racial differences in adherence to cardiac medications. Journal of the National Medical Association. 2003;95(1):17.

270. Francis CK. Hypertension, cardiac disease, and compliance in minority patients. The American journal of medicine. 1991;91(1):S29-S36.

271. Lucas GM, Cheever LW, Chaisson RE, Moore RD. Detrimental effects of continued illicit drug use on the treatment of HIV-1 infection. JAIDS Journal of Acquired Immune Deficiency Syndromes. 2001;27(3):251-9.

272. Opolka JL, Rascati KL, Brown CM, Gibson PJ. Role of ethnicity in predicting antipsychotic medication adherence. Annals of Pharmacotherapy. 2003;37(5):625-30.

273. Oh DL, Sarafian F, Silvestre A, Brown T, Jacobson L, Badri S, et al. Evaluation of adherence and factors affecting adherence to combination antiretroviral therapy among White, Hispanic, and Black men in the MACS Cohort. Journal of acquired immune deficiency syndromes (1999). 2009;52(2):290.

274. Sleath B, Rubin RH, Huston SA. Hispanic ethnicity, physician-patient communication, and antidepressant adherence. Comprehensive Psychiatry. 2003;44(3):198-204.

275. Tebbi CK. Treatment compliance in childhood and adolescence. Cancer. 1993;71(S10):3441-9.

276. Patel NC, Crismon ML, Miller AL, Johnsrud MT. Drug adherence: effects of decreased visit frequency on adherence to clozapine therapy. Pharmacotherapy: The Journal of Human Pharmacology and Drug Therapy. 2005;25(9):1242-7.

277. Plantinga LC, Fink NE, Sadler JH, Levey AS, Levin NW, Rubin HR, et al. Frequency of patientphysician contact and patient outcomes in hemodialysis care. Journal of the American Society of Nephrology. 2004;15(1):210-8.

278. Morrison F, Shubina M, Turchin A. Encounter frequency and serum glucose level, blood pressure, and cholesterol level control in patients with diabetes mellitus. Archives of internal medicine. 2011;171(17):1542-50

279. Turchin A, Goldberg SI, Shubina M, Einbinder JS, Conlin PR. Encounter frequency and blood pressure in hypertensive patients with diabetes mellitus. Hypertension. 2010;56(1):68-74.

280. Fredriksen-Goldsen KI, Shiu C-S, Starks H, Chen W-T, Simoni J, Kim H-J, et al. "You must take the medications for you and for me": family caregivers promoting HIV medication adherence in China. AIDS patient care and STDs. 2011;25(12):735-41.

281. Sung J, Nichol MB, Venturini F, Bailey KL, McCombs JS, Cody M. Factors affecting patient compliance with antihyperlipidemic medications in an HMO population. The American journal of managed care. 1998;4(10):1421-30.

282. McManus R, Mant J, Roalfe A, Oakes R, Bryan S, Pattison HM, et al. Targets and self monitoring in hypertension: randomised controlled trial and cost effectiveness analysis. Bmj. 2005;331(7515):493.

283. Cappuccio FP, Kerry SM, Forbes L, Donald A. Blood pressure control by home monitoring: metaanalysis of randomised trials. Bmj. 2004;329(7458):145.

284. Ogedegbe G, Schoenthaler A. A systematic review of the effects of home blood pressure monitoring on medication adherence. The Journal of Clinical Hypertension. 2006;8(3):174-80.

285. Sicras MA, Muñoz OG, Font RB, Majós ON, Navarro AR, Ibáñez NJ. [Relationship of polymedication in controlling blood pressure: compliance, persistence, costs and incidence of new cardiovascular events]. Medicina clinica. 2013;141(2):53-61. 
286. Kramer AM. Health care for elderly persons - myths and realities. En: Gottlieb H. Medication Nonadherence: Finding Solutions to a Costly Medical Problem CME. Drug Benefit Trends. 2000;12(6):57-62.

287. Jovell AJ, Rubio MDN, Maldonado LF, Blancafort S. Nuevo rol del paciente en el sistema sanitario. Atención primaria. 2006;38(4):234-7.

288. Martín Fombellida AB, Alonso Sardón M, Iglesias de Sena H, Sáez Lorenzo M, Mirón Canelo JA. Información sobre medicamentos y automedicación en las redes sociales. Revista Cubana de Información en Ciencias de la Salud. 2014;25(2):145-56.

289. Martín Fombellida AB, Sáez Lorenzo M, Iglesias de Sena H, Alonso Sardón M, Alonso Arévalo J, Mirón Canelo JA. ¿ La información sobre automedicación disponible en internet reúne criterios de calidad? Revista Cubana de Información en Ciencias de la Salud. 2016;27(1):19-34.

290. Shortliffe EH, Altman R, Brennan P, Davie B, Detmer W, Florance V, et al. Networking health: Prescriptions for the Internet. Computer Science and Telecommunications Board, The National Academies, Washington DC. 2000.

291. Buetow S, Henshaw J, Bryant L, O'Sullivan D. Medication timing errors for Parkinson's disease: perspectives held by caregivers and people with Parkinson's in New Zealand. Parkinson's Disease. 2009 Nov 5;2010.

292. Vervloet M, Linn AJ, van Weert JC, De Bakker DH, Bouvy ML, Van Dijk L. The effectiveness of interventions using electronic reminders to improve adherence to chronic medication: a systematic review of the literature. Journal of the American Medical Informatics Association. 2012;19(5):696704.

293. Ryan GW, Wagner G. Pill taking 'routinization': a critical factor to understanding episodic medication adherence. AIDS care. 2003;15(6):795-806.

294. Bosworth HB, Oddone EZ, Weinberger M. Patient treatment adherence: concepts, interventions, and measurement: Psychology Press; 2006.

295. George C, Peveler R, Heiliger S, Thompson C. Compliance with tricyclic antidepressants: the value of four different methods of assessment. British Journal of Clinical Pharmacology. 2000; 50(2):166-71.

296. Elm JJ, Kamp C, Tilley BC, Guimaraes P, Fraser D, Deppen P, et al. Self-reported adherence versus pill count in Parkinson's disease: The NET-PD experience. Movement disorders. 2007;22(6):822-7.

297. de Macedo LA, Gómez MM, Canelo JAM, Sardón MA, del Pino Montes J. Evaluación de la adherencia y factores relacionados en pacientes con osteoporosis. Atención Farmaceutica. 2010;12(1):25-32.

298. Gómez MM, Canelo JAM, Sardón MA, González MdCS. Cumplimiento terapéutico y resultados del tratamiento en pacientes con tuberculosis. Atención farmacéutica. 2005;7(6):428-37.

299. Office of The Assistant Secretary for Planning and Evaluation. 2015 Poverty Guidelines for The 48 Contiguos States and The Disctrict of Columbia. [Internet]. Washington, D.C.: U.S.Department of Health and Human Services. [consultado el 10-10-2014]. Disponible en: https://aspe.hhs.gov/2015-poverty-guidelineshttps://aspe.hhs.gov/2015-poverty-guidelines 
Anexos 

ANEXO I. Definición funcional de paciente pluripatológico. Aquel que presenta enfermedades crónicas definidas en dos o más de las siguientes categorías clínicas:

\section{Categoría A:}

- Insuficiencia cardiaca que en situación de estabilidad clínica haya estado en grado II NYHA ${ }^{(a)}$.

- Cardiopatía isquémica

\section{Categoría B:}

- Vasculitis y enfermedades autoinmunes sistémicas.

- Enfermedad renal crónica definida por elevación de creatinina $(>1,4 \mathrm{mg} / \mathrm{dl}$ en hombres o $>1,3$ $\mathrm{mg} / \mathrm{dl}$ en mujeres) o proteinuria ${ }^{(b)}$, mantenidas durante 3 meses.

\section{Categoría C:}

- Enfermedad respiratoria crónica que en situación de estabilidad clínica haya estado con disnea grado 2 de la $\mathrm{MRC}^{(\mathrm{c})}$, o FEV $1<65 \%, \mathrm{o} \mathrm{SaO}_{2} \leq 90 \%$.

\section{Categoría D:}

- Enfermedad inflamatoria crónica intestinal.

- Hepatopatía crónica con datos de insuficiencia hepatocelular ${ }^{(\mathrm{d})} \mathrm{o}$ hipertensión portal ${ }^{(\mathrm{e})}$. Categoría E:

- Ataque cerebrovascular.

- Enfermedad neurológica con déficit motor permanente que provoque una limitación para las actividades básicas de la vida diaria (Índice de Barthel <.60)

- Enfermedad neurológica con deterioro cognitivo permanente, al menos moderado (Pfeiffer con 5 ó más errores).

\section{Categoría F:}

- Arteriopatía periférica sintomática.

- Diabetes mellitus con retinopatía proliferativa o neuropatía sintomática.

\section{Categoría G:}

- Anemia crónica por pérdidas digestivas o hemopatía adquirida no subsidiaria de tratamiento curativo que presente $\mathrm{Hb}<10 \mathrm{mg} / \mathrm{dl}$ en dos determinaciones separadas más de tres meses.

- Neoplasia sólida o hematológica activa no subsidiaria de tratamiento con intención curativa

\section{Categoría H}

- Enfermedad osteoarticular crónica que provoque por sí misma una limitación para las actividades básicas de la vida diaria (índice de Barthel < 60).

\footnotetext{
(a) Ligera limitación de la actividad física. La actividad física habitual le produce disnea, angina, cansancio o palpitaciones.

(b) Índice albúmina/creatinina $>300 \mathrm{mg} / \mathrm{g}$, microalbuminuria $>3 \mathrm{mg} / \mathrm{dl}$ en muestra de orina o albúmina $>300 \mathrm{mg} / \mathrm{d}$ ía en orina de 24 horas.

(c) Incapacidad de mantener el paso de otra persona de la misma edad, caminando en llano, debido a la dificultad respiratoria o tener que parar a descansar al andar en llano al propio paso.

(d) INR $>1,7$, albúmina $<3,5 \mathrm{~g} / \mathrm{dl}$, bilirrubina $>2 \mathrm{mg} / \mathrm{dl}$.

(e) Definida por la presencia de datos clínicos, analíticos, ecográficos o endoscópicos.
} 
ANEXO II. Nivel de Pobreza Federal Año 2015*

\begin{tabular}{|c|c|c|c|c|c|c|}
\cline { 2 - 7 } & \multicolumn{5}{|c|}{ Umbral de Pobreza } \\
\hline $\begin{array}{c}\text { No de Personas en } \\
\text { la Familia }\end{array}$ & $\mathbf{1 0 0 \%}$ & $\mathbf{1 2 5 \%}$ & $\mathbf{1 5 0 \%}$ & $\mathbf{2 0 0 \%}$ & $\mathbf{3 0 0 \%}$ & $\mathbf{4 0 0 \%}$ \\
\hline $\mathbf{1}$ & $\$ 11.770$ & $\$ 14.713$ & $\$ 17655$ & $\$ 23.540$ & $\$ 35.310$ & $\$ 47.080$ \\
\hline $\mathbf{2}$ & $\$ 15.930$ & $\$ 19.913$ & $\$ 23.895$ & $\$ 31.860$ & $\$ 47.790$ & $\$ 63.720$ \\
\hline $\mathbf{3}$ & $\$ 20.090$ & $\$ 25.113$ & $\$ 30.135$ & $\$ 40.180$ & $\$ 60.270$ & $\$ 80.360$ \\
\hline $\mathbf{4}$ & $\$ 24.250$ & $\$ 30.313$ & $\$ 36.375$ & $\$ 48.500$ & $\$ 72.750$ & $\$ 97.000$ \\
\hline $\mathbf{5}$ & $\$ 28.410$ & $\$ 35.513$ & $\$ 42.615$ & $\$ 56.820$ & $\$ 85.230$ & $\$ 113.640$ \\
\hline $\mathbf{7}$ & $\$ 32.570$ & $\$ 40.713$ & $\$ 48.865$ & $\$ 65.140$ & $\$ 97.710$ & $\$ 130.280$ \\
\hline $\mathbf{8}$ & $\$ 36.730$ & $\$ 45.913$ & $\$ 55.095$ & $\$ 73.460$ & $\$ 110.190$ & $\$ 146.920$ \\
\hline $\mathbf{m i e m b r o}$ & $\$ 4.160$ & $\$ 5.200$ & $\$ 6.240$ & $\$ 8.320$ & $\$ 12.480$ & $\$ 16.640$ \\
\hline
\end{tabular}

* Obtenido de The Office of The Assistant Secretary for Planning and Evaluation United Nations, $2015^{299}$.

* El diagrama es válido para los 48 estados contiguos norteamericanos y el Distrito de Columbia, para Hawái y Alaska.

** Las cantidades en dólares son calculadas en base a la columna del 100\%; las reglas de redondeo pueden variar dependiendo de los programas federales, estatales, y locales.

*** Cada año, el Nivel de Pobreza Federal es incrementado dependiendo de los niveles del coste de vida. 
ANEXO III. Condiciones Crónicas Incluidas en el Estudio, Categorizadas por Sistema y Definidas por Frecuencia de Prescripción y CIE-9.

\begin{tabular}{|c|c|}
\hline Sistema & Definición \\
\hline \multicolumn{2}{|l|}{ 1- CATEGORIA A: Enfermedad sanguínea y circulatorio } \\
\hline \multicolumn{2}{|l|}{ Enfermedades Sanguíneas } \\
\hline Anemia crónica, autoinmune, hemolítica $(280,281,282.0,283-284,285.2)$ & Código registrado en historia \\
\hline \multicolumn{2}{|l|}{ Circulatorio } \\
\hline Enfermedad arterial hipertensiva (401-405) & Código registrado en historia \\
\hline Ataque isquémico transitorio y angina (410-414) & Código registrado en historia \\
\hline Enfermedad de las válvulas del corazón (424) & Código registrado en historia \\
\hline Arritmia Cardiaca (427) & Código registrado en historia \\
\hline Insuficiencia cardiaca (428-429) & Código registrado en historia \\
\hline Accidente cerebrovascular (430-438) & Código registrado en historia \\
\hline Enfermedad vascular periférica (443) & Código registrado en historia \\
\hline \multicolumn{2}{|l|}{ 2- CATEGORIA B: Respiratorio } \\
\hline \multicolumn{2}{|l|}{ Respiratoria } \\
\hline Sinusitis crónica (473) & Código registrado en historia \\
\hline $\begin{array}{l}\text { Enfermedad pulmonar obstructiva crónica }(491.0,491.1,491.20,491.21, \\
491.9,492.0,492.8,496)\end{array}$ & Código registrado en historia \\
\hline Asma siendo tratado actualmente (493) & $\begin{array}{l}\text { Código registrado en historia } \mathbf{Y} \text { cualquier } \\
\text { prescripción en los últimos } 12 \text { meses }\end{array}$ \\
\hline Bronquiectasia (494) & Código registrado en historia \\
\hline \multicolumn{2}{|l|}{ 3- CATEGORIA C: Digestivo } \\
\hline \multicolumn{2}{|l|}{ Digestivo } \\
\hline Enfermedad diverticular del intestino (562) & Código registrado en historia \\
\hline Estreñimiento siendo tratado actualmente (564.0) & $\geq 4$ prescripciones laxativas en último año \\
\hline Síndrome del intestino irritable (564.1) & $\begin{array}{l}\text { Código registrado en historia } \mathbf{O} \geq 4 \\
\text { prescripciones de medicamentos } \\
\text { antiespasmódicos en los últimos } 12 \text { meses }\end{array}$ \\
\hline Cirrosis hepática $(571,572.3,572.8,456)$ & Código registrado en historia \\
\hline \multicolumn{2}{|l|}{ 4- CATEGORIA D: Nervioso y mental-conducta } \\
\hline \multicolumn{2}{|l|}{ Nervioso } \\
\hline Alzheimer y demencia $(331,290,294)$ & Código registrado en historia \\
\hline Enfermedad de Parkinson (332) & Código registrado en historia \\
\hline Esclerosis Múltiple (340) & Código registrado en historia \\
\hline Epilepsia siendo tratada actualmente (345) & $\begin{array}{l}\text { Código registrado en historia } \mathbf{Y} \text { prescrip } \\
\text { antiepiléptica en los últimos } 12 \text { meses }\end{array}$ \\
\hline Migrañas (346) & $\geq 4$ prescripciones especificas último año \\
\hline Neuropatía periférica $(356,357.4)$ & Código registrado en historia \\
\hline \multicolumn{2}{|l|}{ Mental-Conducta } \\
\hline Ansiedad (300.0) & $\begin{array}{l}\text { Código registrado en los últimos } 12 \\
\text { meses } \mathbf{O} \geq 4 \text { prescripciones antidepresivas } \\
\text { en los últimos } 12 \text { meses }\end{array}$ \\
\hline Abuso de consumo de alcohol (305.0) & Código registrado en historia \\
\hline Abuso de consumo de tabaco (305.1) & Código registrado en historia \\
\hline Abuso de sustancias psicotrópicas (305.2-305.9) & Código registrado en historia \\
\hline Anorexia nerviosa, Bulimia $(307.1,307.51)$ & Código registrado en historia \\
\hline Depresión menor (311) & $\begin{array}{l}\text { Código registrado en los últimos } 12 \\
\text { meses Ó } \geq 4 \text { prescripciones antidepresivas } \\
\text { en los últimos } 12 \text { meses }\end{array}$ \\
\hline Discapacidad de aprendizaje (V40.0) & Código registrado en historia \\
\hline
\end{tabular}


ANEXO III. Continuación de las Condiciones Crónicas Incluidas en el Estudio, Categorizadas por Sistema y Definidas por Frecuencia de Prescripción y CIE-9.

\begin{tabular}{|c|c|}
\hline Sistema & Definición \\
\hline \multicolumn{2}{|l|}{ 5- CATEGORIA E: Endocrino-nutricional-metabólico } \\
\hline \multicolumn{2}{|l|}{ Endocrino, nutricional, y metabólico } \\
\hline Desorden del tiroides $(240-246)$ & Código registrado en historia \\
\hline Diabetes (250) & Código registrado en historia \\
\hline Hiperlipidemia (272) & Código registrado en historia \\
\hline Gota $(274)$ & Código registrado en historia \\
\hline Síndrome Metabólico (277.7) & Código registrado en historia \\
\hline Obesidad Mórbida (278.01) & $\begin{array}{l}\text { Código registrado en historia } \mathbf{Y} \\
\text { prescripción especifica en el último año }\end{array}$ \\
\hline \multicolumn{2}{|l|}{$\begin{array}{l}\text { 6- CATEGORIA F: Renal, genitourinario, reproductor, y enfermedad } \\
\text { congénita }\end{array}$} \\
\hline \multicolumn{2}{|l|}{ Desordenes Renales } \\
\hline Insuficiencia Renal (585-6) & Código registrado en historia \\
\hline \multicolumn{2}{|l|}{ Genitourinario } \\
\hline Desordenes de próstata $(600,602)$ & Código registrado en historia \\
\hline \multicolumn{2}{|l|}{ Reproductor } \\
\hline Endometriosis (617) & Código registrado en historia \\
\hline \multicolumn{2}{|l|}{ Enfermedad Congénita } \\
\hline Desorden congénito $(753.4,752.49)$ & Código registrado en historia \\
\hline \multicolumn{2}{|l|}{ 7- CATEGORIA G: Musculo-esquelético } \\
\hline \multicolumn{2}{|l|}{ Musculo-esquelético y tejidos conectivos } \\
\hline $\begin{array}{l}\text { Artritis reumatoide, otras poliartropatías inflamatorias y trastornos del } \\
\text { tejido conectivo }(695.4,710,714-716)\end{array}$ & Código registrado en historia \\
\hline Afección dolorosa & $\begin{array}{l}\geq 4 \text { prescripciones de medicamentos } \\
\text { analgésicos en el último año }\end{array}$ \\
\hline \multicolumn{2}{|l|}{$\begin{array}{l}\text { 8- CATEGORIA H: Infecciones, cáncer, órganos sensoriales, y } \\
\text { enfermedad de la piel }\end{array}$} \\
\hline \multicolumn{2}{|l|}{ Infecciones } \\
\hline HIV/AIDS (V08,042) & Código registrado en historia \\
\hline Hepatitis viral (v070, v02.69,573) & Código registrado en historia \\
\hline \multicolumn{2}{|l|}{ Cáncer (y secuelas) } \\
\hline Nuevo diagnóstico de cáncer en los últimos 5 años (140-239) & $\begin{array}{l}\text { Código registrado en historia en los } \\
\text { últimos } 5 \text { años }\end{array}$ \\
\hline \multicolumn{2}{|l|}{ Órganos sensoriales } \\
\hline Glaucoma (365) & Código registrado en historia \\
\hline Ceguera y problemas de visión (369) & Código registrado en historia \\
\hline Pérdida de audición (389) & Código registrado en historia \\
\hline \multicolumn{2}{|l|}{ Enfermedad de la piel y tejidos subcutáneos } \\
\hline Psoriasis o eczema (696) & $\begin{array}{l}\text { Código registrado en historia } \mathbf{Y} \text { prescrip } \\
\text { en los últimos } 12 \text { meses (excluyendo } \\
\text { simples emolientes) }\end{array}$ \\
\hline
\end{tabular}


ANEXO IV. Cuestionario de Adherencia a la Medicación Morisky-Green-Levine ${ }^{178}$.

\section{Questions:}

1) Do you ever forget to take your medication?

2) Are you careless at times about taking your medication?

3) When you feel better, do you sometimes stop taking your medicine?

4) Sometimes if you feel worse when you take the medicine, do you stop taking it? 
ANEXO V. Versión Validada en Español del Cuestionario de Adherencia a la Medicación Morisky-Green-Levine ${ }^{179}$.

\section{Preguntas:}

1) ¿Olvida alguna vez tomar los medicamentos para tratar su enfermedad?

2) ¿Toma los medicamentos a las horas indicadas?

3) Cuando se encuentra bien, ¿deja de tomar la medicación?

4) Si alguna vez le sientan mal, ¿deja de tomarla? 
ANEXO VI. Autorización para la Utilización del Cuestionario de Adherencia a la Medicación Morisky-Green-Levine

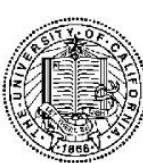

UCLA

\section{TO WHOM IT MAY CONCERN:}

I hereby give permission to Cesar Fernandez Lazaro to use the Morisky, Green and Levine medication adherence scale that appears in the Medical Care 1986 Journal for his Master of Public Health (MPH) at Armstrong State University, in Savannah, $\mathrm{Ga}$. The title of his thesis is "Treatment adherence among minorities with multiple chronic conditions".

Sincerely,<smiles>C(#CC1CCC1)CC1CC1</smiles>

Donald E. Morisky, Sc.D., MSPH, ScM

Professor and Former Chair

Department of Community Health Sciences 
ANEXO VII. Cuestionario de Recogida de Datos (versión en inglés)

\section{SECTION I}

Patient Code:

Age:

Weight:

$\square$ Male

Ethnic:

$\square$ American
Clinic/Health Care Center:

Height:

Body Mass Index:

$\square$ Female

$\square$ Afric-Amer

$\square$ Asian

$\square$ Other

\section{Chronic Information}

\begin{tabular}{|l|l|l|}
\hline Condition & $\begin{array}{c}\text { Starting day of } \\
\text { New Therapy }\end{array}$ & \\
\hline & & \\
\hline & & \\
\hline & & \\
\hline & & \\
\hline & & \\
\hline Number of Total Conditions & & \multicolumn{1}{|l|}{} \\
\hline
\end{tabular}

Current Therapy

\begin{tabular}{|l|l|l|l|l|}
\hline Drug & Dosage & $\begin{array}{c}\text { Frequency of } \\
\text { Dosage }\end{array}$ & $\begin{array}{c}\text { Number of } \\
\text { Pills/Day }\end{array}$ & $\begin{array}{c}\text { Route of } \\
\text { Administration }\end{array}$ \\
\hline & & & & \\
\hline & & & & \\
\hline & & & & \\
\hline & & & & \\
\hline & & & & \\
\hline & & & & \\
\hline & & & & \\
\hline
\end{tabular}

$\square$ Renal Failure

$\square$ Yes

$\square$ No

Intolerances/Allergies

\section{Observations}


ANEXO VII. Continuación del Cuestionario de Recogida de Datos (versión en inglés) SECTION II

$\begin{array}{llll}\text { Place of birth: } & \square \text { USA } & & \\ \text { Education Level: } \quad \square \text { No Formal Education } \quad \square \text { Secondary School } \quad \square \text { Primary School } & \square \text { University } \\ \text { House Hold Inc: } \quad \square<\$ 5,000 \quad \square \$ 5,000-\$ 9,999 \quad \square \$ 10,000-\$ 14,999 \quad \square \$ 15,000-\$ 19,999 \quad \square>\$ 20,000 & \\ \text { Cohabitation: } & \square \text { Living Alone } \quad \square \text { Living with family } \quad \square \text { Living with sentimental othe } \\ \text { Geographic Area: } & \square \text { Urban } & \square \text { Rural } & \\ \text { Occupational Status: } & \square \text { Actively Working } & \square \text { Unemployment } & \square \text { Other } \\ & \square \text { Temporary Incapacitated } & \square \text { Retired } & \\ \text { Literacy Issues: } & \square \text { Reading } & \square \text { Listening } & \square \text { Numeracy }\end{array}$

Sensory Difficulties:

Smoker:

$\square$ Yes $\square$ No $\square$ Ex-smoker

$$
\square \geq 20 \text { cigars/day } \quad \square 11-19 \text { cigars/day } \quad \square \leq 10 \text { cigars/day }
$$

Alcohol Intake: $\square$ Heavy consumption $\square$ Moderate consumption $\square$ Light Consumption $\square$ None

\begin{tabular}{|c|c|c|c|c|c|c|}
\hline & $\square$ Win & & $\square$ Beer & $\square$ Distilled Spirits & $\square$ Othe & \\
\hline Use of Drugs: & $\square$ Yes & $\square$ No & $\square$ Past & Specific Diet: & $\square$ Yes & $\square$ No \\
\hline Physical Activity: & $\square$ Yes & $\square$ No & & Self-Monitoring Tech.: & $\square$ Yes & $\square$ No \\
\hline
\end{tabular}

In general, would you say that your health in the last 12 months has been?

Very Poor

Fair

$\begin{array}{lllll}0 & 1 & 2 & 3 & 4\end{array}$

$\begin{array}{lll}5 & 6 & 7\end{array}$

89

Very Good

10 
ANEXO VII. Continuación del Cuestionario de Recogida de Datos (versión en inglés)

\section{SECTION III}

\section{About Taking Your Medicine}

Do you sometimes forget to take your medicine?

$\square$ Yes $\square$ No

Are you careless at times about taking your medicines?

$\square$ Yes $\square$ No

Do you sometimes skip your medicines when you are feeling well?

$\square$ Yes $\square$ No

Sometimes if you feel worse when you take your medicines, do you stop taking it?

$\square$ Yes $\square$ No

\section{About Your Medicines}

Do you know why you take each medication?

$\square$ Yes $\square$ No

Do you know how many medications you take and what time you have to take them?

$\square$ Yes $\square$ No

Do you receive any family support (financial, comprehensive, emotional, etc.)

regarding your medication treatment?

$\square$ Yes $\square$ No

Do you need any help to control and follow up your medication treatment?

$\square$ Yes $\square$ No

Who is the responsible of your follow-up medication treatment?

$\square$ Myself $\quad \square$ Family Member $\quad \square$ Professional Care Giver $\quad \square$ Informal Care Giver $\quad \square$ Other

Do you relay on any method (alarms, pill boxes, cell phones, etc.)

for taking your medication on time every day?

$\square$ Yes $\square$ No

Explain the method/strategy used for taking your medication on time every day?

\section{About Your Access to Medicine}

Have you ever stayed without medication to save money and spend that money

on basic needs such as water and food?

$\square$ Yes $\square$ No

Have you ever stopped taking a medication because of its expensive price?

$\square$ Yes $\square$ No

Have you ever gone without a medication because you could not get

to the pharmacy/store/clinic to pick up the medicines?

$\square$ Yes $\square$ No

Have you ever experienced travel issues (troubles getting a ride or bus,

covering long distances, etc.) to have access to your medication?

$\square$ Yes $\square$ No

How many places (clinics, pharmacies, stores,etc.) do you receive the medicines from? $\square$ None $\square 1 \square 2 \square<3$ 
ANEXO VII. Continuación del Cuestionario de Recogida de Datos (versión en inglés) SECTION IV

\section{About Your Medication Information}

Did you receive individual information about your current

medication and side/adverse effects?

$\square$ Yes $\quad \square$ No

Do you believe that your doctor, nurse, and pharmacist appropriately explained?

your conditions and the medication you have to follow?

$\square$ Yes $\square$ No

Were you included in any individualized education program or received

any additional information such as written materials or medication websites?

$\square$ Yes $\square$ No

\section{About Your Patient-Provider Relationship}

Are you satisfied with the relationship you have with your health care provider? $\quad \square$ Yes $\square$ No

Rate from 1 to 10 :

¿How would you rate your communication with your health care provider?

\begin{tabular}{ccccccccccc} 
Very Poor & & \multicolumn{10}{c}{ Fair } & \multicolumn{1}{c}{ Very Good } \\
0 & 1 & 2 & 3 & 4 & 5 & 6 & 7 & 8 & 9 & 10
\end{tabular}

¿How would you rate the social support received by your health care provider?

\begin{tabular}{clllllllll} 
Very Poor & & \multicolumn{1}{c}{ Fair } & \multicolumn{1}{c}{ Very Good } \\
0 & 1 & 2 & 3 & 4 & 5 & 6 & 7 & 8 & 9
\end{tabular}

¿How frequently do you visit your health care/clinic annually? 
ANEXO VII. Continuación del Cuestionario de Recogida de Datos (versión en inglés)

\section{SECTION V}

The Barthel Index

$\underline{\text { Score }}$

Activity

FEEDING

$0=$ unable

$5=$ needs help cutting, spreading butter, etc., or requires modified diet

$10=$ independent

\section{BATHING HIMSELF}

$0=$ dependent

5 = independent (or in shower)

\section{GROOMING HIMSELF}

$0=$ needs to help with personal care

5 = independent face/hair/teeth/shaving (implements provided)

DRESSING

$0=$ dependent

$5=$ needs help but can do about half unaided

$10=$ independent (including buttons, zips, laces, etc.)

\section{CONTROLLING BOWELS}

$0=$ incontinent (or needs to be given enemas)

$5=$ occasional accident

$10=$ continent

\section{CONTROLLING BLADDER}

$0=$ incontinent, or catheterized and unable to manage alone

$5=$ occasional accident

$10=$ continent

\section{GETTING ON AND OF TOILET}

$0=$ dependent

$5=$ needs some help, but can do something alone

$10=$ independent (on and off, dressing, wiping)

TRANSFERS (BED TO CHAIR AND BACK)

$0=$ unable, no sitting balance

$5=$ major help (one or two people, physical), can sit

$10=$ minor help (verbal or physical)

$15=$ independent

\section{MOBILITY (ON LEVEL SURFACES)}

$0=$ immobile or $<50$ yards

$5=$ wheelchair independent, including corners, $>50$ yards

$10=$ walks with help of one person (verbal or physical) $>50$ yards

15 = independent (but may use any aid; for example, stick) $>50$ yards

\section{STAIRS}

$0=$ unable

$5=$ needs help (verbal, physical, carrying aid)

$10=$ independent 
ANEXO VIII. Cuestionario de Recogida de Datos (versión en español)

PARTE I

Código de Paciente:

Centro/Clínica:

Edad:

Peso:

Altura:

Índice de Masa Corporal:

Género:

$\square$ Masculino

Raza-Etnia:

$\square$ Americana

$\square$ Afric-Amer

$\square$ Femenino

$\square$ Otra

Información sobre Condiciones

\begin{tabular}{|l|l|l|}
\hline Condición & $\begin{array}{c}\text { Día de Comienzo del } \\
\text { Nuevo Tratamiento }\end{array}$ & \\
\hline & & \\
\hline & & \\
\hline & & \\
\hline & & \\
\hline & & \\
\hline Número total de condiciones & & \multicolumn{1}{|l}{} \\
\hline
\end{tabular}

Tratamiento Farmacoterapeutico:

\begin{tabular}{|c|c|c|c|c|}
\hline Medicamento & Dosis & Posología & $\begin{array}{c}\text { Numero de } \\
\text { Pastillas/Día }\end{array}$ & $\begin{array}{c}\text { Vía de } \\
\text { Administración }\end{array}$ \\
\hline & & & & \\
\hline & & & & \\
\hline & & & & \\
\hline & & & & \\
\hline & & & & \\
\hline & & & & \\
\hline
\end{tabular}

$\square$ Fallo Renal

$\square$ Yes $\square$ No

Intolerancias/Alergias

\section{Observaciones}

Interacciones

Duplicidades

Ajuste Fallo Renal

Otros 
ANEXO VIII. Continuación del Cuestionario de Recogida de Datos (versión en español) PARTE II
Lugar de nacimiento:
$\square$ EEUU
$\square$ Otro
Nivel de Educación: $\square$ Sin educación formal $\square$ Estudios secundarios $\quad \square \quad$ Estudios primarios
Universidad
Ingresos: $\quad \square<\$ 5,000 \quad \square \$ 5,000-\$ 9,999 \quad \square \$ 10,000-\$ 14,999 \quad \square \$ 15,000-\$ 19,999 \quad \square>\$ 20,000$
Tipo de Convivencia: $\square$ Vive solo $\square$ Vive con la familia $\quad \square$ Vive con pareja/amigo
Área Geográfica: $\quad \square$ Urbana $\quad \square$ Rural
Estado ocupacional: $\quad \square$ Activo trabajador $\quad \square$ Jubilado $\quad \square$ Otro
Alfabetización: $\quad \square$ Leer $\quad \square$ Cálculo
$\square$ Escribir $\square$ Intérprete

Dificultades sensoriales:

Fumador: $\quad \square$ Yes $\quad \square$ No $\square$ Ex-fumador

$$
\square \geq 20 \text { cigars/ día } \quad \square 11-19 \text { cigars/día } \quad \square \leq 10 \text { cigars/día }
$$

Toma de Alcohol: $\square$ Empedernido bebedor $\square$ Moderado bebedor $\quad \square$ Ligero bebedor $\square$ No bebedor

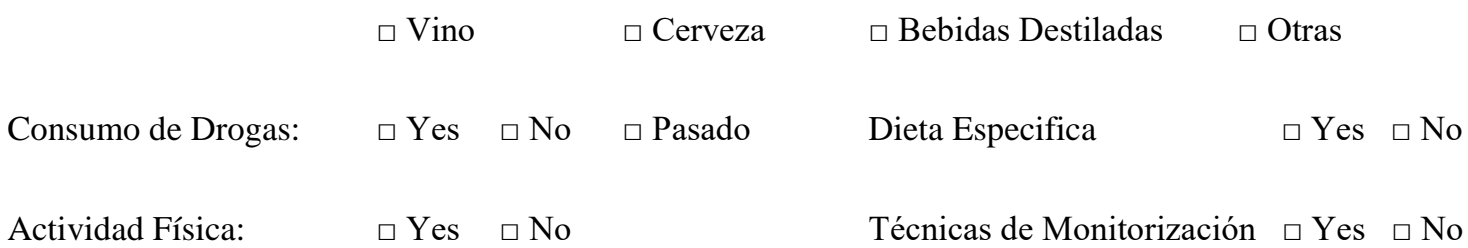

Índice de Barthel: $\quad \square$ Autónomo $\quad \square$ Ligeramente Moderado $\quad \square$ Moderado $\quad \square$ Severo $\quad \square$ Total En los últimos doce meses, ¿cómo diría que ha sido su estado de salud?

\begin{tabular}{ccccccccccc} 
Muy Malo & \multicolumn{1}{c}{ Normal } & \multicolumn{3}{c}{ Muy Bueno } \\
0 & 1 & 2 & 3 & 4 & 5 & 6 & 7 & 8 & 9
\end{tabular}


ANEXO VIII. Continuación del Cuestionario de Recogida de Datos (versión en español)

\section{PARTE III}

\section{Sobre la Toma de Medicación}

¿Olvida alguna vez tomar sus medicamentos?

$\square \mathrm{Si} \quad \square \mathrm{No}$

¿Es descuidado con la hora en la que debe tomar la medicación?

$\square \mathrm{Si} \quad \square \mathrm{No}$

Cuando se encuentra mejor, ¿deja de tomar la medicación?

$\square \mathrm{Si} \quad \square \mathrm{No}$

Si alguna vez le sientan mal los medicamentos, ¿deja de tomarlos?

$\square \mathrm{Si} \square \mathrm{No}$

\section{Sobre su Medicación}

¿Sabe por qué toma cada medicamento?

$\square \mathrm{Si} \quad \square \mathrm{No}$

¿Sabe cuántos medicamentos está tomando y a qué hora debe de tomar cada uno

$\square \mathrm{Si} \quad \square \mathrm{No}$

¿Recibe apoyo familiar (financiero, comprensivo, emocional, etc.)

respecto a su tratamiento farmacológico?

$\square \mathrm{Si} \quad \square \mathrm{No}$

¿Está satisfecho con el apoyo que recibe de su familia?

$\square \mathrm{Si} \quad \square \mathrm{No}$

¿Quién es el responsable de su seguimiento farmacológico?

$\square$ Usted Mismo $\quad \square$ Familiar $\quad \square$ Cuidador Profesional $\quad \square$ Cuidador Informal $\quad \square$ Otra Persona

¿Utiliza algún método (alarmas, pastilleros, teléfono, etc.)

para tomar su medicación a la hora cada día?

$\square \mathrm{Si} \quad \square$ No

Explicar qué método/estrategia utiliza para recordar la toma de su medicación a la hora indicada cada día:

\section{Sobre el Acceso a la Medicación}

¿Alguna vez ha dejado de estar sin medicación para ahorrar dinero y gastarlo en otras necesidades básicas como agua o comida??

$\square \mathrm{Si} \quad \square \mathrm{No}$

¿Alguna vez ha dejado de tomar la medicación debido a su elevado precio?

$\square \mathrm{Si} \quad \square \mathrm{No}$

¿Ha estado alguna vez sin medicación porque no podía llegar a recogerla a la

farmacia/tienda/clínica?

$\square \mathrm{Si} \quad \square \mathrm{No}$

¿Ha experimentado alguna vez dificultades de desplazamiento de transporte

(problemas al ir en coche, coger el autobús, largas distancias

de desplazamiento, etc.) para acceder a su medicación?

$\square \mathrm{Si} \quad \square \mathrm{No}$

¿En cuántos lugares (clínicas, comercios, o farmacias) recoge las medicinas? ` $\square$ Ninguna $\square 1 \quad \square 2 \quad \square>3$ 
ANEXO VIII. Continuación del Cuestionario de Recogida de Datos (versión en español)

\section{PARTE IV}

\section{Sobre Información de su Medicación}

¿Recibe información individual sobre su medicación actual

y efectos secundarios/adversos?

$\square \mathrm{Si} \quad \square \mathrm{No}$

¿Piensa que su doctor, enfermera y farmacéutico le han explicado

apropiadamente las condiciones que padece y la medicación que debe seguir?

$\square \mathrm{Si} \quad \square \mathrm{No}$

¿Fue incluido en un programa de educación individual o recibió información

adicional por escrito o a través de páginas web sobre medicación que toma?

$\square \mathrm{Si} \quad \square$ No

\section{Sobre la Relación Paciente-Profesional Sanitario}

¿Está satisfecho con la relación que tiene con el personal sanitario, enfermera y/o doctor? $\square \mathrm{Si} \quad \square$ No Valoración 1-10:

¿Cómo calificaría su comunicación con el personal sanitario?

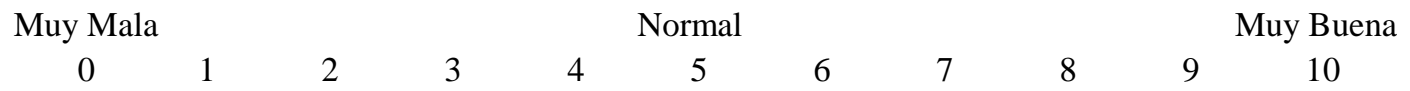

¿Cómo evaluaría el apoyo social recibido por los profesionales sanitarios? Muy Malo

Normal

Muy Bueno

$\begin{array}{lllllllllll}0 & 1 & 2 & 3 & 4 & 5 & 6 & 7 & 8 & 9 & 10\end{array}$

¿Con que frecuencia acude a su centro de salud/clínica anualmente? 
ANEXO VIII. Continuación del Cuestionario de Recogida de Datos (versión en español) PARTE V

\author{
Índice de Barthel
}

\title{
$\underline{\text { Actividad }}$
}

Puntuación

Comer

$0=$ incapaz

$5=$ necesita ayuda para cortar, extender mantequilla, usar condimentos, etc.

$10=$ independiente (la comida está al alcance de la mano)

Trasladarse entre la silla y la cama

$0=$ incapaz, no se mantiene sentado

5 = necesita ayuda importante (una persona entrenada o dos personas), puede estar sentado

$10=$ necesita algo de ayuda (una pequeña ayuda física o ayuda verbal)

$15=$ independiente

Aseo personal

$0=$ necesita ayuda con el aseo personal.

5 = independiente para lavarse la cara, las manos y los dientes, peinarse y afeitarse.

Uso del retrete

$0=$ dependiente

5 = necesita alguna ayuda, pero puede hacer algo sólo.

$10=$ independiente (entrar y salir, limpiarse y vestirse)

Bañarse/Ducharse

$0=$ dependiente.

5 = independiente para bañarse o ducharse.

Desplazarse

0 = inmóvil

5 = independiente en silla de ruedas en $50 \mathrm{~m}$.

$10=$ anda con pequeña ayuda de una persona (física o verbal).

15 = independiente al menos $50 \mathrm{~m}$, con cualquier tipo de muleta, excepto andador

Subir y bajar escaleras

$0=$ incapaz

$5=$ necesita ayuda física o verbal, puede llevar cualquier tipo de muleta.

$10=$ independiente para subir y bajar.

Vestirse y desvestirse

$0=$ dependiente

$5=$ necesita ayuda, pero puede hacer la mitad aproximadamente, sin ayuda.

$10=$ independiente, incluyendo botones, cremalleras, cordones, etc

Control de heces:

$0=$ incontinente (o necesita que le suministren enema)

$5=$ accidente excepcional (uno/semana)

$10=$ continente

Control de orina

$0=$ incontinente, $\mathrm{o}$ sondado incapaz de cambiarse la bolsa.

5 = accidente excepcional (máximo uno/24 horas).

$10=$ continente, durante al menos 7 días .

TOTAL (0-100): 
ANEXO IX. Consentimiento Informado del Estudio

"TREATMENT ADHERENCE AMONG MINORITIES WITH MULTIPLE CHRONIC CONDITIONS"

\author{
Principal Investigador: Cesar Fernandez Lazaro \\ Faculty Supervisor: Dr. Nandi Marshall \\ Health Department, Armstrong State University \\ This Informed Consent Form has two parts: \\ - Information Sheet (to share information about the research with you) \\ - Certificate of Consent (for signatures if you agree to take part)
}

You will be given a copy of the full Informed Consent Form

PART I: Information Sheet

Introduction

I am Cesar Fernandez Lazaro, working on my research practicum for Armstrong State University. We are doing research on medication adherence and factors related to adherence. I am going to give you information and invite you to be part of this research. You do not have to decide today whether you will participate in the research. Please take whatever time you need to discuss the study with your family and friends, or anyone else you wish. The decision to join, or not to join, is up to you.

There may be some words that you do not understand. Please ask me to stop as we go through the information and I will take time to explain. If you have questions later, you can ask my faculty supervisor or me.

\title{
Purpose of the research
}

The prevalence of chronic conditions in any given individual has significantly increased in the last decade and represents a main concern for the public health authorities. Patients with multiple chronic conditions must deal with a complex system of polypharmaceutical regimens and multiple recommendations received from healthcare professionals. The purpose of this study is to analyse the adherence to pharmacological treatment in patients with multiple chronic conditions who require multiple drug therapy regimens and its potential barriers.

\section{Type of Research Intervention}

This research will involve an interview, in which you will be asked information regarding your current treatment. Every interview will last 10-15 minutes. 
ANEXO IX. Continuación del Consentimiento Informado del Estudio

\section{Participant selection}

We are inviting all adults who suffer from $\geq 1$ chronic conditions and attend to Good Samaritan Clinic and St. Mary's Health Center to participate in the research on medication adherence.

\section{Voluntary Participation}

Your participation in this research is entirely voluntary. It is your choice whether to participate or not. Whether you choose to participate or not, all the services you receive at this clinic will continue and nothing will change. You may change your mind later and stop participating even if you agreed earlier. The investigators may stop the study or take you out of it at any time they judge it is in your best interest. They may also remove you from the study for other reasons. They can do this without your consent.

\section{Risks}

The present study involves no risks for the involved participants.

\section{Benefits}

The study will be beneficial for understanding the factors that influence patient adherence and evaluating strategies to improve medication adherence among patients. However, we cannot guarantee that you will personally experience benefits from participating in this study but future generations are likely to benefit.

\section{Reimbursements}

You will not be given any other money or gifts to take part in this research.

\section{I.R.B. Disclaimer}

You understand that in the event of physical or psychological injury from this procedure, neither Armstrong State University nor St. Joseph's/Candler Health System Inc. are responsible for patient compensation either for lost wages or for treatment. Therefore, St. Armstrong State University and Joseph's/Candler Health System, Inc. do not provide reimbursement for such injuries. You are not waiving any legal rights, however, nor are you releasing the hospital or physician from liability for negligence unrelated to the nature and risk of the treatment.

\section{Confidentiality}

The information that we collect from this research project will be kept confidential. Information about you that will be collected during the research will be put away and no one but the researchers will be able to see it. Any information about you will have a number on it instead of your name. Only the researcher will know what your number is and we will lock that information up with a lock and key. It will not be shared with or given to anyone.

\section{Sharing the Results}

The knowledge that we get from doing this research will be shared with you through community meetings before it is made widely available to the public. Confidential information will not be shared. After these meetings, we will publish the results in order that other interested people may learn from our research. 
ANEXO IX. Continuación del Consentimiento Informado del Estudio

Right to Refuse or Withdraw

You do not have to take part in this research if you do not wish to do so. You may also stop participating in the research at any time you choose. It is your choice and all of your rights will still be respected.

\section{Who to Contact}

If you have any questions you may ask them now or later, even after the study has started. If you wish to ask questions later, you may contact any of the following: Cesar Fernandez Lazaro at 912-272-3565 or email him at cf2369@armstrong.edu and Dr. Nandi Marshall at 912-344-3307 or email her at nandi.marshall@armstrong.edu

This proposal has been reviewed and approved by The Armstrong State University IRB and The St. Joseph Candler's IRB, which are committees whose task it is to make sure that research participants are protected from harm. If you wish to find about more about the IRB and your rights as a study subject, you may contact Dr. Donna Brooks, Chair of the Armstrong State University IRB at 912-344-2896 or Dr. Harold A. Black, Chair of the St. Joseph's/Candler Health System IRB at 912-819-8087.

\section{PART II: Certificate of Consent}

I have read the foregoing information, or it has been read to me. I have had the opportunity to ask questions about it and any questions that $I$ have asked have been answered to my satisfaction. I consent voluntarily to participate as a participant in this research.

\section{Print Name of Participant}

Signature of Participant

Date

$$
\text { Day/month/year }
$$

A copy of this ICF has been provided to the participant.

Print Name of Researcher/person taking the consent

Signature of Researcher/person taking the consent

Date

Day/month/year 


\title{
Armstrong State University
}

\author{
Notice of IRB Approval
}

Name: Cesar F. Lazaro

Co-Investigators: Nandi Marshall, Faculty Advisor

Academic Unit: College of Health Professions

Date: September 11, 2015

RE: \# 1280 Treatment Adherence among Minorities with Multiple Chronic Conditions

The above project has been reviewed and is approved by the IRB under the provisions of Federal Regulations 45 CFR 46.

This approval is based on the following conditions:

1. The materials you submitted to the IRB provide a complete and accurate account of how human subjects are involved in your project.

2. You will carry on your research strictly according to the procedures as described in the materials presented to the IRB

3. You will report to the IRB any changes in procedures that may have a bearing on this approval and require another IRB review.

4. If any changes are made, you will submit the modified project for IRB review.

5. You will immediately report to the IRB any problem(s) that you encounter while using human subjects.

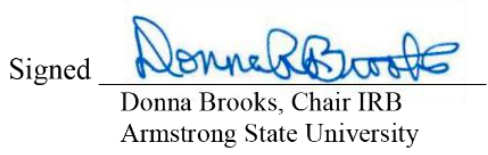

cc: 
ANEXO XI. Aprobación del Estudio por el IRB de la Fundación St. Joseph's/Candler

ST.Joseph's/Candler

Live smart.

September 17,2015

Cesar Fernandez Lazaro

St. Mary's Health Center

1302 Drayton St.

Savannah GA. 31408

Study Title: Treatment Adherence Among Minorities with Multiple Chronic Conditions (MCC)

Type Review: Expedited - Initial Approval

Expiration Date: September 17, 2016

Progress Report Due: July 2016

Dear Dr. Howell:

The observational cross-sectional survey for the above captioned study, has been approved through expedited review for use at St. Joseph's/Candler Health System, Inc. for one year. Your study will be presented for information purposes to the full IRB at their meeting.

If your study concludes before the above due date, please send a letter of closure, progress report, and summary of findings (if available) to the address listed below.

Please refer to IRB\# 15-022 on all correspondence relating to this study.

Sincerely,
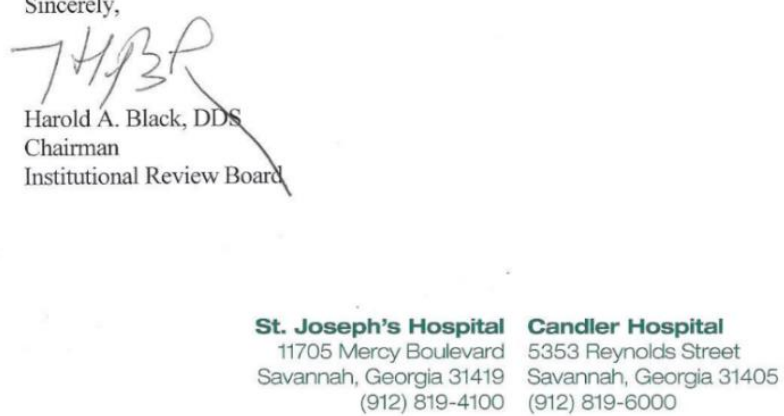

1804 Candler Hospital 1832 Georgia Infirmary 1875 St. Joseph's Hospital $\cdot 1886$ Mary Telfair Hospital for Women 
ANEXO XII. Certificado Protecting Human Research Participants

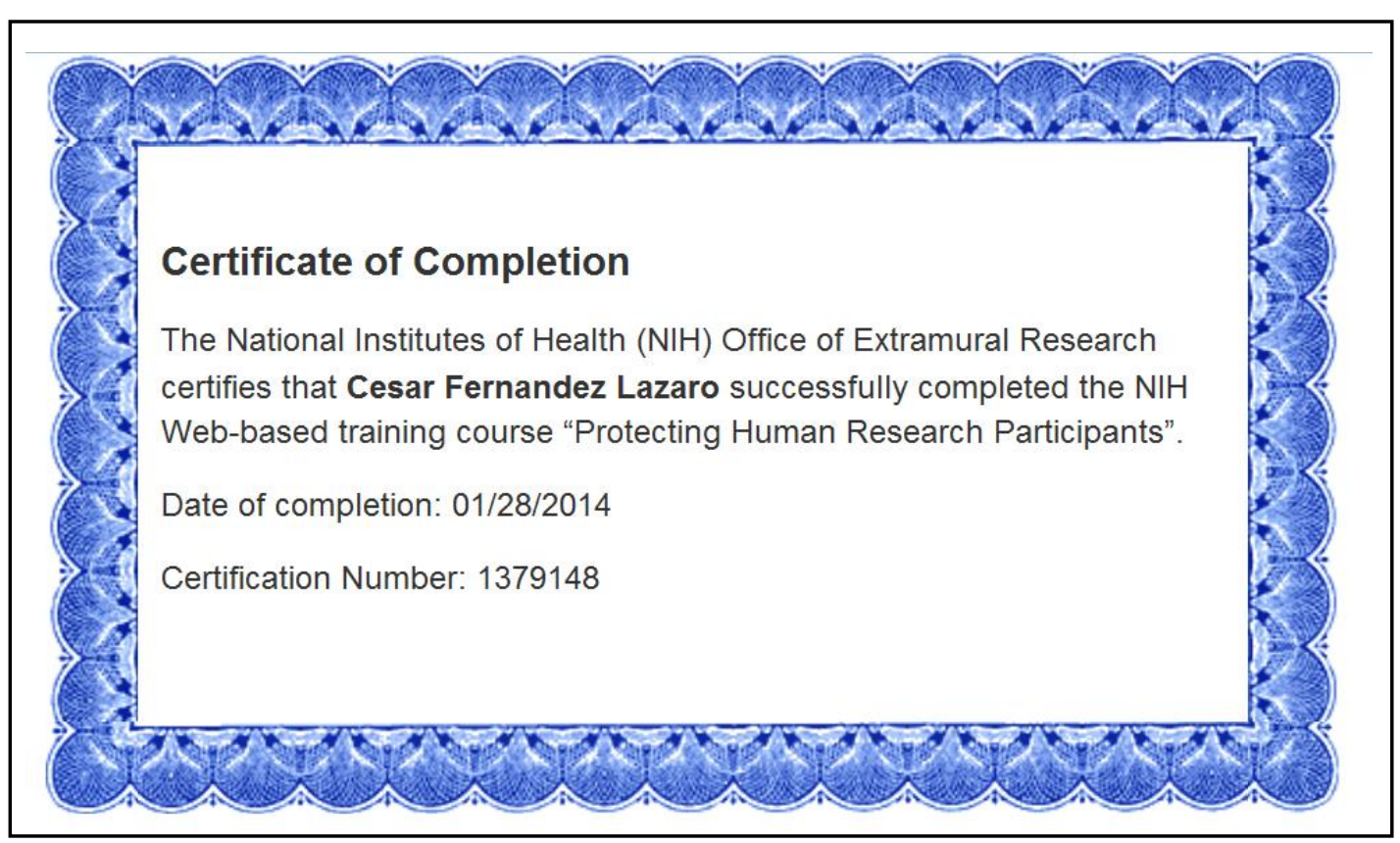





\section{Glosario De \\ Abreviaturas}



ARij Residuos Tipificados Corregidos

apps $\quad$ Aplicaciones de Teléfono Móvil

AVAD Años de Vida Ajustados por Discapacidad

AVD Actividades de la Vida Diaria

CCM Chronic Care Model

CIE-9 Clasificación Estadística Internacional de Enfermedades y Problemas Relacionados con las Salud, Novena Edición

CHC Community Health Center

CMS Centers for Medicare and Medicaid Services

CVRS Calidad de Vida Relacionada con la Salud

DE Desviación Estándar

EEUU Estados Unidos

EPOC Enfermedad Obstructiva Crónica

ERET Enfermedad Renal en Etapa Terminal

GA Georgia

HHS Health and Human Services

IC Intervalo de Confianza 
IRB Institutional Review Bord

K-S Kolmogorov-Smirnov

MCS Modelo de Creencia de Salud

MENS Monitores Acoplados al Envase de los Medicamento

NEHI New England Health Institute

NIH National Institutes of Health

OMS Organización Mundial de la Salud

PPACA Patient Protection and Affordable Care Act

PIB Producto Interior Bruto

SPSS Statistical Package for the Social Sciences

OR Odds Ratio

TB Tuberculosis

TIC Tecnologías de la Información y la Comunicación

V V de Cramer

VIH Virus de la Inmunodeficiencia Humana

ф Phi



